Portland State University

PDXScholar

Dissertations and Theses

Dissertations and Theses

1990

\title{
Chemistry of Pentafluorothio (SF5) Alkyl Derivatives
}

Rolf Walter Winter

Portland State University

Follow this and additional works at: https://pdxscholar.library.pdx.edu/open_access_etds

Part of the Environmental Sciences Commons

Let us know how access to this document benefits you.

Recommended Citation

Winter, Rolf Walter, "Chemistry of Pentafluorothio (SF5) Alkyl Derivatives" (1990). Dissertations and Theses. Paper 1281.

https://doi.org/10.15760/etd.1280

This Dissertation is brought to you for free and open access. It has been accepted for inclusion in Dissertations and Theses by an authorized administrator of PDXScholar. Please contact us if we can make this document more accessible: pdxscholar@pdx.edu. 
CHEMISTRY OF PENTAFLUOROTHIO $\left(\mathrm{SF}_{5}\right)$ ALKYL DERIVATIVES

by

ROLF WALTER WINTER

A dissertation submitted in partial fulfillment of the requirements for the degree of

DOCTOR OF PHILOSOPHY

in

ENVIRONMENTAL SCIENCES AND RESOURCES/CHEMISTRY

Portland State University

1990 
TO THE OFFICE OF GRADUATE STUDIES:

The members of the Committee approve the dissertation of Rolf Winter presented October 4, 1990.

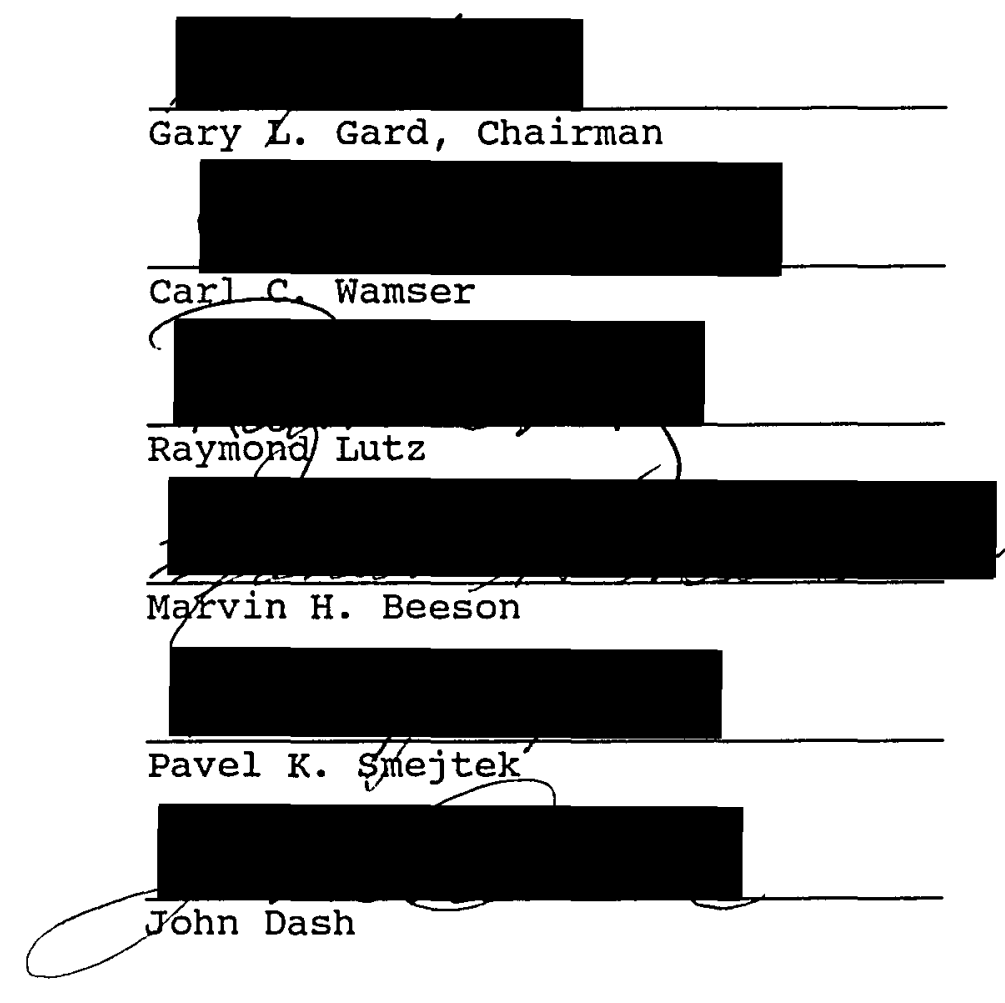

APPROVED :

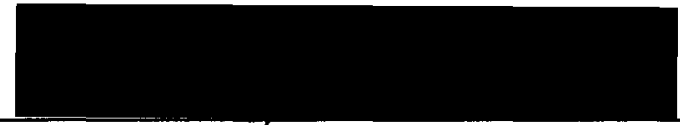

Pavel K. Smejtek, Director, Environmental Sciences and Resources Ph.D. Program

C. William Savery, Interim Viqé Provost for Graduate studies and Research 
AN ABSTRACT OF THE DISSERTATION OF ROLF WALTER WINTER FOR

THE DOCTOR OF PHILOSOPHY in Environmental sciences and Resources/Chemistry presented october 4, 1990.

Title: Chemistry of Pentafluorothio $\left(\mathrm{SF}_{5}\right)$ Alkyl

Derivatives.

APPROVED BY MEMBERS OF THE DISSERTATION COMMITTEE:

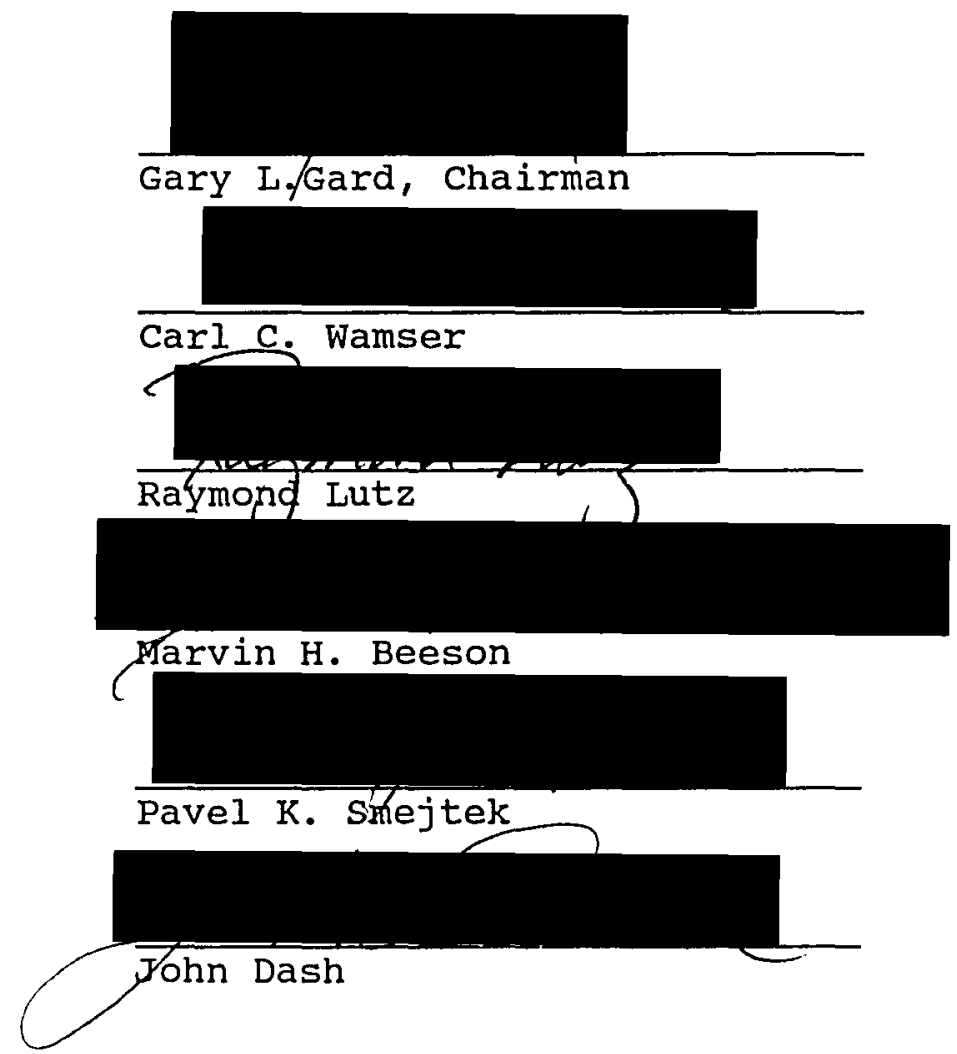

This thesis is divided into four parts:

Part I describes the preparation of a number of useful intermediates from the sultone $\mathrm{F}_{5} \mathrm{SCHCF}_{2} \mathrm{OSO}_{2}$, () . These intermediates include the following: the ketene 
$\mathrm{F}_{5} \mathrm{SC}\left(\mathrm{SO}_{2}\right)=\mathrm{C}=0$ (21), the unique sultone $\mathrm{F}_{4} \mathrm{~S}=\overline{\mathrm{CFF}}_{2} \mathrm{OSO}_{2}$ (23) , and various ionic intermediates of the form $\mathrm{Y}^{+}$ $\left[\mathrm{F}_{5} \mathrm{SC}\left(\mathrm{SO}_{2} \mathrm{~F}\right) \mathrm{COX}\right]^{-}$. These intermediates play an important role in providing new pathways for preparing fluorosulfonic acid precursors. Fluorosulforic acids are excellent candidates to improve the efficiency of environmentally safe fuel cells. It was possible to obtain new derivatives of 1 by various reactions of $\underline{21}, \underline{23}$ and the ionic intermediates, but it was not possible to introduce an alkyl substituent with either of the intermediates.

Part II is concerned with the synthesis of $\mathrm{SF}_{5}$ containing epoxides as possible monomers. When polymerized, materials of high dielectric strength and high chemical resistance should be obtained. The reaction chemistry of one of the epoxides was investigated and it was found that all reactions studied were accompanied by the loss of the $\mathrm{SF}_{5}$ group. Thus, it was not possible to obtain any polymeric materials.

Part III deals with the synthetic accessibility of $\mathrm{SF}_{5}$ malonic esters and thence of $\mathrm{SF}_{5}$ acrylic esters. These compounds should serve as building blocks in the synthesis of $\mathrm{SF}_{5}$ containing pyrimidines. The $\mathrm{CF}_{3}$ analogue, 5trifluoromethyl uracil, is used as an antiviral drug. In order to synthesize either $\mathrm{SF}_{5}$ malonic ester or $2-\mathrm{SF}_{5}$ acrylic ester an $\mathrm{SF}_{5}$ group has to be introduced at a secondary carbon. A secondary $\mathrm{SF}_{5}$ compound could be 
synthesized $\left(\mathrm{F}_{5} \mathrm{SCH}\left(\mathrm{COOC}_{2} \mathrm{H}_{5}\right)(\mathrm{CHBrOAC})\right)$ but could not be converted to the respective malonic ester $\mathrm{F}_{5} \mathrm{SCH}\left(\mathrm{COOC}_{2} \mathrm{H}_{5}\right)_{2}$. compound.

Part IV describes the reactions and preparations of part I-III. 
To My Family 


\section{ACKNOWLEDGEMENT}

I would like to thank Professor Gard for his support and kindness in the course of this work. I am grateful to the bright stars on their celestial path that guided me in the years past towards Arcadia. 
TABLE OF CONTENTS

PAGE

DEDICATION............................ ACKNOWLEDGEMENT ........................ iv LIST OF TABLES......................... LIST OF FIGURES...................... CHAPTER

PART I: DERIVITIZATIONS OF $\mathrm{F}_{5} \mathrm{SCHCF}_{2} \mathrm{OSO}_{2}$

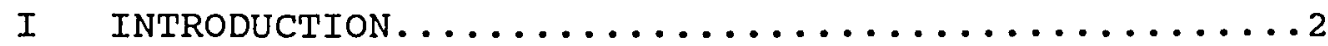

II SIGNIFICANCE AND ENVIRONMENTAL RELATIONSHIP.......4

III GENERAL DISCUSSION, DERIVITIZATION OF $\mathrm{F}_{5} \mathrm{SCHCF}_{2} \mathrm{OSO}_{2} \cdot 9$

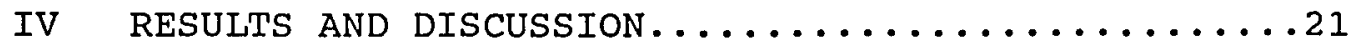

Synthesis and Reactions of $\mathrm{SF}_{5} \mathrm{C}\left(\mathrm{SO}_{2} \mathrm{~F}\right)=\mathrm{C}=0 \ldots \ldots 21$

The Formal Addition of $\mathrm{RO}^{-}$to $\mathrm{SF}_{5} \mathrm{C}\left(\mathrm{SO}_{2} \mathrm{~F}\right)=\mathrm{C}=\mathrm{O}$;

Synthesis and Reactions of $\mathrm{F} 5 \mathrm{SC}^{-}\left(\mathrm{SO}_{2} \mathrm{~F}\right) \mathrm{COOR} \ldots . .35$

Properties of $\mathrm{Cs}^{+}\left[\mathrm{SF}_{5} \mathrm{C}\left(\mathrm{SO}_{2} \mathrm{~F}\right) \mathrm{COF}\right]^{-} \ldots \ldots \ldots . . .43$

Synthesis and Properties of $\mathrm{F}_{4} \mathrm{~S}=\mathrm{CCF}_{2} \mathrm{OSO}_{2} \ldots \ldots 51$ The conversion of an $\mathrm{SF}_{5}$ Group into an $\left(\mathrm{F}_{2} \mathrm{~S}=0\right)=$

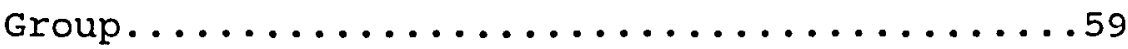

Nuclear Magnetic Resonance Spectra.........63

Features of $\mathrm{x}$-Ray structures............74

$\mathrm{V}$ SUNTHESIS OF PENTAFLUOROSULFUR BROMIDE, $\mathrm{SF}_{5} \mathrm{BR} \ldots . .83$

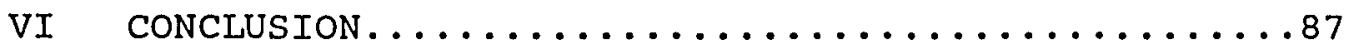


PART II: SYNTHESIS AND REACTIONS OF SF 5 -EPOXIDES

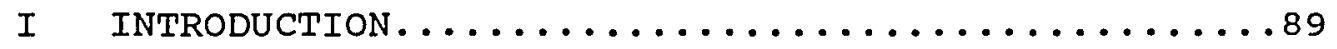

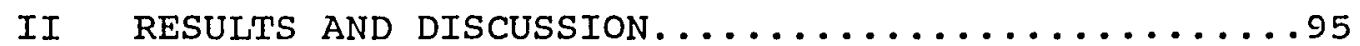



Synthesis of the starting olefins..........105

IV INFRARED, ${ }^{19} \mathrm{~F}$ AND ${ }^{13} \mathrm{C}$ N.M.R. SPECTRA......... 107

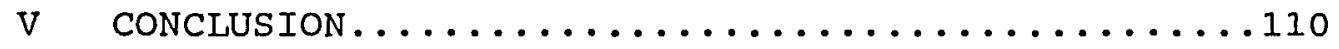

PART III: TOWARDS THE SUNTHESIS OF PENTAFLUOROTHIO MALONIC ACID



II A GENERAL OUTLINE FOR THE SYNTHESIS OF $\mathrm{SF}_{5}$ COMPOUNDS

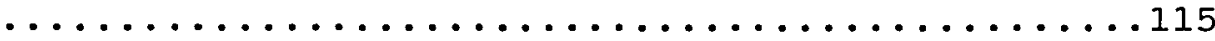

III RESULTS AND DISCUSSION AND THE SYNTHESIS OF $\mathrm{SF}_{5} \mathrm{CH}\left(\mathrm{COOC}_{2} \mathrm{H}_{5}\right) \mathrm{CHBROCOCH}_{3} \ldots \ldots \ldots \ldots \ldots \ldots \ldots \ldots \ldots$

IV THE X-RAY STRUCTURE OF $\left(\mathrm{F} 5 \mathrm{SCH}_{2} \mathrm{CHO}\right)_{3} \ldots \ldots \ldots \ldots 133$

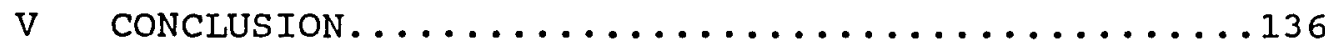

PART IV: EXPERIMENTAL PART

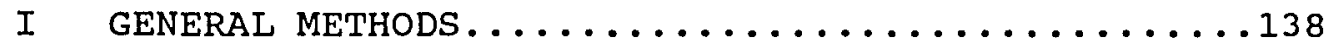

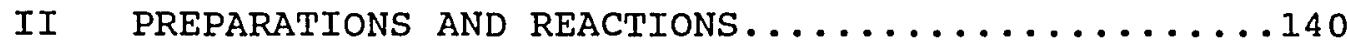

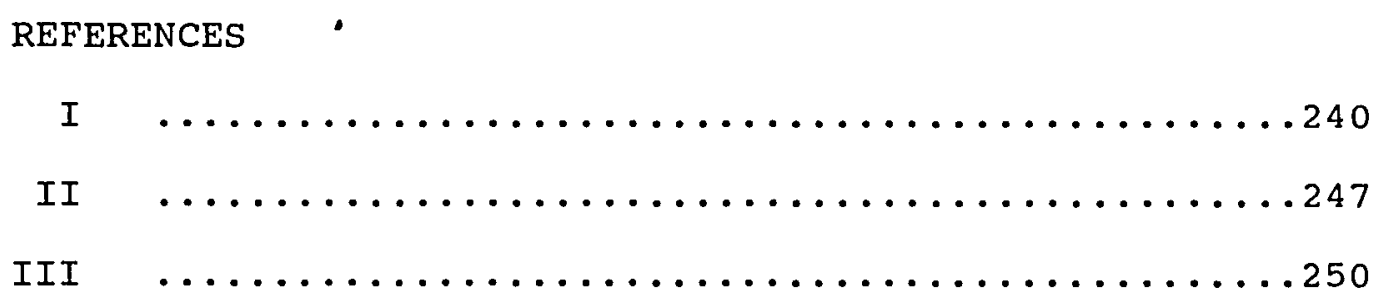




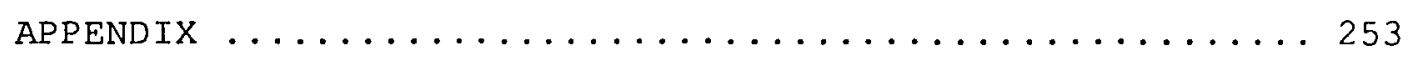




\section{LIST OF TABLES}

TABLE

PAGE

I ${ }^{19} \mathrm{~F}$ N.M.R. and I.R. Table of $\mathrm{SF}_{5}$-Anions.......73

II ${ }^{13} \mathrm{C}$ N.M.R. Table of $\mathrm{SF}_{5} \mathrm{C}_{\alpha} \mathrm{C}_{\beta}$ Compounds........73

III Bond Distances [pm] and Angles [ $\left.{ }^{\circ}\right]$ of the Salt $\mathrm{F}_{5} \mathrm{SC}\left(\mathrm{SO}_{2} \mathrm{~F}\right) \mathrm{COOCH}_{3}-\mathrm{HN}\left(\mathrm{C}_{2} \mathrm{H}_{5}\right)_{3}{ }^{+}, \underline{32 \mathrm{~b}} \ldots \ldots \ldots \ldots 75$

IV Bond Distances [pm] and Angles [ $\left.{ }^{\circ}\right]$ in $\mathrm{F}_{5} \mathrm{SCH}\left(\mathrm{SO}_{2} \mathrm{~F}\right) \mathrm{CON}\left(\mathrm{C}_{2} \mathrm{H}_{5}\right)_{2}, \underline{27} \ldots \ldots \ldots \ldots \ldots \ldots \ldots$

$\mathrm{V}$ Bond Lengths [pm] and Angles [ $\left.{ }^{\circ}\right]$ in $\left(\mathrm{F}_{5} \mathrm{SCH}\left(\mathrm{SO}_{2} \mathrm{~F}\right) \mathrm{CH}_{2}\right)_{2} \mathrm{O}, \underline{29} \ldots \ldots \ldots \ldots \ldots \ldots \ldots \ldots \ldots \ldots$

VI ${ }^{19} \mathrm{~F}$ and ${ }^{13} \mathrm{C}$ N.M.R. Data of $\mathrm{SF}_{5}$-Epoxides........109

VII Non-Hydrogen Bond Lengths [pm] and Angles [ ${ }^{\circ}$ ] for $\left(\mathrm{F}_{5} \mathrm{SCH}_{2} \mathrm{CHO}\right)_{3} \ldots \ldots \ldots \ldots \ldots \ldots \ldots \ldots \ldots \ldots \ldots \ldots \ldots \ldots \ldots$ 


\section{LIST OF FIGURES}

FIGURES

PAGE

1 The Change of an $\mathrm{AB}_{4}$ Spectrum (84.7 MHz) for Various $\phi_{\mathrm{A}}-\phi_{\mathrm{B}} \ldots \ldots \ldots \ldots \ldots \ldots \ldots \ldots \ldots \ldots \ldots \ldots \ldots \ldots \ldots \ldots \ldots \ldots \ldots \ldots \ldots \ldots$

2 Experimental and Calculated ${ }^{19} \mathrm{~F}$ N.M.R. Spectrum of

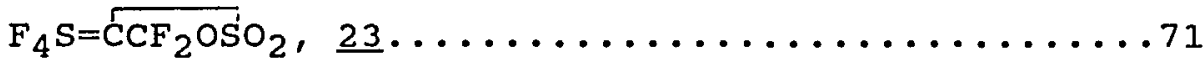

3 X-Ray structure of $\underline{32 \mathrm{~b}}, \mathrm{~F}_{5} \mathrm{SC}\left(\mathrm{SO}_{2} \mathrm{~F}\right) \mathrm{COOCH}_{3}-\mathrm{NH}\left(\mathrm{C}_{2} \mathrm{H}_{5}\right)_{3}+$

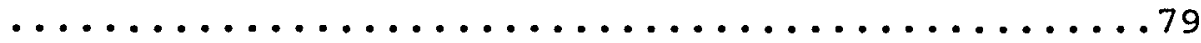

4 X-Ray structure of $27, \mathrm{~F}_{5} \mathrm{SCH}\left(\mathrm{SO}_{2} \mathrm{~F}\right) \mathrm{CON}\left(\mathrm{C}_{2} \mathrm{H}_{5}\right)_{2} \ldots \ldots 80$

$5 \mathrm{X}$-Ray structure of $29,\left(\mathrm{~F}_{5} \mathrm{SCH}\left(\mathrm{SO}_{2} \mathrm{~F}\right) \mathrm{CH}_{2}\right)_{2} \mathrm{O} \ldots \ldots .81$

6 Recorded and simulated $A B$ Part of the ${ }^{19}$ F N.M.R.

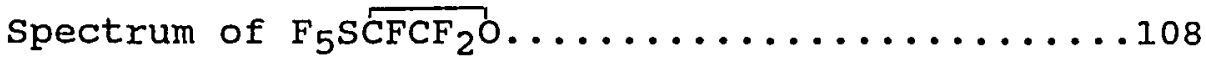

$7 \mathrm{X}$-Ray stereographic view of $\left(\mathrm{F}_{5} \mathrm{SCH}_{2} \mathrm{CHO}\right)_{3} \ldots \ldots \ldots 134$ 
PART I

DERIVITIZATIONS OF $\mathrm { F } _ { 5 } \mathrm { S } \longdiv { \mathrm { CHCF } } \mathrm { OSO } _ { 2 }$ 


\section{CHAPTER I}

\section{INTRODUCTION}

The investigation of compounds containing the $\mathrm{SF}_{5}$ substituent is relatively new. It originated in 1934 with the discovery of disulfur decafluoride, $\mathrm{s}_{2} \mathrm{~F}_{10}$, as a byproduct of the fluorination of sulfur; the main product in this reaction is sulfur hexafluoride, $\mathrm{SF}_{6}{ }^{1}$ sulfur hexafluoride can be considered as an $\mathrm{SF}_{5}$ compound ("pentafluorosulfur fluoride"), but for chemical purposes this kinship cannot be employed due to the great inertness of this compound. On the other hand, $S_{2} F_{10}$ is useful as a starting material for making $\mathrm{SF}_{5}$ compounds because the relatively weak $\mathrm{s}-\mathrm{S}$ bond $[55 \pm 5 \mathrm{kcal} / \mathrm{mol}$, as derived from an empirical relationship between the bond energy and force constant] ${ }^{2}$ breaks easily upon heating and can be used in certain cases to obtain $\mathrm{SF}_{5}$ derivatives directly, or more commonly, through the intermediate formation of $\mathrm{SF}_{5} \mathrm{Br}$, pentafluorosulfur bromide. $S_{5} \mathrm{Br}$ was used as the chief starting material in this work and in the course of this investigation it was necessary to develop a new method of synthesis, due to the difficulty of obtaining sufficient quantities of $\mathrm{S}_{2} \mathrm{~F}_{10}$. There are some remarkable similarities between the derivatives of $\mathrm{SF}_{6}$ and $\mathrm{CF}_{4}$, and there is the 
possibility of the existence of a homologous series, analogous to $C_{n} F_{2 n+2}$, of the general composition $S_{n} F_{4 n+2}$, of which $\mathrm{SF}_{6}$ and $\mathrm{S}_{2} \mathrm{~F}_{10}$ are the first and so-far only members. $\mathrm{SF}_{5}-$ and $\mathrm{CF}_{3}$-alkyl compounds usually show little tendency to react at their $C_{3}$ and $\mathrm{SF}_{5}$ sites, respectively. They are thermally very stable, form olefins with electrophilic $\pi-$ bonds, and do not allow for nucleophilic displacement of halogens in the vicinity of the perfluoro groups. Such substitution reactions do occur for $\mathrm{CF}_{3}$ (perfluoroalkyl) derivatives, but with a different mechanism $\left(\mathrm{S}_{\mathrm{RN}} \mathrm{I}\right)$; for similar $\mathrm{SF}_{5}$ compounds a different course of reaction is usually observed, that is, loss of $\mathrm{SF}_{5}$, although in some cases substitution reactions were successful. ${ }^{3}$ Here, and as will be seen later, some examples of the divergence in the behavior of the two types of compounds $\left(\mathrm{SF}_{5}\right.$ vs. $\left.\mathrm{CF}_{3}\right)$ are already seen. 


\section{SIGNIFICANCE AND ENVIRONMENTAL RELATIONSHIP}

The development of electrochemical energy converters, or fuel cells ${ }^{4}$, as convenient and clean sources of electrical energy requires also the knowledge of suitable mobile charge carriers. Schematically, a fuel cell consists of two electrodes, separated by a diaphragm and connected by an external circuit. The charge transport within the solution is provided by the electrolyte. oxygen is reduced at the cathode and hydrogen or another hydrocarbon fuel is oxidized at the anode; both electrodes act also as electrochemical catalysts by lowering the activation barrier for the two half reactions. It is especially advantageous to use platinum as part of the electrode material. The process of combustion is thus spatially separated, which allows one to make use of the electron flux stemming from the oxidation and reduction processes taking place. High efficiency and no product formation, other than water, carbon dioxide and nitrogen, depending on the fuel, is expected from such a device. There are only a certain number of fluorosulfonic acids available as possible replacements for phosphoric acid, which is now used as the fuel cell electrolyte of choice. Trifluoromethane sulfonic acid is comparable to 
$\mathrm{H}_{3} \mathrm{PO}_{4}$ as a fuel cell electrolyte, but is too volatile at the required operating temperature. Nafion, a solid polymeric fluorosulfonic acid electrolyte, has been found to be useful. Therefore, fluorosulfonic acids offer promise as fuel cell electrolytes and the search for new and improved materials continues. Desirable properties of or changes brought about by a new fuel cell electrolyte are as follows:

a.) Chemical, electrochemical and thermal stability

b.) Good ionic conductivity

c.) High boiling point

d.) High capacity of oxygen solubility

e.) Improvement of the kinetics of the cell

Fuel cells increase in efficiency as the temperature rises, thus thermal stability and high boiling point, to minimize losses by evaporation, are a chief concern in choosing an electrolyte.

The above listed criteria (a-e) are largely met by fluorinated sulfonic acids; whereas chemical and thermal stability can be predicted as a property, this is not obvious for the electrochemical behavior. At that point, structural modifications of such acids can be quite arbitrary, but certain alterations of existing sulfonic acids are desirable. A high degree of fluorination conveys the property of chemical and thermal stability and increases the acid strength, due to the anion stabilizing inductive and hyperconjugative effect of the fluoroalkyl group, 
particularly perfluoroalkyl residues. The introduction of alkyl-residues, particularly fluoroalkyl radicals, should be advantageous, accounting for greater branching of the acid, with the ensuing properties, such as the increase of $\mathrm{O}_{2}$ solubility.

The present work was conducted with the aim towards modifying sulfonic acids that contain already the pentafluorosulfur, $\mathrm{SF}_{5}$, group. Most fluorosulfonic acids are obtained from fluoro olefins via their intermediate $\beta-$ sultones. Sultones are sulfonic acid analogues of lactones, i.e., they are internal esters of hydroxy sulfonic acids and in the present case of $\beta$-hydroxy sulfonic acids. The substitution pattern of the acid is determined by the structure of the olefin. Modification of the substituents of an already existing sulfonic acid or its precursor, the sulfonyl fluoride, is thus a possible method for the synthesis of new fluorosulfonic acids, bypassing the need for certain olefins. If the respective olefins cannot be synthesized, or cannot be sulfur trioxidized, then the need for such a general procedure, which involves either synthesis of sultones by a different route, and their subsequen't rearrangement, or the chemical manipulation of the rearranged forms of the sultones and their secondary products, usually acyl fluorides or esters, becomes obvious. A further possibility for modifying sulfonic acids is by integrating them in a polymeric chain. This strategy has led 
to the synthesis of Nafion (a tradename by E.I. DuPont de Nemours). Nafion is a polymeric perfluoro sulfonic acid which is obtained by sequential ionic co-polymerization of a fluorosulfonyl perfluoroalkoxide (obtained from the sultone $\mathrm{CF}_{2} \mathrm{CF}_{2} \mathrm{OSO}_{2}$ ) with hexafluoropropylene oxide, treatment with base, leading to salt formation, decarboxylation and elimination of $\mathrm{NaF}$ and the formation of a terminal fluoroolefin (a polyether). This olefin is then cross-Iinked with tetrafluoroethylene. The last step consists of hydrolyzing the $\mathrm{SO}_{2} \mathrm{~F}$ group, and the result is the formation of a strong-acid membrane. In order to obtain an "SF 5 Nafion" the synthesis of $\mathrm{SF}_{5}$-epoxides or $\mathrm{SF}_{5}$-sultones is necessary. In this context is is also worthwile to mention that these epoxides should provide dielectric materials because the superb electron capture capability of $\mathrm{SF}_{6}$ is carried over to its derivatives. It is generally believed that $\mathrm{SF}_{5} \mathrm{C} \mathrm{N}^{5}$ has a greater dielectric strength than the parent compound and $\mathrm{CF}_{3} \mathrm{SF}_{5}{ }^{6}$ and $\mathrm{SF}_{5} \mathrm{CF}=\mathrm{CF}_{2}{ }^{7}$ actually do have a greater dielectric strength than $\mathrm{SF}_{6}$. Retaining the essential parts of these molecules, it is expected that a polymer of an epoxide should also retain the dielectric property. Epoxides like $\mathrm{SF}_{5} \overline{\mathrm{CFCF}_{2} \mathrm{O}}$ or $\mathrm{SF}_{5} \mathrm{CF}_{2} \overline{\mathrm{CFCF}_{2} \delta}$, when polymerized, would fulfill the structural requirement. Like $\mathrm{CF}_{3}$ analogues, which have also great dielectric strength, one would expect them to be high-boiling, chemically and thermally highly inert, non-poisonous compounds. 8 This would 
make them ideal substitutes of other dielectrics, which are usually noxious compounds. The synthesis and some reactions of two simple $S_{5}$-epoxides are dealt with in PART II of this manuscript. 
CHAPTER III

GENERAL DISCUSSION, DERIVITIZATION OF $\mathrm{F}_{5} \mathrm{SCHCF}_{2} \mathrm{OSO}_{2}$

One of the aims of this research was to investigate ways that would allow for the derivatization of the sultone $\mathrm{SF}_{5} \mathrm{CHCF}_{2} \mathrm{OSO}_{2} \underline{1}$. It will be most useful in this context to review related perfluoroalkyl systems. Fluorosultones are precursors of sulfonic acids via a base catalyzed rearrangement:

$\begin{array}{lllll}\mathrm{R}_{\mathrm{f}} \mathrm{CX}-\mathrm{CF}_{2} & \mathrm{R}_{\mathrm{f}} \mathrm{CXCFO} & \mathrm{SO}_{2} \mathrm{~F} & & \mathrm{R}_{\mathrm{f}} \mathrm{SOCFO}_{3} \mathrm{H}\end{array}$ $\mathrm{X}=\mathrm{H}$, halogen; $\mathrm{R}_{\mathrm{f}}=$ fluoroalkyl

The carbonyl fluoride does not survive the basic conditions necessary for the sequence $\mathrm{SO}_{2} \mathrm{~F}-->\mathrm{SO}_{3} \mathrm{H}$, but can be either converted to esters, and thence to ethers (by treatment with $\mathrm{SF}_{4}$, which causes the conversion $\mathrm{C}=0 \rightarrow \mathrm{CF}_{2}$ ), or hydrolyzed to a $\mathrm{C}-\mathrm{H}$ derivative, as described subsequently.

Fluorinated sultones do exhibit, as investigated particularly thoroughly in Russia, a very diverse derivative chemistry. It was expected to encounter many similar reactions with the present sultone 1 , as were found with other fluoro sultones. They are obtained by the electrophilic addition of sulfur trioxide to a fluoro olefin. Hydrolysis leads then, in sulfuric acid, to the formation of a carboxylic acid - the sulfur from the $\mathrm{SO}_{3}$ is lost - and in basic media to the formation of a carboxylate 
or sulfonate, sometimes accompanied by decarboxylation. 9 Alcoholysis results in the formation of $\mathrm{SO}_{2} \mathrm{~F}$-containing esters. It is of interest to alter these secondary products structurally, as not all olefins that could add $\mathrm{SO}_{3}$ are readily available or do not react in the wished-for manner. There is the possibility of the formation of reactive intermediates, like ketenes or carbanions. of the reactions that were investigated it was generally found that it is especially simple to obtain stable anionic species derived from the sultone $\mathrm{F}_{5} \mathrm{SCHCF}_{2} \mathrm{OSO}_{2}$ (1).

All reactions can be carried out with the respective sulfonyl fluorides, and they can be rather simply converted to sulfonic acids. A close kin to $\mathrm{F}_{5} \mathrm{SCHCF}_{2} \mathrm{OSO}_{2}$ is $\mathrm{F}_{3} \mathrm{CCHCF}_{2} \mathrm{OSO}_{2} 10$ (2), the simplest member of the series $\mathrm{R}_{\mathrm{f}} \mathrm{CHCF}_{2} \mathrm{OSO}_{2}$. Its reaction chemistry has been investigated by Knunyanz (references are given subsequently).

The sultone $\mathrm{CF}_{3} \mathrm{CHCF}_{2} \mathrm{OSO}_{2}$ forms a ketene, $\mathrm{F}_{3} \mathrm{CC}\left(\mathrm{SO}_{2} \mathrm{~F}\right)=\mathrm{C}=0^{11}(\underline{3})$, when treated with the base $\mathrm{F}_{3} \mathrm{~B} \cdot \mathrm{N}\left(\mathrm{C}_{2} \mathrm{H}_{5}\right)_{3}$ in $\approx 69 \%$ yield; when its isomer $\mathrm{CF}_{3} \mathrm{CH}\left(\mathrm{SO}_{2} \mathrm{~F}\right) \mathrm{COF}$ (4), obtained by base catalyzed rearrangement of $\underline{2}$, was treated with the same base, the ketene was obtained in nearly $90 \%$ yield; it could also be obtained by heating the esters $\mathrm{CF}_{3} \mathrm{CH}\left(\mathrm{SO}_{2} \mathrm{~F}\right) \mathrm{COOR}$ ( $\mathrm{R}=$ isopropyl, $t$-butyl, but not ethyl or methyl) with $\mathrm{P}_{2} \mathrm{O}_{5}(\approx 70 \%)$. Originally it was synthesized by sulfurtrioxidation of 3-methoxy-3,3-difluoro-2trifluoromethylpropionic acid.12 This ketene reacts with 
$\mathrm{SO}_{3}$ at $150-160^{\circ} \mathrm{C}$, in contrast to $\left(\mathrm{CF}_{3}\right)_{2}=\mathrm{C}=0$ (ㅁ), which reacts already at $-30^{\circ} \mathrm{C} .13$ From this the much greater electrophilicity of $\mathrm{CF}_{3} \mathrm{C}\left(\mathrm{SO}_{2} \mathrm{~F}\right)=\mathrm{C}=0$, as compared to $\left(\mathrm{CF}_{3}\right)_{2}=\mathrm{C}=0$, is inferred. Sulfur trioxidation is usually assumed to be an electrophilic reaction. 14

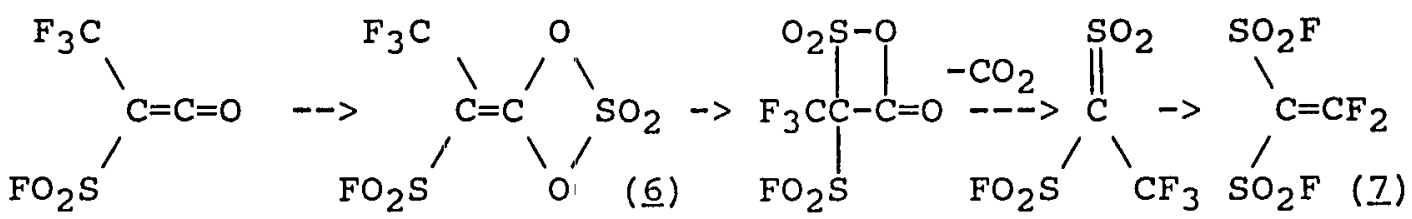

The rather harsh conditions that were necessary for the sulfur trioxidation of $\mathrm{CF}_{3} \mathrm{FC}\left(\mathrm{SO}_{2} \mathrm{~F}\right)=\mathrm{C}=0$ demonstrate the strong electron withdrawing capability of the $\mathrm{SO}_{2} \mathrm{~F}$-group. The reactivity of this ketene has not been established on a broader basis. The result of the sulfur trioxidation reaction implies that there is a substantial difference between the reactivity of $\mathrm{CF}_{3} \mathrm{C}\left(\mathrm{SO}_{2} \mathrm{~F}\right)=\mathrm{C}=0$ and $\left(\mathrm{CF}_{3}\right)_{2} \mathrm{C}=\mathrm{C}=0$, but a detailed comparison is not possible, due to the few experimental results from trifluoromethyl fluorosulfonyl ketene. The reactivity of bistrifluoromethyl ketene is wellinvestigated 15 and it is found that it is susceptible to the attack of electron rich olefins and acetylenes, and both double-bonds can take part in bond formation. For example, the reaction with vinylbenzoate leads to a mixture of

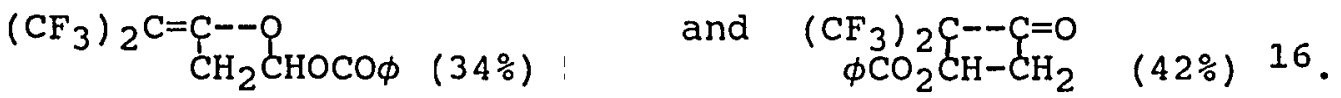
The attack of $\mathrm{SO}_{3}$ on $\mathrm{CF}_{3} \mathrm{C}\left(\mathrm{SO}_{2} \mathrm{~F}\right)=\mathrm{C}=0$ takes place exclusively at the $\mathrm{C}=\mathrm{O}$ bond, while reaction of $\left(\mathrm{CF}_{3}\right)_{2} \mathrm{C}=\mathrm{C}=\mathrm{O}$ with $\left(\mathrm{CH}_{2}=\mathrm{O}\right)_{3}$ 
at $150^{\circ} \mathrm{C}$ (catalyzed by $\mathrm{ZnCl}_{2}$ ) leads only to the cyclobutanone derivative.11 Nucleophilic attack of the oxygen in tropone on the $\mathrm{C}=0$ group in $\mathrm{Cl}_{2} \mathrm{C}_{\alpha}=\mathrm{C}_{\beta}=0$ is probably responsible for the formation of a 1,3-cycloaddition product, and bond formation is between $c_{\alpha}, c_{\beta}$ and tropone.17 This constitutes still the normal direction of addition, which leads here to a $\tau$-lactone.

An important reaction of $\left(\mathrm{CF}_{3}\right)_{2} \mathrm{C}=\mathrm{C}=\mathrm{O}$ is the anionotropic rearrangement to perfluoromethacroyl fluoride (모 $: 18$

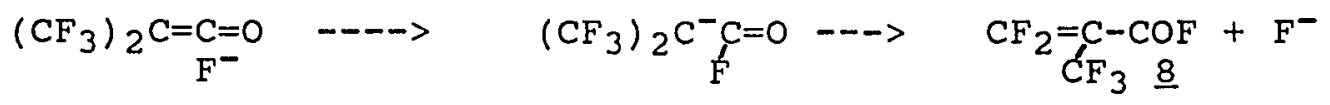

Perfluoromethacryloyl fluoride is a useful intermediate19; for example, it allows one to obtain rather simply derivatives of trifluoromethyl malonic acid ${ }^{20}$ :

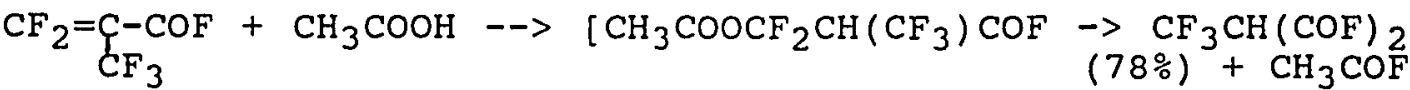

The formation of $\beta$-alkylperfluoromethacryloyl fluoride is even more favored for $\beta, \beta$-difluoro- $\alpha$-trifluoromethyl carboxylic acids; the intermediate ketene that is formed upon heating the carboxylic acid with $\mathrm{P}_{2} \mathrm{O}_{5}$ must have rearranged to the $\beta$-alkylperfluoromethacryloyl fluoride. 21 The dimer of $\left(\mathrm{CF}_{3}\right)_{2} \mathrm{C}=\mathrm{C}=0, \quad\left(\mathrm{CF}_{3}\right)_{2} \mathrm{C}=\mathrm{C}-\mathrm{C}\left(\mathrm{CF}_{3}\right)_{2}$

a $\beta$-lactone, which, after Krespan and England 22 , is formed from perfluoromethacryloyl fluoride and bistrifluoromethyl ketene in an $\mathrm{F}^{-}$-catalyzed reaction, can also be obtained 
from $\left(\mathrm{CF}_{3}\right)_{2} \mathrm{C}=\mathrm{C}=0$ through the catalysis by weak bases like triethyl phosphite, tetraalkylureas, diethylnitrosamine, or dimethylacetamide. 23 The formation of a $\beta$-lactone is unusual in that disubstituted ketenes form more commonly 1,3cyclobutanones as dimers. From the dimer of $\left(\mathrm{CF}_{3}\right)_{2} \mathrm{C}=\mathrm{C}=\mathrm{O}$ one can then synthesize derivatives that contain several $\mathrm{CF}_{3}-$ groups, e.g. the reaction with water results in $1,1,3,3-$ tetratrifluoromethylacetone 24 , or pyrolysis or treatment with $\mathrm{P}\left(\mathrm{OC}_{2} \mathrm{H}_{5}\right)_{3}$ leads to $\left(\mathrm{CF}_{3}\right)_{2} \mathrm{C}=\mathrm{C}=\mathrm{C}\left(\mathrm{CF}_{3}\right)_{2}$ (93\%), which can also be obtained directly from $\left(\mathrm{CF}_{3}\right)_{2} \mathrm{C}=\mathrm{C}=\mathrm{O}$ and $\mathrm{P}\left(\mathrm{OC}_{2} \mathrm{H}_{5}\right)_{3}$. Thus, there is a broad spectrum of reactions that give access to complicated compounds which would otherwise not be easily synthesized.

Addition of an alkoxide to the $c=0$ carbon of ketenes results in ester anions (enolates). Such anions, which have to be regarded within the larger group of allene and heteroallene adducts ${ }^{25}$, were not described for bistrifluoromethyl ketene until recently, when the salt $\left[\left(\left(\mathrm{CH}_{3}\right)_{2} \mathrm{~N}\right)_{3} \mathrm{~S}\right]^{+}\left[\left(\mathrm{CF}_{3}\right)_{2} \mathrm{CCOF}\right]^{-}$was obtained. The stability of these adducts should depend upon the electrophilic nature of ketene; possibly, other nucleophiles could also add. An example is the addition of dichloroketene to tropone (page 12), which is a regioselective reaction, or the addition of amines $\mathrm{HNR}_{2}$, which leads to amides. For bistrifluoromethyl ketene several reactions are described in the literature, which, although not resulting in a ketene salt, must pass 
through an ionic intermediate, formed by nucleophilic attack at the $\mathrm{C}=\mathrm{O}$ group. $\mathrm{NaNO}_{2}$ addition 26 results, after hydrolysis, in hexafluoroacetone oxime $\left(\mathrm{CO}_{2}\right.$ is lost in the reaction) and dimethyl formamide leads to the formation of $\left(\mathrm{CF}_{3}\right)_{2} \mathrm{C}=\mathrm{CHN}\left(\mathrm{CH}_{3}\right)_{2} \cdot{ }^{27}$ Alkoxide adducts are well-investigated for $\mathrm{F}_{3} \mathrm{CC}\left(\mathrm{SO}_{2} \mathrm{~F}\right)=\mathrm{C}=\mathrm{O}$ :

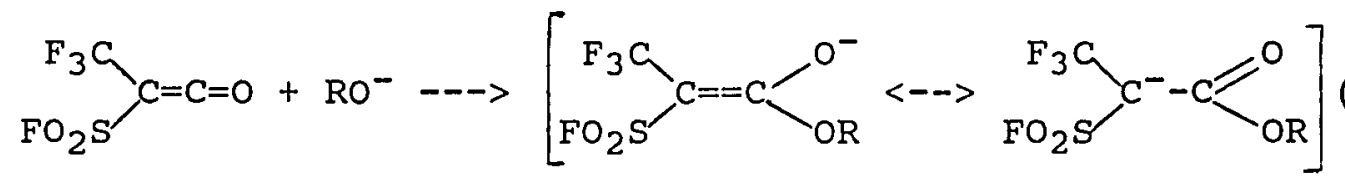

In reality, these anions are obtained by proton abstraction from esters of the composition $\mathrm{F}_{3} \mathrm{CCH}\left(\mathrm{SO}_{2} \mathrm{~F}\right) \mathrm{COOR}$ with suitable bases and they can be chlorinated and brominated ${ }^{10}$ :



$\mathrm{R}=\mathrm{CH}_{3}, \mathrm{C}_{2} \mathrm{H}_{5}$

The bromo adduct $11 \mathrm{a}$ (with $\mathrm{Br}_{2}$ ) was obtained in $60 \%$ yield, and the chloro adduct $\underline{1 \mathrm{lb}}$ (with $\mathrm{SO}_{2} \mathrm{Cl}_{2}$ ) in $80 \%\left(\mathrm{R}=\mathrm{CH}_{3}\right.$ ) and $82 \%\left(\mathrm{R}=\mathrm{C}_{2} \mathrm{H}_{5}\right)$ yield. Chlorination with $\mathrm{N}, \mathrm{N}$-dichlorobenzenesulfonamide led to a dichloro compound:

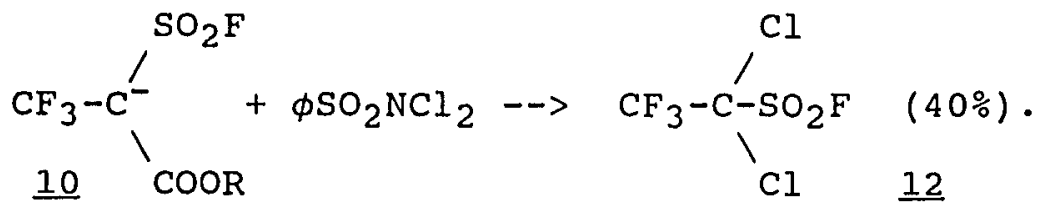

The fate of the ester group was not investigated. Since the esters $\mathrm{CF}_{3} \mathrm{CH}\left(\mathrm{SO}_{2} \mathrm{~F}\right) \mathrm{COOR}(\underline{13})$ descend directly from the sultone $\mathrm{CF}_{3} \mathrm{CHCF}_{2} \mathrm{OSO}_{2}$ (2), there is, at least formally, a 
relationship between the sultone, the ketene and the enolates. This relationship was employed for the sultone $\mathrm{SF}_{5} \overline{\mathrm{CHCF}}_{2} \mathrm{OSO}_{2}$ (1) and found upon study to go beyond formal considerations. It is alo possible to synthesize the ketene $\left(\mathrm{FO}_{2} \mathrm{~S}\right)_{2} \mathrm{C}=\mathrm{C}=\mathrm{O}$ (from $\left.\mathrm{FO}_{2} \mathrm{SCH}=\mathrm{CF}_{2}\right)^{13}$, which would probably be the most electrophilic one of this series. It reacts with methanol with loss of one $\mathrm{SO}_{2} \mathrm{~F}$-group but has not been appreciably investigated.

A comparison with similar fluorosulfonyl carbanions delineates to some degree the reactivity of these species. Other fluorosulfonyl carbanions can be obtained as stable salts or are implicated as intermediates in chemical transformations. The bistrifluoromethyl fluorosulfonyl carbanion (14) is obtained from $\left(\mathrm{CF}_{3}\right)_{2} \mathrm{CHSO}_{2} \mathrm{~F}$ (15) or $\left[\left(\mathrm{CF}_{3}\right)_{2} \mathrm{C}=\mathrm{SO}_{2}\right]_{3}$ with either pyridine or triethylamine ${ }^{28}$ or from 2,2,4,4-tetratrifluoromethyl-1,3-dithietane-1,1 dioxide with $\left[\left(\left(\mathrm{CH}_{3}\right)_{2} \mathrm{~N}\right)_{3} \mathrm{~S}\right]^{+}\left[\mathrm{Si}\left(\mathrm{CH}_{3}\right)_{3} \mathrm{~F}_{2}\right]^{-} .29$ When boiled with pyridine for a long time, the compound $\left(\mathrm{CF}_{3}\right)_{2} \mathrm{CHSO}_{2} \mathrm{~F}$ gave a sulfene complex 26 :

$$
\left(\mathrm{CF}_{3}\right)_{2} \mathrm{CHSO}_{2} \mathrm{~F}+\mathrm{C}_{5} \mathrm{H}_{5} \mathrm{~N}--->\quad\left(\mathrm{CF}_{3}\right)_{2} \mathrm{C}=\mathrm{SO}_{2} \cdot \mathrm{C}_{5} \mathrm{H}_{5} \mathrm{~N} \text { (86\%) }
$$

The free sulfene was obtained by smart and Middleton from their tri-diaminomethylsulfonium salt by treatment with $\mathrm{BF}_{3}$, $\mathrm{BF}_{3} \cdot\left(\mathrm{C}_{2} \mathrm{H}_{5}\right)_{2} \mathrm{O}$ or $\mathrm{SiF}_{4}$, which form $\mathrm{BF}_{4}^{-}$or $\mathrm{SiF}_{5}{ }^{-}$. The sulfene can be intercepted by reaction with suitable captors. Without a reactive partner, the olefin $\mathrm{CF}_{2}=\mathrm{C}\left(\mathrm{CF}_{3}\right) \mathrm{SO}_{2} \mathrm{~F}$ (16) was obtained, apparently formed by rearrangement of the 
sulfene. Substitution reactions of anion $\underline{14}$ were complicated in some cases, e.g. in the reaction with perfluoroacetic anhydride, a $\mathrm{CF}_{3}$ - fluorine was replaced, leading to $\mathrm{CF}_{3} \mathrm{COOCF}_{2} \mathrm{C}^{-}\left(\mathrm{CF}_{3}\right) \mathrm{SO}_{2} \mathrm{~F} \mathrm{HN}\left(\mathrm{C}_{2} \mathrm{H}_{5}\right)_{3}{ }^{+}$and $\mathrm{CF}_{3} \mathrm{COF}$. The mechanism of this transformation was formulated with a consecution of substitutions, additions and eliminations, with the assumption that $\mathrm{CF}_{2}=\mathrm{C}\left(\mathrm{CF}_{3}\right) \mathrm{SO}_{2} \mathrm{~F}(\underline{16})$, as the final intermediate, add $\mathrm{CF}_{3} \mathrm{COO}^{-}$. Based on these considerations it was possible to obtain the cesium salt, $\mathrm{Cs}^{+}\left[\left(\mathrm{CF}_{3}\right)_{2} \mathrm{CSO}_{2} \mathrm{~F}\right]^{-}$ (17) by reacting $\mathrm{CsF}$ with $\mathrm{CF}_{2}=\mathrm{C}\left(\mathrm{CF}_{3}\right) \mathrm{SO}_{2} \mathrm{~F}$ (16), which was obtained from $\left(\mathrm{CF}_{3}\right)_{2} \mathrm{CHSO}_{2} \mathrm{~F} \quad(\underline{15})$ and $\mathrm{F}_{3} \mathrm{~B} \cdot$ Pyridine.26 The cesium salt underwent normal substitution reactions with bromine or sulfuryl chloride, but also with $\mathrm{BrCN}$ :

$$
\left(\mathrm{CF}_{3}\right)_{2} \mathrm{C}^{-} \mathrm{SO}_{2} \mathrm{~F}+\mathrm{BrCN}--->\quad\left(\mathrm{CF}_{3}\right)_{2} \mathrm{C}\left(\mathrm{SO}_{2} \mathrm{~F}\right) \mathrm{CN} \text { (34\%) }
$$

The fact that a carbon substituent could be introduced at the anionic center in this case is significant in light of the failure which was encountered in this study with Kat+ $\left[\mathrm{SF}_{5} \mathrm{C}\left(\mathrm{SO}_{2} \mathrm{~F}\right) \mathrm{COR}\right]^{-} \quad\left(\mathrm{R}=\mathrm{F}, \mathrm{Kat}^{+}=\mathrm{Cs}^{+}\right.$and $\mathrm{Ag}^{+} ; \mathrm{R}=\mathrm{OCH}_{3}$, $\left.\mathrm{Kat}^{+}=\mathrm{HN}\left(\mathrm{C}_{2} \mathrm{H}_{5}\right)_{3}{ }^{+} ; \mathrm{R}=\mathrm{OCH}\left(\mathrm{CH}_{3}\right)_{2}, \mathrm{Kat}^{+}=\mathrm{HN}\left(\mathrm{C}_{2} \mathrm{H}_{5}\right)^{+}, \mathrm{Na}^{+}\right)$.

The sultone $\mathrm{F}_{3} \mathrm{CCHCF}_{2} \mathrm{OSO}_{2}$ (ㄹ), when treated with the base $\mathrm{F}_{3} \mathrm{~B} \cdot \mathrm{N}\left(\mathrm{C}_{2} \mathrm{H}_{5}\right)_{3}(\underline{18}$,"Kazmina's base"), a strong hydrogen fluoride acceptor, leads cleanly to the ketene $\mathrm{F}_{3} \mathrm{CC}\left(\mathrm{SO}_{2} \mathrm{~F}\right)=\mathrm{C}=0$ (Ref.11), although there are two possible directions of HF-abstraction:

$$
\begin{aligned}
& \text { H }--\mathrm{X}->\mathrm{F}_{2} \mathrm{C}={\mathrm{C}-\mathrm{CF}_{2} \mathrm{OSO}_{2}}_{(19}
\end{aligned}
$$

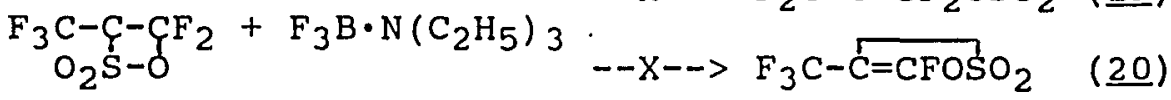

$$
\begin{aligned}
& ---\rightarrow \mathrm{F}_{3} \mathrm{CC}\left(\mathrm{SO}_{2} \mathrm{~F}\right)=\mathrm{C}=\mathrm{O} \quad(\underline{3}, \approx 90 \%)
\end{aligned}
$$


It is contended that the base causes first rearrangement to the isomeric acyl fluoride $\mathrm{F}_{3} \mathrm{CCH}\left(\mathrm{SO}_{2} \mathrm{~F}\right) \mathrm{COF}$ (ㄴ) , which then upon loss of hydrogen fluoride yields trifluoromethyl fluorosulfonyl ketene. The fact that $\mathrm{F}_{2} \mathrm{C}=\widehat{\mathrm{CFF}_{2} \mathrm{OSO}_{2}}$ was not formed was to be expected from the reaction of tetrafluoroallene, $\mathrm{F}_{2} \mathrm{C}=\mathrm{C}=\mathrm{CF}_{2}$ with $\mathrm{SO}_{3}$, which led to $\mathrm{F}_{2} \mathrm{C}=\mathrm{C}-\mathrm{CF}_{2} \mathrm{OSO}_{2} \mathrm{OSO}_{2} ;{ }^{30}$ a difluaromethylene group next to a sultone ring has never been described. Compound $\underline{19}$ is also an isomer of 3 ; if formed, it might undergo in the reaction environment rearrangement to $\underline{3} . \quad \mathrm{F}_{3} \mathrm{C}-\stackrel{\mathrm{C}=\mathrm{CFOSO}}{2}$ was not expected to be found because the addition addition of $\mathrm{SO}_{3}$ to $\left(\mathrm{F}_{3} \mathrm{C}\right)_{3} \mathrm{CC} \equiv \mathrm{CF}^{31}$, led also to $\mathrm{F}_{3} \mathrm{CC}\left(\mathrm{SO}_{2} \mathrm{~F}\right)=\mathrm{C}=0$ ( $\left.\underline{3}\right)$ and passed probably through $\mathrm{F}_{3} \mathrm{C}-{\mathrm{C}=\mathrm{CFOSO}_{2}}_{(20)}$. In this latter reaction the oxathiacyclobutene derivative was formulated as an intermediate, but these compounds might be incapable of existence under ordinary conditions. Indeed, they have never been observed.

In this study, the ketene $\mathrm{F}_{5} \mathrm{~S}$

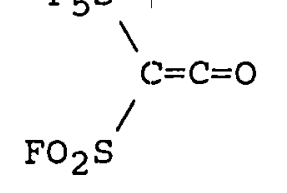

was expected to be the most useful intermediate for further, secondary, transformations of 1 . As with other ketenes with two bulky substituents it was expected to be a stable compound, i.e., it should not be prone to dimerizing without catalysis. It is the internal anhydride of the acid $\mathrm{F}_{5} \mathrm{SCH}\left(\mathrm{SO}_{2} \mathrm{~F}\right) \mathrm{COOH}$, which is not isolable. A similar mechanism 
as with malonic acid can be formulated for the decarboxylation:

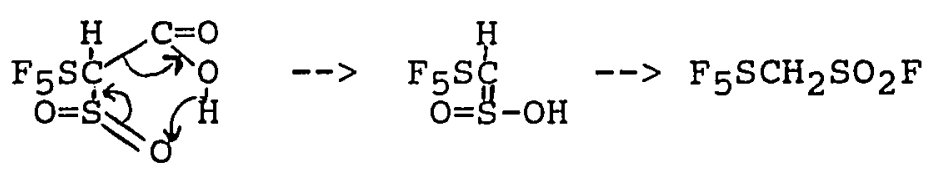

Some conceivable reactions of $\underline{21}$ are delineated below.

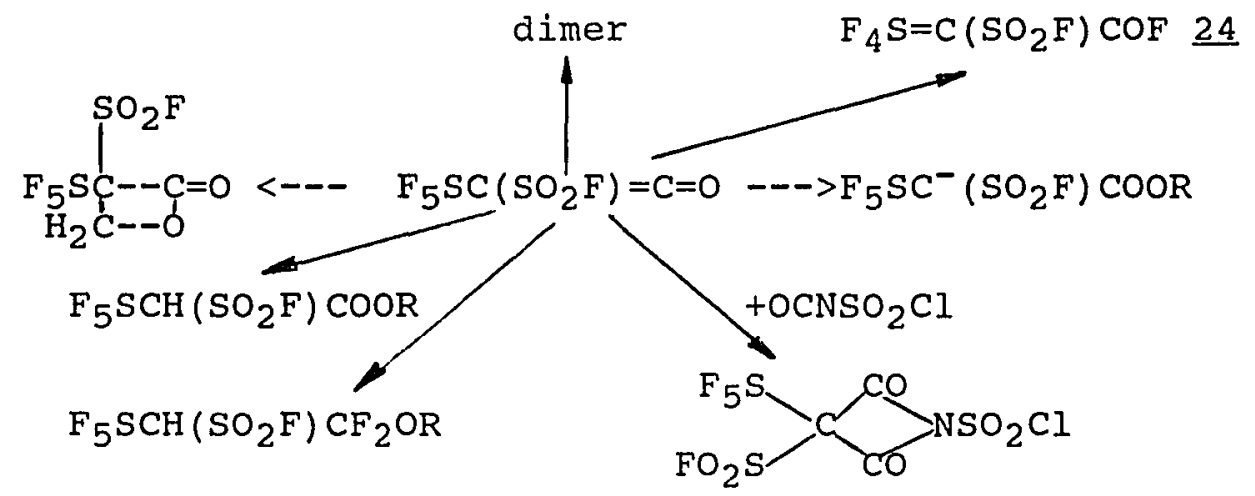

The ketene should be able to react with perfluoro alcohols and this would comprise an easy method for the synthesis of perfluoro esters. These esters can then be converted to perfluoro ethers by treatment with $\mathrm{SF}_{4}+\mathrm{HF}^{32}$. The ether linkage in perfluoro ethers is noted for its chemical and thermal stability. ${ }^{8}$ The carbon-SF 5 bond is also difficult to attack but is weaker than the C-O-C linkage in perfluoroethers. An example is the pyrolysis of 1,4 perfluorothioxane, which forms perfluoro tetrahydrofuran + $\mathrm{SF}_{4}$ at $475^{\circ} \mathrm{C}$ over NaF.33 Cycloadditions with carbonyl compounds, dimerization or nucleophilic reactions of the secondary enolates should lead to compounds substituted in $\alpha$-position of both the $\mathrm{SF}_{5}$ and $\mathrm{SO}_{2} \mathrm{~F}$ group. Moreover, the enolates could be halogenated, and the resulting $\alpha$-halogen 
compounds should undergo reactions with olefins to form $\alpha-C$ substitution products; there is of course the risk that they lose the ester group, as was found with 10 in the reaction with $\phi \mathrm{NCl}_{2}$. A similar ketene, $\mathrm{F}_{5} \mathrm{SCH}=\mathrm{C}=0$, was described by Seppelt etal.34 It formed a dimer upon heating (a $\begin{aligned} \beta \text {-lactone, } & \mathrm{F}_{5} \mathrm{SCH}=\mathrm{C}-\mathrm{Q} \\ & \left.\mathrm{F}_{5} \mathrm{~S}(\mathrm{H}) \mathrm{C}-\mathrm{C}=0\right), \text { polymerized in the reaction with } \mathrm{KF}\end{aligned}$ or CsF, underwent the usual addition reactions of ketenes with ethanol, hydrogen chloride, water and bromine, and was also subject to an anionotropic rearrangement when passed over glass (weakly basic) at $\approx 290^{\circ} \mathrm{C}$ at low pressure. This rearrangement is the analogue to the relationship between $\underline{5}$ and $\underline{8}$.

$$
\mathrm{F}_{5} \mathrm{~S}-\underset{\mathrm{H}}{\mathrm{C}}=\mathrm{C}=\mathrm{O} \quad(\underline{5 \mathrm{a}}) \quad-\rightarrow \quad \mathrm{F}_{4} \mathrm{~S}=\underset{\mathrm{H}}{\mathrm{C}} \mathrm{CFO} \quad(\underline{8 \mathrm{a}})
$$

The $\mathrm{SF}_{4}$ derivatives that are obtained are very reactive compounds (sulfur ylides) and are prone to undergoing polar additions, such that cis adducts are obtained. 35 cis refers to the octahedral sulfur environment. There is thus a possibility to alter the $\mathrm{SF}_{5}$ group by passing through intermediate sulfur ylides. Compound $\underline{8 a}$ can be hydrolyzed to give the compound $\left(\mathrm{F}_{2} \mathrm{~S}=\mathrm{O}\right)=\mathrm{CHCFO}(\underline{8 \mathrm{~b}})$, or it reacts with alcoholic base to form cis- $\left(\mathrm{F}_{4} \mathrm{SOC}_{2} \mathrm{H}_{5}\right) \mathrm{CH}_{2} \mathrm{COOC}_{2} \mathrm{H}_{5} \cdot 36$

Darragh has shown that $\mathrm{R}-\mathrm{SF}_{4}-\mathrm{Cl}$ (trans) reacts completely analogously to $\mathrm{SF}_{5} \mathrm{Cl}$ with olefins and acetylenes to form, for example with ethylene, trans-ClCH $\mathrm{CH}_{2} \mathrm{SF}_{4}-\mathrm{R} .37$ Complementary results were also obtained by Shreeve. 38 There is thus the possibility that the $c i s-\mathrm{RSF}_{4} \mathrm{Cl}$ adducts react 
similarly to the trans-adducts. With the latter, configurational stability was observed, trans $\mathrm{ClSF}_{4} \mathrm{R}$ gave a product trans-ClC $\mathrm{SF}_{4} \mathrm{R} \quad\left(\mathrm{C}_{2}\right.$ stands for a two-carbon fragment originating in a $\mathrm{C}=\mathrm{C}$ or $\mathrm{C} \equiv \mathrm{C}$ bond). For the cis-compounds no comparable results are available. The corresponding bromine adduct, cis $-\mathrm{SF}_{4}-\mathrm{Br}$ would, naturally, be more reactive than the chlorine adduct, as the s-halogene bond-strength in $\mathrm{SF}_{5} \mathrm{X}$ falls in the order $\mathrm{X}=\mathrm{F}>\mathrm{Cl}{ }^{39}(>\mathrm{Br}>\mathrm{I})$. For bromine no value is published, but the trend and the greater reactivity of $\mathrm{SF}_{5} \mathrm{Br}$ as compared to $\mathrm{SF}_{5} \mathrm{Cl}$ support this conclusion. $\mathrm{A}$ comparable sulfur-iodine bond has not yet been detected. When $\mathrm{CH}_{2}=\mathrm{SF}_{4}$ is allowed to react with $\mathrm{HI}$, formation of iodine is observed 40 . In only one case the existence of $S_{5} I$ has been conjectured 41 , and in this case (the reaction: $\left.\mathrm{S}_{2} \mathrm{~F}_{10}+2 \mathrm{C}_{2} \mathrm{~F}_{4}+\mathrm{I}_{2} \rightarrow 2 \mathrm{~F}_{5} \mathrm{SCF}_{2} \mathrm{CF}_{2} \mathrm{I}\right)$ it is easy to formulate an alternate mechanism. It is likely that iodine would conform to the general trend of falling $s-x$ bondstrength. 
CHAPTER IV

RESULTS AND DISCUSSION

SYNTHESIS AND REACTIONS OF $\mathrm{F}_{5} \mathrm{SC}\left(\mathrm{SO}_{2} \mathrm{~F}\right)=\mathrm{C}=0$

To prepare the ketene $\underline{21}, \mathrm{~F}_{5} \mathrm{SC}\left(\mathrm{SO}_{2} \mathrm{~F}\right)=\mathrm{C}=0$, three possibilities were considered. As with $\underline{3}$, the ketene should be formed either from $\underline{1}$ (the sultone) or $\mathrm{F}_{5} \mathrm{SCH}\left(\mathrm{SO}_{2} \mathrm{~F}\right) \mathrm{COF}(\underline{22})$ and 18 or from an ester $\mathrm{F}_{5} \mathrm{SCH}\left(\mathrm{SO}_{2} \mathrm{~F}\right) \mathrm{COOR}\left(\mathrm{R}=\left(\mathrm{CH}_{3}\right)_{2} \mathrm{CH}\right.$ or $\left(\mathrm{CH}_{3}\right)_{3} \mathrm{C}$ ) and $\mathrm{P}_{4} \mathrm{O}_{10}$, analogously to $\underline{3}$. All three methods did indeed work, but only the dehydrofluorination of $\underline{22}$ was of practical value. 1 and 18 produced a mixture:

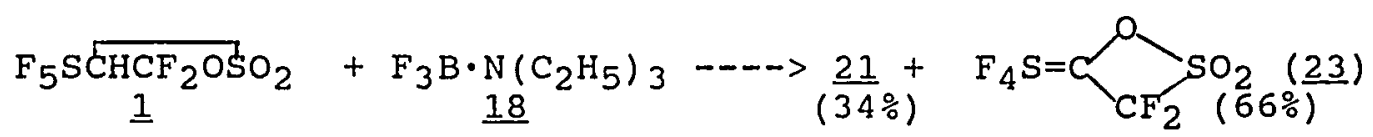

Compound $\underline{23}$ is a novel sultone, and its reactions will be considered later (page 44). The separation of $\underline{21}$ and $\underline{2} \underline{3}$ was considerably difficult and made the method, besides the low yield for the ketene in the reaction, impractical.

The second method employed dehydrofluorination of $\underline{22}$ :

$$
\mathrm{F}_{5} \mathrm{SCH}\left(\mathrm{SO}_{2} \mathrm{~F}\right) \mathrm{COF}+\underline{18} \rightarrow \underline{21}\left(+\mathrm{BF}_{4}^{-}+\mathrm{HN}^{+}\left(\mathrm{C}_{2} \mathrm{H}_{5}\right)_{3}\right)
$$

\section{$\underline{22}$}

This method worked very well, and yields of up to $95 \%$ of the ketene (of high purity) could be regularly obtained.

The third method consisted of heating an ester with phosphorus pentoxide: 
$\mathrm{F}_{5} \mathrm{SCH}\left(\mathrm{SO}_{2} \mathrm{~F}\right) \mathrm{COOCH}\left(\mathrm{CH}_{3}\right)_{2}+\mathrm{P}_{4} \mathrm{O}_{10} \rightarrow \underline{21}$

Although the ketene may be synthesized in this way, there are several difficulties involved. For one, the yields in this reaction were not very consistent ( $\approx 50-90 \%)$ from run to run and dropped when larger quantities were used (e.g. from $2.65 \mathrm{~g}$ of ester $1.6 \mathrm{~g}$ of crude $\underline{21}$ could be collected, but from $8.7 \mathrm{~g}$ of ester only $\approx 1 \mathrm{~g}$ ). Also, there was always a contamination with $\mathrm{F}_{5} \mathrm{SCH}_{2} \mathrm{SO}_{2} \mathrm{~F}$, and the reaction was very time-consuming, even when only small quantities of $\underline{21}$ were made.

The synthesis of the ester from 1 is accomplished in the following way :

$\underline{1}+\left(\mathrm{CH}_{3}\right)_{2} \mathrm{CHOH}+\mathrm{NaF} \longrightarrow \mathrm{F}_{5} \mathrm{SCH}\left(\mathrm{SO}_{2} \mathrm{~F}\right) \mathrm{COOCH}\left(\mathrm{CH}_{3}\right)_{2}(\underline{21 \mathrm{a}}, 73 \%)+$ $\mathrm{NaHF}_{2}$

It is recommendable to have NaF present, as otherwise the yields were found to be lower, as for the methyl ester:

$$
\underline{1}+\mathrm{CH}_{3} \mathrm{OH}--->\quad \mathrm{F}_{5} \mathrm{SCH}\left(\mathrm{SO}_{2} \mathrm{~F}\right) \mathrm{COOCH}_{3}(\underline{21 \mathrm{~b}}, 35 \%)
$$

When one considers the yield of the (isopropyl) ester synthesis in the conversion of $\underline{1}-\rightarrow \underline{21}$ also, one has an overall yield of $\approx 40 \%$. This could be improved by converting only small quantities of the ester per run, but then one has an additional time-expenditure and even more phosphorous pentoxide consumption.

The dehydrofluorination of $\underline{22}$ requires first rearranging 1 to $\underline{22}$. Interestingly, $\underline{21}$ is found in this rearrangement as a by-product in varying ratios. The 
comparatively weak base NaF acts apparently also as a dehydrofluorination reagent, but it was not possible to bring this reaction to completion. Sodium fluoride failed to give pure 21 even upon warming to $135^{\circ} \mathrm{C}(15 \mathrm{~h})$; under these conditions some carbonyl fluoride and a 50:50 mixture of $\underline{21}$ and $\underline{22}$ were produced. It was also observed that the rearrangement of $\underline{1}$ to $\underline{22}$ only went well when a large excess of NaF was used; a further improvement could be achieved by powdering the NaF. In this case mixtures with more than $80 \%$ ketene contents could be obtained. The reaction vessel had to be heated in vacuo for several hours to $\approx 120^{\circ} \mathrm{C}$ in order to drive off the apparently absorbed $\underline{21}$. HF would transfer under the same conditions from $\mathrm{NaHF}_{2}$ (a method to obtain HF of high purity).

When $\underline{21}$ was heated to $220^{\circ} \mathrm{C}(4 \mathrm{~h})$, it could be almost completely recovered (98\%). It shares this property with other perfluoro ketenes ${ }^{14}$.

of interest were reactions of $\underline{21}$ with electrophiles and with nucleophiles; of the electrophilic reagents, $\mathrm{SO}_{3}$ was particularly interesting, as this would not only allow one to compare the electrophilicity of $\underline{21}$ with $\underline{3}$ and $\underline{5}$, but could also lead to the sulfur ylide $\underline{z}$.

When 21 was subjected to sulfur trioxidation, the expected product ${ }^{11} \quad \mathrm{~F}_{4} \mathrm{~S}=\mathrm{C}\left(\mathrm{SO}_{2} \mathrm{~F}\right)_{2}$ (see reference above) was not observed: 
<smiles>[R5]SC(=O)S[R5]#[SH]</smiles>
Up to $240^{\circ} \mathrm{C}$ almost no reaction was observed in two days, but at $270^{\circ} \mathrm{C}$ rather quick formation of $\mathrm{CO}_{2}$ occurred, accompanied by the formation of dark material. It is not unlikely that the $\mathrm{SF}_{4}=$ product $\underline{7}$ had been formed indeed but did not withstand the high temperature.

The order of electrophilicity (= the reverse order of nucleophilicity) is thus: $\left(\mathrm{CF}_{3}\right)_{2} \mathrm{CCO}\left(-30^{\circ} \mathrm{C}\right)<\mathrm{CF}_{3}\left(\mathrm{SO}_{2} \mathrm{~F}\right) \mathrm{CCO} \cdot\left(160^{\circ} \mathrm{C}\right)<\underline{21}\left(280^{\circ} \mathrm{C}\right)$ The numbers in parentheses indicate the reaction temperature with $\mathrm{SO}_{3}$ (p. 11).

Corresponding to this order, there is a great proneness to undergo nucleophilic additions. Whereas bistrifluoromethyl ketene undergoes $\mathrm{F}^{-}$-catalyzed rearrangement (with $\mathrm{NaF}$ ) and the intermediate $\left(\mathrm{CF}_{3}\right)_{2} \mathrm{C}^{-} \mathrm{COF} \mathrm{Na}^{+}$is assumed, 42 and a mercury compound, $\left(\left(\mathrm{CF}_{3}\right)_{2} \mathrm{C}(\mathrm{CFO})\right)_{2} \mathrm{Hg}$, was described in 1972 by Knunyanz et al.43, the corresponding anion could only recently be isolated with the counterion, $\left(\left(\mathrm{CH}_{3}\right)_{2} \mathrm{~N}\right)_{3} \mathrm{~S}^{+44}$, and no corresponding results are available for trifluoromethyl fluorosulfonyl ketene, it is found that anion formation is the predominant mode of reaction of pentafluorothio fluorosulfonyl ketene.

A pertinent observation was made in the NaF-catalyzed rearrangement of $\underline{1}$ to $\underline{22}$. Although both $\underline{21}$ and $\underline{22}$ are 
volatile liquids, it was noticed that it took a long time $(\approx 2 \mathrm{~h})$ and heating $\left(100-120^{\circ} \mathrm{C}\right)$ to collect most of the product by vacuum transfer. From these observations one assumes the formation of a complex between either $\underline{21}$ or $\underline{22}$ and $\mathrm{NaF}$ or $\mathrm{NaHF}_{2}$. Such a complex was later indeed observeã, when the residual solid of the rearrangement $\underline{1} \rightarrow \underline{22}$ was extracted with dry $\mathrm{CH}_{3} \mathrm{CN}$ but could not be isolated; according to ${ }^{19} \mathrm{~F}$ n.m.r. data it is likely that it was $\underline{21} \cdot \mathrm{NaF}$ (25e). Nuclear magnetic resonance data are given in tabular form together with other identified complexes of the form 21.MF (Table 1, p.65). The yield of this rearrangement was $\approx 95$ per cent, and together with the conversion of the acyl fluoride to $\underline{21}$, a total yield of $\approx 90 \%$ can be achieved in the conversion $\underline{1} \rightarrow->\underline{21}$. For most reactions $\underline{21}$, as obtained by reaction of $\underline{22}$ and $\underline{18}$, did not require further purification. of the possible reactions of 21 , its rearrangement to $\underline{24}$ did not occur, instead the compound that would have normally been the intermediate in the reaction, $\underline{25}$, was isolated as the sole product:

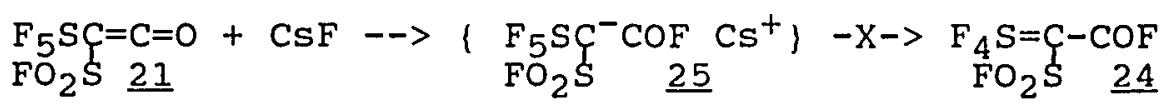

A similar intermediate was formulated in the anionotropic re-arrangement of $\underline{5}$ to $\underline{8}$. Ketene $\underline{5 a}$ is converted to $\underline{8} a$ with glass, but not with CsF or KF:

$$
\begin{aligned}
& \left(\mathrm{CF}_{3}\right)_{2} \mathrm{C}=\mathrm{C}=\mathrm{O} \quad(\underline{5})+\mathrm{NaF} \rightarrow-\rightarrow \quad \mathrm{CF}_{2}=\mathrm{C}\left(\mathrm{CF}_{3}\right) \mathrm{COF}(\underline{8}) \\
& \left.\left.\mathrm{F}_{5} \mathrm{SCH}=\mathrm{C}=0 \quad(\underline{5 a}) \quad \text { glass }\right\} \rightarrow-\rightarrow \quad \mathrm{F}_{4} \mathrm{~S}=\mathrm{CHCOF} \text { (8a }\right)
\end{aligned}
$$


The strongly electron withdrawing capability of the $\mathrm{SO}_{2} \mathrm{~F}$ group is evidenced by the formation of $\underline{25}$. According to an earlier investigation, the $\mathrm{SF}_{5}$ group has a stronger chargestabilizing effect than a $\mathrm{CF}_{3}$ group 45 ; thus there are two highly electronegative substituents at an $\mathrm{sp}^{2}$ carbon, which leads to the proneness for nucleophilic addition. A similar reaction was observed with silver fluoride, where the fluoride dissolved in a vigorous reaction, forming $\mathrm{Ag}^{+}$ $\left[\mathrm{F}_{5} \mathrm{SC}\left(\mathrm{SO}_{2} \mathrm{~F}\right) \mathrm{COF}\right]^{-}(\underline{25 \mathrm{~d}})$, which was light and heat sensitive. Compound $\underline{25}$ was investigated in more detail and will be discussed in a subsequent part.

The reactivity of $\underline{21}$ towards nucleophiles offered the possibility of several derivations. It should have been possible to generate an azide, which by the curtius degradation should lead to an amine:

$\underline{21}+\mathrm{NaN}_{3} \rightarrow \mathrm{F}_{5} \mathrm{SC}^{-}\left(\mathrm{SO}_{2} \mathrm{~F}\right) \mathrm{CON}_{3} \mathrm{Na}^{+}(\underline{46}) \rightarrow \mathrm{F}_{5} \mathrm{SCH}\left(\mathrm{SO}_{2} \mathrm{~F}\right) \mathrm{CON}_{3}$

However, although it was found by ${ }^{19} \mathrm{~F} \mathrm{n.m.r.} \mathrm{that} \mathrm{the}$ reaction passed through an anionic intermediate, only $\mathrm{F}_{5} \mathrm{SCH}_{2} \mathrm{SO}_{2} \mathrm{~F}$ was found as product. It must be assumed that the azide was hydrolyzed faster than it could have undergone loss of nitrogen and rearranged. Hydrolysis would have occurred when aqueous acid was added to convert the anion to the azide $\mathrm{F}_{5} \mathrm{SCH}\left(\mathrm{SO}_{2} \mathrm{~F}\right) \mathrm{CON}_{3}$. The carboxylic acid, formed from the azide, is not stable towards decarboxylation. of special interest would have been the formation of a 
ketene dimer, which should have been, by analogy to 2 or the dimer of $\underline{5 a}$, a $\beta$-lactone, with reactions similar to $\underline{9}$. To effect its formation, reaction with a weak base, tetramethyl urea, was tried. No dimer formation was observed, but instead a crystalline, very mositure-sensitive compound was isolated.

$$
\mathrm{F}_{5} \mathrm{SC}\left(\mathrm{SO}_{2} \mathrm{~F}\right)=\mathrm{C}=\mathrm{O}+\left(\left(\mathrm{CH}_{3}\right)_{2} \mathrm{~N}\right)_{2} \mathrm{C}=\mathrm{O} \rightarrow \underline{21} \cdot\left(\left(\mathrm{CH}_{3}\right)_{2} \mathrm{~N}\right)_{2} \mathrm{C}=\mathrm{O} \quad \underline{26}
$$

Pertinent features of this compound are the relatively low $\mathrm{C}=\mathrm{O}$ stretch vibrations in the infrared spectrum and the typical chemical shifts of anionic $\mathrm{SF}_{5}$ compounds (Table 1 , p. 65), i.e., the $\mathrm{S}-\mathrm{F}$ resonances in the $\mathrm{SF}_{5}$ and $\mathrm{SO}_{2} \mathrm{~F}$ group are observed downfield from appropriate model compounds. The $\mathrm{C}=0$ resonance frequencies lie very close together, so that it is not possible to assign a certain infrared band to a certain carbonyl group. In principle one could infer a probable structure from that knowledge. The methyl protons are observed as a singlet in $1_{H}$ n.m.r.spectroscopy. The structure that accounts best for the properties of $\underline{26}$ has the oxygen bonded to the carbonyl group of ketene 21 , resulting in an oxonium compound:

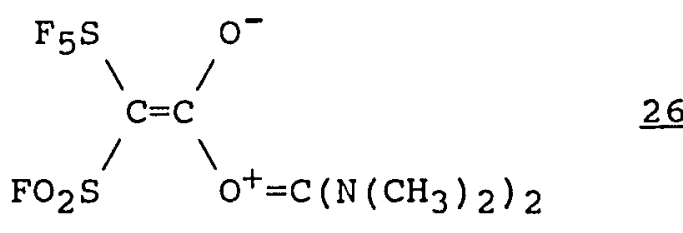

The compound is hydrolyzed completely and instantly by water to $\mathrm{F}_{5} \mathrm{SCH}_{2} \mathrm{SO}_{2} \mathrm{~F}, \mathrm{CO}_{2}$ and tetramethyl urea.

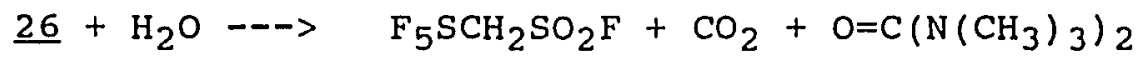


With triethyl amine and $\underline{21}$ a similar reaction seems to take place, but darkening occurs. The infrared spectrum of the dark residue has a $C=0$ band at $\approx 1700 \mathrm{~cm}^{-}$; in this case an ammonium salt should have been formed. The product was not isolated, however.

It is now clear that $\underline{21}$ could be made by the above dehydrofluorination of $\underline{22}$ only because $\mathrm{F}_{3} \mathrm{~B} \cdot \mathrm{N}\left(\mathrm{C}_{2} \mathrm{H}_{5}\right)_{3}$ is a base of low nucleophilicity, and did consequently not react with the ketene.

An attempt to add methoxide ion to $\underline{21}$ was partially successful; it was observed (by ${ }^{19} \mathrm{~F}$ n.m.r. spectroscopy) that two anionic species were formed, one of them containing a COF group (probably $\left.\mathrm{Na}^{+}\left[\mathrm{F}_{5} \mathrm{SC}\left(\mathrm{SO}_{2} \mathrm{~F}\right) \mathrm{COF}\right]^{-}\right)$. The reaction was vigorous and the $\left(\mathrm{CH}_{3} \mathrm{CN}\right)$ solution darkened at the same time. The second anion (the major product) that was formed must have been the sodium salt,

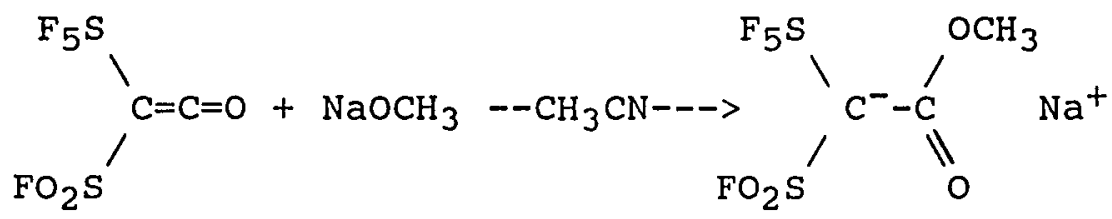

The reaction could not be controlled so as to allow for the formation of the ester enolate alone, but these compounds can be obtained very efficiently by another route. A further reaction is the addition of $\mathrm{HgF}_{2}$ to 21 . This should provide for the compound $\left(\mathrm{F}_{5} \mathrm{SC}\left(\mathrm{SO}_{2} \mathrm{~F}\right) \mathrm{COF}\right)_{2} \mathrm{Hg}(\underline{45})$. Mercury compounds offer some interesting possibilities, as found with other perfluoromercurials 46 , especially the formation of sulfides. 
These could then be converted to another $\mathrm{SF}_{5}$ compound, viz: $\left(\mathrm{F}_{5} \mathrm{SC}\left(\mathrm{SO}_{2} \mathrm{~F}\right) \mathrm{COF}\right)_{2} \mathrm{Hg} \quad(\underline{45}) \quad \rightarrow \quad\left(\mathrm{F}_{5} \mathrm{SC}\left(\mathrm{SO}_{2} \mathrm{~F}\right)(\mathrm{COF}) \mathrm{S}\right)_{2} \mathrm{Hg} \quad \rightarrow$ $\mathrm{F}_{5} \mathrm{~S}\left(\mathrm{SO}_{2} \mathrm{~F}\right)(\mathrm{COF}) \mathrm{CSH} \rightarrow-\left(\mathrm{F}_{5} \mathrm{~S}\left(\mathrm{SO}_{2} \mathrm{~F}\right)(\mathrm{COF}) \mathrm{CS}\right)_{2} \quad->$ $\left(\mathrm{F}_{5} \mathrm{~S}\right)_{2} \mathrm{C}\left(\mathrm{SO}_{2} \mathrm{~F}\right) \mathrm{COF}$, or a bis-sulfuryl derivative, e.g., $\mathrm{F}_{5} \mathrm{SCCOF}\left(\mathrm{SO}_{2} \mathrm{~F}\right)_{2}$, could be obtained by oxidation of the mercurial.

The ${ }^{19} \mathrm{~F}$ n.m.r spectrum of the product of this reaction, in which $\mathrm{HgF}_{2}$ dissolves in $\mathrm{CH}_{3} \mathrm{CN}$ in the presence of $\underline{21}$, is indicative of salt formation (see table 1 p. 65), and it can be isolated as a white amorphous solid by pumping off the solvent $\left(\mathrm{CH}_{3} \mathrm{CN}\right)$. The i.r. spectrum indicates that there is a $\mathrm{CH}_{3} \mathrm{C} \equiv \mathrm{N}-\underline{45}$ complex, and the melting behavior shows gradual softening with final melting at $\approx 80^{\circ} \mathrm{C}$.

Further reactions of $\underline{2} 1$ involved the addition of other nucleophiles. With water, the following reaction took place:

$\underline{21}+\mathrm{H}_{2} \mathrm{O} \longrightarrow-\left\{\mathrm{F}_{5} \mathrm{SCH}\left(\mathrm{SO}_{2} \mathrm{~F}\right) \mathrm{COOH}\right\} \rightarrow \mathrm{F}_{5} \mathrm{SCH}_{2} \mathrm{SO}_{2} \mathrm{~F}+\mathrm{CO}_{2}$ When 21 was exposed to air, a solid formed, which, when pressed on $\mathrm{KBr}$ plates, evolved a gas. This solid must have been the intermediate carboxylic acid. It is often observed that carboxylic acids that contain two strongly electronegative substituents at $C_{\alpha}$ are not stable towards decarboxylation. Malonic acid behaves in this manner, as do other $\beta$-carbonyl carboxylic acids, as well as the half ester of trifluoromethyl malonic acid. 47

Alcohols combined with $\underline{21}$ to form esters: $\underline{21}+\left(\mathrm{CH}_{3}\right)_{2} \mathrm{CHOH}-\rightarrow \mathrm{F}_{5} \mathrm{SCH}\left(\mathrm{SO}_{2} \mathrm{~F}\right) \mathrm{COOCH}\left(\mathrm{CH}_{3}\right)_{2} \underline{21 \mathrm{a}}$ 


$$
\begin{array}{lll}
\underline{21}+\mathrm{CF}_{3} \mathrm{CH}_{2} \mathrm{OH} & --> & \mathrm{F}_{5} \mathrm{SCH}\left(\mathrm{SO}_{2} \mathrm{~F}\right) \mathrm{COOCH}{ }_{2} \mathrm{CF}_{3} \\
\underline{21}+\left(\mathrm{CH}_{3}\right)_{2} \mathrm{CHOH}-\longrightarrow & \mathrm{F}_{5} \mathrm{SCH}\left(\mathrm{SO}_{2} \mathrm{~F}\right) \mathrm{COO}\left(\mathrm{CH}\left(\mathrm{CH}_{3}\right)_{2}\right. \\
\underline{21}+\left(\mathrm{CH}_{3}\right)_{3} \mathrm{COH} \longrightarrow-> & F_{5} \mathrm{SCH}\left(\mathrm{SO}_{2} \mathrm{~F}\right) \mathrm{COOC}\left(\mathrm{CH}_{3}\right)_{3}
\end{array}
$$

Interestingly, the t-butyl ester was not a stable compound; it decomposed upon distillation, and $\mathrm{F}_{5} \mathrm{SCH}_{2} \mathrm{SO}_{2} \mathrm{~F}$ was found as a product. This decomposition occurred also at lower temperature, and a purple product resulted at room temperature after a few days.

With $\mathrm{P}\left(\mathrm{OC}_{2} \mathrm{H}_{5}\right)_{3}$ only a complex mixture was found, and a major product was an acyl fluoride. The products could, however, not be separated nor identified. A similar reaction with $\underline{5}$ and $\mathrm{P}\left(\mathrm{OC}_{2} \mathrm{H}_{5}\right)_{3}$ led to tetrakistrifluoromethyl allene 48 .

$$
\underline{21}+\mathrm{P}\left(\mathrm{OC}_{2} \mathrm{H}_{5}\right)_{3}--->\text { complex mixture }
$$

Diethyl amine formed the amide:

$$
\underline{21}+\mathrm{HN}\left(\mathrm{C}_{2} \mathrm{H}_{5}\right)_{2}--->\mathrm{F}_{5} \mathrm{SCH}\left(\mathrm{SO}_{2} \mathrm{~F}\right) \operatorname{CON}\left(\mathrm{C}_{2} \mathrm{H}_{5}\right)_{2} \text { (47\%) } \underline{27}
$$

The low yield is related to the vigorous nature of the reaction; although the reactants were brought together at low temperature in $\mathrm{CH}_{2} \mathrm{Cl}_{2}$ solution, the formation of a lot of dark tarry product could not be prevented. The amide 27 shows two $\mathrm{CH}_{3}$ groups in the $l_{\mathrm{H}}$ n.m.r. spectrum, and the methylene protons appear as a multiplet. This is certainly an indication of the hindered rotation that is found around the $\mathrm{C}-\mathrm{N}$ bond. The structure of this solid was determined by $\mathrm{x}$-ray crystallography (p.71).

21 reacted readily and cleanly with trimethyl silane 
upon warming to room temperature to give a white solid that was highly susceptible to moisture and exhibited a repugnant odor. After sublimation it was obtained as colorless regular crystals. The structure of this material is not certain. Addition of the silicon could have taken place either at the oxygen or the carbon of the carbonyl group, resulting in the following compositions:

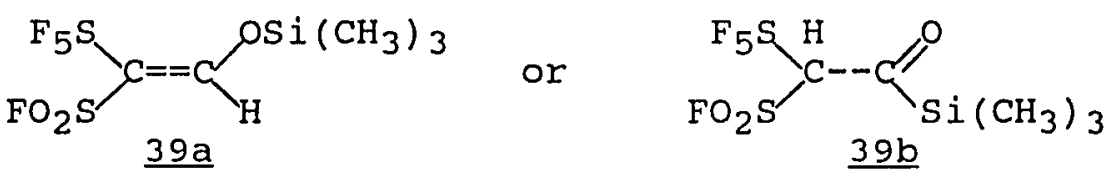

A distinction between these two structures is difficult. As mentioned before, some $\mathrm{SF}_{5}$ olefins have very low i.r. frequencies and intensities. Trimethylsilylketones have also unusually low i.r. frequencies $\left(1600-1640 \mathrm{~cm}^{-1}\right.$ ) (see reference below). A distinction between $\underline{39 a}$ and $\underline{39 b}$ is therefore not possible on the basis of the infrared spectrum. Most trimethylsilyl ketones are yellow 49 , and the adduct $21 \cdot \mathrm{HSi}\left(\mathrm{CH}_{3} \perp_{3}\right.$ is colorless. One distinctive property of trimethylsilyl ketones is the low field position of the carbonyl group in the ${ }^{13} \mathrm{C}$ n.m.r. spectrum 50 , as compared to normal carbonyl compounds. The $\mathrm{C}=0$ resonance is usually observed between 220 and $240 \mathrm{ppm}\left(\mathrm{Si}\left(\mathrm{CH}_{3}\right)_{4}=0\right)$. In the ${ }^{13} \mathrm{C}$ n.m.r. spectrum of $21 \cdot S i H\left(\mathrm{CH}_{3}\right)_{3}$ no such resonance is seen. One has to assign the structure of the adduct to $39 \mathrm{a}$. other reactions of $\underline{21}$ were investigated. With $\mathrm{SF}_{5} \mathrm{Br}$ a transformation was observed that resulted mainly in BrF addition: 


$$
\underline{21}+\mathrm{SF}_{5} \mathrm{Br} \longrightarrow \mathrm{F}_{5} \mathrm{SCBr}\left(\mathrm{SO}_{2} \mathrm{~F}\right) \mathrm{COF}(\underline{28})+\left[\mathrm{SF}_{4}\right]
$$

28 could not be obtained in pure form from this reaction; all attempts to free it from attendant compounds failed, but there is another route leading to it that yields a purer product. This will be described in the chapter dealing with 25. An intermediate formation of a crystalline compound was observed; although not identified, this could correspond to the intermediate formation of $\mathrm{F}_{5} \mathrm{SCBr}\left(\mathrm{SO}_{2} \mathrm{~F}\right) \mathrm{C}(0) \mathrm{SF}_{5}$. Trioxane, used as a source of formaldehyde, reacts with $\underline{21}$ (at $150^{\circ} \mathrm{C}$ ) to give initially a primary product. The colorless liquid that is obtained is characterized by a strong, although not unpleasant, pungent odor. Normally, by analogy to $\underline{5}$, this product should be a $\beta$-lactone,

$$
\begin{gathered}
\mathrm{F}_{5} \mathrm{~S} \\
\mathrm{FO}_{2} \mathrm{~S} C-\mathrm{C}=0 \\
\mathrm{H}_{2} \mathrm{C}--\mathrm{d},
\end{gathered}
$$

but the absence of a carbonyl band in the i.r. spectrum does not support this composition. On the other hand, there is a very weak band at $1616 \mathrm{~cm}^{-1}$. If this is taken as an indication for a double bond (some $\mathrm{SF}_{5}$ olefins show very weak or no $\mathrm{C}=\mathrm{C}$ bands at $\mathrm{al} \mathrm{l}^{51}$ ) together with the information from the proton n.m.r spectrum (two resonances of equal intensity but different couplings at $\approx 7 \mathrm{ppm}$ ) and the mass spectrum, and taking into account its rather high volatility (i.e., not a polymer), one is led to assuming the following structure:

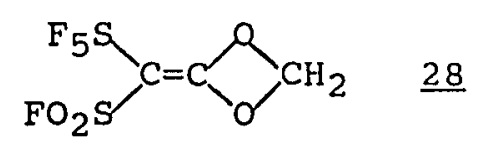


This formulation would also fall into line with the reactions that are observed with other reagents, i.e. nucleophilic attack at $\mathrm{C}=\mathrm{O}$ :

$$
\mathrm{F}_{5} \mathrm{~S}\left(\mathrm{SO}_{2} \mathrm{~F}\right)=\mathrm{C}=\mathrm{O}+\mathrm{CH}_{2}{ }^{+} \mathrm{O}^{-} \longrightarrow \mathrm{F}_{5} \mathrm{~S}\left(\mathrm{SO}_{2} \mathrm{~F}\right)=\underset{\mathrm{O}-\mathrm{CH}_{2}}{\mathrm{C}-\mathrm{O}^{-}}+\underset{28}{-\rightarrow}
$$

The compound exhibits a very unusual instability. The elemental analysis could not be obtained; a white solid separates from the liquid after some time. When the liquid is stored in a capillary, the whole volume of the liquid appears to be replaced by the white solid within weeks, even when stored at $-12^{\circ} \mathrm{C}$. The solid is barely soluble in $\mathrm{CDCl}_{3}$, but is soluble in acetone and in $\mathrm{CD}_{3} \mathrm{CN}$. The amorphous material was converted to crystals by very slow evaporation of an acetone solution. A crystal was used for $\mathrm{x}$-ray analysis and the compound was found to have the following structure:<smiles>O=S(=O)(F)C(COCC(S)S(F)(F)F)S(F)(F)(F)(F)F</smiles>

A mechanism for this conversion $\underline{28} \rightarrow \underline{29}$ is not yet formulated.

Support for this structure comes also from the ${ }^{1_{H}}$ n.m.r spectrum, with a multiplet at $\approx 5.5 \mathrm{ppm}$, and an $A B$ system at $\approx 4.4 \mathrm{ppm}$ (ratio $\approx 1: 2$ ).

When 21 and acetone were allowed to react at room temperature, several products were formed. The main product seems to be an ester:

$\underline{21}+\mathrm{CH}_{3} \mathrm{COCH}_{3}-->\mathrm{F}_{5} \mathrm{SCH}\left(\mathrm{SO}_{2} \mathrm{~F}\right) \mathrm{COOCH}\left(\mathrm{CH}_{3}\right)=\mathrm{CH}_{2} \underline{30}$ 
The product has a $\mathrm{C}=\mathrm{C}\left(1683 \mathrm{~cm}^{-1}\right)$ and a $\mathrm{C}=0\left(1776 \mathrm{~cm}^{-1}\right)$ band in the i.r. spectrum. The remainder of the spectrum looks almost identical to the spectrum of $\mathrm{F}_{5} \mathrm{SCH}\left(\mathrm{SO}_{2} \mathrm{~F}\right) \mathrm{COOCH}\left(\mathrm{CH}_{3}\right)_{2}$, 21a.

A further similarity is seen in the ${ }^{19} \mathrm{~F}$ n.m.r. spectrum, with a collapsed $\mathrm{AB}_{4}$ resonance $\left(\mathrm{SF}_{5}\right)$ and an $\mathrm{SO}_{2} \mathrm{~F}$ signal with nearly the same chemical shifts. The $1_{H}$ n.m.r spectrum has a multiplet at $5.74 \mathrm{ppm}$, a vinyl resonance at $4.89 \mathrm{ppm}$ and a methyl band at $2.00 \mathrm{ppm}$.

This reaction must be brought about through the ketoenol equilibrium of acetone, where the enol would be constantly removed from the mixture. $\underline{30}$ could be isolated only in trace amounts.

Despite the close kinship of $\mathrm{CH}_{2}=\mathrm{O}$ and $\left(\mathrm{CH}_{3}\right)_{2} \mathrm{C}=\mathrm{O}$, two completely different reactions are observed. One reason could be that formaldehyde does not exist in a keto-enol equilibrium. From the ${ }^{19} \mathrm{~F}$ n.m.r. spectrum of the crude product, there is no indication that the dimethyl anlaogue of $\underline{28}$ is present. If the primary product of $\underline{21}$ and $\mathrm{CH}_{2} \mathrm{O}$ is indeed 28 , then it is surprising not to obtain the analogous product with acetone. If $\underline{28}$ were formed by nucleophilic addition to $\underline{21}$, then acetone should react more rapidly, due to the two $+I$ substituents at the carbonyl group. This course must then be slowed down due to either steric hindrance or the much faster addition of $\mathrm{OH}\left(\mathrm{CH}_{2}=\mathrm{CHOH}\left(\mathrm{CH}_{3}\right)\right)$ to the ketene. No reaction between $\underline{21}$ and hexafluoroacetone 
was observed.

THE FORMAL ADDITION OF RO- to $\mathrm{F}_{5} \mathrm{SC}\left(\mathrm{SO}_{2} \mathrm{~F}\right)=\mathrm{C}=0$; SYNTHESIS

$$
\text { AND REACTIONS OF } \mathrm{F}_{5} \mathrm{SC}^{-}\left(\mathrm{SO}_{2} \mathrm{~F}\right) \mathrm{COOR}
$$

If one applies now the formal relationship between ketenes and enolates,

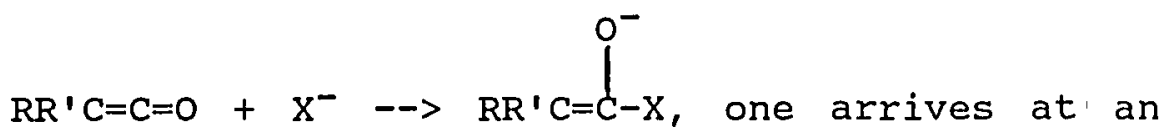
extension of the reactions of 21.

As described above, the synthesis of these enolates from the ketene is not practical, but there is a very convenient route, analogous to 10.

The methyl and isopropylester of the nonisolable acid $\mathrm{F}_{5} \mathrm{SCH}\left(\mathrm{SO}_{2} \mathrm{~F}\right) \mathrm{COOH}$ easily form salts with triethylamine (in ether or acetone):

$\mathrm{F}_{5} \mathrm{SCH}\left(\mathrm{SO}_{2} \mathrm{~F}\right) \mathrm{COOR}+\mathrm{N}\left(\mathrm{C}_{2} \mathrm{H}_{5}\right)_{3} \rightarrow\left[\mathrm{HN}\left(\mathrm{C}_{2} \mathrm{H}_{5}\right)_{3}\right]^{+}\left[\mathrm{F}_{5} \mathrm{SC}\left(\mathrm{SO}_{2} \mathrm{~F}\right) \mathrm{COOR}\right]^{-}$ $\underline{32 a, b}$

$$
\text { 32a, } \mathrm{R}=\mathrm{CH}\left(\mathrm{CH}_{3}\right)_{2} ; \underline{32 \mathrm{~b}}, \mathrm{R}=\mathrm{CH}_{3}
$$

The triethylammonium salts are collected as white amorphous solids and can be recrystallized from either $\mathrm{CH}_{2} \mathrm{Cl}_{2}$ or $\mathrm{CHCl}_{3}$, giving large platelike crystals. It was possible to determine the crystal structure of the methyl ester. The solutions of these compounds are yellowish.

These triethylammonium salts show only low reactivity. Protonation takes place with strong acid immediately, but 
only slowly with water:

$$
\underline{32 \mathrm{a}}+\mathrm{HCl} \longrightarrow \mathrm{F}_{5} \mathrm{SCH}\left(\mathrm{SO}_{2} \mathrm{~F}\right) \mathrm{COOCH}\left(\mathrm{CH}_{3}\right)_{2}+\left\{\left[\mathrm{HN}\left(\mathrm{C}_{2} \mathrm{H}_{5}\right)_{3}\right]^{+} \mathrm{Cl}^{-}\right\}
$$

Two days of refluxing the isopropylester salt with $n$-pentyl bromide in acetone left the 19 F n.m.r. spectrum of the reaction mixture unchanged. An attempt to brominate the same salt led to the isolation of the starting ester. It is clear now from experiments with the sodium salt that the bromo ester is unstable towards hydrolysis. The formation of the starting ester in this case can thus be attributed to the work-up procedure, which involved at one point precipitation with water.

$$
\text { An ammonium salt, } \mathrm{NH}_{4}{ }^{+}\left[\mathrm{F}_{5} \mathrm{SC}\left(\mathrm{SO}_{2} \mathrm{~F}\right) \mathrm{COOCH}\left(\mathrm{CH}_{3}\right)_{2}\right]^{-}, \underline{34} \text {, }
$$

was also obtained by treating the isopropyl ester with gaseous ammonia in diethyl ether at lowered temperatures. The sulfonamide could not be obtained by this method, but in dioxane solution, at $\approx 50-60^{\circ} \mathrm{C}$ (by the heat of reaction), the sulfonyl fluoride was converted to the sulfonamide:

$\mathrm{F}_{5} \mathrm{SCH}\left(\mathrm{SO}_{2} \mathrm{~F}\right) \mathrm{COOCH}\left(\mathrm{CH}_{3}\right)_{2}+\mathrm{NH}_{3} \rightarrow \mathrm{F}_{5} \mathrm{SC}^{-}\left(\mathrm{SO}_{2} \mathrm{~F}\right) \mathrm{COOCH}\left(\mathrm{CH}_{3}\right)_{2} \mathrm{NH}_{4}^{+}$ $\underline{34}$

$$
\longrightarrow \mathrm{F}_{5} \mathrm{SCH}\left(\mathrm{SO}_{2} \mathrm{NH}_{2}\right) \mathrm{COOCH}\left(\mathrm{CH}_{3}\right)_{2} \underline{35}+\left\{\mathrm{NH}_{4} \mathrm{~F}\right\}
$$

This conversion describes one of the few reactions these pentafluorosulfur fluorosulfonyl alkyl acetates undergo. It was also thought that by having a different cation it should be possible to induce reaction with halogen-bearing 
compounds.

of the three ways to obtain these anions with metal cations, only one was practicable. The keten $\mathrm{F}_{5} \mathrm{SC}\left(\mathrm{SO}_{2} \mathrm{~F}\right)=\mathrm{C}=0$ reacted too vigorously with $\mathrm{NaOCH}_{3}$, as described above:

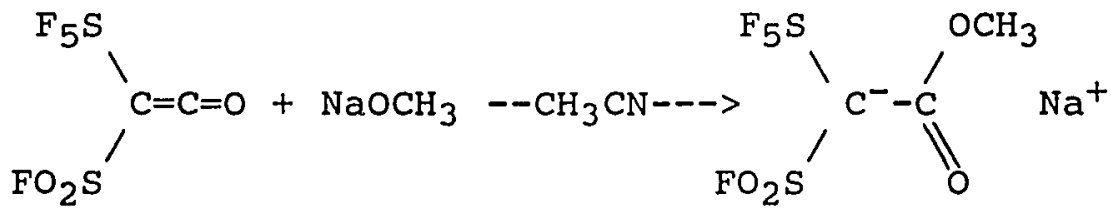

A second route would have led, by analogy to $C F_{2}=C\left(C F_{3}\right) S_{2} F$ (16), to $\mathrm{F}_{4} \mathrm{~S}=\mathrm{C}\left(\mathrm{SO}_{2} \mathrm{~F}\right) \mathrm{COOR}\left(\mathrm{R}=\mathrm{CH}\left(\mathrm{CH}_{3}\right)_{2}, \mathrm{CH}_{3}\right)$, by treating the ester with the base $\mathrm{F}_{3} \mathrm{~B} \cdot \mathrm{N}\left(\mathrm{C}_{2} \mathrm{H}_{5}\right)_{3} \cdot$

$$
\underline{21 \mathrm{a}}+\mathrm{F}_{3} \mathrm{~B} \cdot \mathrm{N}\left(\mathrm{C}_{2} \mathrm{H}_{5}\right)_{3}--\mathrm{X}--->\mathrm{F}_{4} \mathrm{~S}=\mathrm{C}\left(\mathrm{SO}_{2} \mathrm{~F}\right) \mathrm{COOCH}\left(\mathrm{CH}_{3}\right)_{2} \underline{21 \mathrm{C}}
$$

Treatment of this $\mathrm{SF}_{4}=$ compound with $\mathrm{CsF}$ should have led to addition of $\mathrm{F}^{-}$at the sulfur, analogously to 17 . That the sulfur is an electrophilic center in sulfur $\left(\mathrm{SF}_{4} \Rightarrow\right.$ ) ylides has been shown by seppelt et al. earlier 29 , and such an addition direction is now quite well established. This reaction led from the very outset to a completely different product and is thus not a possible route to the ester anion salts. In fact, the isolated product was $\left(\mathrm{F}_{2} \mathrm{~S}=0\right)=\mathrm{C}\left(\mathrm{SO}_{2} \mathrm{~F}\right) \mathrm{COF}$ 44. A detailed description of this reaction will be given elsewhere.

$\mathrm{F}_{5} \mathrm{SCH}\left(\mathrm{SO}_{2} \mathrm{~F}\right) \mathrm{COOCH}_{3}+\mathrm{F}_{3} \mathrm{~B} \cdot \mathrm{N}\left(\mathrm{C}_{2} \mathrm{H}_{5}\right)_{3} \rightarrow\left(\mathrm{F}_{2} \mathrm{SO}\right)=\mathrm{C}\left(\mathrm{SO}_{2} \mathrm{~F}\right) \mathrm{COF}(\underline{4} \underline{)}+$ $\mathrm{CH}_{3} \mathrm{~F}$

It was possible to obtain easily the sodium salt without attendant by-products from the isopropyl ester with sodium isopropoxide in diethyl ether: 


$$
\begin{array}{r}
\mathrm{F}_{5} \mathrm{SCH}\left(\mathrm{SO}_{2} \mathrm{~F}\right) \mathrm{COOCH}\left(\mathrm{CH}_{3}\right)_{2}+\mathrm{Na}^{+}\left(\mathrm{CH}_{3}\right)_{2} \mathrm{CHO}^{-}--\left(\mathrm{C}_{2} \mathrm{H}_{5}\right)_{2} \mathrm{O}---> \\
\mathrm{F}_{5} \mathrm{SC}^{-}\left(\mathrm{SO}_{2} \mathrm{~F}\right) \mathrm{COOCH}\left(\mathrm{CH}_{3}\right)_{2} \mathrm{Na}+(\underline{33})+\left(\mathrm{CH}_{3}\right)_{2} \mathrm{CHOH}
\end{array}
$$

Isolation of this salt was not possible, and it showed a reluctance to react, similar to the triethyl ammonium salts. After each reaction, except for chlorine, where a different product was isolated, about $50 \%$ of the original ester was recovered. This was the case for the reactants $\mathrm{BrCN}, \mathrm{CH}_{2}=\mathrm{CHCH}_{2} \mathrm{Br}, \mathrm{CH}_{3} \mathrm{COCl}$ (after removal of the isopropanol formed in the reaction with sodium isopropoxide), $\mathrm{Cl}_{2}, \mathrm{Br}_{2}$, and $\mathrm{ClCOOCH}_{3}$. The reaction with $\mathrm{CH}_{2} \mathrm{Br}_{2}$ was studied in an n.m.r. tube experiment. The reaction conditions varied in case to case from stirring at room-temperature to refluxing. The recovery of $\underline{21 a}$ from the reaction of $\underline{33}$ with $\mathrm{BrCN}$, $\mathrm{ClCOOCH}_{3}, \mathrm{CH}_{2}=\mathrm{CHCH}_{2} \mathrm{Br}, \mathrm{CH}_{3} \mathrm{COCl}$ and its detection by ${ }^{19} \mathrm{~F}$ n.m.r. spectroscopy in the case of $\mathrm{CH}_{2} \mathrm{Br}_{2}$ is of some interest. In all cases the formation of a white precipitation was observed. It must be assumed, that part of the anion decays with the release of $\mathrm{HF}$, which would then protonate the anion. It was shown in a separate experiment, that the reversion to the ester takes place even without any substrate being present:

$$
33-\cdots-\longrightarrow \mathrm{F}_{5} \mathrm{SCH}\left(\mathrm{SO}_{2} \mathrm{~F}\right) \mathrm{COOCH}\left(\mathrm{CH}_{3}\right)_{2} \quad(53 \%)
$$

Isolated yields of the ester were 40-60\%, respectively in the reactions with and the reaction without a substrate. How this degradation of the anion would take place remains an open question. There could be a similarity to the related 
anion $\left(\mathrm{CF}_{3}\right)_{2} \mathrm{C}^{-} \mathrm{SO}_{2} \mathrm{~F}$ (14), which can lose $\mathrm{F}^{-}$from the $\mathrm{SO}_{2} \mathrm{~F}$ group 27 .

All of these salts were characterized by the nowfamiliar low-field position of the $\mathrm{SF}_{5}$ and $\mathrm{SO}_{2} \mathrm{~F}$ group in the ${ }^{19} \mathrm{~F}$ n.m.r. spectrum and the yellowish color of their solutions.

A ureide 31 , obtained by reacting 1 with urea,

$$
\begin{aligned}
1+\mathrm{H}_{2} \mathrm{NCONH}_{2}--> & \mathrm{F}_{5} \mathrm{~S} C \mathrm{HCONHCONH} \mathrm{HON}_{2} \underline{31}, \\
& \mathrm{FO}_{2} \mathrm{~S}
\end{aligned}
$$

reacted also with triethyl amine to give a salt $\underline{36}$. It was, however, only of marginal stability and could only be characterized by i.r. and fluorine n.m.r. spectroscopy. Again, the low $C O$ frequency and the low-field position of the fluorines indicate the presence of an anion (table 1 ). Upon storing its solutions at room temperature other $\left(\mathrm{SF}_{5}\right)$ products were formed, but their nature was not investigated. It was because of the formation of $\underline{36}$ that it was not possible to cyclize $\underline{31}$ :

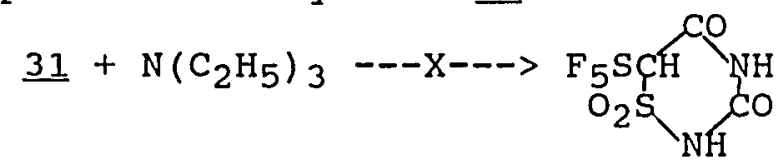

$" \quad " \quad-\cdots--\mathrm{F}_{5} \mathrm{SC}^{-}\left(\mathrm{SO}_{2} \mathrm{~F}\right) \mathrm{COONHCONH}_{2} \mathrm{HN}\left(\mathrm{C}_{2} \mathrm{H}_{5}\right)_{3}+\underline{36}$

on the other hand, both the chlorination and bromination of 33 led to the formation of new compounds:

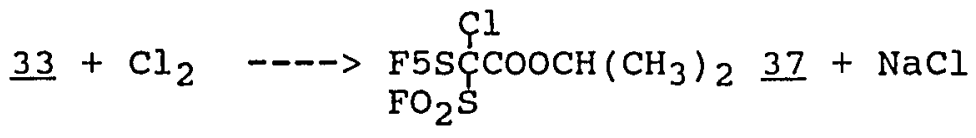

$$
\begin{aligned}
& \underline{33}+\mathrm{Br}_{2}--->\mathrm{FO}_{5} \mathrm{~s} \mathrm{FO}_{2}^{\mathrm{Br}} \mathrm{COOCH}\left(\mathrm{CH}_{3}\right)_{2} \underline{38}+\mathrm{NaBr}
\end{aligned}
$$


While the chloroester 37 could be isolated and is chemically stable, the bromo derivative $\underline{38}$ is highly sensitive towards hydrolysis. When it was tried to remove excess bromine by stirring with $\mathrm{Na}_{2} \mathrm{~S}_{2} \mathrm{O}_{3}$ solution, it was completely consumed and only a compound with the spectral characteristics of $\mathrm{F}_{5} \mathrm{SCH}\left(\mathrm{SO}_{2} \mathrm{~F}\right) \mathrm{CH}\left(\mathrm{CH}_{3}\right)_{2}$ was isolated. Because this conversion could not be completely suppressed, even by using nonaqueous conditions, it was not possible to obtain $\underline{38}$ in pure form. This peculiar instability must be related to bondpolarization by the strongly electron witharawing fluoroalkyl residue. A positively polarized bromine atom should then be easily attackable by water:

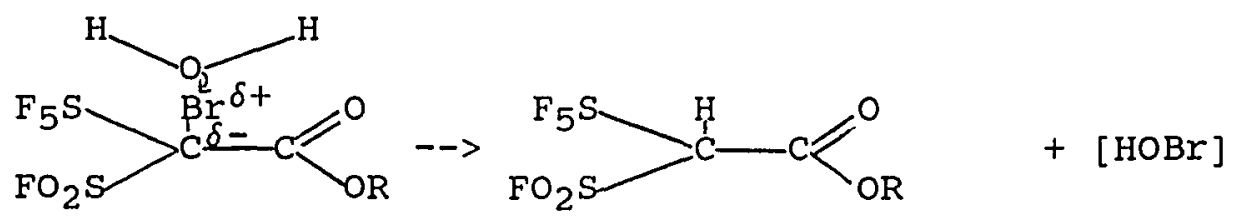

The $C F_{3}$ analogue of $\underline{38}, \underline{11 a}$, is, on the other hand, perfectly stable.

One can assume that the environment of the $\alpha$-carbon in $\underline{33}$ is so crowded that an $\mathrm{s}_{\mathrm{N}} 2$ reaction is not normally possible, except for chlorine and bromine, where attack can occur along the $\mathrm{X}-\mathrm{X}$ axis. This could also in principle occur for $\mathrm{BrCN}$, with the consequent formation of an isonitrile, but the reaction might go via an addition-elimination mechanism:

$$
\mathrm{X}^{-}+\underset{\mathrm{Br}}{\mathrm{C} \equiv \mathrm{N}}--->\mathrm{X}-\underset{\mathrm{Br}}{\mathrm{C}=\mathrm{N}^{-}}--->\mathrm{X}-\mathrm{C} \equiv \mathrm{N}+\mathrm{Br}^{-},
$$

which is probably sterically too demanding. 
The sterically more amenable o-substitution, resulting in the formation of ketene acetals, was not observed.

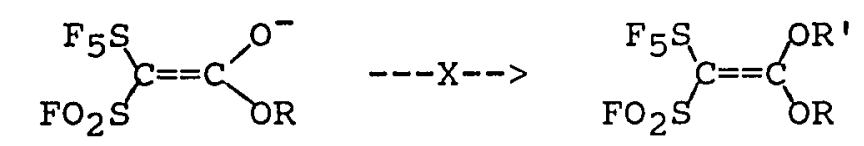

It was now of interest to compare the ease of formation of various anionic species under the same conditions, The compounds $\mathrm{F}_{5} \mathrm{SCH}_{2} \mathrm{SO}_{2} \mathrm{~F}^{52}, \mathrm{~F}_{5} \mathrm{SCH}_{2} \mathrm{COOCH}_{3} 53$, $\mathrm{F}_{5} \mathrm{SCHFSO}_{2} \mathrm{FH}^{5}, \mathrm{~F}_{5} \mathrm{SCH}\left(\mathrm{SO}_{2} \mathrm{~F}\right) \mathrm{COOCH}\left(\mathrm{CH}_{3}\right)_{2}$, $\mathrm{F}_{5} \mathrm{SCH}\left(\mathrm{SO}_{2} \mathrm{NH}_{2}\right) \mathrm{COOCH}\left(\mathrm{CH}_{3}\right)_{2}$ and $\mathrm{F}_{5} \mathrm{SCH}\left(\mathrm{SO}_{2} \mathrm{~F}\right) \mathrm{CONHCONH}{ }_{2}$ were dissolved in acetone in an n.m.r. tube and a drop of triethyl amine was added, causing compounds with the three functional characteristics of an $\mathrm{SO}_{2} \mathrm{~F}, \mathrm{SF}_{5}$ and $\mathrm{COR}(\mathrm{R}=$ $\mathrm{OCH}\left(\mathrm{CH}_{3}\right)_{2}, \mathrm{NHCONH}_{2}$ ) group to exhibit the downfield shift of the $\mathrm{SF}_{5}$ and the $\mathrm{SO}_{2} \mathrm{~F}$ fluorine resonances in anions. In the case of $\mathrm{F}_{5} \mathrm{SCHFSO}_{2} \mathrm{~F}$ the fluorine signals were diminished after base addition, and slow darkening occurred, but no signal attributable to an anion could be detected. Indeed, the sequence for $\mathrm{CH}$-acidity in the analogous $\mathrm{CF}_{3}$ series has $\mathrm{CF}_{3} \mathrm{CHFSO}_{2} \mathrm{~F}$ as its least acidic member ${ }^{10}$ :

$$
\mathrm{CF}_{3} \mathrm{CHFSO}_{2} \mathrm{~F}<\mathrm{CF}_{3} \mathrm{CH}_{2} \mathrm{SO}_{2} \mathrm{~F}<\mathrm{CF}_{3} \mathrm{CH}\left(\mathrm{SO}_{2} \mathrm{~F}\right) \mathrm{COOCH}_{3}, \mathrm{CF}_{3} \mathrm{CHClSO}_{2} \mathrm{~F} \text {. }
$$

Fluorine as a $+M,-I$ substituent should stabilize the anionic site less than chlorine, a weaker $(-M,-I)$ substituent ${ }^{10}$

Neither with $\mathrm{F}_{5} \mathrm{SCH}_{2} \mathrm{COOCH}_{3}$ nor with $\mathrm{F}_{5} \mathrm{SCH}\left(\mathrm{SO}_{2} \mathrm{NH}_{2}\right) \mathrm{COOCH}\left(\mathrm{CH}_{3}\right)_{2}(\underline{35})$ was any reaction observed. In 35, the $\mathrm{SO}_{2} \mathrm{~F}-$ fluorine was replaced by another $+\mathrm{M},-\mathrm{I}$ substituent. Apparently, nitrogen is a stronger $+M$ and $a$ 
weaker -I substituent which leads to the decrease in charge stabilizing capability. With the ester $\mathrm{F}_{5} \mathrm{SCH}_{2} \mathrm{COOCH}_{3}$ it was also not possible to induce reaction with formaldehyde in the presence of diethylamine (Tollens reaction), showing again that it has only a poor ability to form an anion. The extraordinary stability of $\underline{25}$ is additional evidence that the substituent at the $c=0$ group is of minor importance and that the central carbon just needs to be flanked by the $\mathrm{SF}_{5}$, the $\mathrm{SO}_{2} \mathrm{~F}$ and the $\mathrm{C}=0$ group in order to form salts.

The synthetic usefulness of these ester anions is small, because of their great inertness. They make it possible, however, to obtain derivatives of the sultone

$$
{ }_{\mathrm{O}_{5} \mathrm{~S}}^{\mathrm{F}_{2}^{\mathrm{S}}-\mathrm{CF}_{2} \quad 39}
$$

which could not be obtained by the usual sulfur trioxidation of the olefin $\mathrm{F}_{5} \mathrm{CCl}=\mathrm{CF}_{2}$, because loss of $\mathrm{SF}_{5}$ and the formation of unknown products ensued. As described below, it is possible to synthesize 39 by a different and overall tedious route, which is of little synthetic value. It is, however, very easy to prepare derivatives of $\underline{39}$ by chlorination of 33 , with possible further transformations. The bromo ester $\underline{38}$ might be of similar usefulness, as it should be possible to couple it with olefins in a radicaltype reaction. 


$$
\text { PROPERTIES OF Cs }{ }^{+}\left[\mathrm{F}_{5} \mathrm{SC}\left(\mathrm{SO}_{2} \mathrm{~F}\right)=\stackrel{\mathrm{O}^{-}}{\mathrm{C}}-\mathrm{F} \quad(\underline{25})\right.
$$

The reaction of $\underline{21}$ with metal fluorides results in stable complexes. The scope of this reaction has not been completely charted, but with cesium fluoride, silver fluoride and mercury fluoride, vigorous reactions occur when carried out in $\mathrm{CH}_{3} \mathrm{CN}$, causing the fluorides to dissolve with the boiling of the Iiquid mixture:

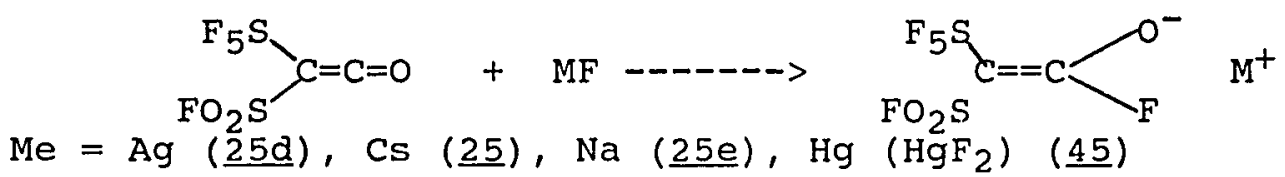

It has been found that NaF will also form such a complex (25e); when the sodium fluoride that was used in the rearrangement of $\underline{1}$ to $\underline{22}$ was extracted with $\mathrm{CH}_{3} \mathrm{CN}$ after removal of the product, a soluble $\mathrm{SF}_{5}$ compound was obtained that had a very similar ${ }^{19} \mathrm{~F}$ n.m.r. spectrum as $\underline{25}$ $\left(\mathrm{F}_{5} \mathrm{SC}\left(\mathrm{SO}_{2} \mathrm{~F}\right) \mathrm{COF}^{-} \mathrm{Cs}^{+}\right)$(table 1$)$. The cesium salt can also be obtained by heating $\underline{21}$ and $\mathrm{CsF}$ without solvent; it can then be obtained by extracting the solid residue with acetone. 25 is of an extraordinary stability. It can be heated for hours in the vacuum to $>200^{\circ} \mathrm{C}$ without significant weight loss, although darkening occurs. The trace of material that distills off is not $\underline{21}$, showing the irreversibility of the reaction of $\underline{21}$ and $\mathrm{CsF}$.

Compound $\underline{25}$ was obtained in quantitative yield, when $\underline{21}$ reacted in excess with cesium fluoride. The initial vivid 
reaction (in $\mathrm{CH}_{3} \mathrm{CN}$ ) slowed down very considerably with time. While $\underline{25}$ could be freed from solvent by vacuum pumping, the sodium and silver salts assumed a glassy consistence and never reached the predetermined weight loss. It must therefore be assumed that they retain solvent. The same observation is made for the $\mathrm{Hg}$ (II) complex.

Acetone and acetonitrile were excellent solvents for 25. It was possible to precipitate it from concentrated acetone solutions by addition of methylene chloride. It was not necessary to observe any special precautions; a sample of 25 was kept in the open air for several weeks at circa $30^{\circ} \mathrm{C}$, and its i.r. spectrum was unchanged after this time. Although it could be slowly converted to cesium fluoride by reaction with water and the formation of the volatile $\mathrm{SF}_{5} \mathrm{CH}_{2} \mathrm{SO}_{2} \mathrm{~F}$, it is clearly demonstrated that it has a very unusual stability for a carbanion and an acyl fluoride. Recrystallization was possible from both acetone and acetonitrile, where conglomerates of crystallites were formed. Unfortunately, these crystals, as far as they could be separated from the conglomerate, were twinned, which excluded an $\mathrm{X}$-ray crystallographic investigation. The ${ }^{19} \mathrm{~F}$ n.m.r. spectrum will be discussed in the n.m.r. section, and the i.r. spectrum showed clearly the presence of an anion, with a comparatively low $\mathrm{C}=0$ stretch frequency (1766 $\mathrm{cm}^{-1}$ ), about $90 \mathrm{~cm}^{-1}$ lower than in the neutral $\underline{22}$.

Although it was possible that the silver salt could 
undergo a facile coupling reaction with alkyl halides, it showed only low reactivity and only complicated prouuct mixtures could be obtained. Particularly conspicuous was the disappearance of the COF signal that was observed when the reactions were followed by ${ }^{19} \mathrm{~F}$ n.m.r. spectroscopy. Although a copious amount of AgI was formed with n-propyl iodide, the respective $\mathrm{SF}_{5}$ products could not be identified. The reactions of the silver salt were not further investigated.

The cesium salt showed a similar reluctance to react; for example, when $\underline{25}$ was refluxed in acetone with $\mathrm{BrCN}$, only $\mathrm{SF}_{5} \mathrm{CH}_{2} \mathrm{SO}_{2} \mathrm{~F}$ could be identified as a reaction product.

$$
\underline{25}+\mathrm{BrCN}-\cdots \quad \mathrm{F}_{5} \mathrm{SCH}_{2} \mathrm{SO}_{2} \mathrm{~F}
$$

This must be a consequence of slow hydrolysis due to small amounts of water being present. Simpler reactants did, however, react well with it. Chlorine formed $\mathrm{F}_{5} \mathrm{SCCl}\left(\mathrm{SO}_{2} \mathrm{~F}\right) \mathrm{COF}$ in very good yield and high purity, $\mathrm{F}_{5} \mathrm{SCBr}\left(\mathrm{SO}_{2} \mathrm{~F}\right) \mathrm{COF}$ was obtained in only fair yield and $\mathrm{F}_{5} \mathrm{SCI}\left(\mathrm{SO}_{2} \mathrm{~F}\right) \mathrm{COF}$ could not be detected:

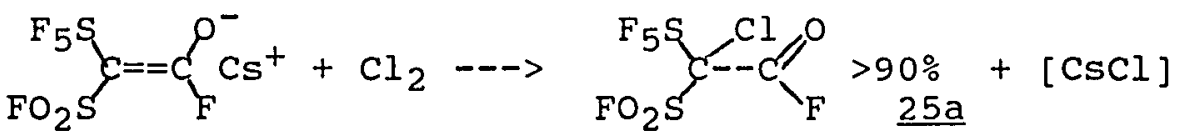

$$
\begin{aligned}
& \text { I } \\
& +\mathrm{Br}_{2} \rightarrow \mathrm{FO}_{2} \mathrm{~S}_{\mathrm{F}}^{\mathrm{F}}=\underset{25 \mathrm{~b}}{\mathrm{~B}} \text { (impure) }+[\mathrm{CsBr}] \\
& " \quad+\mathrm{I}_{2} \quad-\mathrm{X}->\quad \mathrm{FO}_{2} \mathrm{~S}-\mathrm{Cl}_{\mathrm{F}} \underline{25 \mathrm{c}}+[\mathrm{CSI}]
\end{aligned}
$$

Whereas the reactions with chlorine and bromine were run without solvent, the reaction with iodine was tried with and 
without the presence of $\mathrm{CH}_{3} \mathrm{CN}$. Running the reaction without solvent simplifies the isolation process. An interesting aspect is that $\underline{25}$ reacts with bromine in a different way in $\mathrm{CH}_{3} \mathrm{CN}$ than it does without solvent. When $\mathrm{Br}_{2}$ is added to a concentrated (to simplify removal of solvent) $\mathrm{CH}_{3} \mathrm{CN}$ solution, of 25, quick discoloration of the brown $\mathrm{Br}_{2}$ color is observed, accompanied by the formation of gas bubbles and a white precipitate. The solution can be titrated in this fashion until the brown bromine color persists. The product that is obtained has no more co group (i.r.), and shows a conspicuous upfield shift in the ${ }^{19} \mathrm{~F}$ n.m.r. spectrum. Such a shift is usually observed when electronegative elements are attached to the $\mathrm{SF}_{5}$-bearing carbon atom. Further characteristics of this compound, a colorless solid when pure, are its high volatility (it distills with acetonitrile), its halogen-like odor and its low melting point $\left(\approx 40^{\circ} \mathrm{C}\right)$; it dissipates rapidly in air. This compound was identified as:

$$
\mathrm{F}_{5} \mathrm{~S}-\underset{\mathrm{Br}}{\mathrm{Br}}-\mathrm{SO}_{2} \mathrm{~F} \quad \underline{25 \mathrm{f}}
$$

It also seems to react very readily with mercury; when a sample was shaken with mercury, warming was noticed and only a small amount of material could be retrieved. In a similar mode, destruction was observed with AgF.

This rather interesting result offered the 
possibility of synthesizing the compounds $\mathrm{F}_{5} \mathrm{SCCl}_{2} \mathrm{SO}_{2} \mathrm{~F}$ and $\mathrm{F}_{5} \mathrm{SCF}_{2} \mathrm{SO}_{2} \mathrm{~F}$ by a similar route. With chlorine, a different result was obtained; while the reaction stops at the stage of $\mathrm{F}_{5} \mathrm{SCCl}\left(\mathrm{SO}_{2} \mathrm{~F}\right) \mathrm{COF}$ without irradiation, it continues under the irradiation of a sunlamp to give one major product, which is an acyl chloride. This product did not seem to undergo any further changes. The solvent was necessary for the reaction; without $\mathrm{CH}_{3} \mathrm{CN}$ present only $\mathrm{F}_{5} \mathrm{SCCl}\left(\mathrm{SO}_{2} \mathrm{~F}\right) \mathrm{COF}$ was formed, even after long irradiation. The progress of the reaction without solvent could also be conveniently monitored by the drop in chlorine pressure: no further pressure drop was observed after 1 equivalent of $\mathrm{Cl}_{2}$ was consumed: a dichloro compound should have consumed two equivalents and produced either $c 0$ or $\operatorname{CoclF}$ as a by-product. Neither was detected:

$$
\begin{array}{llll} 
& --\mathrm{hv}, \text { no solvent } \rightarrow & \mathrm{F}_{5} \mathrm{SCl}\left(\mathrm{SO}_{2} \mathrm{~F}\right) \mathrm{COF} \\
\underline{25}+\mathrm{Cl}_{2} & -\mathrm{hv}, \mathrm{CH}_{3} \mathrm{CN}-\rightarrow & \mathrm{F}_{5} \mathrm{SCCl}\left(\mathrm{SO}_{2} \mathrm{~F}\right) \mathrm{COCl}(\underline{25 \mathrm{~g}}) \\
& --\mathrm{no} \mathrm{hv}, \mathrm{CH}_{3} \mathrm{CN} \rightarrow-> & \mathrm{F}_{5} \mathrm{SCCl}\left(\mathrm{SO}_{2} \mathrm{~F}\right) \mathrm{COF}
\end{array}
$$

According to n.m.r. spectral comparisons, one byproduct in the reaction is $\mathrm{F}_{5} \mathrm{SCHClSO}_{2} \mathrm{~F}$, and another minor product has an n.m.r. spectrum very similar: to $\mathrm{SF}_{5} \mathrm{CBr}_{2} \mathrm{SO}_{2} \mathrm{~F}$, so that the formation of $\mathrm{F}_{5} \mathrm{SCCl}_{2} \mathrm{SO}_{2} \mathrm{~F}$, which should also have a similar $19 \mathrm{~F}$ n.m.r. spectrum cannot be excluded entirely. From the analogous reaction with fluorine one would have expected the compound $\mathrm{F}_{5} \mathrm{SCF}_{2} \mathrm{SO}_{2} \mathrm{~F}$. The compound $\mathrm{F}_{5} \mathrm{SCHFSO}_{2} \mathrm{~F}$ shows base sensitivity (see above), and recently a similar 
sensitivity of $\mathrm{F}_{5} \mathrm{SCH}_{2} \mathrm{CF}_{2} \mathrm{SO}_{3} \mathrm{H}$ towards aqueous $\mathrm{NaOH}$ was found with the loss of the $\mathrm{SF}_{5}$ group and evolution of gas. This is most certainly connected to the hydrogen at $c_{\alpha}$, which should be easily removable, and the resulting anion, not having the possibilities of charge dispersal like $\underline{32 a}, \underline{32 b}$ or $\underline{33}$, could then decompose. $\mathrm{F}_{5} \mathrm{SCF}_{2} \mathrm{SO}_{2} \mathrm{~F}$ would not undergo such a base attack and it is expected to be convertible into a strong and very stable acid. The different course of this reaction with chlorine makes it unlikely that the reaction with fluorine would go in the desired direction. This would have furnished a particularly easy route to $\mathrm{F}_{5} \mathrm{SCF}_{2} \mathrm{SO}_{2} \mathrm{~F} .55$

The compounds $\mathrm{F}_{5} \mathrm{SCCl}\left(\mathrm{SO}_{2} \mathrm{~F}\right) \mathrm{CFO}$ and $\mathrm{F}_{5} \mathrm{SCBr}\left(\mathrm{SO}_{2} \mathrm{~F}\right) \mathrm{CFO}$ hydrolyzed slowly in water:

$$
\begin{gathered}
\mathrm{F}_{5} \mathrm{SC}(\mathrm{Cl}, \mathrm{Br})\left(\mathrm{SO}_{2} \mathrm{~F}\right) \mathrm{CFO}+\mathrm{H}_{2} \mathrm{O} \rightarrow \mathrm{F}_{5} \mathrm{SCH}(\mathrm{Cl}, \mathrm{Br}) \mathrm{SO}_{2} \mathrm{~F}+\mathrm{HF}+\mathrm{CO}_{2} \\
\mathrm{Br}=\underline{25} \mathrm{j}, \mathrm{Cl}=\underline{25 \mathrm{~h}}
\end{gathered}
$$

It was found that $\mathrm{F}_{5} \mathrm{SCBr}\left(\mathrm{SO}_{2} \mathrm{~F}\right) \mathrm{CFO}$ does react with $\mathrm{C}_{2} \mathrm{H}_{4}$ in the presence of a free radical initiator, but loss of the COF group was observed:

$$
\mathrm{F}_{5} \mathrm{SCBr}\left(\mathrm{SO}_{2} \mathrm{~F}\right) \mathrm{COF}+\mathrm{C}_{2} \mathrm{H}_{4}+(\phi \mathrm{COO})_{2}-->\mathrm{F}_{5} \mathrm{SCH}_{2} \mathrm{SO}_{2} \mathrm{~F} \text { (chiefly) }
$$$$
+\mathrm{F}_{5} \mathrm{SCHCH}_{\mathrm{SO}_{2}} \mathrm{CH}_{2} \mathrm{Br}
$$

The system avoids further substitution ${ }_{a t} \mathrm{C}_{\alpha} \frac{(25 i)}{b y}$ decarboxylation.

The chemical behavior with other cations was tried and reaction with $\mathrm{NO}^{+} \mathrm{BF}_{4}^{-}$and $\mathrm{NO}_{2}{ }^{+} \mathrm{BF}_{4}{ }^{-}$was observed. Nitrosonium tetrafluoroborate reacted rather cleanly to one major product, but it was not possible to isolate it. With $\mathrm{CH}_{3} \mathrm{CN}$ 
codistillation occurred, and the product appeared to have been only marginally stable, as a slow change of the n.m.r. spectrum of the acetonitrile solution suggested. This solution had a faint blue color in the cold. A blue color is typical for nitroso compounds.

A downfield shift of the COF and an upfield shift of the $\mathrm{SF}_{5}$ and $\mathrm{SO}_{2} \mathrm{~F}$ resonances were observed, as compared to 25. From these observations one can safely assume that the product that was obtained was a nitroso compound indeed:

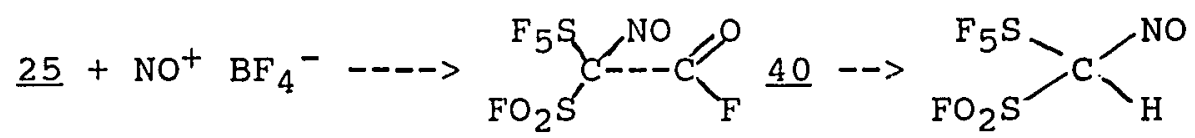

The latter decarbonylated product (which might exist as the tautomeric oxime) is assumed to be the compound that was observed when the initial adduct, which showed a COF resonance in the ${ }^{19} \mathrm{~F}$ n.m.r. spectrum, was kept in $\mathrm{CH}_{3} \mathrm{CN}$ solution for several hours. Addition of water to the solution resulted in the formation of $\mathrm{SF}_{5} \mathrm{CH}_{2} \mathrm{SO}_{2} \mathrm{~F}$. The oxime or the nitroso compound must have been hydrolytically unstable. This is in line with the compound $\left(\mathrm{F}_{3} \mathrm{C}\right)_{2} \mathrm{C}(\mathrm{NO}) \mathrm{COF}$, obtained from $\left(\mathrm{CF}_{3}\right)_{2} \mathrm{C}=\mathrm{C}=\mathrm{O}$ and NOF.56 Hydrolysis leads in this case to $\left(\mathrm{CF}_{3}\right)_{2} \mathrm{CHCOOH}$ (plus traces of $\left(\mathrm{CF}_{3}\right)_{2} \mathrm{C}=\mathrm{NOH}$ ) . Hydrolysis of $\underline{40}$ should also result in the formation of $\mathrm{SF}_{5} \mathrm{CH}_{2} \mathrm{SO}_{2} \mathrm{~F}$, as the intermediate acid $\mathrm{F}_{5} \mathrm{SC}(\mathrm{NO})\left(\mathrm{SO}_{2} \mathrm{~F}\right) \mathrm{COOH}$ would probably be unstable too (like $\left(\mathrm{F}_{3} \mathrm{C}\right)_{2} \mathrm{C}(\mathrm{NO}) \mathrm{COOH}$ ), and, after hydrolysis of the No group, decarboxylate, while $\left(\mathrm{CF}_{3}\right)_{2} \mathrm{CHCOOH}$ is stable and does not undergo loss of $\mathrm{CO}_{2}$. 
The reaction of $\underline{25}$ and nitronium tetrafluoroborate was much slower and resulted in a mixture of compounds as evidenced by the fluorine n.m.r. spectrum of the product. The slowness of the reaction could be attributed to the apparently low solubility of $\mathrm{NO}_{2}{ }^{+} \mathrm{BF}_{4}{ }^{-}$in $\mathrm{CH}_{3} \mathrm{CN}$. Nevertheless, the ${ }^{19} \mathrm{~F}$ n.m.r. spectrum leads to the conclusion that at least one COF resonance is present; this should correspond to compound 41:

$$
\underline{25}+\mathrm{NO}_{2}+\mathrm{BF}_{4}-\rightarrow \underset{\mathrm{FO}_{2} \mathrm{~S}^{-}-\mathrm{C}_{\mathrm{F}}}{\mathrm{F}_{5} \mathrm{~S}_{41}+\mathrm{NO}_{2} \mathrm{O}}+\mathrm{BF}_{4}
$$

Prolonged reaction resulted in an almost clean product that lacked a COF group and had an inverted $\mathrm{AB}_{4}$ resonance, i.e., $\phi_{\mathrm{B}}$ is downfield of $\phi_{\mathrm{A}}$. However, further characterization was not possible, as the material apparently exploded when injected into a gas chromatograph.

A further interesting result was obtained with p$\mathrm{O}_{2}{\mathrm{~N} \phi \mathrm{N}_{2}}^{+} \mathrm{BF}_{4}{ }^{-}$, which did not react with $\underline{25}$. All that was observed was the very slow conversion of $\underline{25}$ into $\mathrm{SF}_{5} \mathrm{CH}_{2} \mathrm{SO}_{2} \mathrm{~F}$ (within weeks) when the reaction was run in $\mathrm{CH}_{3} \mathrm{CN}$ :

$$
\underline{25}+\mathrm{p}-\mathrm{O}_{2}{\mathrm{~N} \phi \mathrm{N}_{2}}_{2} \mathrm{BF}_{4}--\mathrm{X}->\underset{\mathrm{FO}_{2} \mathrm{~S}}{\mathrm{~F}_{5} \mathrm{~S}}=-\mathrm{N}_{2} \phi \mathrm{NO}_{2}
$$

That $\mathrm{SF}_{5} \mathrm{CH}_{2} \mathrm{SO}_{2} \mathrm{~F}$ was formed can be attributed to the presence of trace quantities of water, which would, in a catalytic cycle, lead to hydrolysis of $\underline{21}$, accompanied by $\mathrm{HF}$ evolution, which in turn would react with the glass container, again forming $\mathrm{H}_{2} \mathrm{O}$. 
SYNTHESIS AND PROPERTIES OF $\mathrm{F}_{4} \mathrm{~S}=\mathrm{C}_{\mathrm{SO}_{2}}^{\mathrm{C}}$

When 1 was treated with 18 , a two-directional elimination was observed:

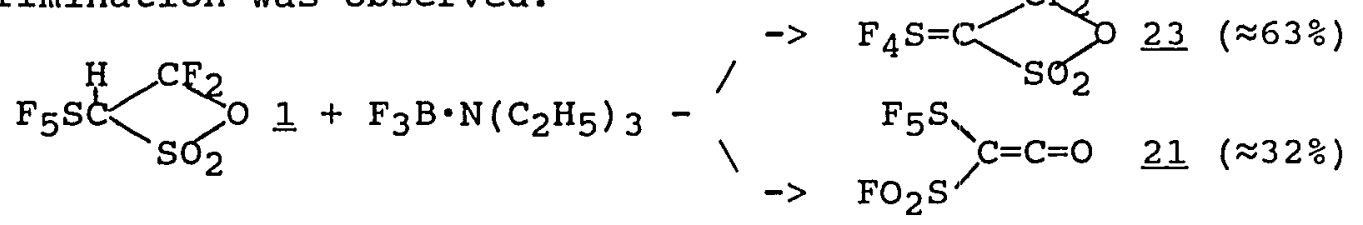

Two facts are remarkable about this reaction:

1:The formation of an unsaturated sultone

2:The formation of ketene $\underline{21}$

As with the formation of $\underline{21}$ from $\underline{18}$ and $\underline{22}$, the weak basicity of 18 allowed this reaction to be carried out. Ketene 21, as was said above, adds even comparatively weak bases very readily to form ionic adducts. other bases, like triethylamine (which reacts vigorously with the ketene) or NaF (which forms an adduct with it) would not have allowed for this reaction to take place.

The ratio $\underline{21}: \underline{23}$ remains nearly constant under a variety of conditions. When sultone 1 is heated with various excesses of base 18 (0.1-0.4-fold), heated longer, reacted by slow addition of hot base to its melt, or reacted in chloroform, the reaction produces a mixture of $30-35 \% \underline{21}$ and $65-70 \%$ of $23\left({ }^{19}\right.$ F n.m.r.).

While $\underline{23}$ could be expected as a normal, although unprecedented, elimination product of 1 , the formation of 21 was, in light of the formation of $\underline{23}$, surprising. As with $\underline{2}$, where the analogous reaction had led to 3 , it was expected 
to obtain only $\underline{21}$ from this reaction. It was suggested that the conversion $\underline{2} \rightarrow \underline{3}$ led through the rearranged form of $\underline{2}$, the acyl fluoride $\underline{4}$. Although no evidence for this was put forward, it must have been concluded from the fact that 1 . the reaction of $\underline{2}$ and $\underline{18}$ was much more vigorous than the reaction of $\underline{4}$ and $\underline{18}$ and 2 . that only a keten product was observed, but no $\mathrm{F}_{2} \mathrm{C}=\mathrm{CCF}_{2} \mathrm{OSO}_{2}$, the analogue to $\underline{23}$. There is no a priori reason as to why an exomethylene group at oxathiacyclobutane should not be capable of existing. In the present case a partial re-arrangement of $\underline{1}$ to $\underline{22}$ cannot be excluded, but it is also possible that a two-directional elimination of $\mathrm{HF}$ from $\underline{1}$ took place, leading to a ringunsaturated sultone $\underline{41}$ and $\underline{23}$ :

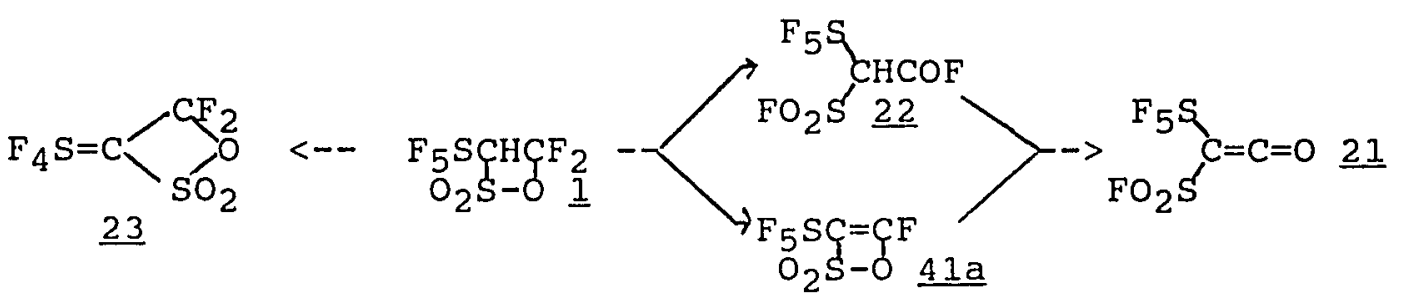

Compound 41 would not be stable towards rearrangement to $\underline{21}$, as only the latter is observed. A similar course of reaction has been suggested in the conversion of $\left(F_{3} C\right)_{3} C C \equiv C F$ to $\left(\mathrm{CF}_{3}\right)_{3} \mathrm{CC}\left(\mathrm{SO}_{2} \mathrm{~F}\right)=\mathrm{C}=0$, when reacted with $\mathrm{SO}_{3}$ (page 13).

The first member of the alkylidene sulfur tetrafluorides, $\mathrm{CH}_{2}=\mathrm{SF}_{4}$, was obtained by Kleemann and Seppelt.57a-d This compound undergoes facile addition 
reactions with the polar agents $\mathrm{HF}, \mathrm{HCl}, \mathrm{HBr}, \mathrm{ICl}, \mathrm{HgF}_{2}$, $\mathrm{ASF}_{5}$, and with chlorine. 58 These additions are such that cis $\mathrm{SF}_{4} \mathrm{X}$ systems are obtained, in contrast to the trans- $\mathrm{SF}_{4} \mathrm{X}$ compounds from the fluorination of fluoroalkyl sulfenylchlorides.59 Additional members of this series include $\mathrm{FC}(\mathrm{O}) \mathrm{CH}=\mathrm{SF}_{4} 60, \mathrm{H}_{3} \mathrm{CCH}=\mathrm{SF}_{4} 61, \mathrm{~F}_{3} \mathrm{CCH}=\mathrm{SF}_{4}$, and $\mathrm{F}_{3} \mathrm{C}\left(\mathrm{CF}_{3}\right)=\mathrm{SF}_{4} \cdot 62,63$

Separation of $\underline{21}$ and $\underline{23}$ is difficult, as their boiling points lie close together. A small quantity of pure $\underline{23}$ may be collected at $92^{\circ} \mathrm{C}$ and of pure $\underline{21}$ at $94^{\circ} \mathrm{C}$, however, most of the material decomposes during the distillation. It was possible to utilize the high affinity of 21 towards bases to effect selective compound formation, leaving pure $\underline{23}$ behind. Treatment of the mixture of $\underline{21}$ and $\underline{23}$ with CsF removes $\underline{21}$, which forms the adduct $\underline{25}$.

$$
\underline{21}+\underline{23}+\mathrm{CsF}---->\underline{25}+\underline{23}
$$

It is necessary to keep the temperature close to room temperature, as otherwise a reaction of $\underline{23}$ with CsF ensues and also to use very finely ground and thoroughly ground CsF in order to effect reaction. One finds, however, always that more $\mathrm{Cs}^{+} \mathrm{F}_{5} \mathrm{SC}\left(\mathrm{SO}_{2} \mathrm{~F}\right) \mathrm{COF}^{-}$is formed than could arise from the amount of $\underline{21}$ in the mixture. Formation of $\underline{25}$ from $\underline{23}$ is confirmed in a separate experiment where pure $\underline{23}$ is treated with CsF:

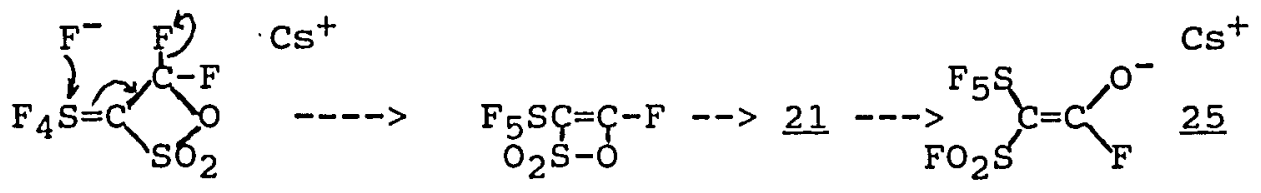


Compound $\underline{23}$ is a stable colorless liquid with an unpleasant odor; it can be handled in air for short times without decomposition.

The addition of other polar species besides $F^{-}$, and in analogy to $\mathrm{CH}_{2}=\mathrm{SF}_{4}$, was expected, with the negatively polarized end attacking the sulfur.

Hydrogen fluoride adds to $\underline{23}$, giving sultone $\underline{1}$ in high yields:

$$
\mathrm{F}_{4} \mathrm{~S}=\mathrm{C} \underset{\mathrm{SO}_{2}}{\mathrm{CF}_{2}}+\mathrm{HF} \rightarrow \mathrm{F}_{5} \mathrm{~S}-\mathrm{C}_{\mathrm{SO}_{2}}^{\mathrm{H} \mathrm{CF}_{2}} \stackrel{\mathrm{I}}{\mathrm{C}}
$$

It is much more difficult to effect addition of $\mathrm{HCl}$ to $\underline{23}$. At room temperature no reaction occurs, only after heating with an excess of gaseous $\mathrm{HCl}$ for nearly 100 hours $\left(68^{\circ} \mathrm{C}\right)$ is reaction complete without significant by-product formation:

$$
\mathrm{F}_{4} \mathrm{~S}=\mathrm{C}_{\mathrm{SO}_{2}}^{\mathrm{CF} \mathrm{C}_{2}}+\mathrm{HCl} \rightarrow->\mathrm{F}_{4} \mathrm{~S}^{\mathrm{l}}-\mathrm{C}_{\mathrm{S} \mathrm{O}_{2}}^{\mathrm{H}}-\sum_{2}^{C F_{2}}
$$

This contrasts very strongly with the ease of $\mathrm{HCl}$ addition to $\mathrm{CH}_{2}=\mathrm{SF}_{4}{ }^{55}$. One reason for this could be that in $\underline{23}$ there is a better charge-dispersal as compared to $\mathrm{CH}_{2}=\mathrm{SF}_{4}$ :

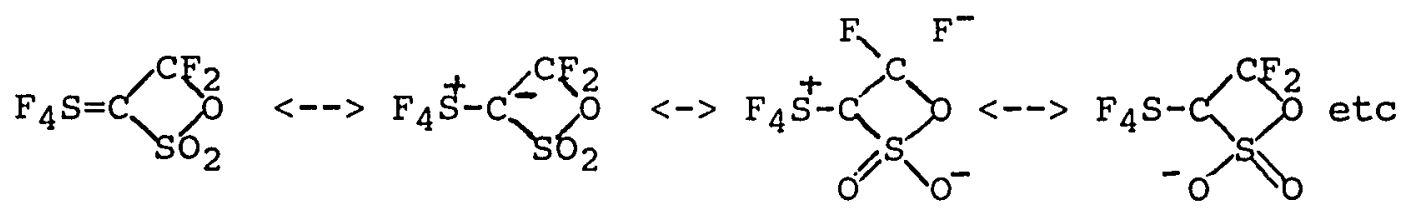
and

$$
\mathrm{F}_{4} \mathrm{~S}=\mathrm{CH}_{2} \longleftrightarrow-\rightarrow \mathrm{F}_{4} \mathrm{~S}^{+}-\mathrm{CH}_{2}^{-} \text {, }
$$

which would lower the polarity of the $S-C$ bond in $\underline{23}$. Another possibility is increased steric hindrance due to the comparatively large sultone ring. Compound $\underline{42}$ bears some 
interesting possibilities. In analogy to trans $\mathrm{R}-\mathrm{SF}_{4}-\mathrm{Cl}$, which reacts with olefins and acetylenes to adducts 35 , there was the hope to see a similar reaction. Upon attempted reaction with $\mathrm{CF}_{2}=\mathrm{CF}_{2}$, only decomposition was seen. A small amount of unreacted $\underline{42}$ was detected in the n.m.r. spectrum of the reaction mixture:

$$
\underline{42}+\mathrm{C}_{2} \mathrm{~F}_{4} \text { (hv) - hex--> }
$$

Similarly, the re-arrangement of $\underline{42}$ with sodium fluoride, which is normally an unproblematic reaction, led to a complicated milxture, and it cannot be said whether the reaction took place at all:

$$
\underline{4} \underline{2}+\mathrm{NaF}--->\text { complicated mixture }
$$

Methanol led to the decomposition of the $\mathrm{SF}_{4} \mathrm{Cl}$ group (in an n.m.r. experiment); thus, at this time, corresponding esters $\mathrm{F}_{4} \mathrm{SClCH}\left(\mathrm{SO}_{2} \mathrm{~F}\right) \mathrm{COOR}$ have not been obtained from $\underline{42}$.

$\underline{42}$ is a colorless liquid with a repugnant odor. Its ${ }^{19} \mathrm{~F}$ n.m.r. spectrum will be discussed in the n.m.r. chapter. The preparation of $\underline{42}$ is quite lengthy, so that only small amounts of it|were available; consquently, its reactivity was not extensively investigated.

A further reaction of $\underline{23}$ is the specific addition of methanol, to yield another $\mathrm{cis}-\mathrm{SF}_{4}-\mathrm{R}$ compound as a white low-melting solid:

$$
\underline{23}+\mathrm{CH}_{3} \mathrm{OH}--\rightarrow \begin{array}{r}
\mathrm{H}_{3} \mathrm{CO} \\
\mathrm{F}_{4} \mathrm{~S}-\mathrm{H}-\mathrm{CF}_{2} \quad \mathrm{43} \\
\mathrm{O}_{2} \mathrm{~S}-\mathrm{O}
\end{array}
$$


The reaction of $\underline{23}$ and isopropanol led to a mixture of what was probably the $\mathrm{cis}-\mathrm{SF}_{4}\left(\mathrm{OCH}\left(\mathrm{CH}_{3}\right)_{2}\right)$ derivative of the sultone and the ester $\mathrm{F}_{5} \mathrm{SCH}\left(\mathrm{SO}_{2} \mathrm{~F}\right) \mathrm{COOCH}\left(\mathrm{CH}_{3}\right)_{2}$ 2la. Attempts to isolate the $\mathrm{SF}_{4}$-derivative failed, as the compound was apparently not stable. The result with $\left(\mathrm{CH}_{3}\right)_{3} \mathrm{COH}$ was even more pronounced, as no more cis- $\mathrm{SF}_{4} \mathrm{OR}$ compound could be detected in the ${ }^{19} \mathrm{~F}$ n.m.r. spectrum. What was found was largely the ester $\mathrm{F}_{5} \mathrm{SCH}\left(\mathrm{SO}_{2} \mathrm{~F}\right) \operatorname{COOC}\left(\mathrm{CH}_{3}\right)_{3} \underline{21 \mathrm{~d}}$, and ${ }^{19} \mathrm{~F} \mathrm{n.m.r}$. results suggest also initial formation of $\underline{1}$, and later $\mathrm{F}_{5} \mathrm{SCH}_{2} \mathrm{SO}_{2} \mathrm{~F}$. In order to explain this result, one has to consider the two possible sites of attack at $\underline{23}$ :

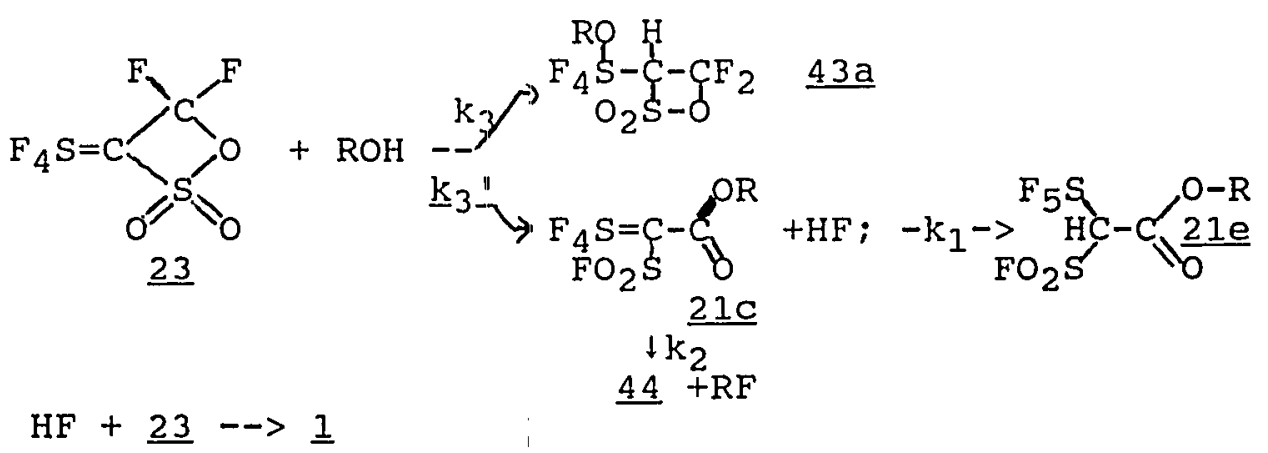

It was described earlier, that an intermediate $\underline{21 \mathrm{c}}$ should have been present leading to the compound $\left(\mathrm{F}_{2} \mathrm{~S}=0\right)=\mathrm{C}\left(\mathrm{SO}_{2} \mathrm{~F}\right) \mathrm{COF}$ $(\underline{44)}$

by a re-arrangement in a $\mathrm{F}_{3} \mathrm{~B} \cdot \mathrm{N}\left(\mathrm{C}_{2} \mathrm{H}_{5}\right)_{3}+\mathrm{BF}_{4}^{-}+$ $\mathrm{NH}\left(\mathrm{C}_{2} \mathrm{H}_{5}\right)_{3}{ }^{+}$medium; $\mathrm{HF}$ would be first absorbed by $\underline{18}$, and no $\mathrm{HF}$ addition to the double-bond is expected in this case. In the present case, no $\underline{44}$ could be detected. This is not surprising, as neither the $\mid F_{2} s=0$, nor the $s=c$, nor the coF moieties are expected to withstand an alcoholic environment. This re-arrangement to $\underline{4} 4$ is also expected to compete with 
the addition of $\mathrm{HF}$ to the $S=C$ double-bond, and $\mathrm{HF}$ addition appears to be quite faster than the rearrangement, as concluded from the product-distribution (mainly the $\mathrm{SF}_{5}$ ester, but also 1 ), $k_{1}>k_{2}$.

The relationship of $\mathrm{k}_{1}$ and $\mathrm{k}_{3}$ seems to be dictated by the alcohol used. The most obvious difference between methanol and t-butanol is the steric bulk, and the fact that with isopropanol an intermediate result is obtained allows one to draw the conclusion that steric reasons are responsible for the different course of the reactions of $\underline{23}$ and various aliphatic alcohols.

The preferred attack of $\mathrm{CH}_{3} \mathrm{OH}$ at the doubly bonded sulfur shows that the $S=C$ bond is more reactive than the sultone ring, but that this increased reactivity is easily offset by steric demands. It is here also pertinent that $\underline{23}$ failed to react with either $\mathrm{C}_{6} \mathrm{~F}_{5} \mathrm{OH}, \mathrm{CF}_{3} \mathrm{CH}_{2} \mathrm{OH},\left(\mathrm{CF}_{3}\right)_{2} \mathrm{CHOH}$ or $\left(\mathrm{CF}_{3}\right)_{2}\left(\mathrm{C}_{2} \mathrm{~F}_{5}\right) \mathrm{COH}$. In all cases a broad new feature was observed at $\approx 73 \mathrm{ppm}$, which is also observed as a decomposition product of pure 23 , accompanied by the slow disappearance of $\underline{23}$.

Furthermore, $\underline{23}$ did not react in the expected fashion with either $\mathrm{CF}_{3} \mathrm{OCl}$ or $\mathrm{CF}_{3} \mathrm{O}^{-} \mathrm{Cs}^{+}$. Familiar products were obtained in these cases:

$$
\begin{array}{ll}
\underline{23}+\mathrm{CF}_{3} \mathrm{OCl}--\rightarrow & \mathrm{F}_{5} \mathrm{SC}(\mathrm{Cl}) \mathrm{CF}_{2} \underline{39} \\
& \mathrm{O}_{2} \mathrm{~S}---\mathrm{O} \\
\underline{23}+\mathrm{CF}_{3} \mathrm{O}^{-} \mathrm{Cs}^{+} \rightarrow-\longrightarrow \underline{25}+\left\{\mathrm{CF}_{2} \mathrm{O}\right\}
\end{array}
$$

The addition of $\mathrm{ClF}$ instead of $\mathrm{CF}_{3} \mathrm{OCl}$ in reactions of $\mathrm{CF}_{3} \mathrm{OCl}$ 
is not uncommon. The addition of $\mathrm{CF}_{3} \mathrm{OCl}$ is now considered a polar addition, rather than a free radical one. This conclusion has been reached from the product distribution in several reactions. 64

Compound $\underline{39}$ can be obtained from $\underline{23}$ and $\mathrm{ClF}$, although not without difficulty: an excess of $\mathrm{ClF}$ and several days of reaction time were necessary in order to have complete reaction.

$$
\underset{\mathrm{O}_{2} \mathrm{~S}-\mathrm{O}}{\mathrm{F}_{5} \mathrm{~S}-\mathrm{C}-\mathrm{CF}_{2}}
$$

It could not be obtained by sulfur trioxidation of $\mathrm{SF}_{5} \mathrm{CCl}=\mathrm{CF}_{2}(\mathrm{p} .42)$. Complete degradation of the $\mathrm{SF}_{5}$ group was observed in this case. This process demanded apparently more than one equivalent of $\mathrm{SO}_{3}$, and the product that was obtained in this fashion could not be analyzed.

$\underline{39}$ is a reactive compound, as is evident from the formation of $\mathrm{F}_{5} \mathrm{SCCl}\left(\mathrm{SO}_{2} \mathrm{~F}\right) \mathrm{COF}$ (25a) as a major by-product in its formation from $\underline{23}$ and $\mathrm{ClF}$; only when acid-washed apparatus was used throughout, formation of $\underline{25 a}$ could be mostly avoided. The conversion of $\underline{39}$ into $\underline{25 a}$ occurred on the potassium bromide plates (apparently catalyzed by $\mathrm{Br}^{-}$) that were used for i.r. analysis: the initially absent CoF band increased slowly. It is much easier to obtain 25 a from the cesium salt $\underline{25}$ than from $\underline{39}$, so that the latter route is of no synthetic value. The conversion of $\underline{39}$ into $\underline{25 \mathrm{a}}$ is part of a general reaction of fluorosultones of the form $\mathrm{R}_{f} \mathrm{CXCF}_{2} \mathrm{OSO}_{2}$ 
$\left(R_{f}=\right.$ fluoro radical, $X=H$ or halogen $)$ with bases that results in the opening of the four-membered ring to give an acyl fluoride.

$\underline{23}$ seems to be completely unreactive towards $\mathrm{SF}_{5} \mathrm{Br}$.

THE CONVERSION OF AN SF 5 GROUP INTO AN $\left(F_{2} \mathrm{SO}\right)=$ GROUP

A peculiar reaction occurs when esters $\underline{21 a}$ or $\underline{21 b}$ are treated with 18. In a vigorous reaction, the complete degradation of the $\mathrm{SF}_{5}$ group is observed. Instead of obtaining the expected $\mathrm{F}_{4} \mathrm{~S}=\mathrm{C}$ derivative it is found, that, in the case of the isopropylester, a mixture of gaseous products and a high-boiling liquid is produced. The gas product was tentatively identified as a mixture of propylene and 2-fluoropropane, whereas the spectral and analytical data of the high-boiling liquid are only consistent with a composition of the form:

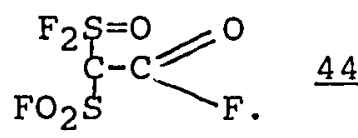

It seemed likely, that isopropyl fluoride was formed first as an elimination product of the ester and underwent then $H F$ loss by reaction with the strong HF-acceptor $\mathrm{F}_{3} \mathrm{~B} \cdot \mathrm{N}\left(\mathrm{C}_{2} \mathrm{H}_{5}\right)_{3}$ to produce propylene as the secondary product.

In order to facilitate the analysis of the gaseous products, and to support the surmise of primary alkyl fluoride formation, the ester $\mathrm{F}_{5} \mathrm{SCH}\left(\mathrm{SO}_{2} \mathrm{~F}\right) \mathrm{COOCH}_{3}$ was synthesized from $\mathrm{F}_{5} \mathrm{SCHCF}_{2} \mathrm{OSO}_{2}$ (1) and $\mathrm{CH}_{3} \mathrm{OH}$. Treatment of 
the methylester with $\mathrm{F}_{3} \mathrm{~B} \cdot \mathrm{N}\left(\mathrm{C}_{2} \mathrm{H}_{5}\right)_{3},(\underline{18})$, should give methyl fluoride as the only volatile product, since HF elimination would not lead to a stable product. When the ester was treated with $\mathrm{F}_{3} \mathrm{~B} \cdot \mathrm{N}\left(\mathrm{C}_{2} \mathrm{H}_{5}\right)_{3}, \mathrm{CH}_{3} \mathrm{~F}$ was produced in a high yield and as the sole gaseous product:

$$
\mathrm{F}_{5} \mathrm{SCH}\left(\mathrm{SO}_{2} \mathrm{~F}\right) \mathrm{COOCH}_{3}+\mathrm{F}_{3} \mathrm{~B} \cdot \mathrm{N}\left(\mathrm{C}_{2} \mathrm{H}_{5}\right)_{3} \rightarrow \underset{\mathrm{FO}_{2} \mathrm{~S} \underline{44}}{\left(\mathrm{~F}_{2} \mathrm{SO}\right)=\mathrm{COF}}+\mathrm{CH}_{3} \mathrm{~F}
$$

The new trifunctional compound $\underline{44}$ is the first of its kind. There is only one other example that contains the COF and $\mathrm{F}_{2}$ So functional groups bonded to carbon. This compound, $\left(\mathrm{F}_{2} \mathrm{SO}\right)=\mathrm{CHCOF}$, was obtained by hydrolysis of $\mathrm{F}_{4} \mathrm{~S}=\mathrm{CHCOF}^{65}$ and seems to exist in a number of rotation isomers, as shown by variable temperature n.m.r.spectroscopy •

The first order ${ }^{19} \mathrm{~F}$ n.m.r. spectrum of $\underline{44}$ at room temperature is very similar to that of $\left(\mathrm{F}_{2} \mathrm{SO}\right)=\mathrm{CHCOF}^{2}$. Chemical shifts and splitting patterns are comparable, with the exception that one has the additional large coupling to the $\mathrm{SO}_{2} \mathrm{~F}$ fluorine. The coupling constants are similar to the ones found in $\mathrm{SF}_{5} \mathrm{CX}\left(\mathrm{SO}_{2} \mathrm{~F}\right) \mathrm{COF}$, where $\mathrm{X}=\mathrm{H}(\underline{1}), \mathrm{F}^{66}, \mathrm{Cl}$ $(\underline{25 a}), \operatorname{Br}(\underline{25 b})$.

The main characteristics of the infrared spectrum include the strong $C=0$ stretching vibration $\left(1825 \mathrm{~cm}^{-1}\right)$, various $\mathrm{S}=0$ stretching vibrations, i.e., $v_{\text {asso2 }}=1448 \mathrm{~cm}^{-1}$, $\mathrm{v}_{\mathrm{SO}}=1419 \mathrm{~cm}^{-1}$. The asymmetric $\mathrm{SO}_{2}$ stretching mode shows only a small variability and appears always between $\approx 1440$ and $1460 \mathrm{~cm}^{-1}$. The symmetric $\mathrm{SO}_{2}$ stretching mode frequency occurs normally at $\approx 1220 \mathrm{~cm}^{-1}$; in the same region $(1100-1300$ 
$\left.\mathrm{cm}^{-1}\right)^{82}$ one expects the resonance for the $\mathrm{S}=\mathrm{C}$ (double) bond. Since there are several bands in this region, an unambiguous assignment is not possible, but the band the band at 1226 $\mathrm{cm}^{-1}$ could correspond to $\mathrm{v}_{\text {symso2 }}$. In particular the $\mathrm{SF}$ (stretching) modes at 875 and $801 \mathrm{~cm}^{-1}$ have a rather unusual appearance, as compared to $\mathrm{SF}_{5}$ band shapes. The two bands are of about equal intensity and show no further structure, whereas in $\mathrm{SF}_{5}-\mathrm{SO}_{2} \mathrm{~F}$ compounds one finds a multitude of bands of various intensity in the same region.

The mass spectrum shows the molecular ion and appropriate fragment ions, but also one rather intense band which can be accounted for if one assumes rearrangement to

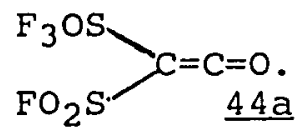

The formation of $\left(\mathrm{F}_{2} \mathrm{SO}\right)=\mathrm{C}\left(\mathrm{SO}_{2} \mathrm{~F}\right) \mathrm{COF}$ and alkyl fluoride can be rationalized by a series of eliminations and rearrangements. In the first step, formation of the $\mathrm{HF}$ elimination product is conjectured:

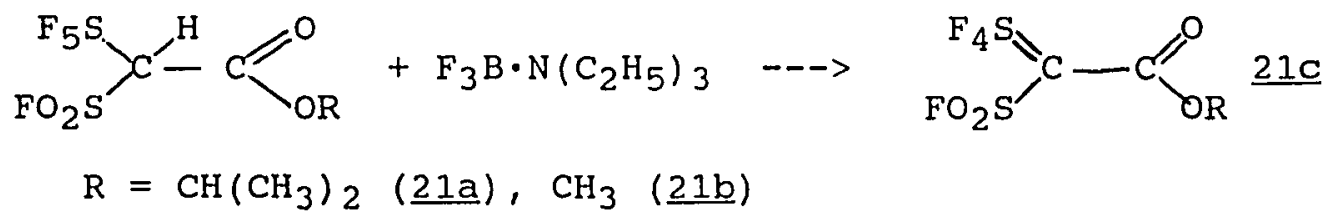

It has to be assumed that the newly-formed $\mathrm{F}_{4} \mathrm{~S}=$ ester is unstable towards rearrangement. The ester could undergo ring closure, lose RF and undergo transformation by a [1,3]sigmatropic shift to $\underline{44}$ : 


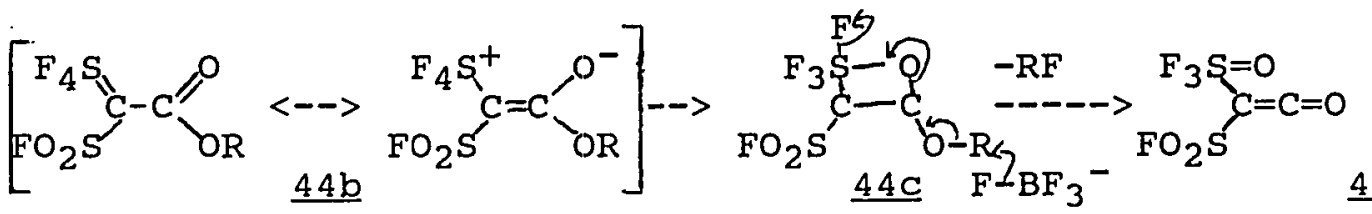

$-(1,3]$<smiles>O=C(F)C(=O)S(=O)(=O)O[Na]</smiles>

Alternatively, attack of the alkoxy group at $\mathrm{SF}_{4}$ is possible, followed by elimination, ring opening and again [1,3]-sigmatropic shift. Although a number of other mechanisms can be formulated, which involve migration of $\mathrm{F}^{-}$, a concerted mechanism seems more likely for the following reasons:

1. $\mathrm{F}^{-}$migration is deemed unlikely in the reaction medium. $\mathrm{BF}_{4}^{-}$is not a good source of $\mathrm{F}^{-}$.

2. In the mass spectrum there is a moderately strong $\mathrm{m} / \mathrm{e}$ $=105$ peak. This could indicate the fragment SOF $_{3}{ }^{+}$, formed from 44 in the reversal of the last step in the scheme formulated above in the mass spectrometer. For the mass 105 the composition $\left(\mathrm{MH}-\mathrm{SOF}_{4}\right)^{+}$is also formulated.

3. Ketene 21 was stable in the presence of $\mathrm{BF}_{4}^{-} \mathrm{NH}\left(\mathrm{C}_{2} \mathrm{H}_{5}\right)_{3}^{+}$ and $44 \mathrm{a}$ is not expected to be very different.

If the mechanism were ionic, then $\mathrm{F}^{-}$addition to 44 a would be a likely step; this would mean that $\underline{44 a}$ could compete| successfully with $\mathrm{BF}_{3}$ for $\mathrm{F}^{-}$. An intermediate

$\left(\mathrm{F}_{3} \mathrm{SO}^{-}\right)=\mathrm{C}\left(\mathrm{SO}_{2} \mathrm{~F}\right) \mathrm{COF}$ would be formed which would give 44 upon loss of $\mathrm{F}^{-} \cdot 1,3$ fluorine migrations can apparently take place thermally as found for $\left(\mathrm{CF}_{3}\right)_{2}=\mathrm{SO}_{2}$ (pyrolysis of $\left(\mathrm{CF}_{3}\right)_{2}\left(\mathrm{SO}_{2}\right)_{2}\left(\mathrm{CF}_{3}\right)_{2}$, leading to $\mathrm{F}_{3} \mathrm{CC}\left(\mathrm{SO}_{2} \mathrm{~F}\right)=\mathrm{CF}_{2} 67 \mathrm{a}$, slow conversion at room temperature of $\left(\mathrm{CF}_{3}\right)_{2} \mathrm{C}=\mathrm{P}\left(\mathrm{O}_{2}\left(\mathrm{CH}_{2}\right)_{2}\right) \mathrm{OCH}_{3}$ $\left(->\quad F_{2} \mathrm{C}=\mathrm{C}\left(\mathrm{CF}_{3}\right) \operatorname{PF}\left(\mathrm{O}_{2} \mid\left(\mathrm{CH}_{2}\right)_{2}\right) \mathrm{OCH}_{3}\right)^{67 \mathrm{~b}}$, pyrolysis of $\left(\mathrm{CH}_{3}\right)_{3} \mathrm{SnP}\left(\mathrm{CF}_{3}\right) \mathrm{CH}\left(\mathrm{CF}_{3}\right)_{2}$, leading to $\left(\mathrm{CF}_{3}\right) \mathrm{FP}=\mathrm{C}\left(\mathrm{CF}_{3}\right)=\mathrm{CF}_{2}{ }^{67 \mathrm{C}}$, 
and the spontaneous conversion of $\left(\mathrm{CF}_{3}\right)_{2} \mathrm{C}=\mathrm{C}=\mathrm{O}$ to $\mathrm{F}_{2} \mathrm{C}\left(\mathrm{CF}_{3}\right) \mathrm{CFO}^{67 d}$. Light induced $1,3 \mathrm{~F}$ migration was found for tetratrifluoromethyl ethylene $) \rightarrow \mathrm{F}_{2} \mathrm{C}=\mathrm{C}\left(\mathrm{CF}_{3}\right) \mathrm{CF}\left(\mathrm{CF}_{3}\right)_{2}$.

Further reactions of the trifunctional molecule could not be completed successfully. Reaction with diethylamine led to an inseparable mixture of many compounds, as evidenced by the ${ }^{19} \mathrm{~F}$ n.m.r. spectrum and reaction with $\mathrm{CsF}$ in $\mathrm{CH}_{3} \mathrm{CN}$ led to the uptake of one equivalent of CsF, but the fluorine spectrum showed the presence of at least two COF groups. Separation was not attempted.

While the esters $\underline{21 a}$ and $\underline{21 b}$ gave $\underline{44}$ when treated with $\mathrm{F}_{3} \mathrm{~B} \cdot \mathrm{N}\left(\mathrm{C}_{2} \mathrm{H}_{5}\right)_{3}$ similar treatment of the ester $\mathrm{SF}_{5} \mathrm{CH}_{2} \mathrm{COOCH}_{3}$ resulted in decomposition; only residual ester and $\mathrm{SF}_{4}$ was observed in the ${ }^{19} \mathrm{~F}$ n.m.r. spectrum of the reaction mixture.

\section{NUCLEAR MAGNETIC RESONANCE SPECTRA}

Most of the compounds that were synthesized and described have no unusual n.m.r. spectra. Covalent $\mathrm{SF}_{5}$ compounds appear in a certain chemical shift range, where $\phi_{A}$ ranges from $\approx 60-85 \mathrm{ppm}$ and $\phi_{\mathrm{B}}$ from $\approx 45$ to $75 \mathrm{ppm}\left(\mathrm{CCl}_{3} F=\right.$ $0.0 \mathrm{ppm})$, and $J_{A B}$ is usually $150 \pm 7 \mathrm{~Hz}$. The octahedral environment of the sulfur leads to two different kinds of fluorine, the 4 equatorial fluorines (B) and one axial fluorine (A), and the spin system is classified as $\mathrm{AB}_{4}$. Furthermore, when the chemical shift difference $\phi_{\mathrm{A}}-\phi_{\mathrm{B}}$ becomes small $(\approx<3 \mathrm{ppm})$, the usual $\mathrm{AB}_{4}$ spectrum, which 
consists of a doublet of a multiplet (the B-resonance) and a 9-line pattern, which is actually the superimposition of a singlet, a triplet and a quintet, becomes degenerate and appears as a multiplet. It cannot be interpreted by manual means anymore. As long as an $\mathrm{AB}_{4}$ spectrum is seen, however, such a hand-analysis can be made with reasonable accuracy. The values that are obtained are usually acceptable, although in most cases not too accurate, as an exact determination of $\phi_{B}$ and $J_{A B}$ rests upon an accurate assignement of lines within the B-resonance. This is not usually possible, as either the lines are not well enough resolved or it is not simple to determine the correct lines within the irregular multiplet. A correct assignment is realistically only possible with a spectral simulation program. Relationships between the individual resonance lines and the sought-after quantities of $\phi_{A}-\phi_{B}$ and $J_{A B}$ were published by Borden et al.68 and by Harris and Packer. 69 Packer's and Harris's procedure was used here. Only $\phi_{\mathrm{A}}$ can be measured accurately as the center line (the singlet) of the 9-line pattern which represents the resonance of the axial fluorine. Most of the ${ }^{19} \mathrm{~F}$ n.m.r. spectra were normal $\mathrm{AB}_{4}$ spectra, with $\phi_{\mathrm{A}}$ downfield of $\phi_{\mathrm{B}}(\mathrm{e} . \mathrm{g} . \underline{25})$, then there were intermediate cases (small $\phi_{A}-\phi_{B}$, e.g. 25a), the degenerate case (e.g. 21a, $\underline{21 b}, \underline{30})$, and again the $\mathrm{AB}_{4}$ case, this time with $\phi_{A}$ upfield of $\phi_{B}$. Fig.l exemplifies the change an $\mathrm{AB}_{4}$ spectrum undergoes when $\phi_{\mathrm{A}}-\phi_{\mathrm{B}}$ is successively 
altered. In the end, one has the mirror image of the original spectrum if one goes from $\phi_{A}-\phi_{B}=x$ ppm to $\phi_{A}-\phi_{B}=$ $-x$ ppm. The $\phi_{A}-\phi_{B}=0$ spectrum is a singlet, although the coupling constant is $150 \mathrm{~Hz}$. This is a similar case to e.g. methane or benzene, where coupling cannot be directly observed. 

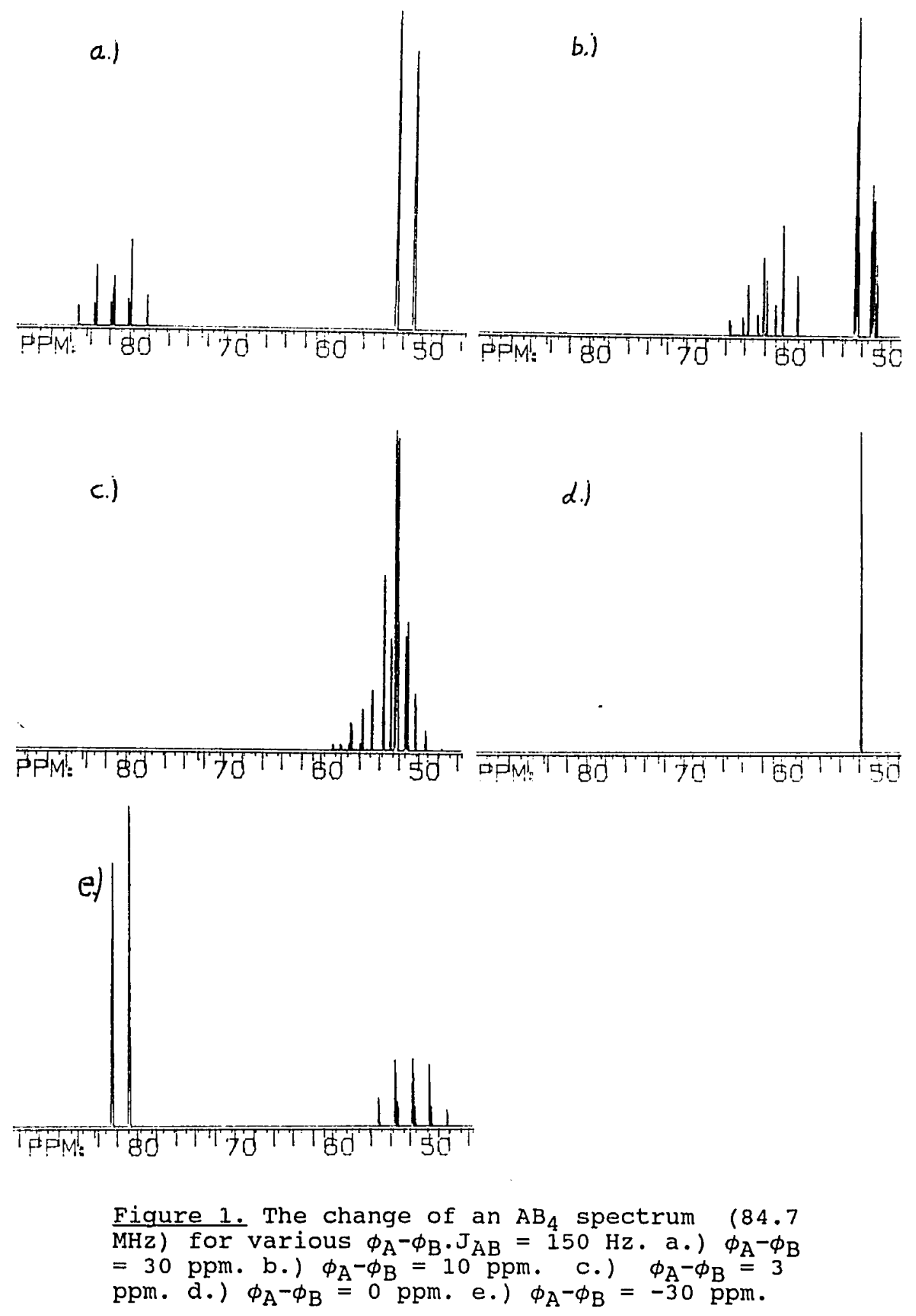
In the ${ }^{19} \mathrm{~F}$ n.m.r. spectra of carbanionic species (2ㄷ, $\underline{32 a}, \underline{32 b}, \underline{33}, \underline{34}, \underline{45})$ it is observed that both the $\mathrm{SO}_{2} \mathrm{~F}$ and the $\mathrm{SF}_{5}$ resonances appear, contrary to the expectation that increased charge density lead to increased shielding and thus an upfield shift, at a downfield position as compared to neutral compounds. This shift showed only a minor dependence on the cation $\left(\mathrm{Cs}^{+}, \mathrm{Ag}^{+}, \mathrm{Na}^{+}, \mathrm{HN}\left(\mathrm{C}_{2} \mathrm{H}_{5}\right)_{3}^{+}, \mathrm{Hg}^{2+}\right)$. A related observation was made with perfluoroalkyl carbanions, e.g. Dyatkin et al 70 notice this effect for $\left(\mathrm{CF}_{3}\right)_{3} \mathrm{C}^{-} \mathrm{Cs}^{+}$and attribute it to the "reverse redistribution of electron density 71 via fluorine atoms to the vacant inner orbitals of the metal atoms". A complexation of the anion with the metal cation is assumed. More recently, the same property was discussed by Bayliff and Chambers 72 who observed this downfield shift for $\mathrm{Cs}^{+}$and $\left(\left(\mathrm{CH}_{3}\right)_{2} \mathrm{~N}\right)_{3} \mathrm{~S}^{+}$ cations and it was noticed that the theory of magnetic shielding was in "some disarray". Apparently, there is no adequate theory that can explain satisfactorily this phenomenon in an anion, as it is also observed with anions that do not have vacant inner orbitals. A related observation was made in neutral compounds, where the fluorine resonance was shifted to a deshielded position by an electron donating substituent. 73 This downfield shift is also observed in a number of compounds that have to be considered as salts or zwitterions (e.g $\underline{26})$. A common feature of the anions that were characterized here is the 
presence of an $\mathrm{SO}_{2} \mathrm{~F}, \mathrm{SF}_{5}$ and $\mathrm{COR}$ at a carbon: in all cases they are enolates.

The CFO group in the compounds $\mathrm{F}_{5} \mathrm{SC}\left(\mathrm{SO}_{2} \mathrm{~F}\right)=\mathrm{CFO}^{-}$ $[\mathrm{Cs}, \mathrm{Ag}, \mathrm{Na}]^{+}$is in a strongly shielded position (17ppm), as compared to neutral CFO-compounds. This suggests that the charge is concentrated mainly at the CFO-group; the lowering of the $\mathrm{C}=\mathrm{O}$ stretch frequency from $\mathrm{F}_{5} \mathrm{SCH}\left(\mathrm{SO}_{2} \mathrm{~F}\right) \mathrm{CFO}$ is about 90 $\mathrm{cm}^{-1}$ for $\underline{25}\left(1766 \mathrm{~cm}^{-1}\right)$, underscoring the latter conclusion. Similar low-field resonances were reported earlier for the anions $\mathrm{FO}_{2} \mathrm{SNCFO}^{-}(\mathrm{Cs}, \mathrm{K}, \mathrm{Na})^{+74}$ and $\mathrm{F}_{5} \mathrm{SC}\left(\mathrm{CF}_{3}\right)_{2}^{-}(\mathrm{Cs}, \mathrm{Rb})^{+} 75$, although they were not discussed.

In the mercurial $\left(\mathrm{F}_{5} \mathrm{SC}\left(\mathrm{SO}_{2} \mathrm{~F}\right) \mathrm{COF}\right)_{2} \mathrm{Hg}$ the $\mathrm{COF}$ resonance appears at a somewhat less shielded position (21.6pp $)^{m}$, as compared to the sodium, silver and cesium salts. The $\mathrm{SF}_{5}$ and $\mathrm{SO}_{2} \mathrm{~F}$ resonance in the mercury compound is in a less deshielded position than in these salts. This observation parallels with the usual property of mercurials as more covalent compounds (they are often soluble in nonpolar solvents and can be distilled), which probably holds here, too. The $\mathrm{C}=0$ resonance of the mercurial appears at $1826 \mathrm{~cm}^{-}$ 1, which argues for a more covalent compound, too.

In the ${ }^{13} \mathrm{C}$ spectra of perfluoroalkyl carbanions ${ }^{68} \mathrm{R}_{f}{ }^{-}$ increased shielding is seen at the anionic center, as expected from theory, but deshielding is observed at the carbon atoms next to the anionic center. A similar effect was observed for $\underline{25}$ and $\underline{22}$, 


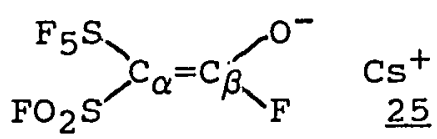

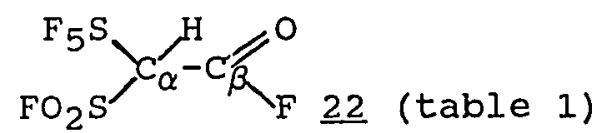

although both carbons showed a downfield shift as compared to 22 . While in the perfluorocarbanions the charge is localized (disregarding hyperconjugation), it can be distributed over the enol system in 25 . This can account for the simultaneous deshielding, if associated with increased charge density, in $\underline{25}$. The observation of a low field resonance for an $\mathrm{SF}_{5}$-compound can thus be rather generally associated with an anionic site next to $\mathrm{SF}_{5}$ i one has to be cautious, though, because some $S_{5}$-hydrocarbons (having the grouping $\mathrm{F}_{5} \mathrm{SCH}_{2}$ ) show $\phi_{\mathrm{B}} \approx 75 \mathrm{ppm}$, and $\phi_{\mathrm{A}} \approx 85 \mathrm{ppm}$, which is very close to the range that was observed for the anions.

The ${ }^{19} \mathrm{~F}$ n.m.r. spectra of compounds $\underline{23}, \underline{42}$ and $\underline{43}$ are complicated. They are classified as AA'BCXX' (며) and as $A B C D X Y(\underline{42}, \underline{43})$ spin systems. For $\underline{42}$ and $\underline{43}$ there are also chiral centers which complicated the analysis even more. The ${ }^{19} \mathrm{~F}$ n.m.r. spectrum of $\underline{23}$ is similar to the spectra of other $\mathrm{SF}_{4}=$ compounds 76 . The spectral parameters were obtained by several steps. 1.:An AA'BC spectrum consists of two (approximately) independent subspectra77. This allowed to determine $\phi_{\mathrm{B}}, \phi_{\mathrm{C}}$ and $\mathrm{J}_{\mathrm{BC}}$, reducing the number of unknown parameters to $3\left(\phi_{A}, J_{A B}, J_{A C}\right) \cdot 2 .: \phi_{A}$ was guessed from the appearance of the spectrum, and the remaining couplings were assumed to fall into a certain range $(145-165 \mathrm{~Hz})$. This latter assumption was warranted by comparison with similar 
compounds. Furthermore, each line in the $\mathrm{SF}_{4}$ spectrum showed further triplet splitting of different magnitude in the A, B and $C$ part of the spectrum. This represented the coupling to the $\mathrm{CF}_{2}$ group, the chemical shift of which was also measurable and which appears roughly as a quintet. A complete set of spectral parameters could then be calculated with the aid of an iterative n.m.r. simulation program.78 From these values, and in analogy to the structure of $\mathrm{CH}_{2}=\mathrm{SF}_{4} 79$ (X-ray structural determination), it was now possible to assign the following structure to 23 :



In this structure, the axial fluorines $F_{B}$ and $F_{C}$ (the $S_{4} S=$ group is a fragment of the $S_{6}$ octahedron) lie in the plane of the sultone ring. The alternative structure where $F_{A}$ and $F_{A}$, lay in the plane of the sultone ring would give the same n.m.r. spectrum. That $\underline{23}$ has an $A A^{\prime} B C$ spectrum shows also that the fluorine atoms do not undergo exchange, as was found for similar $\mathrm{F}_{4} \mathrm{~S}=\mathrm{N}$ systems ${ }^{80}$. 
experimental
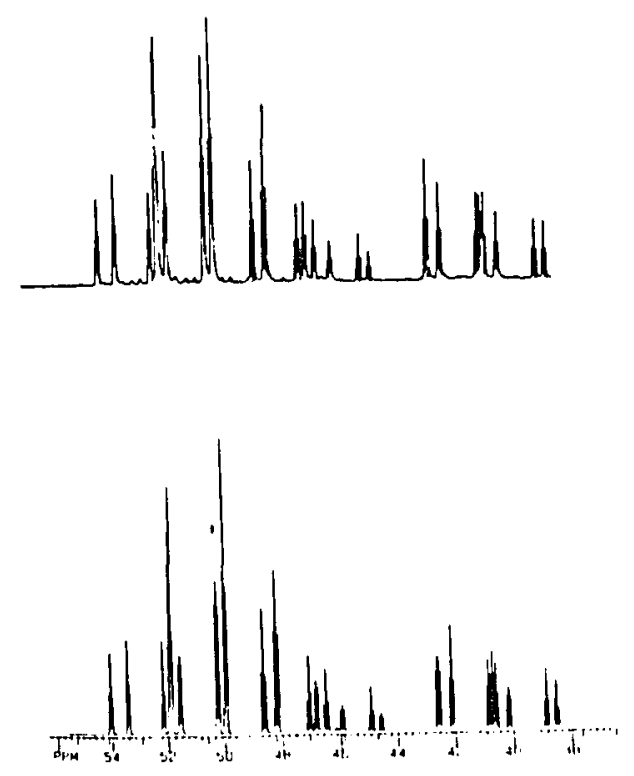

calculated

Figure 2. Experimental and calculated ${ }^{19} \mathrm{~F}$ n.m.r. spectrum of $\mathrm{F}_{4} \mathrm{~S}=\mathrm{CCF}_{2} \mathrm{OSO}_{2}, \underline{23}$.

The ${ }^{13} \mathrm{C}$ n.m.r. spectrum of $\underline{23}$ (table 2) reveals two resonance groups, one at $114.5 \mathrm{ppm}$ and a weaker one at 80.7 ppm. From the intensities and the splitting patterns the resonance at $80.7 \mathrm{ppm}$ is assigned to $\mathrm{c}^{\alpha}$, as the absence of an attached spin-one half nucleus decreases relaxation, leading to partial saturation. The $\mathrm{c}^{\alpha}$ resonance appears approximately as a quintet of triplets; it is assumed that. the four fluorines have coupling constants of comparable magnitude $(\approx 32 \mathrm{~Hz})$ to $c^{\alpha}$ which would account for the quintet splitting, while the triplet coupling $(7.8 \mathrm{~Hz})$ would arise from coupling to the fluorines at $c^{\beta}$. The other resonance signal $\left(C^{\beta}\right)$ is a triplet of doublets. The triplet coupling 
$(282 \mathrm{~Hz})$ is nearly the same as in $\underline{1}(293 \mathrm{~Hz})^{81}$ and is attributet to the $c^{\beta}-F$ couplings, and the smaller doublet coupling $(23.2 \mathrm{~Hz})$ is assumed to arise from trans $-\mathrm{C}^{\beta}-\mathrm{F}_{\mathrm{B}}$ coupling. This latter coupling was unchanged on raising the sample temperature to $40^{\circ} \mathrm{C}$, implying that not multiple ring conformations are resolved.

The ${ }^{19} \mathrm{~F}$ n.m.r. spectrum of $\underline{42}$ shows three types of fluorine in the ratio of $1: 2: 1$, which identifies it clearly as a cis $-\mathrm{SF}_{4} \mathrm{R}$ compound, because for a trans arrangement a singlet is observed for the fluorine resonances, due to their equivalence, whereas the $C_{2}$ group appears as an $A B$ system with asymmetric coupling to the proton, analogous to sultone 1 . The coupling within the $\mathrm{SF}_{4}$ arrangement is complicated and only partial interpretation of the spectrum is possible. In $\underline{42}$ as well as in $\underline{43}$ one observes actually four fluorine resonances. Two of these lie close together, respectively, and are very similar, except that in one of them additional coupling is seen. This suggests that the rotation of the $\mathrm{SF}_{4} \mathrm{X} \quad\left(\mathrm{X}=\mathrm{Cl}, \mathrm{OCH}_{3}\right)$ group is actually hindered, perhaps through hydrogen bonding between either a fluorine or $X$ and the hydrogen at $c_{\alpha}$ of the sultone ring. The assignment of the different fluorines and coupling constants followed the one given for similar compounds. 82 The $\mathrm{CF}_{2}$ group appears as an $\mathrm{AB}$ system.

The ${ }^{13} \mathrm{C}$ n.m.r. spectrum of $\underline{42}$ with proton coupling shows a triplet and two multiplets, which collapse upon ${ }^{1} \mathrm{H}-$ 
decoupling into one at $109 \mathrm{ppm}$. The multiplet consists of nine lines, which show additional splitting and may be assigned to $C^{\alpha}$ (the same numbering is assumed as for $\underline{23}$ ). The remaining resonances, from $c^{\beta}$, appear as four lines, the middle two of which overlap to produce a distorted triplet centered at $113.4 \mathrm{ppm}$.

TABLE I

${ }^{19} \mathrm{~F}$ N.M.R. AND I.R. TABLE OF $\mathrm{SF}_{5}$-ANIONS

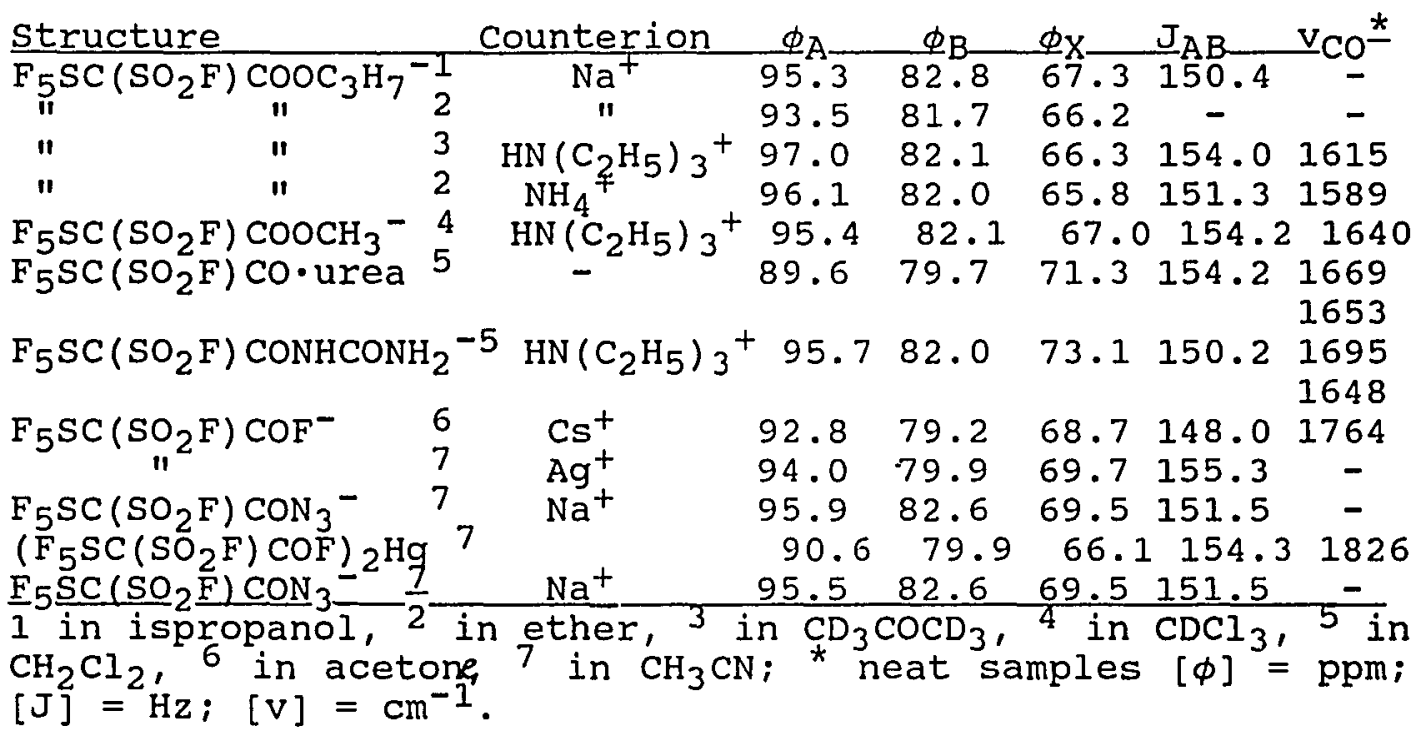

TABLE II

${ }^{13} \mathrm{C}$ N.M.R. TABLE OF $\mathrm{SF}_{5} \mathrm{C}_{\alpha} \mathrm{C}_{\beta}$ COMPOUNDS

\begin{tabular}{|c|c|c|c|c|}
\hline ructu & & $\delta \alpha$ & $\delta_{\beta}$ & \\
\hline $\mathrm{F}_{5} \mathrm{SC}\left(\mathrm{SO}_{2} \mathrm{~F}\right) \mathrm{CFO}^{-} \mathrm{Cs}^{+}$ & $25^{1}$ & 104.33 & 157.50 & \\
\hline $\mathrm{F}_{5} \mathrm{SCH}(\mathrm{SO}, \mathrm{F}) \mathrm{COF}$ & $\overline{22}^{2}$ & 88.5 & 146.8 & \\
\hline $\mathrm{F}_{5} \mathrm{SC}\left(\mathrm{SO}_{2} \mathrm{~F}\right)=\mathrm{C}=\mathrm{O}$ & $\overline{21}^{2}$ & 86.28 & 174.81 & \\
\hline $\mathrm{F}_{4} \mathrm{SClCHCF}_{2} \mathrm{OSO}_{2}$ & $4^{3}$ & 108.8 & 113.4 & \\
\hline $\mathrm{F}_{5} \mathrm{SC}\left(\mathrm{SO}_{2} \mathrm{~F}\right)=\mathrm{CHOSi}\left(\mathrm{CH}_{3}\right)_{3}$ & $\frac{39 a^{2}}{2}$ & 126.95 & 159.36 & \\
\hline $\begin{array}{l}\mathrm{F}_{5} \mathrm{SCF}_{2} \mathrm{CF}_{2} \mathrm{~J} \\
\mathrm{~F}_{5} \mathrm{SCHFCF}_{2} \mathrm{Br}\end{array}$ & 2 & $\begin{array}{l}119.21(t-m) \\
108.15\end{array}$ & $\begin{array}{r}91.304 \\
114.69\end{array}$ & $(t-t)$ \\
\hline $\begin{array}{l}\text { in } \mathrm{CD}_{3} \mathrm{CN}, \quad 2 \text { in } \\
\text { ternal } \mathrm{CDCl}_{3}[\delta]=\end{array}$ & & $\begin{array}{l}\text { eat sample } \\
4=0.0 . \mathrm{J}\end{array}$ & $\begin{array}{l}\text { referenc } \\
\mathrm{JC}_{\alpha} \mathrm{F}_{\alpha}=\end{array}$ & $\begin{array}{l}e d t c \\
314.5\end{array}$ \\
\hline
\end{tabular}


The infrared spectra of $\underline{23}, \underline{42}$ and $\underline{43}$ and are in accord with the proposed structures, too. Bands for the asymmetric (1400-1450 $\left.\mathrm{cm}^{-1}\right)$ and symmetric stretching mode (1200-1250 $\mathrm{cm}^{-1}$ ) of the $\mathrm{SO}_{2}$ group are observed: 1415 and 1192-1235 $\mathrm{cm}^{-1}$ for $2 \underline{3}, 1430$ and $1214 \mathrm{~cm}^{-1}$ for $\underline{42}$ and 1424 and 1216 for 43 . To the $C=S$ bond corresponds a strong band at $\approx 1200 \mathrm{~cm}^{-1} .83$ several bands in this region in the i.r. of could be assigned to the $\mathrm{C}=\mathrm{S}$ bond. Additional typical bands correspond to the $\mathrm{S}-\mathrm{F}$ stretching modes in the $\mathrm{SF}_{4}$ groups of $\underline{23}, \underline{42}$ and $\underline{43}$ at $800-900 \mathrm{~cm}^{-1}$.

\section{FEATURES OF X-RAY STRUCTURES ${ }^{84}$}

It was a good fortune that several of the $\mathrm{SF}_{5}$ compounds were crystalline. This allowed to determine some structural features. In one instance, the roentgenographic determination of the structure allowed the identification of the compound altogether, as only very small amounts of material were at hand, and other techniques were not completely conclusive. This was $\underline{29}$, formed in a notunderstood way from what is probably $\mathrm{F}_{5} \mathrm{SC}\left(\mathrm{SO}_{2} \mathrm{~F}\right)=\mathrm{COCH}_{2} \mathrm{O}(\underline{28})$. The amide $\mathrm{F}_{5} \mathrm{SCH}\left(\mathrm{SO}_{2} \mathrm{~F}\right) \mathrm{CON}\left(\mathrm{C}_{2} \mathrm{H}_{5}\right)_{2}, \underline{27}$, and the salt $\mathrm{F}_{5} \mathrm{SC}\left(\mathrm{SO}_{2} \mathrm{~F}\right) \mathrm{COOCH}_{3}{ }^{-} \mathrm{NH}\left(\mathrm{C}_{2} \mathrm{H}_{5}\right)_{3}{ }^{+} \underline{32 \mathrm{~b}}$ were stable, crystalline compounds, which allowed the determination of their structural parameters as solids. The obvious close relationship between these compounds validates comparisons respecting bond-angles and-lenghts. 
TABLE III

BOND DISTANCES [pm] AND ANGLES [ ${ }^{\circ}$ ] OF THE SALT $\mathrm{F}_{5} \mathrm{SC}\left(\mathrm{SO}_{2} \mathrm{~F}\right) \mathrm{COOCH}_{3}{ }^{-} \mathrm{HN}\left(\mathrm{C}_{2} \mathrm{H}_{5}\right){ }_{3}^{+}, 32 \mathrm{~b}$, STANDARD DEVIATIONS IN PARENTHESES

\begin{tabular}{crcr}
\hline$S(1)-F(1)$ & $157.1(3)$ & $S(1)-F(2)$ & $158.4(2)$ \\
$S(1)-F(3)$ & $157.3(3)$ & $S(1)-F(4)$ & $158.2(3)$ \\
$S(1)-F(5)$ & $159.5(3)$ & $S(1)-C(1)$ & $177.0(4)$ \\
$C(1)-C(2)$ & $144.7(4)$ & $C(1)-S(2)$ & $167.9(4)$ \\
$C(2)-O(1)$ & $120.7(5)$ & $C(2)-O(2)$ & $132.8(4)$ \\
$O(2)-C(3)$ & $143.6(4)$ & $S(2)-O(3)$ & $139.5(3)$ \\
$S(2)-O(4)$ & $157.1(3)$ & $S(2)-F(6)$ & $141.9(4)$ \\
$F(1)-S(1)-F(2)$ & $89.6(1)$ & $F(1)-S(1)-F(3)$ & $90.0(1)$ \\
$F(2)-S(1)-F(3)$ & $173.0(1)$ & $F(1)-S(1)-F(4)$ & $172.8(1)$ \\
$F(2)-S(1)-F(4)$ & $89.4(1)$ & $F(3)-S(1)-F(4)$ & $90.1(1)$ \\
$F(1)-S(1)-F(5)$ & $86.7(1)$ & $F(2)-S(1)-F(5)$ & $86.8(1)$ \\
$F(3)-S(1)-F(5)$ & $86.2(1)$ & $F(4)-S(1)-F(5)$ & $86.1(1)$ \\
$F(1)-S(1)-C(1)$ & $94.1(2)$ & $F(2)-S(1)-C(1)$ & $94.0(1)$ \\
$F(3)-S(1)-C(1)$ & $93.0(2)$ & $F(4)-S(1)-C(1)$ & $93.1(1)$ \\
$F(5)-S(1)-C(1)$ & $178.9(2)$ & $S(1)-C(1)-C(2)$ & $123.5(3)$ \\
$S(1)-C(1)-S(2)$ & $120.2(2)$ & $C(2)-C(1)-S(2)$ & $115.4(3)$ \\
$C(1)-C(2)-O(1)$ & $123.8(3)$ & $C(1)-C(2)-O(2)$ & $115.4(3)$ \\
$O(1)-C(2)-O(2)$ & $120.8(3)$ & $C(2)-O(2)-C(3)$ & $116.2(3)$ \\
$C(1)-S(2)-O(3)$ & $114.3(2)$ & $C(1)-S(2)-F(6)$ & $112.1(2)$ \\
$O(3)-S(2)-O(4)$ & $103.8(2)$ & $C(1)-S(2)-O(4)$ & $104.6(2)$ \\
$O(3)-S(2)-F(6)$ & $118.4(2)$ & $O(4)-S(2)-F(6)$ & $101.3(2)$ \\
$C(11)-N-C(13)$ & $110.9(3)$ & $C(11)-N-C(15)$ & $113.7(3)$ \\
$C(13)-N-C(15)$ & $111.7(3)$ & $N-C(11)-C(12)$ & $115.7(3)$ \\
$N-C(13)-C(14)$ & $113.0(3)$ & $N-C(15)-C(16)$ & $113.9(4)$ \\
\hline
\end{tabular}


TABLE IV

BOND DISTANCES [pm] AND ANGLES [०] IN $\mathrm{F}_{5} \mathrm{SCH}\left(\mathrm{SO}_{2} \mathrm{~F}\right) \mathrm{CON}\left(\mathrm{C}_{2} \mathrm{H}_{5}\right)_{2}$, 27, STANDARD DEVIATIONS IN PARENTHESES

\begin{tabular}{|c|c|c|c|}
\hline $\begin{array}{c}S(1)-F(5) \\
S(1)-F(3) \\
S(1)-F(4) \\
S(1)-F(1) \\
S(1)-F(2) \\
S(1)-C(1) \\
S(2)-O(2) \\
S(2)-O(1) \\
S(2)-F(6) \\
S(2)-C(1) \\
O(3)-C(2) \\
N(1)-C(2) \\
N(1)-C(5) \\
N(1)-C(3) \\
F(5)-S(1)-F(3) \\
F(5)-S(1)-F(4) \\
F(5)-S(1)-F(1) \\
F(5)-S(1)-F(2) \\
F(5)-S(1)-C(1) \\
F(3)-S(1)-F(4) \\
F(3)-S(1)-F(1) \\
F(3)-S(1)-F(2) \\
F(3)-S(1)-C(1) \\
F(4)-S(1)-F(1) \\
F(4)-S(1)-F(2) \\
F(4)-S(1)-C(1) \\
F(1)-S(1)-F(2) \\
F(1)-S(1)-C(1) \\
F(2)-S(1)-C(1) \\
O(2)-S(2)-O(1) \\
O(2)-S(2)-F(6) \\
O(2)-S(2)-C(1) \\
O(1)-S(2)-F(6) \\
O(1)-S(2)-C(1) \\
F(6)-S(2)-C(1) \\
C(2)-N(1)-C(5) \\
C(2)-N(1)-C(3) \\
C(5)-N(1)-C(3) \\
H(1)-C(1)-C(2) \\
H(1)-C(1)-S(2) \\
H(10)-C(6)-H(11 \\
H(9)-C(6)-H(11) \\
H(11)-C(6)-C(5)\end{array}$ & 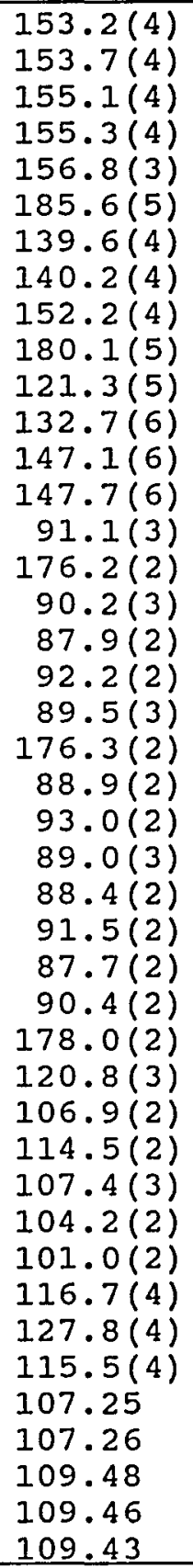 & $\begin{array}{c}\mathrm{C}(1)-\mathrm{H}(1) \\
\mathrm{C}(1)-\mathrm{C}(2) \\
\mathrm{C}(3)-\mathrm{H}(3) \\
\mathrm{C}(3)-\mathrm{H}(2) \\
\mathrm{C}(3)-\mathrm{H}(4) \\
\mathrm{C}(4)-\mathrm{H}(4) \\
\mathrm{C}(4)-\mathrm{H}(5) \\
\mathrm{C}(4)-\mathrm{H}(6) \\
\mathrm{C}(5)-\mathrm{H}(7) \\
\mathrm{C}(5)-\mathrm{H}(8) \\
\mathrm{C}(5)-\mathrm{C}(6) \\
\mathrm{C}(6)-\mathrm{H}(10) \\
\mathrm{C}(6)-\mathrm{H}(9) \\
\mathrm{C}(6)-\mathrm{H}(11) \\
\mathrm{H}(1)-\mathrm{C}(1)-\mathrm{S}(1) \\
\mathrm{C}(2)-\mathrm{C}(1)-\mathrm{S}(2) \\
\mathrm{C}(2)-\mathrm{C}(1)-\mathrm{S}(1) \\
\mathrm{S}(2)-\mathrm{C}(1)-\mathrm{S}(1) \\
\mathrm{O}(3)-\mathrm{C}(2)-\mathrm{N}(1) \\
\mathrm{O}(3)-\mathrm{C}(2)-\mathrm{C}(1) \\
\mathrm{N}(1)-\mathrm{C}(2)-\mathrm{C}(1) \\
\mathrm{H}(3)-\mathrm{C}(3)-\mathrm{H}(2) \\
\mathrm{H}(3)-\mathrm{C}(3)-\mathrm{N}(1) \\
\mathrm{H}(3)-\mathrm{C}(3)-\mathrm{C}(4) \\
\mathrm{H}(2)-\mathrm{C}(3)-\mathrm{N}(1) \\
\mathrm{H}(2)-\mathrm{C}(3)-\mathrm{C}(4) \\
\mathrm{N}(1)-\mathrm{C}(3)-\mathrm{C}(4) \\
\mathrm{H}(4)-\mathrm{C}(4)-\mathrm{H}(5) \\
\mathrm{H}(4)-\mathrm{C}(4)-\mathrm{H}(6) \\
\mathrm{H}(4)-\mathrm{C}(4)-\mathrm{C}(3) \\
\mathrm{H}(5)-\mathrm{C}(4)-\mathrm{H}(6) \\
\mathrm{H}(5)-\mathrm{C}(4)-\mathrm{C}(3) \\
\mathrm{H}(6)-\mathrm{C}(4)-\mathrm{C}(3) \\
\mathrm{H}(7)-\mathrm{C}(5)-\mathrm{H}(8) \\
\mathrm{H}(7)-\mathrm{C}(5)-\mathrm{N}(1) \\
\mathrm{H}(7)-\mathrm{C}(5)-\mathrm{C}(6) \\
\mathrm{H}(8)-\mathrm{C}(5)-\mathrm{N}(1) \\
\mathrm{H}(8)-\mathrm{C}(5)-\mathrm{C}(6) \\
\mathrm{N}(1)-\mathrm{C}(5)-\mathrm{C}(6) \\
\mathrm{H}(10)-\mathrm{C}(6)-\mathrm{H}(9) \\
\mathrm{H}(10)-\mathrm{C}(6)-\mathrm{C}(5) \\
\mathrm{H}(9)-\mathrm{C}(6)-\mathrm{C}(5)\end{array}$ & $\begin{array}{l}95.0 \\
154.4(6) \\
95.0 \\
95.0 \\
150.1(8) \\
95.0 \\
95.0 \\
95.0 \\
95.0 \\
95.0 \\
151.7(9) \\
95.0 \\
95.0 \\
95.0 \\
107.25 \\
104.3(3) \\
112.6(3) \\
117.7(3) \\
124.5(4) \\
117.4(4) \\
118.0(4) \\
109.46 \\
108.54 \\
108.53 \\
108.53 \\
108.53 \\
113.2(4) \\
109.47 \\
109.46 \\
109.49 \\
109.46 \\
109.48 \\
109.48 \\
109.47 \\
108.93 \\
108.94 \\
108.93 \\
108.95 \\
111.6(5) \\
109.51 \\
109.48 \\
109.47\end{array}$ \\
\hline
\end{tabular}


The crystal structure of the cation, triethylammonium, in $\underline{32 b}$ has been determined by James ${ }^{85}$ for the three anions $\mathrm{Cl}^{-}, \mathrm{Br}^{-}$and $\mathrm{J}^{-}$. It was found, that the nitrogen-carbon and the carbon-carbon distances were subject to some change in going from $\mathrm{Cl}^{-}$to $\mathrm{J}^{-}$. The closest resemblance of the cation of $\underline{32 \mathrm{~b}}$ is found by comparison to $\mathrm{HN}\left(\mathrm{C}_{2} \mathrm{H}_{5}\right)_{3}{ }^{+} \mathrm{Br}^{-}$, and from this a significant compression of the ion is concluded. The anion shows some interesting bond-length and -angle changes, as compared to neutral compounds. A comparison will be made between the structures of $\underline{32 b}$ and $\underline{27}$.

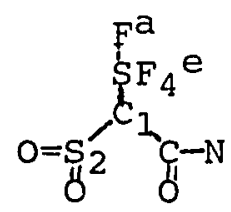

In the anion large angles $s_{1}-c-s_{2}, s_{1}-c_{1}-c_{2}$ and $s_{2}-c_{1}-c_{2}$ are found. They add up to $359.1^{\circ}(120.2+123.5+115.4)$, while the same angle sum in the amide comes to $334.6^{\circ}(117.7+112.6+104.3)$. The variation between a tetrahedron and a plane is from $328.4^{\circ}$ to $360^{\circ}$. This shows that the anion is almost flat, while the amide shows strong pyramidalization. Usually, anions are pyramidal; this behavior is certainly partially caused by the great steric repulsion of the three large substituents. Because a lone pair can normally be considered as an extra substituent, which would favor a non-planar arrangement, another cause for this near-planarity must be the mesomeric interaction between the anion center at $c_{1}$, the keto group and the $\mathrm{So}_{2} \mathrm{~F}$ 
group. This charge dispersal would weaken the effect of the negative charge as a substituent. If one wants to consider hyperconjugation also, then the $\mathrm{SF}_{5}$ group and additional conjugation in the $\mathrm{SO}_{2} \mathrm{~F}$ group has to be included in this scheme, too.

The crystal structures of the anions $\mathrm{SF}_{5}-86$ and $\mathrm{SF}_{5} \mathrm{O}^{-87}$ were determined recently. While in $\mathrm{SF}_{5}{ }^{-} \mathrm{a}$ significant elongation of the equatorial S-F bonds was found, with $d\left(S-F_{e}\right)>d\left(S-F_{a}\right)$, the reverse was seen in $S F_{5} O^{-}$. In $\underline{32 b}$ a similar effect is seen, with $\mathrm{d}\left(S-F_{a}\right)=159.5 \mathrm{pm}$ and $\mathrm{d}\left(\mathrm{S}-\mathrm{F}_{\mathrm{e}}\right)=157.8 \pm 0.6 \mathrm{pm}$. Corresponding values in $\underline{27}$ are $\mathrm{d}\left(\mathrm{S}-\mathrm{F}_{\mathrm{a}}\right)=156.8 \mathrm{pm}$ and $\mathrm{d}\left(\mathrm{S}-\mathrm{F}_{\mathrm{e}}\right)=154.3 \pm 1.0$. These values are very similar and do not indicate an important structural effect of the negative charge on the $\mathrm{SF}_{5}$ moiety. on the other hand the $\mathrm{SF}_{5}-\mathrm{C}$ bond is significantly much shorter in $\underline{32 b}$ than in $\underline{27}(177.0 \mathrm{vs} .185 .6 \mathrm{pm})$. The second $\mathrm{C}-\mathrm{S}$ bond in $\underline{32 \mathrm{~b}}$ is also much shorter than in 27 (167.9 vs. 180.1 pm). Such a bond shrinkage is usually observed when a substituent is attached to an olefinic radical, but this could also indicate conjugation and hyperconjugation of the enolate moiety with both sulfur fragments:

$\mathrm{X}=\mathrm{CH}_{3}$

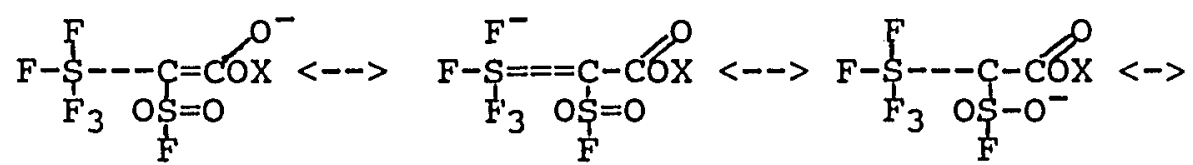

The shortening of the $S-C$ bond shifts it towards the bond length in $\mathrm{F}_{4} \mathrm{~S}=\mathrm{C}$ compounds. Furthermore, this shrinkage is 
observed in the $\mathrm{C}-\mathrm{C}$ bond (라 $: 144.7 \mathrm{pm}, \underline{27}: 154.4 \mathrm{pm}$ ). The $C=0$ bond lenghts in $\underline{27}$ and $\underline{32 b}$ are almost identical, which can be accounted for partially by the well-known conjugation in amides: $-\mathrm{C}_{-\mathrm{NR}} \quad \leftrightarrow-\rightarrow \quad-\mathrm{C}^{-} \mathrm{N}^{+} \mathrm{R}_{2}$, which introduces the same structural feature in $\underline{27}$ as in $\underline{32 b}$. The low $\mathrm{c}=0$ frequency in amides is supportive of this picture. In formamide $\mathrm{d}(\mathrm{C}=\mathrm{O})=124.3 \mathrm{pm}$, and $\mathrm{d}(\mathrm{C}-\mathrm{N})=131.9 \mathrm{pm}$, while in acetamide $\mathrm{d}(\mathrm{C}=\mathrm{O})=124.3 \mathrm{pm}$ and $\mathrm{d}(\mathrm{C}-\mathrm{N})=133.6 \mathrm{pm}^{88}$. One finds $d(\mathrm{C}-\mathrm{N})=132.7 \mathrm{pm}$ and $\mathrm{d}(\mathrm{C}=\mathrm{O})=121.3 \mathrm{pm}$ in 27 . One expects no noteworthy effect at the $\mathrm{N}-\mathrm{C}_{2} \mathrm{H}_{5}$ bond, and this is supported by the measured bond length of $147.4 \mathrm{pm}$ (average), as compared to $\mathrm{d}\left(\mathrm{C}^{\prime}-\mathrm{N}\right)=146.3 \mathrm{pm}$ in methylformamide (this value is calculated) 75 . It appears as though the charge in $\underline{32 b}$ were distributed over the whole molecule. Hyperconjugation seems to play a role in this charge dispersal as concluded from the very substantial bond shortenings. This would be one of the very first direct evidences for this phenomenon. The bond lenghts in $\underline{29},\left(\mathrm{~F}_{5} \mathrm{SCH}\left(\mathrm{SO}_{2} \mathrm{~F}\right) \mathrm{CH}_{2}\right)_{2} \mathrm{O}$, are comparable to 27 , which validates the above comparison even further.

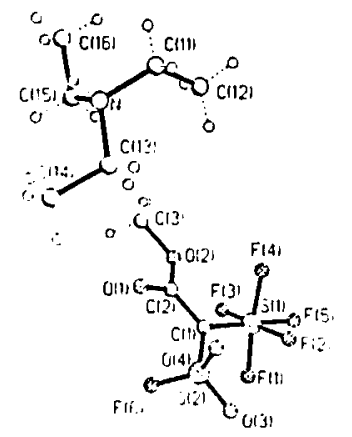

Figure 3 . X-ray structure of $32 \mathrm{~b}, \mathrm{~F}_{5} \mathrm{SC}\left(\mathrm{SO}_{2} \mathrm{~F}\right)$ $\mathrm{COOCH}_{3}{ }^{-} \mathrm{NH}\left(\mathrm{C}_{2} \mathrm{H}_{5}\right)_{3}{ }^{+}$. 


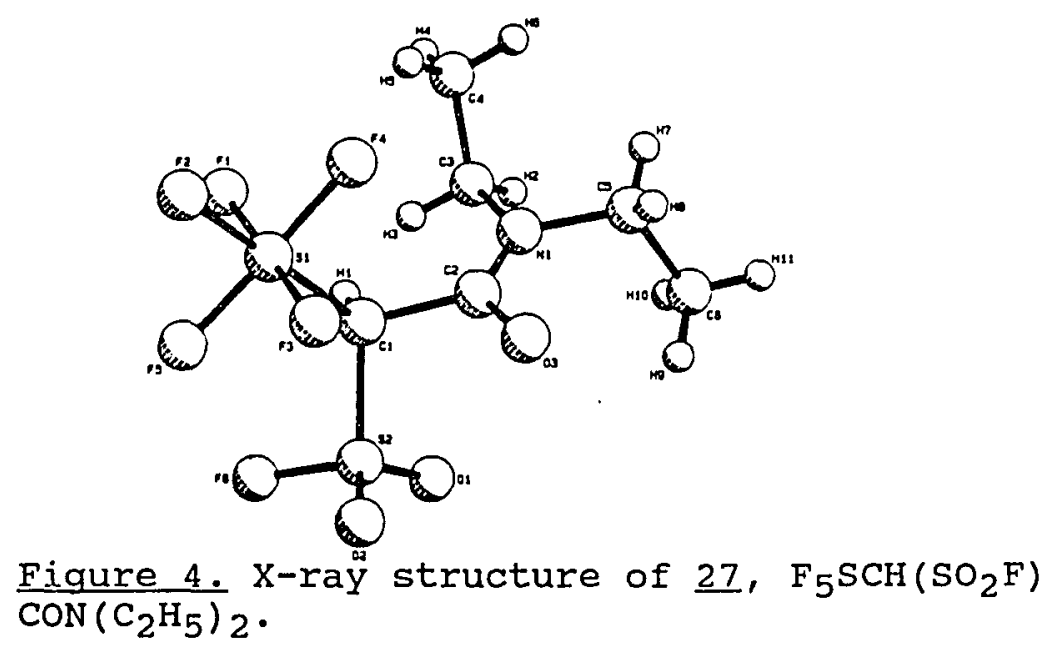

27 was obtained by an unexpected transmutation from what was probably $\mathrm{F}_{5} \mathrm{SC}\left(\mathrm{SO}_{2} \mathrm{~F}\right)=\mathrm{COCH}_{2} \mathrm{O}(\underline{28})$ upon storage.

TABLE V

BOND LENGTHS [pm] AND ANGLES [ $\left.{ }^{\circ}\right]$ IN $\left(\mathrm{F}_{5} \mathrm{SCH}\left(\mathrm{SO}_{2} \mathrm{~F}\right) \mathrm{CH}_{2}\right)_{2} \mathrm{O}$, 29, STANDARD DEVIATIONS IN PARENTHESES

\begin{tabular}{lrlr}
\hline$S(1)-F(1)$ & $154.7(4)$ & $S(1)-F(2)$ & $155.9(3)$ \\
$S(1)-F(3)$ & $158.2(5)$ & $S(1)-F(4)$ & $156.4(3)$ \\
$S(1)-F(5)$ & $156.5(4)$ & $S(1)-C(1)$ & $185.8(5)$ \\
$C(1)-C(2)$ & $151.3(7)$ & $C(1)-S(2)$ & $178.9(5)$ \\
$C(2)-O(3)$ & $140.5(5)$ & $O(3)-C(2 A)$ & $140.5(5)$ \\
$S(2)-O(1)$ & $149.3(4)$ & $S(2)-O(2)$ & $139.5(5)$ \\
$S(2)-F(6)$ & $141.7(4)$ & & \\
$F(1)-S(1)-F(2)$ & $89.8(3)$ & $F(1)-S(1)-F(3)$ & $176.1(2)$ \\
$F(2)-S(1)-F(3)$ & $90.1(2)$ & $F(1)-S(1)-F(4)$ & $91.0(3)$ \\
$F(2)-S(1)-F(4)$ & $176.2(2)$ & $F(3)-S(1)-F(4)$ & $88.9(2)$ \\
$F(1)-S(1)-F(5)$ & $88.5(3)$ & $F(2)-S(1)-F(5)$ & $87.6(2)$ \\
$F(3)-S(1)-F(5)$ & $87.6(2)$ & $F(4)-S(1)-F(5)$ & $88.8(2)$ \\
$F(1)-S(1)-C(1)$ & $95.2(2)$ & $F(2)-S(1)-C(1)$ & $91.0(2)$ \\
$F(3)-S(1)-C(1)$ & $88.7(2)$ & $F(4)-S(1)-C(1)$ & $92.6(2)$ \\
$F(5)-S(1)-C(1)$ & $176.1(3)$ & $S(1)-C(1)-C(2)$ & $114.8(3)$ \\
$S(1)-C(1)-S(2)$ & $116.9(3)$ & $C(2)-C(1)-S(2)$ & $109.8(3)$ \\
$C(1)-C(2)-O(3)$ & $110.5(4)$ & $C(2)-O(3)-C(2 A)$ & $112.0(5)$ \\
$C(1)-S(2)-O(1)$ & $101.8(2)$ & $C(1)-S(2)-O(2)$ & $105.4(3)$ \\
$O(1)-S(2)-O(2)$ & $110.1(3)$ & $C(1)-S(2)-F(6)$ & $112.2(2)$ \\
$O(1)-S(2)-F(6)$ & $108.4(3)$ & $O(2)-S(2)-F(6)$ & $117.7(3)$ \\
\hline
\end{tabular}




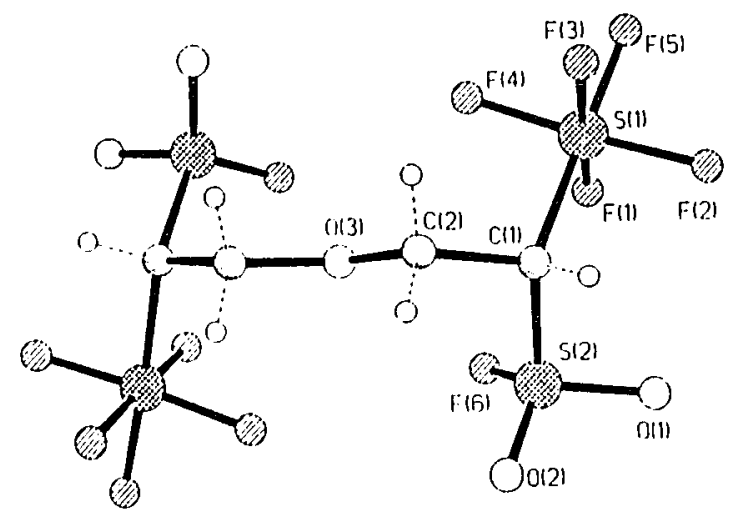

Figure 5. X-ray structure of $29,\left(\mathrm{~F}_{5} \mathrm{SCH}\left(\mathrm{SO}_{2} \mathrm{~F}\right) \mathrm{CH}_{2}\right)_{2} \mathrm{O}$

It is first noticed that the fragment $\mathrm{F}_{5} \mathrm{SCHSO}_{2} \mathrm{~F}$ in $\underline{29}$ has a very similar structure as in 27 ; the average $\mathrm{d}\left(\mathrm{S}-\mathrm{F}_{\mathrm{e}}\right)=$ $156.3 \pm 1.5 \mathrm{pm}$. For $\mathrm{d}\left(\mathrm{S}-\mathrm{F}_{\mathrm{a}}\right)=156.5 \mathrm{pm}$. The bond-length alternation within the group of the equatorial fluorines is considerable. This alternation is found with $\underline{27}$ and $\underline{32 b}$ as well as other $\mathrm{SF}_{5}$ compounds. In the $\mathrm{SO}_{2} \mathrm{~F}$ group a strong bond length difference for the two $S-O$ bonds is found. This is perhaps the result of an error as there is no obvious reason that could account for such a formidable difference. It is, however, noticed that the longer $s-0$ bond is on the opposite side of the $\mathrm{SF}_{5}$ group at the same carbon, and this oxygen is close to one hydrogen of the $\mathrm{CH}_{2}$ group. At the same time the angles C-S-O are 101.8 and $105.4^{\circ}$, respectively, with the larger angle pertaining to the c-s-o triple with the longer 
S-O bond. This behavior of the angles makes it unlikely that there is an $0 \cdots H$ bond, because such a bond, although it could elongate the $\mathrm{s}-\mathrm{O}$ bond, would also lead to a diminishment of the angle c-s-0. The angle at the ether bond is slightly larger than tetrahedral, and it is noticed that the hydrogens of the two $\mathrm{CH}_{2}$ bridges are nearly eclipsed. The molecule has nearly $c_{2}$ symmetry (it is slightly distorted), with the $c_{2}$ axis lying in the $c-0-c$ plane. The $\mathrm{SF}_{5}$ groups are on opposite sides of the plane. The other alternative would have been $c_{2}$ symmetry with the axis perpendicular to the $\mathrm{C}-\mathrm{O}-\mathrm{C}$ plane and the $\mathrm{SF}_{5}$ groups on the same side of it. This arrangement might be the result of the repulsion of the two $\mathrm{SF}_{5}$ groups, which is smaller if they lie trans to each other. The bond lengths in the rest of the molecule are comparable to similar compounds. For example, $\mathrm{d}\left(\mathrm{S}\left(\mathrm{F}_{5}\right)-\mathrm{C}\right)=185.8 \mathrm{pm}$ and $185.6 \mathrm{pm}$ in $\underline{29}$ and $\underline{27}$ respectively, and $d\left(S\left(\mathrm{O}_{2} \mathrm{~F}\right)-\mathrm{C}\right)=178.9(\underline{29})$ and $180.1 \mathrm{pm}$ (27). The ether bond is almost of the same dimension as found in $\left(\mathrm{F}_{5} \mathrm{CH}_{2} \mathrm{CHO}\right)_{3}$ (which will be described later in this manuscript), i.e. $d(C-0)(\underline{29})=140.5 \mathrm{pm}, d(C-0)$ (trimer) $=$ $141.1 \mathrm{pm}$ (average). 
CHAPTER V

SYNTHESIS OF PENTAFLUOROSULFUR BROMIDE, $\mathrm{SF}_{5} \mathrm{Br}$

Pentafluorosulfur bromide can be obtained by a number of methods. It was first synthesized by heating a mixture of $\mathrm{BrF}_{5}, \mathrm{Br}_{2}$ and $\mathrm{SF}_{4}$ to $100^{\circ} \mathrm{C}$ for several days. 89 The easiest and fastest procedure consists of heating bromine and disulfur decafluoride to $140-150^{\circ} \mathrm{C} .90$ The difficulty lies in the accessibility of $S_{2} F_{10}$. Although it is a by-product in the fabrication of $\mathrm{SF}_{6}$, it is usually immediatelly degraded, in order to obviate its noxiousness, by scrubbing the reaction gases with $\mathrm{NaOH}$. For laboratory purposes it can be made through photochemical reduction of $\mathrm{SF}_{5} \mathrm{Cl}$ with $\mathrm{H}_{2} \cdot 91$, where $\mathrm{SF}_{5} \mathrm{Cl}$, which was originally obtained by reacting $\mathrm{Cs}^{+}$ $\mathrm{SF}_{5}{ }^{-}$(from $\mathrm{CsF}+\mathrm{SF}_{4}$ upon heating, $94 \%$ ) with chlorine 92 in $75 \%$ yield, or by reaction of $\mathrm{KF}, \mathrm{SF}_{4}$ and $\mathrm{Cl}_{2}$ (mol ratio $3: 1: 1)$ in $\approx 80 \%$ yield 93 , can now be readily obtained by the cesium fluoride catalyzed reaction of $\mathrm{SF}_{4}$ and $\mathrm{ClF}$ in $92-97 \%$ yield. 94

$$
\mathrm{SF}_{4}+\mathrm{ClF}(\mathrm{CSF})+---\cdots \mathrm{SF}_{5} \mathrm{Cl}
$$

This difficulty in obtaining $S_{2} F_{10}$ easily in sufficient quantity, and the reluctance of some olefins to react with the more easily available $\mathrm{SF}_{5} \mathrm{Cl}$ at all, made it necessary to seek a new method for preparing $\mathrm{SF}_{5} \mathrm{Br}$. 
The method is based on a procedure, which employs the reaction of $\mathrm{SF}_{4}$ and $\mathrm{BrF}$. Since pure $\mathrm{BrF}$ is not stable above $\approx-30^{\circ} \mathrm{C}$ it is first made by prolonged shaking of $\mathrm{Br}_{2}$ and $\mathrm{BrF}_{3}$, and isolated from the equilibrium mixture by lowtemperature vacuum transfer. The equilibrium constant for the following (fast) gas phase reaction has been determined:

$$
\mathrm{Br}_{2}+\mathrm{BrF}_{3} \rightleftharpoons 3 \mathrm{BrF} \quad \mathrm{H}=11.9 \mathrm{kcal} / \mathrm{mol}
$$

The $\mathrm{BrF}$ is then heated with $\mathrm{CsF}$ and $\mathrm{SF}_{4}$ to $100^{\circ} \mathrm{C}(24 \mathrm{~h})$. The yield seems to be $\approx 90 \%$ on a small scale 95 and $34 \%$ on a larger scale.96 several reactions exist that employ the in situ formation of $\mathrm{BrF}$, e.g. the formation of $\mathrm{COBrF}$ from $\mathrm{Br}_{2}$, $\mathrm{BrF}_{3}$ and $\mathrm{CO}(85 \%)^{97}$ or of $\mathrm{SO}_{2} \mathrm{BrF}$ from $\mathrm{SO}_{2}, \mathrm{Br}_{2}$ and $\mathrm{BrF}_{3}$ ( $\approx$ quantitative).98 It seemed possible, that BrF, generated in situ, should react with $\mathrm{SF}_{4}$ in the presence of CsF when shaken at room temperature. This reaction was indeed observed.

$$
\begin{aligned}
& \mathrm{BrF}_{3}+\mathrm{Br}_{2} \rightleftharpoons 3 \mathrm{BrF} \\
& \mathrm{BrF}+\mathrm{SF}_{4}-\mathrm{CsF}->\mathrm{SF}_{5} \mathrm{Br}\left(+\mathrm{SF}_{6}\right)
\end{aligned}
$$

Isolated yields of (pure) $\mathrm{SF}_{5} \mathrm{Br}$ were $25 \%$, but it was usually used as a crude product, and the secondary products were then purified. In these instances yields of up to $70 \%$ of distilled adducts of $\mathrm{SF}_{5} \mathrm{Br}$ and various olefins were obtained. This method is thus comparable to the method of McDiarmid and Cohen for the synthesis of $\mathrm{SF}_{5} \mathrm{Br}$ from $\mathrm{S}_{2} \mathrm{~F}_{10}$ and $\mathrm{Br}_{2}$ with yields to up to $\approx 80 \%$. Purification is usually avoided, too, in this case, as bromine transfer at low 
enough temperatures is slow, while $\mathrm{SF}_{5} \mathrm{Br}$ transfer is fast and the other possible constituents, $\mathrm{SF}_{6}, \mathrm{SF}_{4}$ (decomposition products of $\mathrm{S}_{2} \mathrm{~F}_{10}$ ) and unreacted $\mathrm{S}_{2} \mathrm{~F}_{10}$ are mostly neutral in the addition reactions that follow.

Sulfur hexafluoride was consistently observed as a byproduct of the reaction; it must stem from the oxidation of $\mathrm{SF}_{4}$ by bromine trifluoride. On occasion, the steel reaction vessel warmed up. Regarding this, and in light of the equilibrium between $\mathrm{BrF}_{3}, \mathrm{Br}_{2}$ and $\mathrm{BrF}$, which certainly lies on the $\mathrm{BrF}_{3}$ side at $100^{\circ} \mathrm{C}$, the method of Christe et al., as applied on a large scale by seppelt et al., appeared unsafe when larger amounts of $\mathrm{SF}_{5} \mathrm{Br}$ were to be synthesized. The disadvantage of allowing the reaction to proceed at room temperature is its relative slowness. Shaking times of up to two weeks were necessary to obtain consistently good results, although on occasion good yields were already achieved after just two days of shaking. In order to preserve $\mathrm{SF}_{4}$ (which is expensive), only 70-80\% of its theoretical amount was used, since it was observed, that the sulfur tetrafluoride that was added was never completely consumed, and, as the extent of oxidation to $\mathrm{SF}_{6}$ is not known, this somewhat arbitrary molar ratio was used. Several adducts were made by using the crude $\mathrm{SF}_{5} \mathrm{Br}$ that was isolated by removing it from the steel reaction vessel at$78^{\circ} \mathrm{C}$. Long transfer times were necessary to collect most of the $\mathrm{SF}_{5} \mathrm{Br}$. By this method, some $\mathrm{Br}_{2}$ will always transfer, 
too, and although no difficulties were encountered that would stem from the presence of bromine, it could be removed by treating the crude $\mathrm{SF}_{5} \mathrm{Br}$ at room temperature with mercury 99 . It was possible to collect substantial additional amounts of almost pure $\mathrm{SF}_{5} \mathrm{Br}$ from vessels that were warmed up intermittently and re-cooled. The chief impurity was then bromine, but $\mathrm{SF}_{6}$ or $\mathrm{SF}_{4}$ were present only in small amounts, as judged from the infrared spectrum. For example, runs with 25-30 g of $\mathrm{BrF}_{3}$ yielded up to $20 \mathrm{~g}$ of $\mathrm{SF}_{5} \mathrm{Br}$ in this second transfer. Whereas the initial transfer is comparatively fast (transfer times at $-78^{\circ} \mathrm{C}$ up to 4 hours), the second collection is very slow and lasted up to 10 hours. 
CHAPTER VI

CONCLUSION

In conclusion, starting from sultone 1 , intermediates 21, $\underline{23}$ and several salts of the form $\mathrm{Y}^{+}\left[\mathrm{F}_{5} \mathrm{SC}\left(\mathrm{SO}_{2} \mathrm{~F}\right) \mathrm{COR}\right]^{-}$ were obtained. An outstanding feature was the preferred formation of stable salts which were capable of further reaction. Halogenated compounds of the form $\mathrm{F}_{5} \mathrm{SCX}\left(\mathrm{SO}_{2} \mathrm{~F}\right) \mathrm{COZ}$ and $\mathrm{F}_{5} \mathrm{SCH}(\mathrm{Cl}, \mathrm{Br}) \mathrm{SO}_{2} \mathrm{~F}\left(\mathrm{X}=\mathrm{Br}, \mathrm{Cl} ; \mathrm{Z}=\mathrm{F}, \mathrm{Cl}, \mathrm{OCH}\left(\mathrm{CH}_{3}\right)_{2}\right)$ were obtained but it was not possible to introduce other substituents $X$, such as alkyl groups or cyano. Compound $\underline{23}$, a sulfur ylide, could be converted to several other sultones by polar addition of $\mathrm{ClF}, \mathrm{HF}, \mathrm{HCl}, \mathrm{CH}_{3} \mathrm{OH}$ and $\left(\mathrm{CH}_{3}\right)_{2} \mathrm{CHOH}$ across the $\mathrm{F}_{4} \mathrm{~S}=\mathrm{C}$ bond. These are unprecedented reactions in sultone chemistry, as the $\beta$-sultone ring stayed intact; this has not been described before. Cesium fluoride adds quantitatively to form $\underline{25}$. A novel rearrangement of esters of the form $\mathrm{F}_{5} \mathrm{SCH}\left(\mathrm{SO}_{2} \mathrm{~F}\right) \mathrm{COOR}$ to $\left(\mathrm{O}=\mathrm{SF}_{2}\right)=\mathrm{C}\left(\mathrm{SO}_{2} \mathrm{~F}\right) \mathrm{C}(\mathrm{O}) \mathrm{F}$ was also found. These reactions provided routes to compounds which were inaccessible so far and are of potential value for the synthesis of sulfonic acids for fuel cells. The crystalline nature of several ester salts allowed to determine their structure by $\mathrm{x}$-ray crystallography. An improved large-scale synthesis of $\mathrm{SF}_{5} \mathrm{Br}$ was also found. 
PART II

SYNTHESIS AND REACTIONS OF $\mathrm{SF}_{5}$-EPOXIDES 
CHAPTER I

INTRODUCTION

Hexafluoropropylene epoxide (47) is the most important of the fluorinated epoxides. The reasons are that it was one of the first perfluoro epoxides to be synthesized, and its reaction chemistry has been most widely investigated. It is comparatively readily available. The methods of its preparation include passing $C F_{3} C F=C F_{2}$ through a solution of $\mathrm{KOH}$ and $\mathrm{H}_{2} \mathrm{O}_{2}$ at low temperature, or a solution of a hypochlorite, treatment with $\mathrm{KMnO}_{4}+$ anhydrous $\mathrm{HF}\left(-70^{\circ} \mathrm{C}\right.$, $\mathrm{FMnO}_{3}$ is proposed as the oxidizing agent) ${ }^{1}$ to the treatment with oxygen (or $\mathrm{O}_{2}+\mathrm{O}_{3}$ or $\mathrm{O}_{2}+\mathrm{Br}_{2}$ or $\mathrm{Cl}_{2}=$ light mixtures) or organic peroxides ${ }^{2}$. These syntheses can thus be divided into nucleophilic, electrophilic and radical procedures. A recent review is given in ref. 2 , and a somewhat older one in ref. 7. Other fluoro epoxides were made by adding $\mathrm{CH}_{2}$ or other carbene derivatives ${ }^{3}$ to ketones or aldehydes or (e.g. $\mathrm{CF}_{2}, \mathrm{C}\left(\mathrm{CF}_{3}\right)_{2}$ to hexafluoroacetone). This can, for example, quite easily provide for octafluoroisobutylene epoxide: ${ }^{4}$

$$
\left(\mathrm{CF}_{3}\right)_{2} \mathrm{C}=\mathrm{O}+\mathrm{CF}_{2}-->\quad\left(\mathrm{CF}_{3}\right)_{2}{ }_{2}---\mathrm{CF}_{2}
$$

The difluorocarbene originates mostly in the following reaction: 


$$
\mathrm{F}_{3} \mathrm{CCFCF}_{2}(\underline{47}) \rightleftharpoons \mathrm{CF}_{3} \mathrm{CFO}+\mathrm{CF}_{2} 5 \mathrm{a}, \mathrm{b} \text { (at } 150-180^{\circ} \mathrm{C} \text { ) }
$$

on occasion, the reaction

$$
\left(\mathrm{F}_{3} \mathrm{C}\right)_{3} \mathrm{PF}_{2} \leftrightharpoons\left(\mathrm{F}_{3} \mathrm{C}\right)_{2} \mathrm{PF}_{3}+\mathrm{CF}_{2} \quad \mathrm{~F}_{3} \mathrm{CPF}_{4} \text { etc. (ca. } 130^{\circ} \mathrm{C} \text { ) }
$$

is also used ${ }^{6}$, but $\left(F_{3} C\right)_{3} P_{2}$ is difficult to obtain.

other methods use haloacetates or halohydrines in the synthesis of oxiranes of the type $\mathrm{R}_{f} \mathrm{CH}_{2} \overline{\mathrm{CHCH}_{2} \mathrm{O}}, \mathrm{R}_{\mathrm{f}} \mathrm{CHCH(R)O}$ (R $=$ alkyl) ${ }^{7}$, and $\mathrm{R}_{\mathrm{f}} \overline{\mathrm{CHCH}}_{2} \mathrm{O}^{8}$. The halohydrines or haloacetates are obtained by different routes, i.e. bromination of a suitable ketone, and subsequent reduction, 9

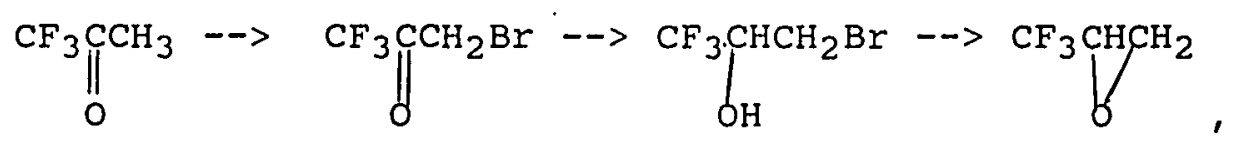

treatment of an olefin with $\mathrm{Br}_{2}, \mathrm{Hg}\left(\mathrm{CH}_{3} \mathrm{COO}\right)_{2}+\mathrm{CH}_{3} \mathrm{COOH}$, and with base,

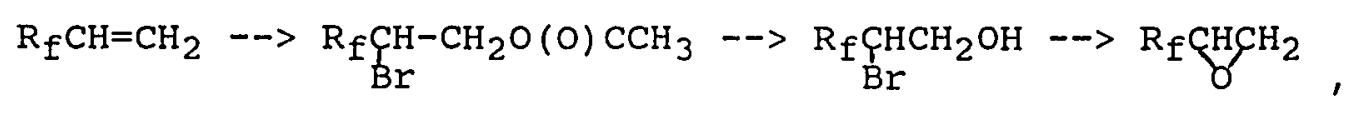

or addition of $R_{f} J$ to allyl acetate or allylalcohol and treatment with base, 10

$$
\mathrm{R}_{\mathrm{f}} \mathrm{I}+\mathrm{CH}_{3} \mathrm{COOCH}_{2} \mathrm{CH}=\mathrm{CH}_{2} \rightarrow \mathrm{CH}_{3} \mathrm{COOCH}_{2} \underset{\mathrm{I}}{\mathrm{H}} \mathrm{HCH}_{2} \mathrm{R}_{\mathrm{f}} \rightarrow \mathrm{R}_{\mathrm{f}} \mathrm{CH}_{2} \mathrm{CHCH}_{2}
$$

A newer method employs treatment of olefins $R_{f} C F=C F R_{f}^{\prime 11}$, $R_{f} R_{f}^{\prime} C=C F R_{f}^{\prime \prime}$ or $R_{f} R_{f}{ }^{\prime C}=C R_{f} R_{f}^{\prime}{ }^{12}$ with NaOCl in aqueous acetonitrile. This method can be suitably accomodated to phase transfer catalysis conditions and is also important because of the difficulty in epoxidizing internal fluoro olefins with other methods.

Epoxides are valuable intermediates. For unsymmetrical 
terminal perfluoro epoxides, rearrangements to either acyl fluorides or fluoro ketones are possible. The formation of a ketone is brought about by acidic reagents (for example, $\left.\mathrm{SbF}_{5}, \quad \tau-\mathrm{Al}_{2} \mathrm{O}_{3}, \mathrm{TiO}_{2}, \mathrm{Cr}_{2} \mathrm{O}_{3}\right)$, and the formation of acyl fluoride by basic reagents, notably $\mathrm{F}^{-}$. Some cyclic oxides rearrange to ketones with alumina,



Hexafluoropropylene oxide is converted by either alumina or $\mathrm{SbF}_{5}$ to hexafluoroacetone; $\mathrm{AlCl}_{3}$ leads chiefly to the ketone but yields also some pentafluoropropionyl fluoride. Perfluoroisobutylene (a highly electrophilic agent) also causes rearrangement to hexafluoroacetone. 13 on the other hand, octafluoroisobutylene epoxide rearranges with antimony pentafluoride to perfluoroisobutyryl fluoride, as the corresponding ketone does not exist. 14 The formation of a ketone or an acyl fluoride corresponds to two different modes of ring opening and can be related to two different sites of attack (in this case by $\mathrm{F}^{-}$):

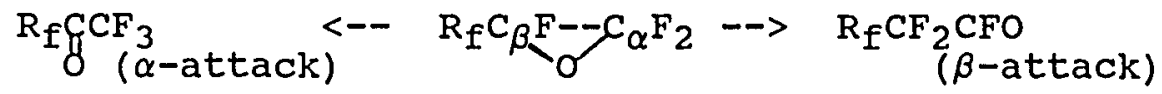

As for the $\mathrm{SF}_{5}$-epoxides of the form $\mathrm{SF}_{5} \mathrm{CXCF}_{2} \mathrm{O}$ (X=H, halogen), only $\alpha$-attack is of interest, because $\mathrm{SF}_{5}$-ketones, formed in $\beta$-attack mode, are not stable towards nucleophilic attack; loss of $\mathrm{SF}_{5}{ }^{-}$occurs ${ }^{15}$. This restricts very severly 
their synthetic utility.

Hexafluoropropylene oxide 47 can be used for a many synthetic purposes, but in the present context its (anionic) oligomerisation behavior is especially important. This can be brought about by different agents, ranging from alkoxides, halide ions, neutral bases, even silver nitrate to activated carbon. The product distribution in the reaction

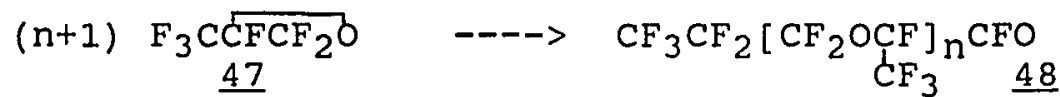

depends on the catalyst and solvent that is used. 16

The value of $\mathrm{n}$ is found between 0 and 100. The process proceeds in the following fashion through the intermediacy of $\mathrm{F}^{-}$:

$$
\begin{aligned}
& \underset{\mathrm{F}}{\mathrm{F}} \mathrm{O}_{\mathrm{O}} \mathrm{CF}_{2} \longrightarrow \mathrm{F}_{3} \mathrm{CCF}_{2} \mathrm{CFO} \longrightarrow \mathrm{F}_{3} \mathrm{CCF}_{2} \mathrm{CF}_{2} \mathrm{O}^{-} ;+\stackrel{\mathrm{F}_{3} \mathrm{C}}{\mathrm{C}} \mathrm{F}_{\mathrm{O}} \mathrm{CF}_{2}-> \\
& \mathrm{F}_{3} \mathrm{CCF}_{2}\left[\mathrm{CF}_{2} \mathrm{OCF} \mathrm{CFF}_{2} \mathrm{O}^{-} \rightarrow-\rightarrow \mathrm{F}_{3} \mathrm{CCF}_{2}\left[\mathrm{CF}_{2} \mathrm{OCF}_{n} \mathrm{CF}_{2} \mathrm{O}^{-} \rightarrow\right.\right. \\
& \mathrm{F}_{3} \mathrm{CCF}_{2}\left[\mathrm{CF}_{2} \mathrm{OCF}_{3}\right]_{n} \mathrm{CFO}+\mathrm{F}^{-}
\end{aligned}
$$

The polyethers are, after removal of the acyl fluoride group, chemically and thermally extremely inert, highboiling and non-toxic and have a high dielectric strength. 17

A similar process accounts for the first step in the synthesis of "Nafion", which is a highly conductive perfluorinated polymeric sulfonic acid that enjoys now widespread use ranging from catalysis to fuel-cell electrolytes. The polymerisation is initiated by an alkoxide which is 
obtained from tetrafluoroethylene sultone. The reaction then goes through a reductive decarboxylation step and is completed by co-polymerizing the product with tetrafluoroethylene and hydrolyzing the sulfonyl fluoride:

$$
\begin{aligned}
& \underset{\mathrm{O}_{2} \mathrm{~S}--\mathrm{O}}{\mathrm{CF}_{2} \mathrm{CF}_{2}}+\mathrm{F}^{-} \quad-\rightarrow \quad \mathrm{F}_{2} \mathrm{SCF}_{2} \mathrm{CF}_{2} \mathrm{O}^{-}-\cdots \\
& \mathrm{FO}_{2} \mathrm{SCF}_{2}\left[\mathrm{CF}_{2} \mathrm{OCF}_{n} \mathrm{CFO} ;+\mathrm{Na}_{2} \mathrm{CO}_{3}\right. \text {, heat ---> } \\
& \mathrm{FO}_{2} \mathrm{SCF}_{2}\left[\mathrm{CF}_{2} \mathrm{OCF}\right]_{\mathrm{n}-1} \mathrm{CF}_{2} \mathrm{OCF}=\mathrm{CF}_{2}+\mathrm{CF}_{2}=\mathrm{CF}_{2}-->
\end{aligned}
$$

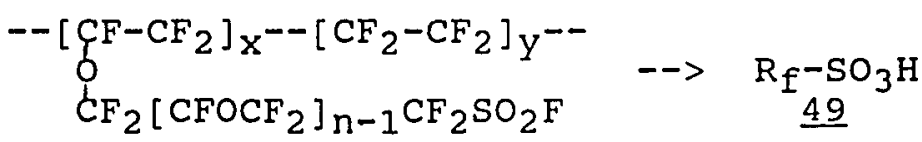

The pentafluorothio epoxides were synthesized in order to obtain $\mathrm{SF}_{5}$ polyethers whence an analogous "SF $5-\mathrm{Nafion"} \mathrm{could}$ be synthesized. Possibly improved properties of this material could be higher heat-resistance, greater hydrophobicity, more elasticity (due to a diminished possibility of crystallization). Polymers of $\mathrm{SF}_{5}$-epoxides are expected to be also highly heat-resistant. The ether linkage in perfluoroethers is thermally extremely stable. For example, the perfluoroether $\mathrm{OC}_{2} \mathrm{~F}_{4} \mathrm{SF}_{4} \mathrm{C}_{2} \mathrm{~F}_{4}$ decomposes only above $475^{\circ} \mathrm{C}$ over NaF under extrusion of $\mathrm{SF}_{4}$; octafluorotetrahydrofuran is the other product. 18 These high boiling polyethers should also be good dielectric materials, as e.g. $\quad \mathrm{F}_{5} \mathrm{SCF}=\mathrm{CF}_{2}{ }^{19}$ (b.p. $\left.+19^{\circ} \mathrm{C}\right)$ and $\mathrm{F}_{5} \mathrm{SCF}_{3} 20$ (b.p. $-7^{\circ} \mathrm{C}$ ) are superior to $\mathrm{SF}_{6}\left(\mathrm{~b} \cdot \mathrm{p} \cdot-63^{\circ} \mathrm{C}\right)$.

The attempted synthesis of $\mathrm{SF}_{5}$-epoxides has once been reported. 21 The compound that was isolated in the following 
reaction, with the oxidant under pressure, an acyl fluoride, cannot have originated in an intermediate epoxide:

$$
\left.\mathrm{F}_{5} \mathrm{SCF}=\mathrm{CF}_{2}+\mathrm{O}_{2} \text { (or } \mathrm{O}_{3}\right)-\cdots \quad \mathrm{F}_{5} \mathrm{SOCF}_{2} \mathrm{CFO}
$$

The easy availability of simple fluoroolefins of the form $\mathrm{F}_{5} \mathrm{SCX}=\mathrm{CF}_{2} \quad(\mathrm{X}=\mathrm{H}(\underline{52}), \mathrm{F}(\underline{50}))$ makes it possible to obtain the epoxides

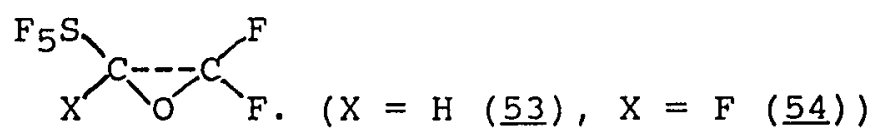

To further this investigation the next logical step would be to insert a $\mathrm{CF}_{2}$-group between the epoxide ring and the substituent to obtain

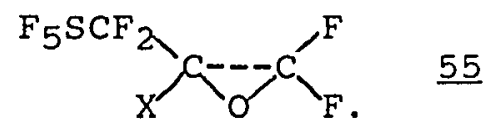

This requires the availbility of olefins of the form $\mathrm{F}_{5} \mathrm{SCF}_{2} \mathrm{CX}=\mathrm{CF}_{2}(\mathrm{X}=\mathrm{H}$, halogen, $\underline{56})$. To introduce a $\mathrm{CF}_{2}$-group, several possibilities exist. It would also be desirable to have an olefin $\mathrm{FO}_{2} \mathrm{SCF}_{2} \mathrm{CF}=\mathrm{CF}_{2}$ (그), which upon epoxidation and polymerization should yield a perfluoro polyethersulfonylfluoride, the direct precursor of a highdensity sulfonic acid. 


\section{RESULTS AND DISCUSSION}

An early attempt to obtain a haloacetate by the following reaction failed, although a preliminary reaction was encouraging:

$$
\mathrm{F}_{5} \mathrm{SCH}_{2} \mathrm{CH}_{2} \mathrm{Br}(\underline{58})+\mathrm{AgOC}(\mathrm{O}) \mathrm{CH}_{3}--\mathrm{F}_{5} \mathrm{SCH}_{2} \mathrm{CH}_{2} \mathrm{OC}(0) \mathrm{CH}_{3}(\underline{59})+
$$

$\mathrm{AgBr}$

but,

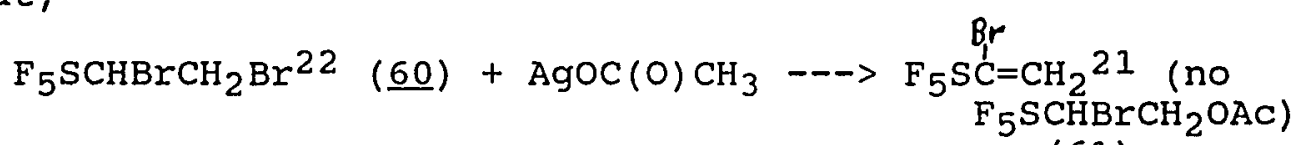

The silver salt reaction was carried out in glacial acetic acid, following a prescription of Park et al.23 It was thus decided to pursue direct epoxidation of olefins. The olefins of the form $\mathrm{F}_{5} \mathrm{SCX}=\mathrm{CF}_{2} \quad(\mathrm{X}=\mathrm{H}, \mathrm{F})$ are easily prepared. Therefore, the epoxides

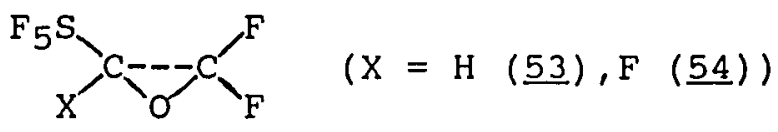

should be accessible with a suitable epoxidation procedure. For $x=F$ the epoxide is the exact analogue of hexafluoropropylene epoxide (47). Earlier attempts to epoxidize $\mathrm{F}_{5} \mathrm{SCH}=\mathrm{CH}_{2}$ with m-chloroperbenzoic acid in $\mathrm{CH}_{2} \mathrm{Cl}_{2}$ in a pressure vessel at $90^{\circ} \mathrm{C}$ were unsuccessful, as was the ozonisation of $\mathrm{F}_{5} \mathrm{SCF}=\mathrm{CF}_{2}$, which lead to unidentified 
pyrophoric products. Epoxidation was effected by taking advantage of the proclivity of fluorinated olefins towards nucleophilic addition. For example, $\mathrm{F}_{5} \mathrm{SCF}=\mathrm{CF}_{2}$, when treated with $\mathrm{COF}_{2}$ in $\mathrm{CH}_{3} \mathrm{CN}$ and in the presence of CsF forms $\mathrm{F}_{5} \mathrm{SCF}\left(\mathrm{CF}_{3}\right) \mathrm{COF} .24$ As the epoxidation of fluorocarbons with hypochlorite passes through an anion intermediate, and the $\mathrm{SF}_{5}$ group can stabilize negative charges better than a $\mathrm{CF}_{3}$ group 25 , it seemed a promising pathway for the preparation of pentafluorothio epoxides. In a two-phase system this route was found effective with a phase-transfer catalyst:

$$
\begin{aligned}
& \mathrm{F}_{5} \mathrm{SCX}=\mathrm{CF}_{2}+\mathrm{NaOCl} \longrightarrow \mathrm{Na}_{5}^{+} \mathrm{SCX}-\mathrm{OCl}_{2} \rightarrow \mathrm{F}_{5} \mathrm{SCX}-\mathrm{CF}_{2} \\
& \mathrm{X}=\mathrm{H}(\underline{52}), \mathrm{F}(\underline{50}) \\
& \text { 1,1,2-trifluorotrichloroethane ("Freon-113") was chosen as }
\end{aligned}
$$


perfluoroolefin a by-product was observed which according to its band shape and chemical shift was identified as $s_{2} F_{10}$.

It was not possible to obtain until now an olefin of the form $F_{5} S\left(C F_{2}\right)_{n} C X=C F_{2}(n=1,2, X=H$, halogen, 56a). The following reaction proved unsuccessful:

$$
\underset{\underline{63}}{\mathrm{~F}_{5} \mathrm{SCF}_{2} \mathrm{CF}_{2} \mathrm{I}}+\mathrm{CHF}=\mathrm{CF}_{2}+(\phi \mathrm{COO})_{2}-\mathrm{X}->\mathrm{F}_{5} \mathrm{SCF}_{2} \mathrm{CF}_{2} \mathrm{CHFCF}_{2} \mathrm{I}
$$

Subsequent dehydroiodination should have provided for a terminal olefin. What was observed was at temperatures up to $170^{\circ} \mathrm{C}$ loss of the $\mathrm{SF}_{5}$ group and formation of $\mathrm{ICF}_{2} \mathrm{CF}_{2} \mathrm{I}$, but none of the desired adduct.

A report by witucki shows the low yield addition of $\mathrm{SF}_{5} \mathrm{Cl}$ to tetrafluoroallene: 26

$$
\mathrm{F}_{5} \mathrm{SCl}+\mathrm{F}_{2} \mathrm{C}=\mathrm{C}=\mathrm{CF}_{2} \rightarrow \mathrm{F}_{5} \mathrm{SCF}_{2} \underset{\mathrm{Cl}}{\mathrm{C}}=\mathrm{CF}_{2} \underline{64}
$$

The synthesis of tetrafluoroallene turns out to be a comparatatively complicated endeavour and it was decided that this route, after several costly failures, was not suitable to provide for sizable amounts of epoxides. Carbene addition to the acyl fluoride $\mathrm{F}_{5} \mathrm{SCF}_{2} \mathrm{CFO}$ (ㅎ5) was also considered. $\mathrm{F}_{5} \mathrm{SCF}_{2} \mathrm{CFO}$ was first described by Haszeldine and Nyman 27 as one of the products of the electrochemical fluorination of thioglycollic acid, but it was obtained in a mixture and could only partially characterized. An attempt to obtain this material by sulfur trioxidation of $\mathrm{F}_{5} \mathrm{SCF}_{2} \mathrm{CF}_{2} \mathrm{~J}$ was made:

$$
\mathrm{F}_{5} \mathrm{SCF}_{2} \mathrm{CF}_{2} \mathrm{~J}(\underline{63})+\text { oleum + heat }-\rightarrow \mathrm{F}_{5} \mathrm{SCF}_{2} \mathrm{CFO}(\underline{65})
$$


Although the reaction worked rather well, the product that was obtained was not pure. Upon cooling the colorless liquid separated into two layers. Despite lenghty trials to separate these materials through flash-evaporation, fractional condensation or preparative gas chromatography: it was not possible to effect separation. Little can be said about the nature of this second constituent, except that it has a singlet in the ${ }^{19} \mathrm{~F}$ n.m.r. spectrum at $\approx-80 \mathrm{ppm}$. It is not an $\mathrm{SF}_{5}$ nor a COF compound.

It was then tried to use this crude $(\approx 70 \%)$ material for further difluorocarbene addition. The $C_{2}$ was either generated by heating hexafluoropropylene oxide or by the method of Burton (treatment of the salt $\phi_{3} \mathrm{PCF}_{2} \mathrm{Br}^{+} \mathrm{Br}^{-}$with $\mathrm{KF}$ in diglyme at $\left.20^{\circ} \mathrm{C}\right)^{28}$. In no case was any product attributable to the reaction

$$
\underset{\mathrm{F}_{5} \mathrm{SCF}_{2} \mathrm{CFO}}{\mathrm{CF}_{2}}+\mathrm{CF}_{2}--\mathrm{F}_{5} \mathrm{SCF}_{2} \mathrm{CFCF}_{2}
$$

identified. Further attempts, like the addition of $\mathrm{SF}_{5} \mathrm{Br}$ to $\mathrm{CF}_{2}=\mathrm{CFCF}_{2} \mathrm{OSO}_{2} \mathrm{~F}^{29}$, with the possible subsequent treatment of the adduct with fluoride ion failed because of the inertness of the olefin towards $\mathrm{SF}_{5} \mathrm{Br}$.

Another attempt to have a $C_{2}$ group inserted between the $\mathrm{SF}_{5}$ group and the epoxide was undertaken by first obtaining a hydrogenated epoxide, which then could be perhaps fluorinated. Such an attempt had apparently been undertaken 30 with $\mathrm{ClCH}_{2} \mathrm{CHCH}_{2} \mathrm{O}$ which should have yielded hexafluoro propylene epoxide upon fluorination, but was not 
successful. The electrochemical fluorination procedure that was used might not have been appropriate, however, as the product was most likely an oxetane ${ }^{31}$. For the present purpose $\mathrm{SF}_{5} \mathrm{Cl}$ was added to allyl acetate. This was a surprisingly slow reaction, as after two weaks of heating the two reactants in $\mathrm{CCl}_{3} \mathrm{~F}$ at $100^{\circ} \mathrm{C}$ there was still unreacted olefin present and only a yield of $\approx 60 \%$ could be realized:

$$
\mathrm{F}_{5} \mathrm{SCl}+\mathrm{CH}_{2}=\mathrm{CHCH}_{2} \mathrm{OC}(\mathrm{O}) \mathrm{CH}_{3} \rightarrow \mathrm{F}_{5} \mathrm{SCH}_{2} \mathrm{CHClCH}_{2} \mathrm{OC}(\mathrm{O}) \mathrm{CH}_{3} \text { (67) }
$$

Base treatment of the analogous $R_{f} I$ addition product gave the epoxide $\mathrm{R}_{\mathrm{f}} \mathrm{CH}_{2} \mathrm{CHCH}_{2} \mathrm{O}$ (see above), but in the present case the product was an alcohol, apparently formed by the simultaneous elimination of $\mathrm{HCl}+\mathrm{CH}_{3} \mathrm{COOH}$ :

$$
\mathrm{F}_{5} \mathrm{SCH}_{2} \mathrm{CHClCH}_{2} \mathrm{OC}(0) \mathrm{CH}_{3}+\text { base } \rightarrow \mathrm{F}_{5} \mathrm{SCH}=\mathrm{CHCH}_{2} \mathrm{OH}(\approx 90 \%) \text {, }
$$

The elimination was originally conducted with aqueous $\mathrm{KOH}$ (in a two-phase system), but it appeared as though water were retained tenaciously by the product. This was chiefly concluded from the i.r. spectrum which shows a broad feature coincident with the water spectrum. Running the reaction under anhydrous conditions (with sodium methoxide in methanol) yielded the same product, however. 
CHAPTER III

\section{REACTIONS OF $\mathrm{F}_{5} \mathrm{SCFCF}$}

Most of the reactions of the epoxide $\mathrm{F}_{5} \mathrm{SCFCF}$ were not quantitatively analyzed because of the impossibility of separating the products that were formed. Nevertheless, one can draw one major inference from these experiments. In all reactions loss of $\mathrm{SF}_{5}$ was observed and $\mathrm{SF}_{4}$ and $\mathrm{CF}_{3} \mathrm{CFO}$ could be identified as major products by their characteristic infrared frequencies. Similar observations have been made before by DesMarteau and Sekiya 32 and by Berry and Fox. In one mode of reaction (attack at $\mathrm{CF}_{2}$ ), the compound $\mathrm{F}_{5} \mathrm{SNCF}_{2} \mathrm{O}$ was found to lose $\mathrm{SF}_{5}{ }^{-}$upon base-treatment,

$$
\mathrm{F}_{5} \mathrm{SN}_{\delta}-\mathrm{FF}_{2}+\mathrm{F}^{-} \rightarrow \mathrm{SF}_{4}+\mathrm{CF}_{3} \mathrm{NO}+\mathrm{COF}_{2}+\text { others }
$$

$\mathrm{COF}_{2}$ would originate in the attack at nitrogen. The loss of $\mathrm{SF}_{5}{ }^{-}$was inferred from the presence of $\mathrm{SOF}_{2}+\mathrm{SiF}_{4} ; \mathrm{SF}_{4}$ was not observed, but $\mathrm{SOF}_{2}$ is the usual hydrolysis product. In the other case, $\mathrm{F}_{5} \mathrm{SCCF}_{3}(\underline{69})$ was found to lose $\mathrm{SF}_{5}$, when bases were present. There is a parallelism between the case of $\mathrm{F}_{5} \mathrm{SCFCF}{ }_{2} \mathrm{O}$ (54) and the isomer $\mathrm{F}_{5} \mathrm{~S}\left(\mathrm{CF}_{3}\right) \mathrm{C}=0$. While all anions seem to attack the epoxide at the $\mathrm{CF}_{2}$ group, leading to an intermediate anion, the attack in the case of the 
ketone is at the co group, leading to the same intermediate:

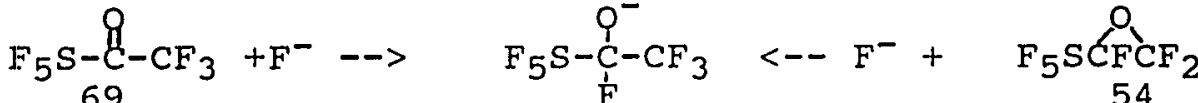

$$
\begin{aligned}
& 69 \\
& \mathrm{CF}_{3} \mathrm{CFO}+\mathrm{SF}_{5}^{-}\left(-\rightarrow \mathrm{SF}_{4}+\mathrm{F}^{-}\right)
\end{aligned}
$$

In the above case, the expected product would be $\mathrm{CF}_{3} \mathrm{CFO}+$ $\mathrm{SF}_{4} \cdot \mathrm{F}_{5} \mathrm{SCFCF}_{2} \mathrm{O}$ as an analogue to hexafluoro propylene epoxide and should exhibit similar reaction behavior. 33 While $\mathrm{CF}_{3} \mathrm{CFCF}_{2} \mathrm{O}$ reacts with methanol to give methyl-2methoxytetrafluoro propionate, its $\mathrm{SF}_{5}$ analogue does not lead to a corresponding product:

$$
\begin{aligned}
& \mathrm{F}_{3} \mathrm{CCFCF}_{2} \mathrm{O}+\mathrm{CH}_{3} \mathrm{OH} \longrightarrow \mathrm{F}_{3} \mathrm{CF}\left(\mathrm{OCH}_{3}\right) \mathrm{COOCH}_{3} \\
& \mathrm{~F}_{5} \mathrm{SCFCF} \mathrm{O}_{2}+\mathrm{CH}_{3} \mathrm{OH}-\mathrm{X}->\quad \mathrm{F}_{5} \mathrm{SCF}\left(\mathrm{OCH}_{3}\right) \mathrm{COOCH}_{3}
\end{aligned}
$$

The product that is obtained is a mixture of several compounds, of which one constitutes $58 \%$ (g.c.). These products could not be identified due to the small amounts of the epoxide that were available, but the $\mathrm{SF}_{5}$ group was destroyed, as seen. in the ${ }^{19} \mathrm{~F}$ n.m.r. spectrum.

Water, which leads with hexafluoropropylene oxide to 2,2-dihydroxytrifluoropropionic acid, does not seem to react appreciatively with $\mathrm{F}_{5} \mathrm{SCFCF}_{2} \mathrm{O}$.

$$
\begin{array}{ll}
\mathrm{F}_{3} \mathrm{CCFCF_{2 } \mathrm { O }}+\mathrm{H}_{2} \mathrm{O}--\rightarrow & \mathrm{F}_{3} \mathrm{CC}(\mathrm{OH})_{2} \mathrm{COOH} \text { (68\%) } \\
\mathrm{F}_{5} \mathrm{SCFCF_{2 } \mathrm { O }}+\mathrm{H}_{2} \mathrm{O}--> & \text { no appreciable reaction }
\end{array}
$$

The reaction was carried out at slightly raised temperature in a Pyrex-glass vessel with a large excess of water, and the progress of the reaction was monitored by measuring the gias pressure occasionally and checking the i.r. spectrum of 
the gaseous material. There was a slight initial pressure drop $(\approx 13 \%)$, which might have its origin in the solubility of the epoxide in water. The change in the i.r. spectrum was confined to the appearance of one weak band at $1374 \mathrm{~cm}^{-1}$, and after 1 week circa $80 \%$ of the epoxide could be recovered. The reaction vessel was severly etched, and a white material had been dislodged from it. This residue, although not identified, originated certainly in the reaction of the glass vessel with hydrogen fluoride. The epoxide does seem to react initially with water, releasing $H F$, which turns the reaction mixture acidic, halting further reaction, but allowing the $\mathrm{HF}$ to etch the vessel in a continuous fashion.

The epoxide is completely inert to boron trifluoride; ring opening does not occur.

The reaction with cesium fluoride in acetonitrile showed the formation of mainly $\mathrm{SF}_{4}$ and $\mathrm{CF}_{3} \mathrm{CFO}$.

$$
\mathrm{F}_{5} \mathrm{SCFCF}_{2}+\mathrm{CsF}+\mathrm{CH}_{3} \mathrm{CN}-->\mathrm{SF}_{4}+\mathrm{CF}_{3} \mathrm{CFO}+\text { other compound(s) }
$$
Preparative gas chromatography showed also the formation of another (minor) product, but it could not be identified. The reaction was conducted with heating and it was first tried to separate the products by fractional condensation. This separated the solvent from the mixture, but the $\mathrm{SF}_{4}$ and $\mathrm{CF}_{3} \mathrm{CFO}$ were collected together in the $-196^{\circ} \mathrm{C}$ trap $(76 \%$ of theory). It was also not possible to separate the products by g.c., but the eluted band was clearly asymmetrical and 
when an i.r. spectrum at different stages of the elution was measured, the changing composition of the eluent was clearly seen. $\mathrm{SiF}_{4}$, SOF 2 and $\mathrm{CF}_{3} \mathrm{CFO}$ could be identified, but no information concerning their amounts was obtained. The fourth product $(\approx 6 \%$ of total area) has strong bands at 816 and $909 \mathrm{~cm}^{-1}$, and also in the $\mathrm{C}-\mathrm{F}$ stretch region (1047$1213 \mathrm{~cm}^{-1}$ ). Thid could indicate a compound that has $\mathrm{S}-\mathrm{F}$ and $\mathrm{C}-\mathrm{F}$ bonds, but the appearance and position makes it unlikely that an $\mathrm{SF}_{5}$ group is present. The few bands that are present indicate that it is a simple compound. Whether it originates in $\mathrm{F}^{-}$attack at $\mathrm{CF}$ instead of $\mathrm{CF}_{2}$ (the origin of $\mathrm{SF}_{4}$ and $\mathrm{CF}_{3} \mathrm{CFO}$ ) must remain an unanswered question.

Further attempts to detect $\operatorname{CsSF}_{5}$ (which should be a primary product of decomposition by CSF) were unsuccessful. When the reaction was conducted at room-temperature in the course of several weeks, blackening was observed, but the residue, when treated with $\mathrm{Br}_{2}$ did not yield $\mathrm{SF}_{5} \mathrm{Br}$. DesMarteau and sekiya showed the presence of $\mathrm{CsSF}_{5}$ by treating the solid residue with fluorine:

$$
\mathrm{CsSF}_{5}+\mathrm{F}_{2}--\rightarrow \mathrm{CsF}+\mathrm{SF}_{6} \text {, }
$$

and Seppelt, Fuchs and Bittner ${ }^{34}$ could isolate CsSF $_{5}$ and $\mathrm{RbSF}_{5}$ from the reaction of the respective fluorides and $\mathrm{F}_{5} \mathrm{SC}\left(\mathrm{CF}_{3}\right)=\mathrm{CF}_{2}$ :

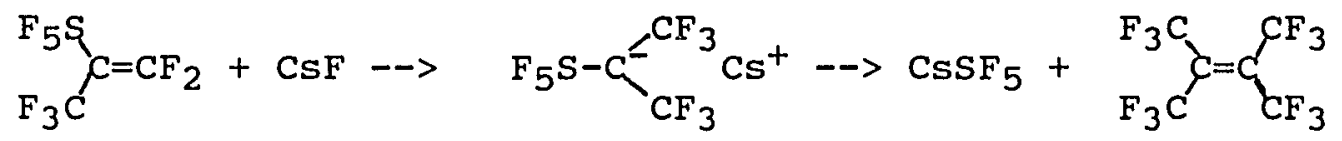
These two reactions show that loss of $\mathrm{SF}_{5}{ }^{-}$is possible when 
other stable product can be formed at the same time. The weight increase of the cesium fluoride in the reaction with $\mathrm{F}_{5} \mathrm{SCFCF}_{2} \mathrm{O}$ was only $24 \%$ of the expected value.

The reaction of $\mathrm{F}_{5} \mathrm{~S} \overparen{\mathrm{CFCF}_{2} \mathrm{O}}$ with $\mathrm{SbF}_{5}$ did not lead to the formation of $\mathrm{F}_{5} \mathrm{SC}(0) \mathrm{CF}_{3}$. Formation of $\mathrm{C}=0$ compounds (carbonyl fluorides or ketones) is observed other with perfluoroolefin epoxides ${ }^{35}$. Instead, the i.r. spectrum of the product shows the presence of $\mathrm{CF}_{3} \mathrm{CFO}, \mathrm{SiF}_{4}+$ perhaps $\mathrm{CO}$ $\left(2185 \mathrm{~cm}^{-1}\right)$. The presence of other products is also possible. The products were not further analyzed except by qualitative view. That $\mathrm{SF}_{4}$ was not observed comes from the following reaction:

$$
\mathrm{SbF}_{5}+\mathrm{SF}_{4}-->\mathrm{SF}_{3}+\mathrm{SbF}_{6}{ }^{-}
$$

A conversion into the isomers $\mathrm{F}_{5} \mathrm{SCF}_{2} \mathrm{CFO}^{36}$ or $\mathrm{F}_{5} \mathrm{SC}(\mathrm{O}) \mathrm{CF}_{3}$ is thus not possible by this route. When $\mathrm{F}_{5} \mathrm{SCFCF_{2 }}$. was heated in the presence of oxygen, no reaction was observed at 50 ${ }^{\circ} \mathrm{C}$, but two days of heating at $130-140^{\circ} \mathrm{C}$ produced a strong band at $1898 \mathrm{~cm}^{-1}$ and there were further bands attributable to $\mathrm{SF}_{4}, \mathrm{SOF}_{2}$ and $\mathrm{SiF}_{4}$. No $\mathrm{F}_{5} \mathrm{SOCF}_{2} \mathrm{CFO}$ was detected; this product could have been formed in a similar fashion as was found in the reaction of $\mathrm{F}_{5} \mathrm{SCF}=\mathrm{CF}_{2}+\mathrm{O}_{2}$. Although the epoxide was not subjected to heat alone, it is quite possible that this is the effect of thermal decomposition rather of the involvement of oxygen.

Bases as weak as diethylether will cause this reaction: When $\mathrm{F}_{5} \mathrm{SCFCF}$ is dissolved in $\left(\mathrm{C}_{2} \mathrm{H}_{5}\right)_{2} \mathrm{O}$ slow 
formation of $\mathrm{SF}_{4}$ is observed. In the case of tetrafluoroethylene epoxide this reaction results in the formation of a diether $\mathrm{ROCF}_{2} \mathrm{CF}_{2} \mathrm{OR} .37$

These reactions show that a preferred mode of action does involve attack at the $\mathrm{CF}_{2}$ group with the following loss of $\mathrm{SF}_{5}{ }^{-}\left(->\mathrm{SF}_{4}+\mathrm{F}^{-}\right)$, always leading to $\mathrm{SF}_{4}$ and $\mathrm{CF}_{3} \mathrm{CFO}$.

This loss of $\mathrm{SF}_{5}$ was also observed with $\mathrm{F}_{5} \mathrm{SC}(\mathrm{O}) \mathrm{CF}_{3}{ }^{38}$ and bases, and is also similar to the observation made by DesMarteau and sekiya with $\mathrm{F}_{5} \mathrm{SNCF}_{2} \mathrm{O}$, and as described above, by Seppelt, Bittner and Fuchs with $\mathrm{F}_{5} \mathrm{SC}\left(\mathrm{CF}_{3}\right)_{2}^{-} \mathrm{Cs}^{+}$.

Although $\mathrm{F}_{5} \mathrm{SCHCF}_{2} \mathrm{O}$ was also synthesized, its reactivity was not investigated. It is expected that it will lose $\mathrm{SF}_{5}{ }^{-}$even more readily than $\mathrm{F}_{5} \mathrm{SCFCF_{2 }}$ in anionic reactions, because it lacks the $\alpha$-fluorine which might stabilize a negative charge at $C_{\alpha}$.

\section{SYNTHESIS OF THE STARTING OLEFINS}

The two olefins that were used as stating materials were synthesized by modified published versions. $\mathrm{F}_{5} \mathrm{SCH}=\mathrm{CF}_{2}$ (52) was obtained as described in conjunction with the synthesis of $\mathrm{F}_{5} \mathrm{SCHCF}_{2} \mathrm{OSO}_{2}$, while $\mathrm{F}_{5} \mathrm{SCF}=\mathrm{CF}_{2}$ (으) was obtained by dehydrobromination of $\mathrm{F}_{5} \mathrm{SCHFCF}_{2} \mathrm{Br}$ with aqueous $\mathrm{KOH}$, also in excellent yield. The more common method of dehydrohalogenation with solid $\mathrm{KOH}$ or with $\mathrm{KOH}$ in petroleum ether is less advantageous, because it is more time consuming and yields are lower. With the analogous 
$\mathrm{F}_{5} \mathrm{SCHFCF}_{2} \mathrm{Cl}$, it was reported that decomposition occurred with aqueous коH. 39 
CHAPTER IV

INFRARED, ${ }^{19} \mathrm{~F}$ AND ${ }^{13} \mathrm{C}$ N.M.R. SPECTRA

In the infrared spectra the epoxide ring band is seen at $1530\left(\mathrm{SF}_{5} \widehat{\mathrm{CFCF}_{2} \mathrm{O}}\right)$ and $\approx 1500 \mathrm{~cm}^{-1}\left(\mathrm{SF}_{5} \overline{\mathrm{CHCF}_{2} \mathrm{O}}\right)$, respectively, at the upper limit of the values observed for other fluorinated epoxides. The ${ }^{19} \mathrm{~F}$ n.m.r spectra of the two epoxides show the typical $\mathrm{AB}_{4}$ spectra of the $\mathrm{SF}_{5}$ group. It is conspicuous that the $\mathrm{SF}_{5}$.resonances in the epoxides have moved upfield, as compared to the olefins, by 6-10 ppm. The $\mathrm{CF}_{2}$ groups in $\mathrm{F}_{5} \mathrm{~S} \overparen{\mathrm{CFCF}_{2} \mathrm{O}}$ and in $\mathrm{F}_{5} \mathrm{SCHCF}_{2} \mathrm{O}$ appeared as $\mathrm{AB}$ and MX system, respectively; in the case of the perfluoro compound this system was rather complicated due to extensive overlap. There was also an explicit dependence on the solvent. For example, the two fluorines in the $\mathrm{CF}_{2}$ group of $\mathrm{SF}_{5} \mathrm{CFCF}_{2} \mathrm{O}$ had a very small chemical shift difference in the pure sample and appeared as an incomprehensible multiplet; in 1,1,2-trifluorotrichloroethane a complicated, partially overlapped, but interpretable, $A B$ system was observed, while in $\mathrm{CDCl}_{3}$ the two resonances were clearly separated. It was possible to reproduce the $C F_{2}$ resonance with an n.m.r. simulation program. 40 The coupling within the $\mathrm{CF}_{2}$ group in hexafluoropropylene oxide is $43.5 \mathrm{~Hz}^{41}$, considerably much larger than in $\mathrm{SF}_{5} \overparen{\mathrm{CFCF}_{2} \mathrm{O}}$, but comparable to the value in 
$\mathrm{SF}_{5} \widehat{\mathrm{CHCF}_{2} \mathrm{O}}$. The $\mathrm{F}-\alpha, \beta$-trans coupling in fluoro olefins and in other fluorinated epoxides is found to be negative. 14 Most likely, $\mathrm{J}_{\mathrm{XF}}{ }^{l}$ is also negative in the present case, but it is given here only as the absolute value.

a.)

b.)


Figure 6. Recorded $\left(a\right.$, in $\left.\mathrm{CDCl}_{3}\right)$ and simulated (b) $\mathrm{AB}$ part of the $19 \mathrm{~F}$ n.m.r. spectrum of $\mathrm{SF}_{5} \overrightarrow{C F C F}_{2} \mathrm{O}$. Linewidth $=2.6 \mathrm{~Hz} \cdot \phi_{\mathrm{F}}^{1}-\phi_{\mathrm{F}}{ }^{2}=1.02 \mathrm{ppm}$.

In the ${ }^{13} \mathrm{C}$ n.m.r. spectra of both epoxides, no unusual shifts are observed; the resonances and coupling constants for both carbons appear in the expected regions, and are comparable with the shifts and couplings in the $\beta$-sultone $\mathrm{F}_{5} \mathrm{SCHCF}_{2} \mathrm{OSO}_{2} 42$ and other (partially) fluorinated oxiranes ${ }^{43}$, with the exception of $\mathrm{J}_{\mathrm{C} \alpha \mathrm{F} \alpha}$ in $\mathrm { SF } _ { 5 } \longdiv { \mathrm { CFCF } _ { 2 } \mathrm { O } }$. 


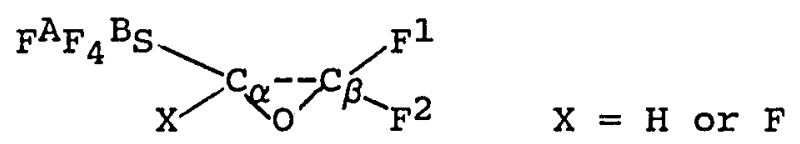

TABLE VI

${ }^{19} \mathrm{~F}$ AND ${ }^{13} \mathrm{C}$ N.M.R. DATA ${ }^{+}$OF $\mathrm{SF}_{5}$-EPOXIDES






\section{CHAPTER V}

\section{CONCLUSION}

Two $\mathrm{SF}_{5}$-epoxides were synthesized and the reaction chemistry of the perfluoro compound was investigated in more detail. It was found that loss of the $\mathrm{SF}_{5}$ group was the dominant reaction with nucleophiles. It was not possible to polymerize this epoxide. Attempts to synthesize an olefin with a $\mathrm{CF}_{2}$ group between the double bond and the $\mathrm{SF}_{5}$ group failed; this should have diminished the tendency for losing the $\mathrm{SF}_{5}$ moiety. 
PART III

TOWARDS THE SYNTHESIS OF PENTAFLUOROTHIO MALONIC ACID 


\section{CHAPTER I}

\section{INTRODUCTION}

Pentafluorosulfur compounds have not yet gained much use; nevertheless, the $\mathrm{SF}_{5}$ group does exhibit some rather intriguing properties, which make it comparable, and in some respects superior to a $\mathrm{CF}_{3}$ group. Comparing the $\mathrm{n}$-octanolwater partition coefficients of a compound bearing different substituents, one obtains the hydrophobicity coefficient ${ }^{1}$, which indicates the affinity of a substituent towards a hydrophobic medium such that a larger number corresponds also to a larger affinity towards the hydrophobic phase. In this series, $\mathrm{SF}_{5}$ is only superseded by trans-CF $\mathrm{SF}_{4}$. Such a property is desirable in several respects. The incorporation of fluorine into biologically active molecules has several motives. A fluorine atom is only slightly larger than a hydrogen atom (van der Waals radii, $F=1.35 \AA, H=1.2 \AA$ ), but has rather different properties. If the fluorine atom is in a position of the molecule that is at some point subject to chemical change in a biochemical transformation, then the normal reaction sequence will be interrupted. Another reason for introducing fluorine is the interruption of a biochemical cycle by the formation of poisonous by products in a chemical reaction; this can be the case in the 
hydrolysis of a $\mathrm{CF}_{3}$ group. These rationales have brought about the synthesis of certain nucleoside analogues, as 5fluorouracil, 5-fluoro-2'-deoxyuridine, 5-fluorocytosine and 5-trifluoromethyl-2'-deoxyuridine ${ }^{2}$, which are used as antiviral and cancerostatic drugs. The activity of 5trifluoromethyl-2'-deoxyuridine seems to be related to its incorporation into the cell DNA. Other derivatives of deoxyuridine were also investigated, as the 5pentafluoroethyl and 5-enneafluoro-n-butyl-2'-deoxyuridine, but were found to have only lessened activity against herpes simplex virus (type 1 and 2) ${ }^{3}$. 51trifluoromethylthioribose ${ }^{4}$, a sugar analogue, shows very high (in-vitro) efficacy against the malaria parasite. A third reason is to increase the lipid solubility of certain drugs, which may be, according to Filler, the most significant factor in improving pharmacological activity. 5 Discounting for particular properties of the $\mathrm{SF}_{5}$ substituent, which are not investigated and are possibly absent, due to its usual chemical inertness, it is thus expected that drugs, in particular central nervous system agents, for which the increase of lipophilicity is considered specially important, due to the increase of absorption and transport across the brain-blood barrier, containing this substituent would be more efficacious than their $C_{3}$ (or $F$ ) analogues. In the case of 5trifluoromethyl-2'-deoxyuridine rapid hydrolysis of the 
trifluoromethyl group upon administration is observed, with the formation of inorganic fluoride and 5-carboxyuracil ${ }^{2}$. Under certain conditions, an $\mathrm{SF}_{5}$-group is, however, also subject to chemical degradation, either under reducing or basic conditions.

Several $\mathrm{SF}_{5}$-compounds have been patented as fumigants, $\mathrm{SF}_{5} \mathrm{CF}=\mathrm{CF}_{2}{ }^{6}, \mathrm{SF}_{5} \mathrm{CFICF}_{3}{ }^{7}, \mathrm{SF}_{5} \mathrm{~N}=\mathrm{CF}_{2}{ }^{8}$ and as a soil fumigant, $\mathrm{SF}_{5} \mathrm{CH}_{2} \mathrm{COOH} .9$ Insecticidal properties are described for compounds derived from $\mathrm{SF}_{5} \mathrm{Cl}$ and ethylene or propylene. 10 


\section{CHAPTER II}

\section{A GENERAL OUTLINE FOR THE SYNTHESIS OF SF 5 -COMPOUNDS}

Most $\mathrm{SF}_{5}$ compounds are obtained by addition of $\mathrm{SF}_{5} \mathrm{Br}$ or $\mathrm{SF}_{5} \mathrm{Cl}$ to olefins. This method allows one to obtain $\mathrm{SF}_{5}$ compounds with the $\mathrm{SF}_{5}$-group at a secondary carbon only in exceptional cases. On the other hand it is not usually possible to manipulate simple $\mathrm{SF}_{5}$-compounds chemically towards the introduction of a carbon substituent at the $\mathrm{SF}_{5}$ carbon. Examples for this failure have been given in the first part of this manuscript.

Whereas in $\mathrm{CF}_{3}$ chemistry a number of reactions already exist, that allow $\mathrm{CF}_{3}$-substitution in suitable substrates, in the $\mathrm{SF}_{5}$-field only few such methods are available:

1. Addition of $\mathrm{SF}_{5} \mathrm{Cl}$ or $\mathrm{SF}_{5} \mathrm{Br}$ to multiple bonds. 11

2. Addition of $S_{2} F_{10}$ to multiple bonds. 12

3. Oxidation of disulfides with $\mathrm{AgF}_{2}$ or $\mathrm{CoF}_{3} \cdot{ }^{13}$

4. Anodic fluorination of thiols or disulfides. 14

5. Direct fluorination. 15

of these methods the most suitable ones are the addition of $\mathrm{SF}_{5} \mathrm{X}$ to multiple bonds, while oxidations of $-\mathrm{SH}$ or -SS- are used for special classes of compounds.

The addition of $\mathrm{SF}_{5} \mathrm{X}$ to a multiple bond, which can be induced by light, heat or free-radical initiators, is a 
radical reaction and involves in the first stage cleavage to $\mathrm{SF}_{5}$. and $\mathrm{X} \cdot$, followed by addition to the multiple bond. 16 The chain reaction is maintained by reaction of the primary product with $\mathrm{SF}_{5} \mathrm{X}$ :

$$
\begin{aligned}
& \mathrm{SF}_{5} \mathrm{X}-\cdots+-\mathrm{S} \cdot \quad(\mathrm{X}=\mathrm{Br}, \mathrm{Cl}) \\
& \mathrm{x} \cdot+\mathrm{C}=\mathrm{C} \quad-----\mathrm{X}-\mathrm{C}-\mathrm{C} \text {. (a) } \\
& \mathrm{SF}_{5} \cdot+\mathrm{C}=\mathrm{C} \quad-\cdots-\cdots \rightarrow \mathrm{F}_{5} \mathrm{~S}-\mathrm{C}-\mathrm{C} \cdot \quad \text { (b) } \\
& \mathrm{F}_{5} \mathrm{~S}-\mathrm{C}-\mathrm{C} \cdot+\mathrm{SF}_{5} \mathrm{X}------->\mathrm{F}_{5} \mathrm{~S}-\mathrm{C}-\mathrm{C}-\mathrm{X}+\mathrm{SF}_{5} \cdot
\end{aligned}
$$

only reaction (b) will lead to propagation, as in the next step both (a) and (b) will react with $\mathrm{SF}_{5} \mathrm{X}$, abstracting $\mathrm{X}$. and leaving $\mathrm{SF}_{5}$, behind. The reaction step (a) continues with (b) in this second step, explaining why neither $\mathrm{x}-\mathrm{c}-\mathrm{c}-\mathrm{X}$ nor $\mathrm{F}_{5} \mathrm{~S}-\mathrm{C}-\mathrm{C}-\mathrm{SF}_{5}$ are usually observed as products in these reactions. 17 It was shown later, that the addition of $\mathrm{SF}_{5}$. to an olefin is reversible $e^{18}$, an observation that was also made upon occasion in the course of this work.

The addition of $\mathrm{SF}_{5} \mathrm{X}(\mathrm{X}=\mathrm{Br}, \mathrm{Cl})$ to olefins or acetylene leads only to compounds which contain the $\mathrm{SF}_{5}$-group at the carbon not bearing a substituent:

$$
\begin{array}{lll}
\mathrm{CH}_{2}=\mathrm{CHCH}_{3}+\mathrm{SF}_{5} \mathrm{X} & -\cdots-> & \mathrm{F}_{5} \mathrm{SCH}_{2} \mathrm{CHXCH}_{3} \\
\mathrm{CH}_{2}=\mathrm{CF}_{2}+\mathrm{SF}_{5} \mathrm{X} & -\cdots-> & \mathrm{F}_{5} \mathrm{SCH}_{2} \mathrm{CF}_{2} \mathrm{X} \\
\mathrm{CH}_{2}=\mathrm{CHCOOC}_{2} \mathrm{H}_{5}+\mathrm{SF}_{5} \mathrm{X} & -\cdots-> & \mathrm{F}_{5} \mathrm{SCH}_{2} \mathrm{CHBrCOOC}_{2} \mathrm{H}_{5} \\
\mathrm{CH}_{2}=\mathrm{CHOAC}+\mathrm{SF}_{5} \mathrm{X} & -\cdots-> & \mathrm{F}_{5} \mathrm{SCH}_{2} \mathrm{CHXOAC}
\end{array}
$$

$\mathrm{SF}_{5} \cdot$ is an electrophilic radical and will thus add preferentially to positions with higher charge density. This is a chief obstacle in making a whole class of $\mathrm{SF}_{5}$ 
compounds, that are additionally substituted at the carbon bearing the $\mathrm{SF}_{5}$-group. Although it is possible to obtain compounds of the form $\mathrm{SF}_{5} \mathrm{CHX}-(\mathrm{X}=\mathrm{H}, \mathrm{Br}, \mathrm{Cl}, \mathrm{F})$, this must be considered an exception, as with an asymmetrically substituted ethylene $\left(\mathrm{CF}_{2}=\mathrm{CHCl}\right.$ e.g.) the addition will not be uni-directional.

only in special cases can $c_{\alpha}$ be substituted with something other than hydrogen or halogen:

$$
\begin{aligned}
& \mathrm{F}_{3} \mathrm{CCH}=\mathrm{CF}_{2}+\mathrm{SF}_{5} \mathrm{Cl}(\mathrm{hv})---\rightarrow \quad\left(\mathrm{F}_{3} \mathrm{C}\right) \mathrm{F}_{5} \mathrm{SCHCF}_{2} \mathrm{Cl} 19 \\
& \left(\mathrm{~F}_{3} \mathrm{C}\right)_{2} \mathrm{C}=\mathrm{CH}_{2}+\mathrm{SF}_{5} \mathrm{Cl} \quad----\left(\mathrm{F}_{3} \mathrm{C}\right)_{2} \mathrm{~F}_{5} \mathrm{SCCH}_{2} \mathrm{Cl}^{20} \\
& \mathrm{~F}_{5} \mathrm{SCH}=\mathrm{CF}_{2}+" \quad---->\quad\left(\mathrm{F}_{5} \mathrm{~S}\right)_{2} \mathrm{CHCF}_{2} \mathrm{Cl}^{21} \\
& \mathrm{H}_{3} \mathrm{CC} \equiv \mathrm{COR}+" \quad-\cdots-\mathrm{F}_{5} \mathrm{~S}\left(\mathrm{CH}_{3}\right) \mathrm{C}=\mathrm{C}(\mathrm{Cl}) \mathrm{OR}^{22} \\
& \mathrm{~F}_{5} \mathrm{SC} \equiv \mathrm{CH}+\mathrm{CH}_{2} \mathrm{~N}_{2} \quad--->3-\mathrm{SF}_{5} \text {-pyrazol }(60 \%)+ \\
& 4-\mathrm{SF}_{5} \text {-pyrazol }(40 \%)^{23} \\
& \mathrm{~F}_{5} \mathrm{SCF}=\mathrm{CF}_{2}+\mathrm{CH}_{2}=\mathrm{CHCH}=\mathrm{CH}_{2}--\rightarrow \quad \begin{array}{r}
\mathrm{F}_{5} \mathrm{SCF}-\mathrm{H}_{2} \mathrm{CF} \\
\mathrm{H}_{2} \\
\mathrm{CHCH}=\mathrm{CH}_{2}
\end{array} \\
& \mathrm{~F}_{5} \mathrm{SCF}=\mathrm{CF}_{2}+\mathrm{COF}_{2}(\mathrm{CsF}) \quad--->\quad \mathrm{F}_{5} \mathrm{SCFCF}_{3} \mathrm{COF}_{3}
\end{aligned}
$$

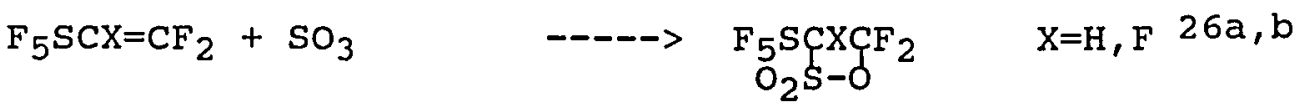

$$
\begin{aligned}
& \mathrm{F}_{5} \mathrm{SCF}\left(\mathrm{CF}_{3}\right) \mathrm{I}+\mathrm{C}_{2} \mathrm{H}_{4} \text { (hv) - - - } \mathrm{F}_{5} \mathrm{SCF}\left(\mathrm{CF}_{3}\right) \mathrm{CH}_{2} \mathrm{CH}_{2} \mathrm{I}^{27}
\end{aligned}
$$

It is obvious, that steric requirements in the addition reactions of $\mathrm{SF}_{5} \mathrm{Cl}$ are of minor importance, for otherwise the direction of addition should have been the opposite.

It was intended to synthesize the compound 5-SF $5-$ uracil, as the analogue of 5-trifluoromethyl-uracil. These compounds are simply related to the respective 2 '-uridines. An important intermediate for syntheses would be 
pentafluorothio malonic acid, $\mathrm{F}_{5} \mathrm{SCH}(\mathrm{COOH})_{2}$ or its esters. As with other malonic acid derivatives, this should allow the synthesis of pyrimidine derivatives, in particular barbituric acids, and further manipulation of $\mathrm{F}_{5} \mathrm{SCH}(\mathrm{COOR})_{2}$ $\left(\mathrm{R}=\mathrm{H}\right.$, alkyl) should lead to $\alpha-S F_{5}$ acrylic acid. The $\mathrm{CF}_{3}-$ analogue, $\mathrm{CF}_{3} \mathrm{CH}\left(\mathrm{COOC}_{2} \mathrm{H}_{5}\right)_{2}$, was synthesized some years ago by Knunyanz 28 , its di-acyl fluoride was described by Krespan 29 , and $\mathrm{CH}_{2}=\mathrm{C}\left(\mathrm{CF}_{3}\right) \mathrm{COOH}$ by Japanese researchers. Trifluoromethyl malonic ester was obtained by successive methanolysis of $\left(\mathrm{CF}_{3}\right)_{2} \mathrm{CHCOOCH}_{3}$, trifluoromethyl malonyl fluoride was obtained by reaction of acetic anhydride with $\alpha-\mathrm{CF}_{3}$ perfluoroacrloyl fluoride, and $\alpha-\mathrm{CF}_{3}$ acrylic acid by a catalytic carbonyl- ation procedure of 2-bromo-3,3,3trifluoroproylene ${ }^{30}$ 1,2-dibromo-3,3,3,-trifluoropropane ${ }^{31}$ in good yield. 5-trifluoromethyluracil or 5-trifluoromethyluridine are accessible by several different routes: by ringclosure 32 , replacement of halogen by reaction with copper perfluoroalkyl compounds 33 or by a radical substitution of the hydrogen at position 5 in pyrimidines ${ }^{3}$. In order to achieve this goal for the $\mathrm{SF}_{5}$ analogue, a suitable reagent for cyclization - most advantageously an acrylic or malonic acid - is necessary; an analogous reaction to the copper catalyzed $R_{f}$-substitutions for $\mathrm{SF}_{5}$ groups has not been devised. 


\section{CHAPTER III}

\section{RESULTS AND DISCUSSION AND THE SYNTHESIS OF $\mathrm{SF}_{5} \mathrm{CH}\left(\mathrm{COOC}_{2} \mathrm{H}_{5}\right) \mathrm{CHBROCOCH}_{3}$}

The introduction of an $\alpha$-carbon substituent in $\mathrm{SF}_{5}-$ compounds should be possible by several routes. A particularly easy reaction would have been the addition of $\mathrm{SF}_{5} \mathrm{Br}$ to maleic anhydride. This compound was completely inert towards $\mathrm{SF}_{5} \mathrm{Br}$, probably due to the electrophilic double bond. Although the equilibrium $\mathrm{OClCCH}_{2} \mathrm{CClO} \leftrightharpoons$ oClCCH$=\mathrm{C}=\mathrm{O}+\mathrm{HCl}$ was described ${ }^{34}$, no product corresponding to $\mathrm{SF}_{5} \mathrm{Cl}$ addition to malonylchloride (more exactly, to chlorocarbonyl ketene) was observed in the respective reactions at $\approx 90^{\circ} \mathrm{C}$ in a steel bomb; only decomposition was seen.

Nucleophilic displacement of halogen by cyanide was another possibility that was considered:

$$
\mathrm{F}_{5} \mathrm{SCHBrCH}_{2} \mathrm{OCH}_{3}+\mathrm{CN}^{-}\left(\left(\mathrm{CH}_{3}\right)_{2} \mathrm{~S}=\mathrm{O}\right)--\mathrm{X}->\mathrm{F}_{5} \mathrm{SCH}(\mathrm{C} \equiv \mathrm{N}) \mathrm{CH}_{2} \mathrm{OCH}_{3}
$$

In this reaction, loss of the $\mathrm{SF}_{5}$ group was observed and a tarry residue was obtained. The $\beta$-bromo- $\beta-S F_{5}$-ethylmethyl ether was obtained by nucleophilic addition of $\mathrm{CH}_{3} \mathrm{O}^{-}$ to $\mathrm{F}_{5} \mathrm{SCBr}=\mathrm{CH}_{2}$.

$$
\mathrm{F}_{5} \mathrm{SCBr}=\mathrm{CH}_{2}+\mathrm{CH}_{3} \mathrm{O}^{-} \mathrm{Na}^{+}-\mathrm{CH}_{3} \mathrm{OH}-->\mathrm{F}_{5} \mathrm{SCHBrCH}_{2} \mathrm{OCH}_{3}
$$


It was initially hoped that the bromine in the olefin might be replacedable by the methoxy group, which then could have been hydrolyzed to a ketone:

$$
\underset{\mathrm{Fr}}{\mathrm{F}_{5} \mathrm{SC}=\mathrm{CH}_{2}}+\underset{\mathrm{H}_{3} \mathrm{CO}}{\mathrm{CH}_{3} \mathrm{O}^{-}} \rightarrow-\underset{\mathrm{C}}{\mathrm{F}_{5} \mathrm{SC}}=\mathrm{CH}_{2} \rightarrow \mathrm{F}_{5} \mathrm{~S}-\mathrm{C}_{\mathrm{C}}-\mathrm{CH}_{3} \rightarrow
$$

It was later learnt that its $\mathrm{CF}_{3}$ analogue loses $\mathrm{SF}_{5}{ }^{-}$upon attack of anions at the carbonyl group; likely, the above ketone would have behaved similarly and this would narrow the synthetic utility of such $\mathrm{SF}_{5}$-ketones severly. An example of this behavior is described in the chapter dealing with the epoxide $\mathrm{F}_{5} \mathrm{SCFCF}_{2} \mathrm{O}$.

Carbonylation of $\mathrm{SF}_{5} \mathrm{CBr}=\mathrm{CH}_{2}$, by analogy to $\mathrm{CF}_{3} \mathrm{CBr}=\mathrm{CH}_{2}$, was also not possible. The reaction led to the loss of the $\mathrm{SF}_{5}$-group.

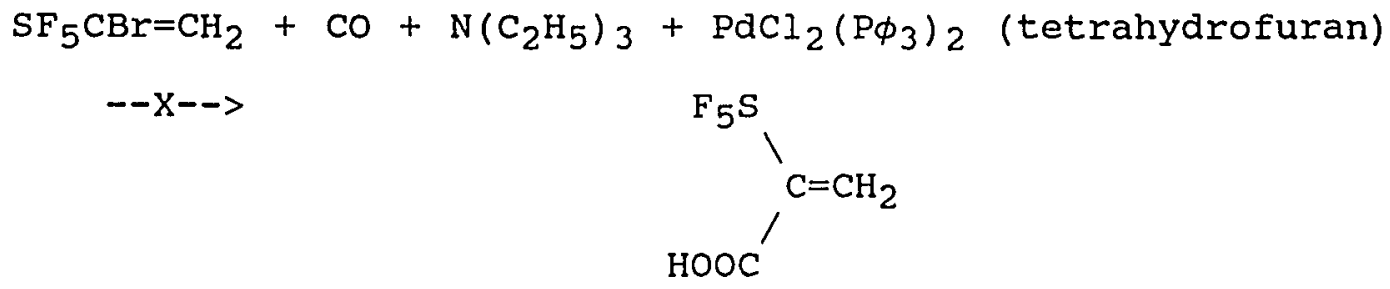

This reaction leads with $\mathrm{F}_{3} \mathrm{CC}(\mathrm{Br})=\mathrm{CH}_{2}$ to $\mathrm{F}_{3} \mathrm{CC}(\mathrm{COOH})=\mathrm{CH}_{2}$ in good yield 26 .

The Tollens reaction of $\mathrm{SF}_{5} \mathrm{CH}_{2} \mathrm{COOCH}_{3}$ was not successful, $\mathrm{F}_{5} \mathrm{SCH}_{2} \mathrm{COOCH}_{3}+\left(\mathrm{CH}_{2} \mathrm{O}\right)_{\mathrm{n}}+\mathrm{HN}\left(\mathrm{C}_{2} \mathrm{H}_{5}\right)_{2}--\mathrm{X}-->\mathrm{F}_{5} \mathrm{SC}\left(\mathrm{COOCH}_{3}\right) \mathrm{CH}_{2} \mathrm{OH}$, neither did it lead to carbon coupling with $\mathrm{SF}_{5} \mathrm{CH}_{2} \mathrm{CHO}$ : 


$$
\mathrm{F}_{5} \mathrm{SCH}_{2} \mathrm{CHO}+\left(\mathrm{CH}_{2} \mathrm{O}\right)_{\mathrm{n}}+\mathrm{Ba}(\mathrm{OH})_{2}--\mathrm{X}--\mathrm{F}_{5} \mathrm{SCH}(\mathrm{CHO}) \mathrm{CH}_{2} \mathrm{OH}
$$

Although some product was formed, it could not be identified, due to its miniscule mass.

The main difficulty with the aldehyde $\mathrm{SF}_{5} \mathrm{CH}_{2} \mathrm{CHO}$ was that it was laborious to obtain it pure in sufficient quantities. Its synthesis involves dehydration (with phosphorous pentoxide) of its hydrate, $\mathrm{F}_{5} \mathrm{SCH}_{2} \mathrm{CH}(\mathrm{OH})_{2}$, which in turn is obtained by hydrolysis of the vinyl ether $\mathrm{F}_{5} \mathrm{SCH}=\mathrm{CHOCH}_{3}$ in aqueous hydrochloric acid35a,b, or by treatment of the adducts $\mathrm{F}_{5} \mathrm{SCH}_{2} \mathrm{CHClOAC}$ with methanolic potassium hydroxide 36 , respectively, followed by precipitation of the aldehyde with water. The intermediate vinyl ether is obtained by several procedures, either by treatment of $\mathrm{F}_{5} \mathrm{SCH}_{2} \mathrm{CHCl}_{2}$ with excess sodium methoxide $35 \mathrm{a}$, by reaction of $\mathrm{F}_{5} \mathrm{SCH}=\mathrm{CHCl}$ with methanolic $\mathrm{KOH}^{37}$ or a suspension of sodium methoxide in xylene $35 \mathrm{~b}$, or by reaction of methanolic $\mathrm{CH}_{3} \mathrm{ONa}$ with $\mathrm{F}_{5} \mathrm{SCH}=\mathrm{CHBr}$ (this work). The aldehyde reacts with water, forming the hydrate, although usually mixtures of the aldehyde and the hydrate are obtained in the above procedures:

$$
\begin{aligned}
& \mathrm{F}_{5} \mathrm{SCH}_{2} \mathrm{CHCl}_{2}+2 \mathrm{CH}_{3} \mathrm{ONa}------->\quad \mathrm{F}_{5} \mathrm{SCH}=\mathrm{CHOCH}_{3} \\
& \mathrm{~F}_{5} \mathrm{SCH}=\mathrm{CHCl}+\mathrm{CH}_{3} \mathrm{ONa}-\cdots \mathrm{F}_{5} \mathrm{CCH}=\mathrm{CHOCH}_{3}+\mathrm{NaCl} \\
& \mathrm{F}_{5} \mathrm{SCH}=\mathrm{CHBr}+\mathrm{CH}_{3} \mathrm{ONa}+\cdots \quad \mathrm{F}_{5} \mathrm{CCH}=\mathrm{CHOCH}_{3}+\mathrm{NaBr} \\
& \mathrm{F}_{5} \mathrm{CCH}=\mathrm{CHOCH}_{3}+\mathrm{HCl} \text { (reflux) - - - } \mathrm{F}_{5} \mathrm{SCH}_{2} \mathrm{CHO}+ \\
& \mathrm{F}_{5} \mathrm{SCH}_{2} \mathrm{CH}(\mathrm{OH})_{2}+\mathrm{CH}_{3} \mathrm{Cl} \uparrow
\end{aligned}
$$




$$
\begin{aligned}
& \mathrm{F}_{5} \mathrm{SCH}_{2} \mathrm{CHClOAC}+2 \mathrm{KOH}------>\mathrm{F}_{5} \mathrm{SCH}_{2} \mathrm{CH}(\mathrm{OH})_{2} \\
& \mathrm{~F}_{5} \mathrm{SCH}_{2} \mathrm{CH}(\mathrm{OH})_{2}+\text { exc. } \mathrm{P}_{2} \mathrm{O} 5----->\mathrm{F}_{5} \mathrm{SCH}_{2} \mathrm{CHO}
\end{aligned}
$$

All the published procedures were found unsatisfactory. For this reason a new method of synthesis was sought.

The new synthesis is simply the acidic hydrolysis of the adduct $\mathrm{F}_{5} \mathrm{SCH}_{2} \mathrm{CHClOC}(0) \mathrm{CH}_{3}$, which is easily obtained from $\mathrm{SF}_{5} \mathrm{Cl}$ and vinyl acetate as described. The corresponding basic hydrolysis with two equivalents of $\mathrm{KOH}$ was published earlier, but proved to be difficult to control, with ensuing low yields of the aldehyde.

Also tried was whether the basic hydrolysis would lead to the aldehyde with only one equivalent of $\mathrm{KOH}$ in methanol, because, depending on the substituent that would be first displaced, two products were possible, which should have been hydolyzable:

$$
\begin{aligned}
& \mathrm{F}_{5} \mathrm{SCH}_{2} \mathrm{CHClOAC}+\mathrm{OH}^{-}-\mathrm{F}_{5} \mathrm{SCH}_{2} \stackrel{\mathrm{OHOAC}}{\mathrm{CHOA}}+\mathrm{Cl}^{-} \\
& \rightarrow \mathrm{F}_{5} \mathrm{SCH}_{2} \stackrel{\mathrm{Cl}}{\mathrm{C}} \mathrm{H}(\mathrm{OH})+\mathrm{ACO}^{-} \text {, }
\end{aligned}
$$

What was found was a mixture of products, $\mathrm{F}_{5} \mathrm{SCH}_{2} \mathrm{CH}\left(\mathrm{OCH}_{3}\right) \mathrm{CC}(\mathrm{O}) \mathrm{CH}_{3}, \quad \mathrm{~F}_{5} \mathrm{SCH}_{2} \mathrm{CH}(\mathrm{OH})_{2}$ and $\mathrm{F}_{5} \mathrm{SCH}_{2} \mathrm{CHO}$ (the latter two products in $\approx 45 \%$ yield):

$$
\mathrm{F}_{5} \mathrm{SCH}_{2} \mathrm{CHClOAC}+\mathrm{OH}^{-}+\mathrm{CH}_{3} \mathrm{OH} \rightarrow \mathrm{F}_{5} \mathrm{SCH}_{2} \underset{\mathrm{CAC}}{\mathrm{OCH}_{3}}
$$

From other reactions, which showed that nucleophilic 
displacement in $\mathrm{SF}_{5}$ compounds is usually not possible, because it leads to the loss of $\mathrm{SF}_{5}{ }^{-}$, it is inferred that this reaction is rather an elimination-addition reaction:

$$
\mathrm{F}_{5} \mathrm{SCH}_{2} \mathrm{CHClOAC} \rightarrow \underset{\mathrm{H}^{\prime}}{\mathrm{C}=\mathrm{C}^{\prime}}{ }_{\mathrm{OAC}}^{\mathrm{H}} i+\mathrm{CH}_{3} \mathrm{OH} \rightarrow \underset{\mathrm{H}-\mathrm{C}-\mathrm{C}_{-}^{\prime} \mathrm{H}_{\mathrm{OAC}}}{\mathrm{OCH}_{3}}
$$

The formation of $\mathrm{F}_{5} \mathrm{SCH}_{2} \mathrm{CH}(\mathrm{OH})_{2}$ and $\mathrm{F}_{5} \mathrm{SCH}_{2} \mathrm{CHO}$ is then explainable on the same grounds as either the hydrolysis of $\underline{A}\left(->\mathrm{F}_{5} \mathrm{SCH}_{2} \mathrm{CHO}\right)$ or the nucleophilic addition of water to $\underline{A}$ followed by hydrolysis of the primary $\mathrm{F}_{5} \mathrm{SCH}_{2} \mathrm{CH}(\mathrm{OH}) \mathrm{OC}(\mathrm{O}) \mathrm{CH}_{3}$ $\left(->\mathrm{F}_{5} \mathrm{SCH}_{2} \mathrm{CH}(\mathrm{OH})_{2}\right)$. A parallel reaction is observed with the compound $\mathrm{F}_{5} \mathrm{SCH}=\mathrm{CHBr}$ when treated with sodium methoxide in methanol. The major product originates in vinyl substitution, but a minor product is an acetal, which is formed by a nucleophilic addition reaction from the primary product:

$$
\mathrm{F}_{5} \mathrm{SCH}=\mathrm{CHBr}+\mathrm{CH}_{3} \mathrm{O}^{-} \longrightarrow \mathrm{F}_{5} \mathrm{SCH}=\mathrm{CHOCH}_{3} \rightarrow \mathrm{F}_{5} \mathrm{SCH}_{2} \mathrm{CH}\left(\mathrm{OCH}_{3}\right)_{2}
$$

The chloro vinyl derivative reacts analogously. In fact, the dimethyl acetal was first obtained by this route 32 .

It was difficult to separate the vinyl ether and the acetal by distillation and the hydrolysis of these acetals (the diethyl acetal was also prepared in the assumption that hydrolysis would be faster ${ }^{38}$ ) was extremely difficult. In an experiment the diethyl acetal (which was prepared by a method described below) was heated for about two weeks with 
concentrated $\mathrm{HCl}$ to $100^{\circ} \mathrm{C}$. The mixture turned slowly dark and a tarry precipitate appeared, but the acetal could be detected (besides the aldehyde) to the very end. When it was heated with gaseous $\mathrm{HCl}$ A chloro acetal was formed:

$$
\mathrm{F}_{5} \mathrm{SCH}_{2} \mathrm{CH}\left(\mathrm{OCH}_{3}\right)_{2}+\text { exC. } \mathrm{HCl}(\mathrm{g})-->\mathrm{F}_{5} \mathrm{SCH}_{2} \mathrm{CHCl}\left(\mathrm{OCH}_{3}\right)
$$

The acidic hydrolysis of $\mathrm{F}_{5} \mathrm{SCH}_{2} \mathrm{CHClOAC}$ did not pose any problems, although the yield is only $\approx 50 \%$. This is still higher than in most published procedures. In only one case a yield of almost $90 \%$ was claimed.

$$
\mathrm{F}_{5} \mathrm{SCH}_{2} \mathrm{CHClOC}(\mathrm{O}) \mathrm{CH}_{3}+\mathrm{HCl}(\mathrm{aq})--- \text { heat---> } \mathrm{F}_{5} \mathrm{SCH}_{2} \mathrm{CHO}
$$

In contrast to the other hydrolytic methods, the aldehyde was obtained and not the aldehyde hydrate, so that the dehydration step could be omitted. The only successful reaction of this aldehyde was its trimerization by acid catalysis to yield a trioxane. At $80^{\circ} \mathrm{C}$, $85 \%$ phosphoric acid did not produce any change, concentrated sulfuric acid led to charring at elevated temperatures $\left(90-105^{\circ} \mathrm{C}\right)$, but converted the aldehyde at room temperature quickly to the solid trimer, by the usual, acid-catalyzed polymerization of aldehydes:

$3 \mathrm{~F}_{5} \mathrm{SCH}_{2} \mathrm{CHO}\left(\mathrm{H}^{+}\right)-->$

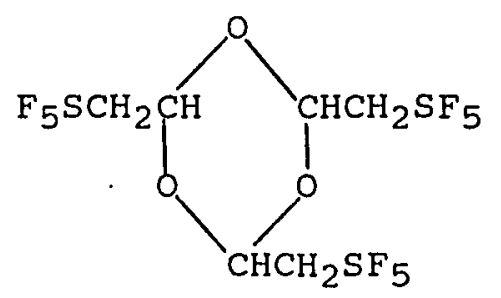


Initially, the trimer was found as large, very appealing, lustrous, uncolored crystals as a product of partial conversion when the aldehyde was stored in the refrigerator for several weeks at $\approx-5^{\circ} \mathrm{C}$. Conversion seems to hinge upon unknown variables, because it was usually very slow, never complete and did not proceed to the same degree for different preparations of the aldehyde. It is possible that residual acid or perhaps small amounts of the aldehyde hydrate caused the conversion in this case. The trimer was initially found when the phosphorous pentoxide that was used to dehydrate the aldehyde hydrate was dissolved in water and extracted with chloroform. This compound was then recrystallized from hexane and exhibited a sharp melting point $\left(110.5-111.5^{\circ} \mathrm{C}\right)$, and an $1_{\mathrm{H}}$ n.m.r. spectrum consistent with a 1,3,5-trioxane structure, although the mass spectrum indicated a dimer with ionization voltages as low as $15 \mathrm{eV}$. The structure of this material was determined crystallographically, and will be discussed subsequently.

As described earlier (Part I), it was not possible to substitute the anions $\mathrm{F}_{5} \mathrm{SC}^{-}\left(\mathrm{SO}_{2} \mathrm{~F}\right) \mathrm{COR}\left(\mathrm{R}=\mathrm{F}, \mathrm{OCH}\left(\mathrm{CH}_{3}\right)_{2}\right)$ with carbon substituents, nor was it possible to react the ketene $\mathrm{F}_{5} \mathrm{SC}\left(\mathrm{SO}_{2} \mathrm{~F}\right)=\mathrm{C}=0$ with $\mathrm{O}=\mathrm{C}=\mathrm{NSO}_{2} \mathrm{Cl}$. This latter reaction should have led to a derivative of a malonic acid ${ }^{39}$ :

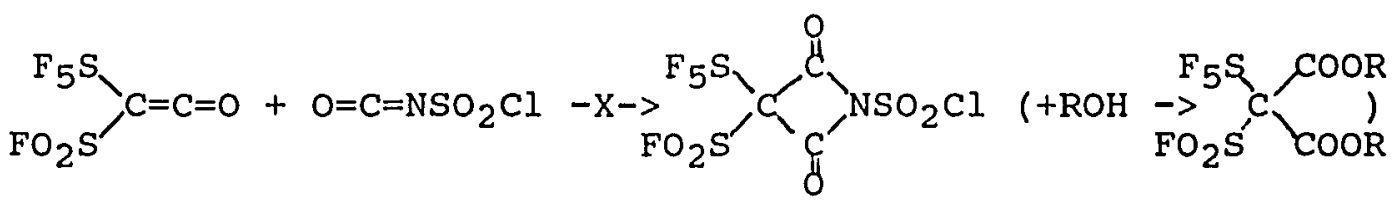


In these cases, the $\mathrm{SO}_{2} \mathrm{~F}$ group in the primary products should have been removable by heating with chloro or fluorosulfonic acid 40 .

It is quite clear that a functionality in position $\alpha$ to the $\mathrm{SF}_{5}$ group has to be introduced from the very beginning. To achieve this goal, several observations from different reactions were used. The adduct $\mathrm{F}_{5} \mathrm{SCH}_{2} \mathrm{CHClOC}(0) \mathrm{CH}_{3}$ is formed readily, but relatively slowly at elevated temperatures from vinyl acetate and pentafluorothio chloride 41 :

$$
\mathrm{F}_{5} \mathrm{SCl}+\mathrm{CH}_{2}=\mathrm{CHOC}(0) \mathrm{CH}_{3} \rightarrow \mathrm{F}_{5} \mathrm{SCH}_{2} \mathrm{CHClOC}(0) \mathrm{CH}_{3}(>80 \%)
$$

The analogous reaction with $S F_{5} B r$ is very difficult to control; only at low temperature $\left(<-110^{\circ} \mathrm{C}\right)$ in an inert solvent $\left(\mathrm{CCl}_{3} \mathrm{~F}\right)$ is the reaction controllable.

$$
\mathrm{F}_{5} \mathrm{SBr}+\mathrm{CH}_{2}=\mathrm{CHOC}(\mathrm{O}) \mathrm{CH}_{3}-->\mathrm{F}_{5} \mathrm{SCH}_{2} \mathrm{CHBrOC}(\mathrm{O}) \mathrm{CH}_{3}(\approx 50 \%)
$$

When the precautions of low temperature and high dilution are not observed, another product is formed which originates probably in BrF addition to the olefin; it was also not possible to run the reaction on a large scale. This product is of a very decomposable nature and could never be satisfactorily characterized, but it did not contain an $\mathrm{SF}_{5}$ group.

on the other hand, $S F_{5} \mathrm{Br}$ adds in a controlled fashion to ethyl acrylate: 


$$
\mathrm{F}_{5} \mathrm{SBr}+\mathrm{CH}_{2}=\mathrm{CHCOOC}_{2} \mathrm{H}_{5} \rightarrow \mathrm{F}_{5} \mathrm{SCH}_{2} \mathrm{CHBrCOOC}_{2} \mathrm{H}_{5}
$$

The product cannot be dehydrohalogenated, it loses instead "HSF 5 " as a pseudo halogen hydride, both with $\mathrm{N}, \mathrm{N}$-dimethyl aniline 42 and diazabicyclononane 43 :

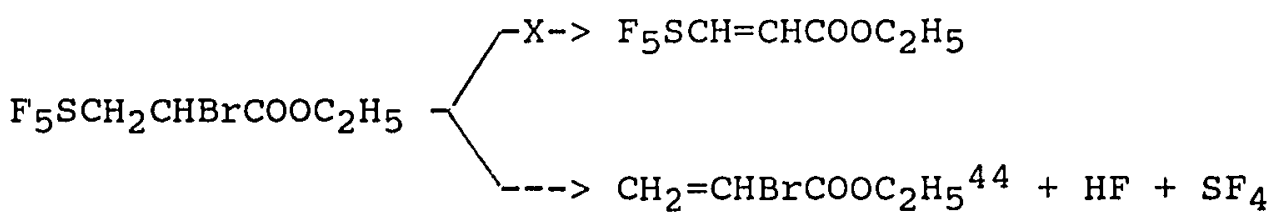

The $\mathrm{SF}_{4}$ can be detected in the n.m.r. spectrum. The result is not surprising, although unfortunate, as the hydrogen in 1-position should be the most acidic one in the molecule. The synthesis of $\beta-\mathrm{SF}_{5}$ acrylates has thus to be conducted by a more elaborate course.

A further important observation is that the adduct $\mathrm{F}_{5} \mathrm{SCH}_{2} \mathrm{CHClOC}(\mathrm{O}) \mathrm{CH}_{3}$ reacts with alcohols, completely analogousily to the compounds $\mathrm{JCH}_{2} \mathrm{CHClOC}(0) \mathrm{CH}_{3}$ and $\mathrm{BrCH}_{2} \mathrm{CHClOC}(\mathrm{O}) \mathrm{CH}_{3}$, to form acetals by setting the mixture aside 45 :

$$
\begin{array}{r}
\mathrm{F}_{5} \mathrm{SCH}_{2} \mathrm{CHClOC}(\mathrm{O}) \mathrm{CH}_{3}+\mathrm{ROH} \text { (exc, ) } \rightarrow \mathrm{F}_{5} \mathrm{SCH}_{2} \mathrm{CH}(\mathrm{OR})_{2}(70-80 \%) \\
\mathrm{R}=\mathrm{CH}_{3}, \mathrm{C}_{2} \mathrm{H}_{5}, \text { but not } \mathrm{CH}\left(\mathrm{CF}_{3}\right)_{2}+\mathrm{ROAC}+\mathrm{HCl}+\mathrm{H}_{2} \mathrm{O}
\end{array}
$$

These acetals can be oxidized by percarboxylic acid to a carboxylic acid 46 :

$$
\mathrm{F}_{5} \mathrm{SCH}_{2} \mathrm{CH}\left(\mathrm{OCH}_{3}\right)_{2}+\mathrm{m}-\mathrm{Cl}-\phi \mathrm{COOOH} \rightarrow \mathrm{F}_{5} \mathrm{SCH}_{2} \mathrm{COOCH}_{3}(60 \%)
$$

Esters of pentafluorosulfur acetic acid are mostly made by converting the acyl chloride, which is easily accessible 
from ketene $\left(\mathrm{H}_{2} \mathrm{C}=\mathrm{C}=\mathrm{O}\right)$ and alcohols.47 For small scale preparations the abovementioned alternative synthesis can be used which avoids the use of the noxious ketene.

The final oxidation of the acetal with m-chloro perbenzoic acid was done without addition of sulfuric acid, as recommended by Heywood and Phillips. During the reaction a precipitate was observed, that dissolved later again. This could have been the intermediate as suggested by Heywood and Phillips, a hemiacetal m-chloro-perbenzoate, but this point was not further followed.

If one combines all the above observations one recognizes the following pattern:

1. $\mathrm{SF}_{5} \mathrm{X}(\mathrm{X}=\mathrm{Br}, \mathrm{Cl})$ adds to vinyl acetate as well as to ethyl acrylate such that the $\mathrm{SF}_{5}$ group is attached at the terminal carbon. In the case of ethyl acrylate this is a site of reduced charge density, and in the case of vinyl acetate of increased charge density:

$$
\begin{aligned}
& \mathrm{H}_{2} \mathrm{C}=\underset{\mathrm{H}}{\mathrm{C}}-\mathrm{O}-\mathrm{C}(\mathrm{O}) \mathrm{CH}_{3} \leftrightarrow \rightarrow \mathrm{H}_{2} \mathrm{C}=\underset{\mathrm{H}}{\mathrm{C}}=\mathrm{O} \pm \mathrm{C}(\mathrm{O}) \mathrm{CH}_{3}, \\
& \mathrm{H}_{2} \mathrm{C}=\underset{\mathrm{H}}{\mathrm{C}}-\mathrm{C}-\mathrm{OC}_{2} \mathrm{H}_{5} \leftrightarrow->\mathrm{H}_{2}+\underset{\mathrm{H}}{\mathrm{C}}=\mathrm{COCH}_{3}
\end{aligned}
$$

The addition to vinyl acetate is much more efficient than the addition to ethyl acrylate as inferred from the almost uncontrollable reaction of the former with $\mathrm{SF}_{5} \mathrm{Br}$ and the comparatively mild reaction with the latter.

2. If the charge density is the dominating criterion for the addition then the addition of an electrophilic 
radical trans to an acetyl group should preponderate in the addition trans to a carboxylic ester group. This is also consistent with the transfer coefficients of bromo and chloro alkanes with different substrates. For example, vinyl acetate reacts almost 10000 times faster with $\mathrm{CCl}_{4}$ than methyl acrylate, which is attributed to the greater reactivity of the intermediate chain propagating radical.48 Bromo alkanes react even faster than chloro alkanes because of the weaker $\mathrm{C}-\mathrm{Hal}$ bond. As the $\mathrm{S}-\mathrm{Br}$ bond is weaker than the $\mathrm{S}-\mathrm{Cl}$ bond, this should be true for $\mathrm{SF}_{5} \mathrm{Br}$ additions, as compared to $\mathrm{SF}_{5} \mathrm{Cl}$ additions, too. This is observed experimentally.

3. Such an addition direction should be possible with $\beta-$ acetyl acrylic ester.

4. The adduct thus obtained should be convertible to an acetal and thence to an ester, or to an aldehydeester, as with the adduct $\mathrm{F}_{5} \mathrm{SCH}_{2} \mathrm{CHClOC}(0) \mathrm{CH}_{3}$ :

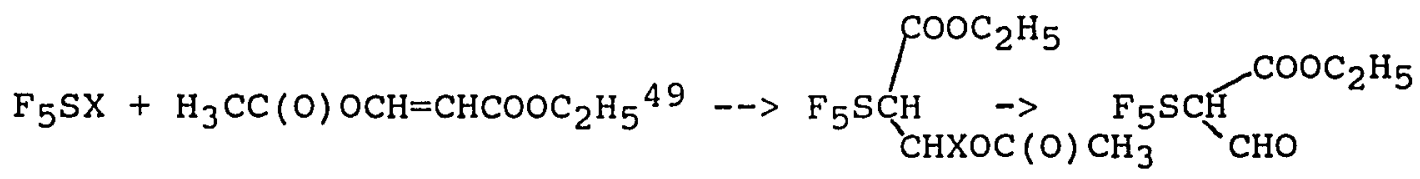

$$
\begin{aligned}
& \rightarrow \mathrm{F}_{5} \mathrm{SCH} \overbrace{\mathrm{CH}(\mathrm{OR})_{2}}^{\mathrm{COOC}_{2} \mathrm{H}_{5}} \\
& \rightarrow \mathrm{F}_{5} \mathrm{SCP} \underset{\mathrm{COOR}}{\mathrm{COOC}_{2} \mathrm{H}_{5}}
\end{aligned}
$$

The aldehyde-ester should be reducible to an alcohol and thence convertible to an acrylic acid: 


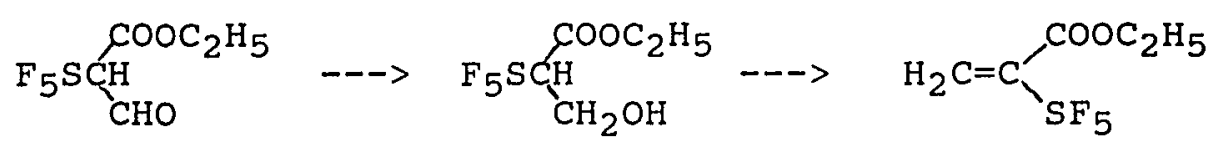

This acid would be equivalent to the compound $\mathrm{H}_{2}=\mathrm{C}-\mathrm{COOH}$

that was used to synthesize a number of $5-\mathrm{CF}_{3}-$ uracils.

It was found that $\mathrm{SF}_{5} \mathrm{Cl}$ was completely unreactive towards $\beta$-acetylacrylacetate in $\mathrm{CCl}_{3} \mathrm{~F}$; without the solvent decomposition occurred of both the olefin and the $\mathrm{SF}_{5} \mathrm{Cl}$. $\mathrm{SF}_{5} \mathrm{Br}$ decomposed in a thermal reaction in the same fashion with and without solvent, but when the reaction was done in a glass bomb in the laboratory light, or better, with the irradiation of a sunlamp, $\mathrm{SF}_{5} \mathrm{Br}$ addition could be indeed observed. No addition was observed when the glass bomb was kept in the dark. By-product formation could be decreased when the irradiation was done in an ice-bath, such that only the upper part of the bomb was exposed to light, while the lower part was in the cold-bath and the solution was stirred. The product that was obtained, a colorless highboiling oil, was very unstable and decomposed within days at room temperature but was stable in the refrigerator. That the product is a a secondary $\mathrm{SF}_{5}$ compound was deduced from its ${ }^{19} \mathrm{~F}$ n.m.r spectrum, which showed the $\mathrm{SF}_{5}$ resonance at $\approx$ $70 \mathrm{ppm}\left(\phi_{\mathrm{B}}\right)$ and $80 \mathrm{ppm}\left(\phi_{\mathrm{A}}\right)$. There was a second (minor) product with $\phi_{\mathrm{B}}$ at $52 \mathrm{ppm}$. The observation is made that electronegative substituents at the $\mathrm{SF}_{5}$ carbon lead to an upfield shift of the $\mathrm{SF}_{5}$ resonance (e.g. with the epoxides 
$\mathrm{F}_{5} \mathrm{SCFCF} \mathrm{CF}_{2}$ and $\mathrm{F}_{5} \mathrm{~S} \widehat{\mathrm{CHCF}_{2} \mathrm{O}}$, as compared to their starting olefines), so that the product with $\phi_{\mathrm{B}}=52 \mathrm{ppm}$ is probably $\mathrm{F}_{5} \mathrm{SCH}(\mathrm{OAC}) \mathrm{CHBrCOOC}_{2} \mathrm{H}_{5}$. The product could be purified by distillatin. The infrared spectrum is also supportive of the assumed structure of the chief product $\mathrm{F}_{5} \mathrm{SCHCOOC}_{2} \mathrm{H}_{5}$ (CHBrOAC). Two $\mathrm{C}=0$ bands were present, one of them $\left(1783 \mathrm{~cm}^{-1}\right)$ similar to the compounds $\mathrm{F}_{5} \mathrm{SCH}_{2} \mathrm{CH}(\mathrm{Cl}, \mathrm{Br}) \mathrm{OAC}$ (1778 $\left.\mathrm{cm}^{-1}\right)$, and the other at $1754 \mathrm{~cm}^{-1}$, similar to $\mathrm{F}_{5} \mathrm{SCH}_{2} \mathrm{COOCH}_{3}\left(1757 \mathrm{~cm}^{-1}\right)$. For subsequent reactions the impure material was used. It was found that the material reacted in a very intricate manner with alcohols. When ethanol was added to it in excess the reaction, as followed by ${ }^{19} \mathrm{~F}$ n.m.r. spectroscopy, displayed the disappearance and appearance of several $\mathrm{SF}_{5}$ compounds, with the formation of two major product after several days. The infrared spectrum showed the disappearance of the band at $1783 \mathrm{~cm}^{-1}$, corresponding to the loss of the acetyl group. Distillation of the material resulted in decomposition and the formation of at least four new $\mathrm{SF}_{5}$ compounds. Attempts to separate them by preparative gas chromatography were unsuccessful.

Attempts to induce reduction of the $\mathrm{SF}_{5} \mathrm{Br}$ adduct with $\mathrm{NaBH}_{4}$ were unsuccessful, treatment with aqueous $\mathrm{HCl}$ led to decomposition (this should have resulted in the formation of an aldehyde, analogously to $\mathrm{F}_{5} \mathrm{SCH}_{2} \mathrm{CHClOAC}$ ), but treatment with an excess of gaseous $\mathrm{HCl}$ led to mainly one product, but it could again not be separated. 
Although with this reaction one important problem was solved, namely the synthesis of a secondary SF 5 -compound, the subsequent screening reactions gave a disappointing result. This behavior is not understood at this point. It cannot be ruled out that the probably severe sterical crowding prevents effective acetal formation.

This work was stopped at this point. 


\section{CHAPTER IV}

THE X-RAY STRUCTURE OF $\left(\mathrm{F}_{5} \mathrm{SCH}_{2} \mathrm{CHO}\right)_{3}$

The mass spectrum of this aldehyde oligomer did not show a molecular ion signal, even at ionization potentials as low as $15 \mathrm{eV}$. The highest mass was seen at $\mathrm{m} / \mathrm{e}=341$ $\left(\left(\mathrm{F}_{5} \mathrm{SCH}_{2} \mathrm{CHO}\right)_{2} \mathrm{H}^{+}\right)$, which could have originated in a dimer. It was thus of interest to determine the actual structure. To determine the molecular weight would have answered the question of the structure (dimer or trimer) also, but it seemed important to have more structural information in order to build up a reference file for $S_{5}$ compounds, as this is a developing field of chemistry, with little information available from the literature.

The crystal structure of $\left(\mathrm{SF}_{5} \mathrm{CH}_{2} \mathrm{CHO}\right)_{3}$ consists of trimeric units with threefold symmetry in which the trioxane ring is situated in a chair-type condormation. The $\mathrm{SF}_{5} \mathrm{CH}_{2}$ groups lie in an equitorial position. A similar chair-type conformation has been found for $\alpha$ - and $\beta$-parabutylchloral, $\left(\mathrm{CH}_{3} \mathrm{CHClCCl}_{2} \mathrm{CHO}\right)_{3}$, in which the 1,1,2-trichloropropyl groups are located in a cis, cis arrangement; all $\mathrm{CH}_{3} \mathrm{CHClCCl}_{2}$-groups are in the equatorial positions 50 .

In $\alpha-\left(\mathrm{CH}_{3} \mathrm{CHClCCl}_{2} \mathrm{CHO}\right)_{3}$, the $\mathrm{C}-\mathrm{O}$ bond- lengths vary from $1.396(7) \AA$ to $1.425(8) \AA$ and the $\mathrm{C}-\mathrm{O}-\mathrm{C}$ and $\mathrm{O}-\mathrm{C}-\mathrm{O}$ bond 
angles for the ring are $109.9(5)^{\circ}$ to $110.1(5)^{\circ}$ and $109.6(5)^{\circ}$ to $110.5(5)^{\circ}$, respectively. In $\left(\mathrm{SF}_{5} \mathrm{CH}_{2} \mathrm{CHO}\right)_{3}$ a larger alternation of $\mathrm{C}-\mathrm{O}$ bond-lenghts of $1.435 \AA$ and $1.387 \AA$ is found with $C-O-C$ and $O-C-O$ bond angles of $109.6^{\circ}$ and $110.4^{\circ}$, respectively. This alternation must be due to the steric influence of the $\mathrm{CH}_{2} \mathrm{SF}_{5}$ groups which are rotated about the $\mathrm{C}-\mathrm{C}$ bonds so as to lie closer to the oxygen atom involved in the longer $\mathrm{C}-\mathrm{O}$ bond.

There is no evidence for isomerism as is reported for other trioxane compounds, e.g., in parachloral an $\alpha$-form and a $\beta$-form exist 51 .

The $\alpha$-form is derived from the cis-trans isomerism of the $\mathrm{CCl}_{3}$ substituents. The $\alpha$-trans-isomer assumes a tub conformation, apparently stabilized by an intramolecular hydrogen bond. The $\beta$-form, or all-cis isomer, has a twisted chair conformation.

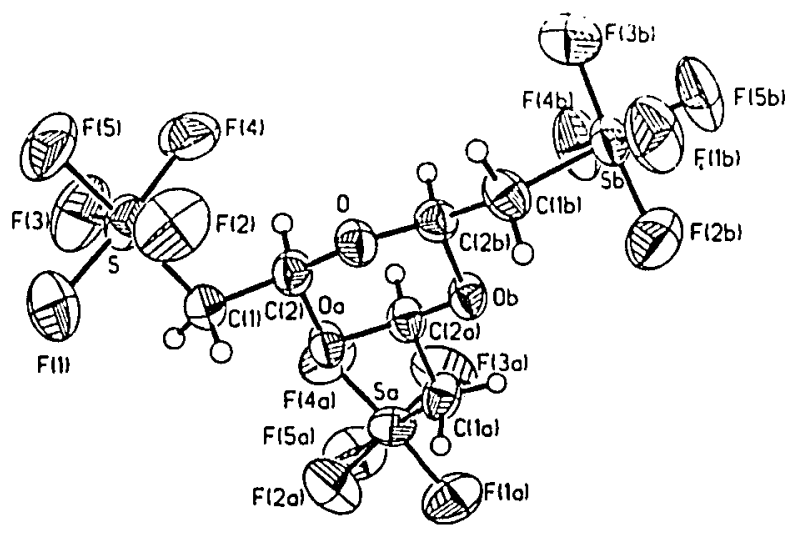

Figure 7. X-ray stereographic view of $\left(\mathrm{F}_{5} \mathrm{SCH}_{2} \mathrm{CHO}\right)_{3}$ 
TABLE VII

NON-HYDROGEN BOND LENGTHS [pm] AND ANGLES [ ${ }^{\circ}$ ] FOR $\left(\mathrm{SF}_{5} \mathrm{CH}_{2} \mathrm{CHO}\right)_{3}$. STANDARD DEVIATIONS IN PARENTHESES

\begin{tabular}{lrlr}
\hline$S-C(1)$ & $179.8(6)$ & $S-F 5)$ & $157.4(6)$ \\
$S-F(1)$ & $158.1(3)$ & $O-C(2)$ & $143.5(4)$ \\
$S-F(2)$ & $156.2(4)$ & $C(1)-C(2)$ & $151.0(6)$ \\
$S-F(3)$ & $155.2(4)$ & $C(2)-O(A)$ & $138.7(6)$ \\
$S-F(4)$ & $157.3(3)$ & & \\
$C(1)-S-F(1)$ & $89.6(2)$ & $C(1)-S-F(5)$ & $177.3(2)$ \\
$C(1)-S-F(2)$ & $92.0(3)$ & $F(1)-S-F(5)$ & $87.8(2)$ \\
$F(1)-S-F(2)$ & $90.4(2)$ & $F(2)-S-F(5)$ & $88.5(3)$ \\
$C(1)-S-F(3)$ & $92.3(3)$ & $F(3)-S-F(5)$ & $87.2(3)$ \\
$F(1)-S-F(3)$ & $90.3(2)$ & $F(4)-S-F(5)$ & $87.4(2)$ \\
$F(2)-S-F(3)$ & $175.7(3)$ & $C(2)-O-C(2 A)$ & $109.6(4)$ \\
$C(1)-S-F(4)$ & $95.2(2)$ & $S-C(1)-C(2)$ & $118.1(3)$ \\
$F(1)-S-F(4)$ & $175.3(3)$ & $O-C(2)-C(1)$ & $108.8(4)$ \\
$F(2)-S-F(4)$ & $89.4(2)$ & $O-C(2)-O(A)$ & $110.4(4)$ \\
$F(3)-S-F(4)$ & $89.6(2)$ & $C(1)-C(2)-O(A)$ & $105.8(3)$
\end{tabular}


CHAPTER V

CONCLUSION

Neither pentafluorosulfur malonic ester nor $\alpha$ - or $\beta-$ $\mathrm{SF}_{5}$ acrylic ester were obtained. It was, however, possible to devise a method for the synthesis of $\mathrm{SF}_{5}$-acetaldehyde acetals (from 1-chloro-1-acetoxy-2-pentafluorothio ethane) and their conversion to esters, and the synthesis of a secondary $\mathrm{SF}_{5}$ compound, $\mathrm{F}_{5} \mathrm{SCH}\left(\mathrm{COOC}_{2} \mathrm{H}_{5}\right) \mathrm{CHBrOCOCH}_{3}$, which should have been convertible, in analogy to the abovementioned procedure, to an acetal, $\mathrm{F}_{5} \mathrm{SCH}\left(\mathrm{COOC}_{2} \mathrm{H}_{5}\right) \mathrm{CH}\left(\mathrm{O}_{2} \mathrm{H}_{5}\right)_{2}$ and thence to an ester, $\mathrm{F}_{5} \mathrm{SCH}\left(\mathrm{COOC}_{2} \mathrm{H}_{5}\right)_{2}$. The chemical behavior of this system is not understood. A new method for the synthesis of pentafluorothio acetaldehyde was also found. 
PART IV

EXPERIMENTAL PART 


\section{CHAPTER I}

\section{GENERAL METHODS}

Volatile materials were handled in conventional Pyrexglass vacuum lines, equipped with either mercury manometers or Heise-Bourdon tube gauges and a Televac vacuum gauge. $1 \mathrm{H}$ and ${ }^{19} \mathrm{~F}$ n.m.r. spectra were usually run at $90\left({ }^{1} \mathrm{H}\right)$ and $84.67\left({ }^{19} \mathrm{~F}\right) \mathrm{MHz}$ on a Varian EM-390 spectrometer, otherwise they were run on a General Electric QE-300 spectrometer at $300\left({ }^{1} \mathrm{H}\right)$ and $75\left({ }^{13} \mathrm{C}\right) \mathrm{MHz}$, or on a Bruker AMX-400 spectrometer $\left({ }^{19} \mathrm{~F}\right.$ at $376 \mathrm{MHz},{ }^{13} \mathrm{C}$ at $100.6 \mathrm{MHz},{ }^{1} \mathrm{H}$ at 400.6 MHz). The following abbreviations are used to indicate splitting patterns: $s=$ singlet; $d$ = doublet; $t=$ triplet; $q$ = quartet; $\mathrm{p}=$ pentet, quintet; $\mathrm{m}=$ multiplet. Infrared spectra were obtained from neat samples between $\mathrm{KBr}$ or $\mathrm{NaCl}$ plates on a Nicolet DX-20 spectrometer.

Band intensities are indicated by the following: vs $=$ very strong; $s=$ strong; $m$ = medium; $w=$ weak; $v w=$ very weak, $b r$ $=$ broad, $\mathrm{sh}=$ shoulder. The band positions are always given in $1 / \mathrm{cm}$. The mass spectra were obtained on a VG 7070 mass spectrometer under the conditions indicated with each compound. In the mass spectra of bromine or chlorine compounds the masses of fragments of only one isotope are listed, i.e., for ${ }^{35} \mathrm{Cl}$ and ${ }^{79} \mathrm{Br}$. The mode of ionization is 
indicated by the following short-hands: e.i. = electron impact; c.i. = chemical ionization; n.i. = negative ion. Acetonitrile was distilled from phosphorous pentoxide; other solvents were used without further treatment. Chemicals that were used in standard reactions were obtained from ozarkMahoning-Pennwalt $\left(\mathrm{BrF}_{3}, \mathrm{SF}_{4}\right)$, Aldrich or Peninsula Chemical Research Corporation (PCR) (CsF, $\mathrm{C}_{2} \mathrm{HF}_{3}, \mathrm{CH}_{2} \mathrm{CF}_{2}$ ), $\mathrm{NaF}$ (Baker), Mallinckrodt $\left(\mathrm{CH}_{3} \mathrm{OH}, \mathrm{C}_{2} \mathrm{H}_{5} \mathrm{OH}\right)$. The sources of other chemicals will be named in the respective preparations where they were used. $\mathrm{F}_{5} \mathrm{SCHCF}_{2} \mathrm{OSO}_{2}$ was prepared as described.

Elemental analyses were carried out by Mikroanalytisches Laboratorium Beller, Göttingen, Federal Republic of Germany. 
PREPARATIONS AND REACTIONS

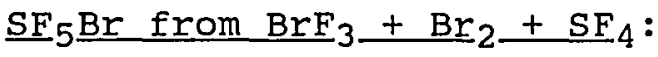

In a typical experiment, a $150 \mathrm{ml}$ stainless steel bomb was charged with CSF (7.53 g, $49.2 \mathrm{mmol}$ ) and dried (15 hours, $100-110^{\circ} \mathrm{C}$, high vacuum). Bromine trifluoride (29.72 g, 217 mmol) was added by vacuum transfer, then bromine $(34.4 \mathrm{~g}, 215 \mathrm{mmol})$, and lastly $\mathrm{SF}_{4}(48.71 \mathrm{~g}, 451 \mathrm{mmol}$ equals $70 \%$ of theory, in two portions, $1.32 .42 \mathrm{~g}$, then $16.28 \mathrm{~g}$ ); the bomb was allowed to attain room temperature in an automatic shaker between the two additions. shaking was continued for $289 \mathrm{~h}$ at room temperature, and $74.5 \mathrm{~g}$ of crude $\mathrm{SF}_{5} \mathrm{Br}$ were transferred out from the bomb (at $-78^{\circ} \mathrm{C}$ ) during 4 hours $(56.8 \%)$. Major by-products were $\mathrm{SF}_{6}$ and unreacted $\mathrm{SF}_{4}$. This crude material was used without further purification and reacted with acetylene to the adduct $\mathrm{F}_{5} \mathrm{SCH}=\mathrm{CHBr} \quad(57 \%$ yield after distillation). Similar reactions were conducted with other olefins, and yields ranging from $39-69 \%$ were realized:

$\begin{array}{lll}\text { Olefin } & \text { Adduct } & \text { yield (\%) } \\ \mathrm{CHF}=\mathrm{CF}_{2} & \mathrm{~F}_{5} \mathrm{SCHFCF}_{2} \mathrm{FBr} & 38.6-57.8 \\ \mathrm{CH}_{2}=\mathrm{CF}_{2} & \mathrm{~F}_{5} \mathrm{SCH}_{2} \mathrm{CF}_{2} \mathrm{Br} & 69.5 \\ \mathrm{HC} \equiv \mathrm{CH} & \mathrm{F}_{5} \mathrm{SCH}=\mathrm{CHBr} & 45.5-61.6\end{array}$


$\mathrm{CH}_{2}=\mathrm{CH}_{2} \quad \mathrm{~F}_{5} \mathrm{SCH}_{2} \mathrm{CH}_{2} \mathrm{Br} \quad 35$

Although only small amounts of bromine transfer at $-78^{\circ} \mathrm{C}$, its olefin adducts might interfere later. However, it was easily removed by shaking the crude $\mathrm{SF}_{5} \mathrm{Br}$ with mercury (10$15 \mathrm{~g}$ for $70 \mathrm{~g}$ of crude $\mathrm{SF}_{5} \mathrm{Br}$; the mercury may be used several times). It was also found that using more CsF (up to 50 mol\% with respect to $\mathrm{BrF}_{3}$ ) did not raise the yield of $\mathrm{SF}_{5} \mathrm{Br}$. Shaking was generally not extended beyond 2 weeks. When a vessel had been used several times, yields dropped. It was also found that there were still substantial quantities of $\mathrm{SF}_{5} \mathrm{Br}$ left, even when a transfer had lasted for several hours at $-78^{\circ} \mathrm{C}$. Up to $20 \mathrm{~g}$ of $\mathrm{SF}_{5} \mathrm{Br}$ that contained almost no $\mathrm{SF}_{4}$ and $\mathrm{SF}_{6}$ could be collected from bombs with a similar charge as described above, by prolonged transfer (up to $10 \mathrm{~h}$ ) at $-78^{\circ} \mathrm{C}$, after thawing and recooling. It was later found that quantities of up to $56 \mathrm{~g}$ of $\mathrm{SF}_{4}$ could be transferred at once into the $150 \mathrm{ml}$ bombs containing the $\mathrm{BrF}_{3}+\mathrm{Br}_{2}$ mixture, without any incident. Larger quantities were not tried.

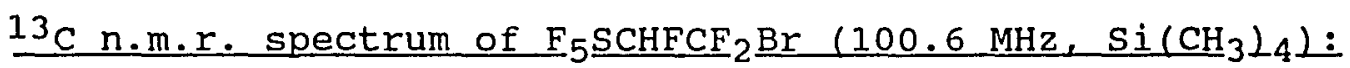

$\mathrm{A} \mathrm{CDCl}_{3}$ solution, $\approx 50 \%$ in the $\mathrm{SF}_{5}$ compound was used. The spectrum is ${ }^{l_{H}}$ decoupled. $F^{A_{F}}{ }_{4}{ }^{B} C_{\alpha} \mathrm{HF}_{\alpha} C_{\beta} F_{\beta}{ }^{1} F_{\beta}{ }^{2} \mathrm{Br}: \delta_{\alpha}=$ $108.15 \mathrm{ppm}, d-d-d-p . \delta_{\beta}=114.87 \mathrm{ppm}, d-d-d . J_{C} \mathrm{~F} \alpha=249.0$

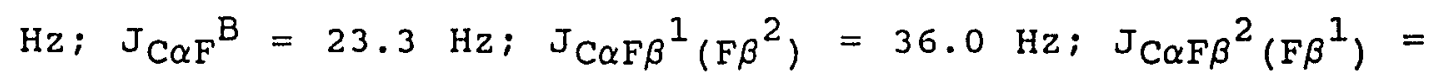

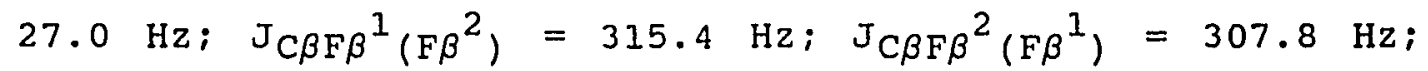


$J_{\mathrm{C} \beta \mathrm{F} \alpha}=30.2 \mathrm{~Hz}$.

$\underline{F}_{5} \underline{S C H}=\mathrm{CF}_{2}$

To an aqueous potassium hydroxide solution $(81.5 \mathrm{~g}$,

$42.5 \%$ by weight $\mathrm{KOH}$ ) in a $100 \mathrm{~mL}$ Pyrex-glass round bottomed flask, equipped with a magnetic stirring bar, $\mathrm{F}_{5} \mathrm{SCH}_{2} \mathrm{CF}_{2} \mathrm{Br}$ (33.70 g, $124.4 \mathrm{mmol}$ ) was added at room temperature. A $20-\mathrm{cm}$ reflux condenser that was connected to a cold trap $\left(-78^{\circ} \mathrm{C}\right)$ was then attached to the reaction vessel.The mixture was slowly heated with vigorous stirring to a temperature of $100^{\circ} \mathrm{C}$, and warm water $\left(40^{\circ} \mathrm{C}\right)^{\circ}$ was passed through the condenser; after the disappearance of the bottom layer in the reaction flask (30 $\mathrm{min})$, heating was maintained for another 3 hours. The product was collected in the cold trap (22.90g, $120.5 \mathrm{mmol}, 96.9 \%$ yield). A gas chromatogram (Carbowax, $20 \%$ on Chromosorb W, $100^{\circ} \mathrm{C}$ ) showed only one product to be present; the i.r. spectrum agreed with the literature values, except that for the latter several other lines (weak) are reported, indicating that the present product is purer.

$\left.\underline{\mathrm{F}}_{5} \mathrm{SCH}_{\left(\mathrm{SO}_{2}\right.} \mathrm{F}\right) \mathrm{COOCH}\left(\mathrm{CH}_{3} \perp_{2}(2 \mathrm{la}):\right.$

To a $100 \mathrm{ml}$ Pyrex-glass reaction vessel, equipped with a Teflon stir bar and a Kontes Teflon valve, and containing dry sodium fluoride $(30.08 \mathrm{~g}, 716.2 \mathrm{mmols})$, isopropanol (10.13g, $168.8 \mathrm{mmol})$ was added by vacuum condensation. The 
sultone $\mathrm{F}_{5} \mathrm{SCHCF}_{2} \mathrm{OSO}_{2}$ was then added in three portions $(12.37 \mathrm{~g}, 45.8 \mathrm{mmol} ; 8.70 \mathrm{~g}, 32.20 \mathrm{mmol} ; 15.91 \mathrm{~g}, 58.9 \mathrm{mmol})$ at $-196{ }^{\circ} \mathrm{C}$, with the vessel being warmed to room temperature after each addition and stirred for a few minutes. For each addition slight warming was noticed when room temperature was reached. After addition was complete, the mixture was stirred at $52^{\circ} \mathrm{C}$ for $15 \mathrm{~h}$ and at $68^{\circ} \mathrm{C}$ for $0.5 \mathrm{~h}$. The crude product was condensed (41.29g) and distillation gave $31.12 \mathrm{~g}$ (100.5 mol) of a colorless oily liquid with an unpleasant odor; yield $=73.3 \% ;$ b.p. $92-94^{\circ} \mathrm{C}(26-28)$ torr.

Infrared spectrum (neat sample, $\mathrm{KBr}, \mathrm{cm}^{-1}$ ): 2995, $\mathrm{m}$; 2952, w, sh; 1761, s; 1443, s; 1395, vw; 1382, w; 1352, vw; 1296, $\mathrm{m} ;$ 1276, $\mathrm{m} ;$ 1221, $\mathrm{w} ;$ 1168, vw; 1102, m-s; 981, vw; 875, vs, sh at $900 ; 837, w-m ; 819, w-m ; 801, w-m ; 781, w$; 769, w; 733, vw; 688, vw; 650, vw; 612, w; 572, s; 491, vw; 458, vw.

${ }^{19} \mathrm{~F}$ n.m.r. spectrum (neat sample, external $\mathrm{CCl}_{3} \mathrm{~F}$ ): multiplet, centered at $\phi=70.9 \mathrm{ppm}$, area $=5.0\left(\mathrm{SF}_{5}\right)$; multiplet at $\phi=58.8 \mathrm{ppm}$, area $=1.0\left(\mathrm{SO}_{2} \mathrm{~F}\right)$.

$I_{\mathrm{H}}$ n.m.r. spectrum (neat sample, $\mathrm{Si}\left(\mathrm{CH}_{3}\right)$ ext.): multiplet, $\delta=6.4 \mathrm{ppm}$, area $=1.0\left(\mathrm{~F}_{5} \mathrm{SC}-\underline{\mathrm{H}}\right)$; septet, $\delta=5.4$ ppm, area $=1.1,\left(0-\mathrm{CH}\left(\mathrm{CH}_{3}\right)_{2}\right) ;$ doublet, $\delta=1.5 \mathrm{ppm}$, area $=$ $6.2,\left(\mathrm{O}-\mathrm{CH}\left(\mathrm{CH}_{3}\right)_{2}\right), \mathrm{J}_{\mathrm{H}-\mathrm{H}}=6.22 \mathrm{~Hz}$.

Mass spectrum (c.i., m/e, species, \%): $311,(\mathrm{M}+\mathrm{H})^{+}$, $0.32 ; 269,(\mathrm{M}-3 \mathrm{H}-2 \mathrm{~F})^{+}, 4 ; 205,\left(\mathrm{M}+\mathrm{H}-\left(\mathrm{CH}_{3}\right)_{2} \mathrm{CHCOO}-\mathrm{F}\right)^{+}, 7.5$; 143, $\mathrm{C}_{2} \mathrm{HF}_{2} \mathrm{OS}_{2}{ }^{+}, 14.8 ; 127, \mathrm{SF}_{5}{ }^{+}, \mathrm{FSCSO}_{2}{ }^{+}, 20.5 ; 125$, $\mathrm{C}_{2} \mathrm{H}_{2} \mathrm{FO}_{3} \mathrm{~S}^{+}, 8.4 ; 99, \mathrm{C}_{4} \mathrm{H}_{3} \mathrm{SO}^{+}, 9.2 ; 91, \mathrm{C}_{2} \mathrm{FOS}^{+}, 4.2 ; 89, \mathrm{SF}_{3}^{+}$, 
$100 ; 79, \mathrm{FSCO}^{+}, 4.1 ; 70, \mathrm{SF}_{2}{ }^{+}, 10.8 ; 67, \mathrm{FSO}^{+}, 24.6 ; 65$, $\mathrm{CH}_{2} \mathrm{FS}^{+}, 19 ; 59, \mathrm{C}_{3} \mathrm{H}_{7} \mathrm{O}^{+}, 55.8 ; 58, \mathrm{C}_{3} \mathrm{H}_{6} \mathrm{O}_{+}, 5.5 ; 55, \mathrm{C}_{3} \mathrm{H}_{3} \mathrm{O}^{+}$, 4.8 .

Anal. Calcd for $\mathrm{C}_{5} \mathrm{H}_{8} \mathrm{~F}_{6} \mathrm{O}_{4} \mathrm{~S}_{2}: \mathrm{C}$, 19.36; $\mathrm{H}, 2.60 ; \mathrm{F}$, $36.8 ; \mathrm{S}, 20.67$. Found: C, 19.27; H, 2.55; F, 37.1; S, 20.82.

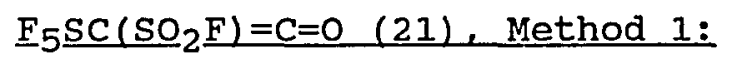

In a representative experiment, $\mathrm{F}_{5} \mathrm{SCH}\left(\mathrm{SO}_{2} \mathrm{~F}\right) \mathrm{COOCH}\left(\mathrm{CH}_{3}\right)_{2}$ $\left(2.65 \mathrm{~g}, 8.55 \mathrm{mmol}\right.$ ) was mixed with powdered $\mathrm{P}_{4} \mathrm{O}_{10}$ (Baker, $8.85 \mathrm{~g}, 31.1 \mathrm{mmol})$ in a $100 \mathrm{~mL}$ Pyrex-glass round bottomed flask. The flask was connected to a short vacuum-transfer line, with a $10 \mathrm{~mL}$ receiving flask that was cooled to

$-196^{\circ} \mathrm{C}$. The pressure was lowered to 500 torr and the mixture was heated to $100^{\circ} \mathrm{C}(10 \mathrm{~min})$. The reaction flask was cooled to $-196^{\circ} \mathrm{C}$, evacuated, and reheated $\left(100^{\circ} \mathrm{C}\right)$. In $30 \mathrm{~min}$

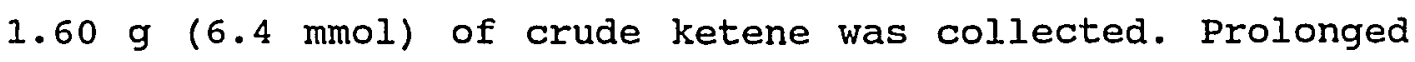
heating led to transfer of unreacted ester $10.34 \mathrm{~g}, 1.1$ mol). Yield: $85.9 \%$ (with respect to recovered ester). In similar experiments, the yields varied from 49 to 89 per cent.In this fashion, $4.92 \mathrm{~g}$ of crude ketene 21 was obtained from $9.35 \mathrm{~g}$ ( $30.16 \mathrm{mmol})$ of ester. Distillation (125-128 torr, $\left.(54-56)^{\circ} \mathrm{C}\right)$ gave $4.09 \mathrm{~g}(16.36 \mathrm{mmol})$ of pure ketene 21 in $54.2 \%$ overall yield.

${ }^{19} \mathrm{~F}$ n.m.r. spectrum $\left(\mathrm{CDCl}_{3}, \mathrm{CCl}_{3} \mathrm{~F}\right.$ ext., $\mathrm{AB}_{4} \mathrm{X}$ spectrum): $\phi_{\mathrm{A}}=73.1 \mathrm{ppm}$, (nine lines), area $=1.0 ; \phi_{\mathrm{B}}=$ $86.7 \mathrm{ppm},(\mathrm{d}-\mathrm{m})$, area $=3.9 ; \phi_{\mathrm{X}}=76.3 \mathrm{ppm},\left(\mathrm{SO}_{2} \mathrm{~F}\right)$, pentet, 
area $=1.0 ; \mathrm{J}_{\mathrm{AB}}=155 \mathrm{~Hz}, \mathrm{~J}_{\mathrm{BX}}=6.8 \mathrm{~Hz}$.

${ }^{13} \mathrm{C}$ n.m.r.spectrum $\left(100.6 \mathrm{MHz}, \mathrm{CDCl}_{3}, \mathrm{Si}\left(\mathrm{CH}_{3}\right)_{4}\right): \delta_{1}=$ $86.28 \mathrm{ppm}, \mathrm{d}-\mathrm{p},\left(\mathrm{F}_{5} \mathrm{SC}\right) ; \delta_{2}=174.81 \mathrm{ppm}, \approx$ pentet (illresolved, $\mathrm{CO}) ; \mathrm{J}_{1 \mathrm{X}}=39.70 \mathrm{~Hz}\left(\mathrm{X}=\mathrm{SO}_{2} \mathrm{~F}\right) ; \mathrm{J}_{2 \mathrm{~B}}=32.46 \mathrm{~Hz}$; $\mathrm{J}_{2 \mathrm{~B}} \approx 3.3 \mathrm{~Hz}$.

Infrared spectrum (neat sample, $\mathrm{KBr}, \mathrm{cm}^{-1}$ ): 2193(vs), 1445 (vs), $1305(\mathrm{~m}), 1214$ (vs)，1025(vs)，875(vs)，845(s,sh), $801(\mathrm{~s}), 689(\mathrm{~m}), 635(\mathrm{~m}), 618(\mathrm{~m}), \quad 590(\mathrm{~m}), \quad 520(\mathrm{w}), \quad 470(\mathrm{w})$, $432(\mathrm{VW})$.

Mass spectrum (electron impact, m/e, species, \%): 250, $\mathrm{M}^{+}\left({ }^{32} \mathrm{~S}\right), 16.4 ; 231,(\mathrm{M}-\mathrm{F})^{+}, 3.2 ; 129,\left(\mathrm{M}-\mathrm{SO}_{2} \mathrm{~F}_{3}\right)^{+}, 5.3 ; 1^{27}$, $\mathrm{SF}_{5}{ }^{+}, \mathrm{FSCSO}_{2}+, 94.7 ; 91, \mathrm{C}_{2} \mathrm{FOS}^{+}, 6.4 ; 89, \mathrm{SF}_{3}^{+}, 100 ; 72$, $\mathrm{C}_{2} \mathrm{OS}^{+}, 1.9 ; 70, \mathrm{SF}_{2}^{+}, 11.6 ; 67, \mathrm{FSO}^{+}, 25.2 ; 63, \mathrm{CFS}^{+}, 7.1$. Anal. calcd: for $\mathrm{C}_{2} \mathrm{~F}_{6} \mathrm{O}_{3} \mathrm{~S}_{2}: \mathrm{C}, 9.60 ; \mathrm{F}, 45.6 ; \mathrm{S}$, 25.63. Found: C, 9.86; F, 45.4; S, 25.82.

NaF catalyzed rearrangement of $\mathrm{F}_{5} \underline{\mathrm{SCHCF}}_{2} \underline{\mathrm{OSO}}_{2}:$

In a dry 100mL Pyrex-glass flask, equipped with a Kontes Teflon valve and a stirrring bar, NaF (5.30 g, 126.2 mmol) was dried and the sultone $\mathrm{F}_{4} \mathrm{SCHCF}_{2} \mathrm{OSO}_{2}(14.99 \mathrm{~g}, 44.4$ mmol) was added. The mixture was stirred at $(83-85)^{\circ} \mathrm{C}$ for 4 days. Vacuum transfer afforded $14.15 \mathrm{~g}$ of a mixture which consisted ( ${ }^{19} \mathrm{~F}$ n.m.r.) solely of a $14: 86$ (\%) mixture of ketene $21, \mathrm{~F}_{5} \mathrm{SC}\left(\mathrm{SO}_{2} \mathrm{~F}\right) \mathrm{CO}$, and the acyl fluoride $\mathrm{F}_{5} \mathrm{SCH}\left(\mathrm{SO}_{2} \mathrm{~F}\right) \mathrm{COF} \underline{22}$ (yield $\approx 95 \%$ ). It was later found that using an excess of finely ground NaF speeds up the 
rearrangement considerably. In this case much of the contents of the flask solidify, and it is possible to transfer out from the heated reaction vessel mixtures with much higher ketene contents $(>80 \%)$, but 21 could never be obtained pure by this method.

$\underline{\mathrm{F}}_{5} \mathrm{SC}_{\mathrm{SO}} \mathrm{SHCO}_{2}(21)$, Method 2:

To $5.00 \mathrm{~g}$ of the 14:86 (\%) mixture of ketene $\underline{21}$ and acyl fluoride $\underline{22}$, as obtained from the NaF-catalyzed rearrangement of the sultone $\mathrm{F}_{5} \mathrm{SCHCF}_{2} \mathrm{OSO}_{2}$ (1), in a $25 \mathrm{ml}$ Pyrex-glass round bottomed flask, equipped with a stirring bar, the base $\mathrm{BF}_{3} \cdot \mathrm{N}\left(\mathrm{C}_{2} \mathrm{H}_{5}\right)_{3}(\underline{18}, 3.17 \mathrm{~g}, 18.8 \mathrm{mmol})$ was added. The flask was attached to a vacuum-transfer line, with a 10 $\mathrm{mL}$ receiving flask that was cooled to $-196^{\circ} \mathrm{C}$. The pressure in the line was lowered to 500 torr, and the mixture was heated to $100^{\circ} \mathrm{C}$ over a $25-\mathrm{min}$ period. At $\approx 85^{\circ} \mathrm{C}$ a crystalline precipitate was observed in the homogeneous melt, and which disappeared at $\approx 90^{\circ} \mathrm{C}$, leaving an upper brown and a lower colorless liquid layer. Heating was continued at $100^{\circ} \mathrm{C}(25 \mathrm{~min})$. The product $(4.45 \mathrm{~g})$ was transferred under high vacuum $(30 \mathrm{~min})$ to the $10 \mathrm{ml}$ receiving flask cooled to $-196^{\circ} \mathrm{C}$. The ${ }^{19} \mathrm{~F}$ n.m.r. and i.r. spectra showed that only ketene 21 was present, although the product was slightly fuming. Yield (based on the 14:86 mixture): $95 \%$. 
$\left.\underline{\mathrm{F}}_{5} \mathrm{SC}^{\mathrm{SO}} \mathrm{SO}_{2} \mathrm{~F}\right) \mathrm{CO}$ in a sealed tube:

Ketene $\underline{21}(0.499,1.96$ mmols) was heated in an evacuated dry $50 \mathrm{~mL}$ Carius tube to $220^{\circ} \mathrm{C}$ for $4 \mathrm{~h}$. The liquid inside was slightly discolored but $0.48 \mathrm{~g}$ of unchanged ketene was recovered.

\section{$\left.\underline{F}_{5}{\underline{S C}\left(\mathrm{SO}_{2}\right.}_{2} \mathrm{~F}\right) \mathrm{CO}$ and iso-propanol:}

To $118 \mathrm{mg}$ of iso-propanol (1.94 mmol) in a $1 \mathrm{ml}$ dry reaction vessel ketene $\underline{21}(497 \mathrm{mg}, 1.99 \mathrm{mmol})$ was added dropwise. Initially, the reaction was vigorous, but subsided after addition of approximately $1 / 2$ of the ketene. After addition was complete, the reaction vessel was kept at room temperature $(1 / 2 \mathrm{~h})$ and $568 \mathrm{mg}$ of product was collected $(94.2 \%)$. The infrared spectrum and ${ }^{19} \mathrm{~F}$ n.m.r. spectra agreed with the spectra of the ester $\mathrm{F}_{5} \mathrm{SCH}\left(\mathrm{SO}_{2} \mathrm{~F}\right) \mathrm{COOCH}\left(\mathrm{CH}_{3}\right)_{2}$, as described above. Gas chromatography (Carbowax 20\%, 6ft, on Chromosorb $\mathrm{W}, 110^{\circ} \mathrm{C}$ ) of the product showed the product to be essentially pure (>95\%).

\section{$\left.\underline{F}_{5}{\underline{S C}\left(\mathrm{SO}_{2}\right.}_{2} \mathrm{~F}\right) \mathrm{CO}$ and $2,2,2-\mathrm{Trifluoroethanol:}$}

To $0.50 \mathrm{~g}(2.0 \mathrm{mmol})$ of ketene $\underline{21}$ in a dry $30 \mathrm{ml}$ Pyrexglass reaction vessel, equipped with a Kontes Teflon valve, $\mathrm{CF}_{3} \mathrm{CH}_{2} \mathrm{OH}(0.24 \mathrm{~g}, 2.4 \mathrm{mmol})$ was condensed at $-196^{\circ} \mathrm{C}$. The mixture was allowed to attain room temperature slowly and heated to $83^{\circ} \mathrm{C}$ for 1 hour. The liquid product was transferred out, washed with water $(2 \times 0.5 \mathrm{ml})$, the lower 
layer was taken up with a pipet, transferred to a $5 \mathrm{ml}$ flask and dried $\left(\mathrm{Na}_{2} \mathrm{SO}_{4}\right)$. The infrared spectrum of the product $(0.59 \mathrm{~g}, 1.7 \mathrm{mmol})$ was essentially identical with the published spectrum of $\mathrm{F}_{5} \mathrm{SCH}\left(\mathrm{SO}_{2} \mathrm{~F}\right) \mathrm{COOCH}_{2} \mathrm{CF}_{3}$. The ${ }^{19} \mathrm{~F}$ n.m.r. spectrum revealed that the product was chiefly the trifluoroethyl ester with some $\mathrm{F}_{5} \mathrm{SCH}_{2} \mathrm{SO}_{2} \mathrm{~F}$ as a minor impurity. Yield $82 \%$ (n.m.r. spectrum).

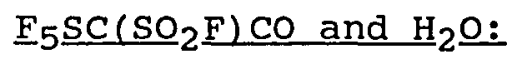

Into a $100 \mathrm{ml}$ reaction vessel, equipped with a Kontes Teflon valve and containing water $(40.5 \mathrm{mg}, 2.25 \mathrm{mmol})$ ketene $\underline{21}$ (485.3 $\mathrm{mg} 1.94 \mathrm{mmol})$ was condensed. The mixture was allowed to attain room temperature and to remain there for $2 \mathrm{~h}$. It was then cooled to $-78^{\circ} \mathrm{C}$ and the infrared spectrum of the off-gas showed $\mathrm{CO}_{2}$ to be present with trace impurities. The amount of $\mathrm{CO}_{2}$ formed was $85.4 \mathrm{mg}$ (1.94 mmol), theor. (1.94 mmol, $85.4 \mathrm{mg})$. The residue was transferred at elevated temperature and dried $\left(\mathrm{Na}_{2} \mathrm{SO}_{4}\right)$. A total of $369.0 \mathrm{mg}$ of product was collected. A gas chromatogram (Carbowax, 20\%, $6 \mathrm{ft}$, on Chromosorb W, $100{ }^{\circ} \mathrm{C}$ ) showed only one product; its infrared and ${ }^{19} \mathrm{~F}$ n.m.r. spectra were identical with the published spectra of $\mathrm{F}_{5} \mathrm{SCH}_{2} \mathrm{SO}_{2} \mathrm{~F}$. Yield: $84.9 \%$.

$\left.\underline{\mathrm{F}}_{5} \underline{\mathrm{SC}}_{\left(\mathrm{SO}_{2}\right.} \mathrm{F}\right) \mathrm{CO}$ and $\left(\mathrm{C}_{2} \underline{\mathrm{H}}_{5} \perp_{2} \underline{\mathrm{NH}}(27):\right.$

Ketene $\underline{21}(0.49 \mathrm{~g}, 1.96 \mathrm{mmol})$ was condensed into a 50 
ml Pyrex-glass reaction vessel, equipped with a Kontes Teflon valve and containing $2 \mathrm{ml}$ of $\mathrm{dry} \mathrm{CH}_{2} \mathrm{Cl}_{2}$ at $-196^{\circ} \mathrm{C}$. The vessel was warmed above the melting point of the $\mathrm{CH}_{2} \mathrm{Cl}_{2}$, shaken, and cooled again to $-196^{\circ} \mathrm{C}$, and diethylamine $(0.142$ g, $1.94 \mathrm{mmol}$ ) was added by vacuum-transfet. Upon being warmed to the melting temperature the solution was shaken, frozen $\left(-196^{\circ} \mathrm{C}\right)$ and allowed to attain room temperature slowly. During warming to room temperature the solution turned brownish. At room temperature it was decanted, concentrated and recrystallized from $\mathrm{CH}_{2} \mathrm{Cl}_{2}$, leaving $302 \mathrm{mg}$ $\left(0.93 \mathrm{mmol}\right.$ of $\mathrm{F}_{5} \mathrm{SCH}\left(\mathrm{SO}_{2} \mathrm{~F}(\mathrm{C}) \mathrm{N}\left(\mathrm{C}_{2} \mathrm{H}_{5}\right)_{2}, \mathrm{~m} \cdot \mathrm{p} .108-110^{\circ} \mathrm{C}\right.$. Yield: $47.7 \%$

${ }^{19} \mathrm{~F}$ n.m.r. spectrum $\left(\mathrm{CDCl}_{3}, \mathrm{CCl}_{3} \mathrm{~F}\right.$, ext.): multiplet, $\phi$ $=72.2 \mathrm{ppm}$, area $=4.8\left(\mathrm{SF}_{5}\right) ;$ multiplet, $\phi=62.3 \mathrm{ppm}$, area $=1.0\left(\mathrm{SO}_{2} \mathrm{~F}\right)$.

$l_{\mathrm{H}}$ n.m.r. $\left(300 \mathrm{MHz}, \mathrm{CDCl}_{3}, \mathrm{Si}\left(\mathrm{CH}_{3}\right)_{4}\right):$ triplet, $\delta=$ $1.19 \mathrm{ppm}, \mathrm{J}_{\mathrm{H}-\mathrm{H}}=7.1 \mathrm{~Hz}$, area $=3.0\left(\mathrm{CH}_{3}\right)$; triplet, $\delta=$ 1.32, $\mathrm{J}_{\mathrm{H}-\mathrm{H}}=7.1 \mathrm{~Hz}$, area $=3.0\left(\mathrm{CH}_{3}\right) ;$ multiplet, centered at $3.5 \mathrm{ppm}$, area $=4.3\left(\mathrm{CH}_{2}\right)$; pentet, $\delta=6.00 \mathrm{ppm}, \mathrm{J}_{\mathrm{H}-\mathrm{F}}=$ $4.0 \mathrm{~Hz}$, area $=0.9(\mathrm{CH})$.

I.r. spectrum (neat sample, squeezed on $\mathrm{KBr}$ plate), $\left.\mathrm{cm}^{-1}\right): 2990(\mathrm{w}), \quad 1661$ (vs), $1460(\mathrm{Vw}), \quad 1432(\mathrm{~s}), \quad 1390(\mathrm{w})$, $1363(w), 1320(w), 1278(w), 1222(\mathrm{~m}), \quad 1212(\mathrm{~m}), \quad 1129(\mathrm{w})$, $1096(\mathrm{w}), 1083(\mathrm{Vw}), 953(\mathrm{w}), 899(\mathrm{~m}), 860(\mathrm{vs}), 820(\mathrm{~m}), 799(\mathrm{~m})$, $740(w), 647(w), 562(m), 488(w), 458(w)$.

Mass spectrum $\left(70 \mathrm{eV}\right.$, mass, species, \%): $323, \mathrm{M}^{+}, 1.6$; 
$308,\left(\mathrm{M}-\mathrm{CH}_{3}\right)^{+}, 12.1 ; 280, \mathrm{C}_{6} \mathrm{H}_{4} \mathrm{~F}_{6} \mathrm{NO}_{3} \mathrm{~S}_{2}{ }^{+}, 2.0 ; 231, \mathrm{C}_{2} \mathrm{~F}_{5} \mathrm{O}_{3} \mathrm{~S}_{2}{ }^{+}$, $4.6 ; 196,\left(\mathrm{M}-\mathrm{SF}_{5}\right)^{+}, 14.9 ; 176,\left(\mathrm{M}-\mathrm{HF}-\mathrm{SF}_{5}\right)^{+}, 5.8 ; 127,\left(\mathrm{SF}_{5}\right.$, $\left.\mathrm{CFO}_{2} \mathrm{~S}_{2}\right)^{+}, 7.4 ; 125, \mathrm{C}_{2} \mathrm{H}_{2} \mathrm{FO}_{3} \mathrm{~S}^{+}, 2.9 ; 112,\left(\mathrm{C}_{2} \mathrm{H}_{5}\right)_{2} \mathrm{NCOC}^{+}, 2.9$; $105, \mathrm{C}_{2} \mathrm{HO}_{3} \mathrm{~S}^{+}, 2.7 ; 100, \mathrm{C}_{5} \mathrm{H}_{10} \mathrm{NO}^{+}, 5.8 ; 89, \mathrm{SF}_{3}^{+}, 14.8 ; 73$, $\mathrm{C}_{2} \mathrm{HOS}^{+}, 2.0 ; 72,\left(\mathrm{C}_{2} \mathrm{H}_{5}\right)_{2} \mathrm{~N}^{+}, \mathrm{C}_{2} \mathrm{OS}^{+}, 42.4 ; 71, \mathrm{C}_{4} \mathrm{H}_{9} \mathrm{~N}^{+}, 3.4 ;$ $70, \mathrm{C}_{4} \mathrm{H}_{8} \mathrm{~N}^{+}, \mathrm{SF}_{2}{ }^{+}, 4.4 ; 67, \mathrm{FSO}^{+}, 5.5 ; 58, \mathrm{C}_{2} \mathrm{H}_{4} \mathrm{NO}^{+}, \mathrm{SCN}^{+}$ (rearr.), $100 ; 56, \mathrm{C}_{3} \mathrm{H}_{6} \mathrm{~N}^{+}, \mathrm{C}_{2} \mathrm{H}_{2} \mathrm{NO}^{+}, \mathrm{C}_{2} \mathrm{~S}^{+}, 21.5 ; 54, \mathrm{C}_{2} \mathrm{NO}^{+}$, 2.0 .

Anal.calcd for $\mathrm{C}_{6} \mathrm{H}_{11} \mathrm{~F}_{6} \mathrm{NO}_{3} \mathrm{~S}_{2}: \mathrm{C}, 22.29 ; \mathrm{H}, 3.43 ; \mathrm{F}$, $35.3 ; \mathrm{N}, 4.33 ; \mathrm{S}, 19.83$. Found: $\mathrm{C}, 22.37 ; \mathrm{H}, 3.54 ; \mathrm{F}, 35.2$; $N, 4.26 ; S, 19.91$.

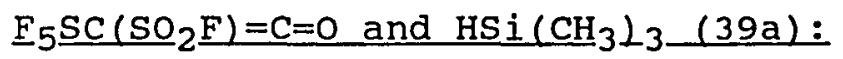

The reaction was carried out in dry glassware under strict exclusion of moisture.

Into a $50 \mathrm{ml}$ pear shaped Pyrex-glass vessel, equipped with a Kontes Teflon valve, $1.1536 \mathrm{~g}$ of $\underline{21}$ were added by vacuum-transfer. The stoichiometric amount of $\mathrm{SiH}\left(\mathrm{CH}_{3}\right)_{3}$ (Petrarch) was added by vacuum transfer ( 190 torr, 0.4551 , $\left.295^{\circ} \mathrm{C}\right)$, and the vessel was allowed to attain $0^{\circ} \mathrm{C}$ slowly by allowing it to warm up in a pre-cooled Dewar container. A white, somewhat moist-looking solid was obtained. Another $\frac{1}{2}$ equivalent of $\mathrm{SiH}\left(\mathrm{CH}_{3}\right)_{3}$ was added (total $=1.5$ equiv.). No more reaction was observed. The vessel was immersed in an ice-bath and volatile materials were pumped off through a $-196^{\circ} \mathrm{C}$ cold-trap $(45$ minutes). Residue $=1.3445 \mathrm{~g}$ (theor. $=$ 
$1.4951 \mathrm{~g})$. The material was transferred to a sublimation apparatus in a dry-box and sublimed in an oil bath $\left(48^{\circ} \mathrm{C}\right)$. A white crystalline solid collected quickly on the coldfinger and the sublimation was over in $\frac{1}{2}$ hour. Yield = $0.9290 \mathrm{~g}(62.1 \%), \mathrm{m} . \mathrm{p}$. (sealed tube) $44-48^{\circ} \mathrm{C}$. The compound seems to be perfectly stable when kept in a vacuum-sealed glass tube, but turns dark slowly in a screwcap vial in the dry-box.

$1_{\mathrm{H}}$ n.n.r. spectrum $\left(\mathrm{CDCl}_{3}, \mathrm{Si}\left(\mathrm{CH}_{3}\right)_{4}\right.$ ext. $): \delta_{1}=0.43$ ppm, $s$ (evidence of shoulders), area $=9.00\left(\mathrm{Si}\left(\mathrm{CH}_{3}\right)_{3}\right) ; \delta_{2}=$ $8.10 \mathrm{ppm}, \mathrm{d}-\mathrm{p}$ (poorly resolved), area $=0.95 ;$ coupling to $\mathrm{AB}_{4} \mathrm{X}\left(\mathrm{l}(\mathrm{F}): \mathrm{J}_{2 \mathrm{~B}} \approx 4.2 \mathrm{~Hz} ; \mathrm{J}_{2 \mathrm{X}} \approx 1.7 \mathrm{~Hz}\right.$.

${ }^{19} \mathrm{~F}$ n.n.r. spectrum $\left(\mathrm{CDCl}_{3}, \mathrm{CCl}_{3} \mathrm{~F}\right.$ ext. $): \phi_{\mathrm{SF} 5} \approx 75$ $\mathrm{ppm}, \mathrm{m}$, int. $=5.00$ (the appearance of the spectrum is still $\approx \mathrm{AB}_{4}$, but $\mathrm{J}_{\mathrm{AB}}=160.7 \mathrm{~Hz}$, well above the usual range, indicating that the spectrum cannot be interpreted by simple means) $; \phi_{\mathrm{SO} 2 \mathrm{~F}}=68.6 \mathrm{ppm}$, partially resolved pentet, intensity $=1.09, \mathrm{~J}_{\mathrm{SF} 4-\mathrm{SO} 2 \mathrm{~F}}=8.3 \mathrm{~Hz}$.

${ }^{13} \mathrm{C}$ n.m.r. spectrum $\left(100.6 \mathrm{MHz}, \mathrm{CDCl}_{3}, \mathrm{Si}\left(\mathrm{CH}_{3}\right)_{3}\right): \delta_{1}=$ $1.83 \mathrm{ppm}$, quartet $\left(\mathrm{CH}_{3}\right), \mathrm{J}_{1 \mathrm{H}}=116.4 \mathrm{~Hz} ; \delta_{2}=128.95 \mathrm{ppm}, \mathrm{m}$; $\delta_{3}=159.24 \mathrm{ppm}, \mathrm{d}, \mathrm{J}_{3 \mathrm{H}}=179.0 \mathrm{~Hz}$.

I.r. spectrum (neat sample, $\mathrm{KBr}, \mathrm{cm}^{-1}$ ): 3028, w; 2976, $\mathrm{w} ;$ 2919, vw; 1600, m-s,br; 1415, s; 1363, m; 1310, m; 1257, m-s; 1209, s; 1044, m-s; 980, w; 874, vs,sh; 861, vs; 822, vs; 772 , vs; $721, \mathrm{~s} ; 682, \mathrm{~s} ; 634, \mathrm{~m}-\mathrm{s} ; 609, \mathrm{~s} ; 579$, vs; 494, $\mathrm{w}-\mathrm{m} ; 460, \mathrm{~m}$. 
Mass spectrum (e.i., 70 e.V., mass, species, $>1 \%$, only ${ }^{28} \mathrm{Si}$ listed): $309,\left(\mathrm{M}-\mathrm{CH}_{3}\right)^{+}, 21.5 ; 261,\left(\mathrm{M}+\mathrm{H}-3 \mathrm{CH}_{3}\right)^{+}$, $7.0 ; 213,\left(\mathrm{M}-\mathrm{Si}\left(\mathrm{CH}_{3}\right)_{3}-2 \mathrm{~F}\right)^{+}, 2.2 ; 187,\left(\mathrm{~F}_{5} \mathrm{SCSO}\right)^{+}, 1.3 ; 185$, $\mathrm{CHF}_{4} \mathrm{O}_{2} \mathrm{~S}_{2}{ }^{+}, 11.9 ; \quad 165, \mathrm{CF}_{3} \mathrm{O}_{2} \mathrm{~S}_{2}{ }^{+}, 4.4 ; 126, \mathrm{C}_{4} \mathrm{H}_{2} \mathrm{OSSi}^{+}, 1.1$; 125, $\mathrm{C}_{5} \mathrm{H}_{5} \mathrm{SSi}^{+}, 13.3 ; 124, \mathrm{C}_{5} \mathrm{H}_{3} \mathrm{SSi}^{+}, \mathrm{C}_{2} \mathrm{HFO}_{3} \mathrm{~S}^{+}, 3.7 ;$ 105, $\mathrm{C}_{2} \mathrm{HO}_{3} \mathrm{~S}^{+}, 4.6 ; 103, \mathrm{CHSF}_{3}^{+}, 1.0 ; 97, \mathrm{C}_{2} \mathrm{Si}\left(\mathrm{CH}_{3}\right)_{3}^{+}, \mathrm{CH}_{2} \mathrm{SO}_{2} \mathrm{~F}^{+}$, $9.6 ; 92, \mathrm{C}_{4} \mathrm{OSi}^{+}, \operatorname{Cos}_{2}+, 2.1,91, \mathrm{FSCCO}^{+}, 1.8 ; 89, \mathrm{SF}_{3}^{+}$, $24.2 ; 81, \mathrm{C}_{3} \mathrm{HOSi}^{+}, 2.6 ; 79,(3.6), 78,(6.5), 77,(100.0)$, $\mathrm{C}_{4} \mathrm{HSi}^{+}, ; 76, \mathrm{C}_{4} \mathrm{Si}^{+}, 1.6 ; 75,(2.9), 74,(4.8), 73,(56.3)$, $\mathrm{Si}\left(\mathrm{CH}_{3}\right)_{3}^{+} ; 72, \mathrm{C}_{3} \mathrm{H}_{8} \mathrm{Si}^{+}, 2.2 ; 70, \mathrm{SF}_{2}^{+}, 2.4 ; 67, \mathrm{SOF}^{+}, 3.4 ;$ $64, \mathrm{SO}_{2}^{+}, 4.3 ; 63, \mathrm{CSF}^{+}, 7.1 ; 62, \mathrm{CH}_{2} \mathrm{OS}^{+}, 1.5 ; 57, \mathrm{C}_{2} \mathrm{H}_{5} \mathrm{Si}^{+}$, 1.4 .

Anal.calcd for $\mathrm{C}_{5} \mathrm{H}_{10} \mathrm{~F}_{6} \mathrm{O}_{3} \mathrm{~S}_{2} \mathrm{Si}: \mathrm{C}$, 18.52; $\mathrm{H}, 3.11 ; \mathrm{F}$, $35.2 ; \mathrm{S}, 19.77$. Found: C, 18.42; H, 3.00; F, 35.5; S, 19.92.

$\left.\underline{F}_{5}{\underline{S C}\left(\mathrm{SO}_{2}\right.}_{2} \mathrm{~F}\right)=\mathrm{C}=0$ and Acetone $(30):$

Dry acetone $(1.05 \mathrm{~g}, 18.10 \mathrm{mmol})$ and $0.67 \mathrm{~g}$ of $\underline{21}$ $(2.68 \mathrm{mmol})$ were mixed at room temperature in a $5 \mathrm{ml}$ flask; the flask was stoppered and kept at room temperature overnight $(17 \mathrm{~h})$. The solution was yellow the next morning and all ketene was consumed. Water was added $(3 \mathrm{ml})$, the mixture was swirled and the water pipetted off. This was repeated twice with $2 \mathrm{ml} \mathrm{H}_{2} \mathrm{O}$ each. After drying $\left(\mathrm{Na}_{2} \mathrm{SO}_{4}\right)$ $0.73 \mathrm{~g}$ of a light yellow product was obtained. This material was subjected to preparative gas chromatography $(20 \% \mathrm{SE}-30$, $\left.45 / 60,3 \mathrm{~m}, 95^{\circ} \mathrm{C}\right)$. Three bands were eluted of which the 
first one ( $R_{f}=13$ minutes) was acetone, the second one $\left(R_{f}\right.$ $=17$ minutes) evaporated rapidly upon warming up, leaving a very small amount of an oily, colorless residue, and the third band $\left(\mathrm{R}_{\mathrm{f}}=23\right.$ minutes) was almost pure $\mathrm{F}_{5} \mathrm{SCH}_{2} \mathrm{SO}_{2} \mathrm{~F}$ (this was confirmed with the infrared spectrum). The rsidue from fraction 2 was just enough to obtain the $1_{\mathrm{H}}$ and ${ }^{19} \mathrm{~F}$ n.m.r. and infrared spectra.

$I_{\mathrm{H}}$ n.m.r. spectrum $\left(400 \mathrm{MHz}, \mathrm{CDCl}_{3}\right.$, internal $\left.\mathrm{Si}\left(\mathrm{CH}_{3}\right)_{4}\right): \delta_{1}=2.00 \mathrm{ppm}, \mathrm{s},(3 \mathrm{H}) ; \delta_{2}=4.89 \mathrm{ppm}, \mathrm{s},(1.86$ $\mathrm{H}) ; \delta_{3}=5.77 \mathrm{ppm}, \mathrm{m},(0.85 \mathrm{H})$.

$19 \mathrm{~F}$ n.m.r. $\left(\mathrm{CDCl}_{3}\right.$, external $\left.\mathrm{CCl}_{3} \mathrm{~F}\right): \phi=73.0 \mathrm{ppm}, \mathrm{m}$, area $=5.00\left(\mathrm{SF}_{5}\right) ; \phi=60.9 \mathrm{ppm}, \mathrm{m}$, area $=0.94\left(\mathrm{SO}_{2} \mathrm{~F}\right)$.

I.r. spectrum (neat sample, on $\mathrm{KBr}, \mathrm{cm}^{-1}$ ): 2979, w; 1776, s; $1683(\mathrm{C}=\mathrm{C}), \mathrm{w}-\mathrm{m} ; 1446, \mathrm{~s} ; 1382, \mathrm{vw} ; 1301, \mathrm{~m} ; 1267$, $\mathrm{m} ; 1226, \mathrm{~m}-\mathrm{s} ; 1212, \mathrm{~m}-\mathrm{s} ; 1193, \mathrm{~m}-2 ; 1148, \mathrm{~m}-\mathrm{s} ; 981, \mathrm{vw} ; 874$, vs; 833, m; 816, m, sh; 796, m; 773, w-m; 747, wi 688, w; $647, w ; 610, w-m ; 569, s ; 487, w-m$.

\section{$\left.\underline{F}_{5} \underline{S C} S_{2} F\right)=C=0$ and paraldehyde $(28):$}

In a $50 \mathrm{ml}$ Carius tube $0.66 \mathrm{~g}$ of $\underline{21}(2.64 \mathrm{mmol})$ and $0.08 \mathrm{~g}$ of trioxane (TCI, $0.89 \mathrm{mmol}$ ) were heated to $155^{\circ} \mathrm{C}$ after evcacuation at $-196^{\circ} \mathrm{C}$ for 2 hours. The mixture had darkened and $0.60 \mathrm{~g}$ of colorless liquid was vacuumtransferred; a dark residue was left behind. of the three components (g.C., $20 \% \mathrm{SE}-30,45 / 60,3 \mathrm{~m}, 95^{\circ} \mathrm{C}$ ) the major constituent $\left(R_{f}=15.0 \mathrm{~min}\right)$ was collected via preparative 
gas chromatography (the same column was used), yielding 0.25 $\mathrm{g}$ of product, probably $\mathrm{F}_{5} \mathrm{SC}\left(\mathrm{SO}_{2} \mathrm{~F}\right)=\overline{\mathrm{CCH}_{2} \mathrm{O}}, \underline{28},(34 \%)$, as a colorless, volatile liquid of a peculiar odor. The elemental analysis could not be obtained correctly, as the liquid deposited some solid after some time, and underwent an apparent chemical transformation.

${ }^{1_{H}}$ n.m.r. spectrum (300 MHz, internal $\mathrm{Si}\left(\mathrm{CH}_{3}\right)_{4}$, $\left.\mathrm{CDCl}_{3}\right): \delta_{1}=7.10 \mathrm{ppm}, t$, area $=1.0, \mathrm{~J}=4.65 \mathrm{~Hz}\left(=\mathrm{J}_{12}=\right.$ $\left.J_{1 X}\right) ; \delta_{2}=7.26 \mathrm{ppm}, \approx$ sextet, area $=1.0, J_{\text {average }}=3.48$ $\mathrm{Hz}$;

${ }^{19} \mathrm{~F}$ n.m.r. spectrum: $\left(\mathrm{CDCl}_{3}\right.$, external $\left.\mathrm{CCl}_{3} \mathrm{~F}\right): \mathrm{AB}_{4} \mathrm{X} \quad \phi_{\mathrm{A}}$ $=74.4 \mathrm{ppm}, 9$ Iines, area $=1.00 ; \phi_{\mathrm{B}}=68.3 \mathrm{ppm}, \mathrm{d}-\mathrm{m}-\mathrm{d}$, area $=4.87 ; \phi_{\mathrm{X}}=60.6 \mathrm{ppm}, \mathrm{d}-\mathrm{p}$, area $\left.=1.05 \mathrm{sO}_{2} \mathrm{~F}\right) ; \mathrm{J}_{\mathrm{AB}}=155.3$ $\mathrm{Hz}, \mathrm{J}_{\mathrm{BH}^{2}}$ or $\mathrm{J}_{\mathrm{BH}}^{2}=3.44 \mathrm{~Hz}$ (average); $\mathrm{J}_{\mathrm{BX}}=9.67 \mathrm{~Hz} ; \mathrm{J}_{1 \mathrm{X}}=$ $4.65 \mathrm{~Hz}$.

I.r. spectrum (neat sample, capillary film on $\mathrm{KBr}, \mathrm{cm}^{-}$ 1): 3142, w-m; 3051, w; 2981, vw; 1614,w; 1440, s-vs; 1379, s; 1227, s-vs; 1135, w; 1060, vw; 1005, m; 867, vs; $820, \mathrm{~s}-$ vs; 775, s; 710, vw; 687, m-s; 631, m-s; $582, \mathrm{~s}-\mathrm{vs} ; 535, \mathrm{~m}$; $481, w-m ; 443, \mathrm{~m}$.

G.C.mass spectrum (e.i., $70 \mathrm{eV}$, mass, fragment, $\%$

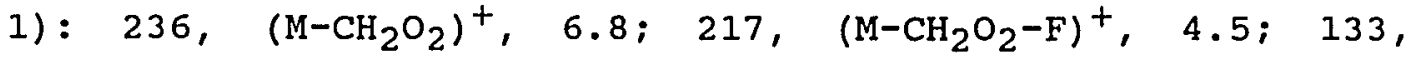
$\mathrm{C}_{3} \mathrm{HS}_{2} \mathrm{O}_{2}{ }^{+}, 2.6 ; 129,{ }^{34} \mathrm{SF}_{5}{ }^{+}, \mathrm{SF}_{3} \mathrm{C}_{2} \mathrm{O}^{+}, 3.3 ; 128,{ }^{33} \mathrm{SF}_{5}{ }^{+}$, $\mathrm{CHFO}_{2} \mathrm{~S}_{2}{ }^{+}, 8.5 ; 127, \mathrm{SF}_{5}{ }^{+}, 75.5 ; 109, \mathrm{CHO}_{2} \mathrm{~S}_{2}^{+}, 2.6 ; 108$, $\mathrm{SF}_{4}{ }^{+}, 4.3 ; 91,{ }^{34} \mathrm{SF}_{3}{ }^{+}, 3.8 ; 90,{ }^{33} \mathrm{SF}_{3}{ }^{+}, 1.1 ; 89,{ }^{32} \mathrm{SF}_{3}{ }^{+}$, $100.0 ; 83, \mathrm{SO}_{2} \mathrm{~F}^{+}, 11.5 ; 77, \mathrm{CHO}_{2} \mathrm{~S}^{+}, 2.3 ; 76, \mathrm{CO}_{2} \mathrm{~S}^{+}, 1.7 ; 70$, 
$\mathrm{SF}_{2}{ }^{+}, \mathrm{C}_{3} \mathrm{H}_{2} \mathrm{O}_{2}{ }^{+}, 14.4 ; 69, \mathrm{C}_{3} \mathrm{HO}_{2}{ }^{+}, 3.3 ; 68, \mathrm{C}_{3} \mathrm{O}_{2}{ }^{+}, 1.3 ; 67$, $\mathrm{FSO}^{+}, 84.1 ; 65, \mathrm{FSCH}_{2}{ }^{+}, 1.6 ; 64, \mathrm{SO}_{2}+, 4.9 ; 61, \mathrm{CHSO}^{+}, 3.8$; $58, \mathrm{C}_{2} \mathrm{H}_{2} \mathrm{O}_{2}^{+}, 8.4 ; 57, \mathrm{C}_{2} \mathrm{HO}_{2}^{+}, 7.2 ; 56, \mathrm{C}_{2} \mathrm{O}_{2}^{+}, 1.2 ; 52, \mathrm{C}_{3} \mathrm{O}^{+}$, $1.1 ; 51, \mathrm{SF}^{+}, 4.8$.

Product of the autoconversion of 28 (29):

A sample of 28 was kept for several weeks sealed in a glass tube in the freezer $\left(-12^{\circ} \mathrm{C}\right)$. It was found that the originally clear liquid was partially converted to a white solid. The tube was opened and the contents were dissolved in acetone and the solvent was allowed to evaporate slowly at room temperature; within several days, small needleshaped crystals were obtained. This material was apparently free of impurities. The conversion seems to be more complete in capillary tubes where after several weeks of storage seemingly all the liquid (28) was converted to a solid.

$1_{\mathrm{H}}$ n.m.r. spectrum $\left(400 \mathrm{MHz}, \mathrm{CDCl}_{3}\right.$, internal $\left.\mathrm{Si}\left(\mathrm{CH}_{3}\right)_{4}\right): \operatorname{ABX} \delta_{\mathrm{A}}=4.448 \mathrm{ppm}, \mathrm{d}-\mathrm{m}$, multiplet is probably d$\mathrm{p}$ (partially superposed with second line of $\left.\delta_{A}\right) ; J_{A B}=12.9$ $\mathrm{Hz} ; \mathrm{J}_{\mathrm{ASF} 4 \mathrm{~F}}=2.2 \mathrm{~Hz} ; \mathrm{J}_{\mathrm{ASO} 2 \mathrm{~F}}$ or $\mathrm{J}_{\mathrm{AX}}=4.4 \mathrm{~Hz} \cdot \delta_{\mathrm{B}}=4.512 \mathrm{ppm}$, d (each line has shoulders), area $\mathrm{A}+\mathrm{B}=2.00\left(\mathrm{CH}_{\mathrm{A}} \mathrm{H}_{\mathrm{B}}\right) \cdot \delta_{\mathrm{X}}=$ $5.98 \mathrm{ppm}, \mathrm{m}$, area $=0.85 . \mathrm{F}_{5} \mathrm{SC}$ ㅂ.

${ }^{19} \mathrm{~F}$ n.m.r. spectrum (375 $\mathrm{MHz}, \mathrm{CDCl}_{3}$, internal $\mathrm{CCl}_{3} \mathrm{~F}$ ): $\mathrm{AB}_{4} \mathrm{X}, \phi_{\mathrm{A}}=76.5 \mathrm{ppm}, 9$ lines; $\phi_{\mathrm{B}}=68.3 \mathrm{ppm}$, asymmetric doublet; $\phi_{X}=62.3 \mathrm{ppm}$, ill-resolved pentet (some lines have shoulders). $J_{A B}=146.6 \mathrm{~Hz} ; J_{B X} \approx 11.7 \mathrm{~Hz}$. 
I.r. spectrum (neat sample, squeezed on $\mathrm{KBr}$ ): 2972, m; 2909, vw; 1431, vs; 1377, m; 1257, m; 1237, m,sh; 1222, s; $1202, \mathrm{~m}-\mathrm{s} ; 1143, \mathrm{~s} ; 1080, \mathrm{~m} ; 1060, \mathrm{~m} ; 1045, \mathrm{~m} ; 988, \mathrm{~m} ; 940$, vw; 877, s-vs,sh; 857, vs; $803, \mathrm{~s} ; 743, \mathrm{~m}-\mathrm{s} ; 726, \mathrm{~m}-\mathrm{s} ; 706$, $\mathrm{m} ; 677, \mathrm{~m}-\mathrm{s} ; 649, \mathrm{~m} ; 634, \mathrm{~m}-\mathrm{s} ; 620, \mathrm{~m}-\mathrm{s} ; 600, \mathrm{~m} ; 580, \mathrm{~s}-\mathrm{vs}$; $554, \mathrm{~s} ; 534, \mathrm{~s} ; 483, \mathrm{~s}$.

Anal.calcd. for $\mathrm{C}_{4} \mathrm{H}_{6} \mathrm{~F}_{12} \mathrm{O}_{5} \mathrm{~S}_{4}: \mathrm{C}, 9.80 ; \mathrm{H}, 1.23 ; \mathrm{F}$, 46.5. Found: C, 9.99; H, 1.24; F, 45.7.

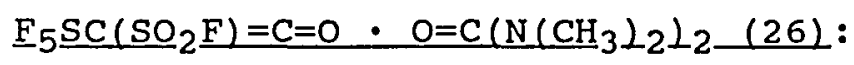

To $0.68 \mathrm{~g}$ of $\left(\left(\mathrm{CH}_{3}\right)_{2} \mathrm{~N}\right)_{2} \mathrm{C}=0(5.9 \mathrm{mmol})$ in a $10 \mathrm{ml}$ pearshaped flask, equipped with a Kontes Teflon valve connector, $1.18 \mathrm{~g}$ of $\mathrm{F}_{5} \mathrm{SC}\left(\mathrm{SO}_{2} \mathrm{~F}\right)=\mathrm{C}=0 \quad(4.7 \mathrm{mmol})$ were added through vacuum-transfer. The mixture was allowed to attain roomtemperature slowly. It bubbled slightly and became viscous. After warming cautiously with a heat-gun, and keeping the sample at room-temperature for $45 \mathrm{~min}$, volatile materials were removed by pumping them off on the vacuum-line overnight, leading to a loss of $0.24 \mathrm{~g}$. The sample was still oily and was re-crystallized from $\mathrm{CH}_{2} \mathrm{Cl}_{2}\left(-12^{\circ} \mathrm{C}\right)$, where large colorless, extremely moisture-sensitive crystals were formed. Yield: $0.94 \mathrm{~g}=54.5 \% \mathrm{M} . \mathrm{p} .=100-102^{\circ} \mathrm{C}$ (sealed tube).

$1 \mathrm{H}$ n.m.r. $\left(\mathrm{CDCl}_{3}, \mathrm{Si}\left(\mathrm{CH}_{3}\right)_{4}\right.$ ext. $): \delta=3.42 \mathrm{ppm}, \mathrm{s}$. ${ }^{19} \mathrm{~F} \mathrm{n} \mathrm{m} \mathrm{r.}\left(\mathrm{CH}_{2} \mathrm{Cl}_{2}, \mathrm{CCl}_{3} \mathrm{~F}\right.$ ext. $):\left(\mathrm{AB}_{4} \mathrm{X}\right) \phi=89.6 \mathrm{ppm}$, 9 lines, int. $1.0\left(F_{A}\right) ; \phi=79.7 \mathrm{ppm}, \mathrm{d}-\mathrm{m}$, int. $=3.88\left(\mathrm{~F}_{\mathrm{B}}\right)$; 
$\phi=71.3 \mathrm{ppm}, \mathrm{p}$, int. $=1.0\left(\mathrm{~F}_{\mathrm{X}}, \mathrm{SO}_{2} \mathrm{~F}\right) ; \mathrm{J}_{\mathrm{AB}}=154.2 \mathrm{~Hz} ; \mathrm{J}_{\mathrm{BX}}=$ $9.1 \mathrm{~Hz}$.

I.r. spectrum $\left(\mathrm{cm}^{-1}\right.$, neat sample): 2910, w, broad; $1726, \mathrm{~s} ; 1669, \mathrm{~s} ; 1653, \mathrm{~s}, \mathrm{sh} ; 1531, \mathrm{~m} ; 1442, \mathrm{~m}-\mathrm{w} ; 1414, \mathrm{~m}-\mathrm{s}$; 1390, s; 1248, m-s; 1203, s; 1179, s; 1057, m-s; 1049, m-s; $895, \mathrm{~m} ; 858$, vs; 842 , vs; 777 , vs; 729 , vs; $713, \mathrm{~s} ; 660$, vs; $615, \mathrm{~m} ; 587, \mathrm{~m}$.

Anal. calcd for $\mathrm{C}_{7} \mathrm{H}_{12} \mathrm{~F}_{6} \mathrm{~N}_{2} \mathrm{O}_{4} \mathrm{~S}_{2}: \mathrm{C}, 22.96 ; \mathrm{H}, 3.03 ; \mathrm{F}$, $31.1 ; \mathrm{N}, 7.65 ; \mathrm{S}, 17.50$. Found: C, 22.10; H, 3.46; F, 31.3; $N, 8.27 ; s, 16.70$.

\section{$\left.\underline{F}_{5}{\underline{S C C}\left(\mathrm{SO}_{2}\right.}_{2} \underline{F}\right)=\mathrm{C}=0$ and $\mathrm{SF}_{5} \underline{\mathrm{Br}}$}

Pentafluorosulfur bromide $(0.55 \mathrm{~g})$ and $\underline{21}$ were heated in a $50 \mathrm{ml}$ Carius tube for 2 days to $110^{\circ} \mathrm{C}$. After $\approx 1 \mathrm{~h}$, large crystals were observed at the colder parts of the tube, but disappeared later. After 2 days, $0.87 \mathrm{~g}$ of a brownish liquid was transferred out; its i.r. spectrum was alomost identical with the i.r. spectrum of crude $\mathrm{F}_{5} \mathrm{SCBr}\left(\mathrm{SO}_{2} \mathrm{~F}\right) \mathrm{COF}(\underline{25 \mathrm{~b}})$. Repeated fractional distillation resulted in $0.12 \mathrm{~g}$ of a slightly brown solid. Both the i.r. and the ${ }^{19} \mathrm{~F}$ n.m.r. spectrum were consistent with the composition $\underline{25 b}$.

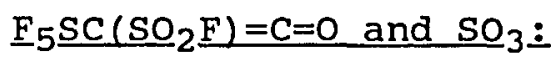

Ketene $\underline{21}(0.96 \mathrm{~g}, 3.8 \mathrm{mmol})$ was heated with $\left(\mathrm{SO}_{3}\right)_{3}$ $(0.31 \mathrm{~g}, 3.9 \mathrm{mmol})$ under anaerobic conditions in a $50 \mathrm{ml}$ 
Carius tube (the lower two thirds were in the upright oven) to $128^{\circ} \mathrm{C}\left(20\right.$ hours) then to $150^{\circ} \mathrm{C}$ (50 hours). The mixture was slightly darkened. Infrared spectroscopy (gas phase) showed only a weak $\mathrm{CO}_{2}$ band; the liquid sample showed a very strong keten band, and ${ }^{19} \mathrm{~F}$ n.m.r. indicated chiefly unchanged keten, and bands at $\approx 73,61$ and $50 \mathrm{ppm}$ (weak). There was no sign of an $\mathrm{A}_{2} \mathrm{BC}$ spectrum as would be expected for the compound $\mathrm{F}_{4} \mathrm{~S}=\mathrm{C}\left(\mathrm{SO}_{2} \mathrm{~F}\right)_{2}$. The product was condensed back into the carius tube and heated to $235^{\circ} \mathrm{C}$ (20 hours). I.r spectroscopy indicated an increase in $\mathrm{CO}_{2}$, and the presence of $\underline{21}, \mathrm{SiF}_{4}$ and perhaps $\mathrm{COF}_{2}$ (weak). The mixture was condensed back into the reaction vessel and heated for another $24 \mathrm{~h}$ to $270^{\circ} \mathrm{C}$. A comparatively strong $\mathrm{CO}_{2}$ band was present in the i.r.spectrum, but there was also still 21 and $\mathrm{SF}_{4}$ (very strong). The product was condensed out $(1.08 \mathrm{~g}$ before, $0.36 \mathrm{~g}$ after degassing) and its ${ }^{19} \mathrm{~F}$ n.m.r.spectrum showed 21 , + bands at $\approx 69, \approx 56$ (5:1, probably $\mathrm{F}_{5} \mathrm{SCH}_{2} \mathrm{SO}_{2} \mathrm{~F}$ ) and $45 \mathrm{ppm}$.

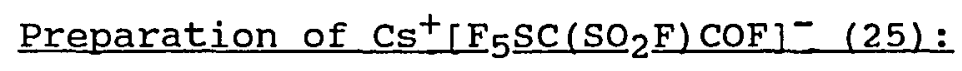

Into a $30 \mathrm{ml}$ Pyrex-glass reaction vessel, with a ground glass cap and a side-arm with a ground glass stopcock containing $3.0555 \mathrm{~g}$ of dried CsF (20.1 mmol, PCR) $2.62 \mathrm{~g}$ of acetonitrile was distilled from $\mathrm{P}_{4} \mathrm{O}_{10}$. Then $6.6535 \mathrm{~g} 1$ (26.6 mmol) was vacuum-transferred $\left(-196^{\circ} \mathrm{C}\right)$ into the vessel. Upon reaching room temperature most of the CsF dissolved in a 
vigorous reaction causing the flask to warm. Dissolution slowed down towards the end and was complete $31 / 2 \mathrm{~h}$ of shaking. A slightly turbid and thick yellowish solution was obtained. Pumping away excess ketene $\underline{1}$ and solvent at room temperature through a cold trap $\left(-196^{\circ} \mathrm{C}\right)$ to constant weight left $8.0795 \mathrm{~g}$ of an off-white solid. This corresponds to a ketene: CsF ratio of 0.9985 and a yield of $99.91 \%$, m.p. $=148-151{ }^{\circ} \mathrm{C}$

${ }^{19} \mathrm{~F}$ n.m.r. spectrum, $\mathrm{AB}_{4} \mathrm{MX}$ (acetone, $\mathrm{CCl}_{3} \mathrm{~F}$ ext.): $\phi_{\mathrm{A}}=$ $92.3 \mathrm{ppm}$ (9 lines), $\phi_{\mathrm{B}}=79.5 \mathrm{ppm}(\mathrm{d}-\mathrm{m}) ; \phi_{\mathrm{M}}=68.5 \mathrm{ppm}, \mathrm{d}-\mathrm{p}$, $\mathrm{SO}_{2} \mathrm{~F} ; \phi_{\mathrm{X}}=16.4 \mathrm{ppm}, \mathrm{d}-\mathrm{p}, \mathrm{COF}$; intensity $\mathrm{A}: \mathrm{B}: \mathrm{M}: \mathrm{X}=1.0: 4.4:$ $1.1: 1.0 . \mathrm{J}_{\mathrm{AB}}=148.0 \mathrm{~Hz} ; \mathrm{J}_{\mathrm{BM}}=9.7 \mathrm{~Hz} ; \mathrm{J}_{\mathrm{BX}}=21.5 \mathrm{~Hz} ; \mathrm{J}_{\mathrm{MX}}=$ $7.1 \mathrm{~Hz}$.

${ }^{13} \mathrm{C}$ n.m.r. spectrum $\left(100.6 \mathrm{MHz}, \mathrm{CD}_{3} \mathrm{CN}, \mathrm{Si}\left(\mathrm{CH}_{3}\right)_{4}\right): \delta_{1}=$ 104.33 ppm, either d-quartet or d-quintet, but a quintet is assumed, $F_{5} S \underline{C} ; \delta_{2}=174.81 \mathrm{ppm}, d$ ， $\underline{C} F O ; J_{1 B}=20.7 \mathrm{~Hz} ; J_{1 C O F}$ $=70.60 \mathrm{~Hz} ; \mathrm{J}_{2 \mathrm{COF}}=297.5 \mathrm{~Hz}$.

Infrared spectrum: (neat sample, $\mathrm{NaCl}, \mathrm{cm}^{-1}$ ): 1766 (vs); 1395 (m)； 1380 (m)； 1257 (m)； 1203 (s); 1077 (m); 948 (w) ; 864 (s); 843 (vs) ; 789 (vs); 747 (m); 726 (m); 705 (m); 666 (m); 616 (s); 584 (s); 569 (s).

Anal.calcd.: for $\mathrm{C}_{2} \mathrm{CsF}_{7} \mathrm{O}_{3} \mathrm{~S}_{2}: \mathrm{C}, 5.97 ; \mathrm{Cs}, 33.06 ; \mathrm{F}$, $33.1 ; S, 15.95$. Found: C, 6.00; CS, 33.13; F, 33.6; S, 15.95

$\underline{\mathrm{HgF}}_{2}+21(45):$

Fresh mercury(II)-fluoride $10.4089 \mathrm{~g}, 1.71 \mathrm{mmol}$, 
Aldrich) was kept overnight in a $50 \mathrm{ml}$ pear-shaped flask with a Kontes Teflon valve connector under high vacuum (0.003 torr) at room temperature. A solution of $0.91 \mathrm{~g}$ of $\underline{21}$ (3.64 mmol) in $1.0 \mathrm{ml}$ of dry acetonitrile was added via vacuum transfer, and the flask was allowed to warm up slowly, while being swirled, once the contents started melting. The mercury fluoride dissolved largely in a vigorous reaction, and the process was moderated by dipping the flask occasionally into liquid nitrogen. A small residue was left behind, but was dissolved after keeping the flask at room temperature for 66 hours. Excess ketene and solvent were removed at room temperature by pumping on the flask through a $-196^{\circ} \mathrm{C}$ trap for 8 hours. The rate of weight loss slowed down constantly, but never reached zero. After 8 hours, $1.2559 \mathrm{~g}$ of a white slightly sticky mass was left behind. Although this corresponds to a ratio $\underline{21}: \mathrm{HgF}_{2}=$ 1.976:1.000, the product was apparently a non-stoichiometric compound $\left(\mathrm{F}_{5} \mathrm{SC}\left(\mathrm{SO}_{2} \mathrm{~F}\right) \mathrm{CFO}\right)_{2} \mathrm{Hg} \cdot \mathrm{nCH}_{3} \mathrm{CN}$, as inferred from the melting behavior and the i.r. spectrum, and therefore the complex must be volatile. Melting range $40-\approx 80^{\circ} \mathrm{C}$, bubbling starts at $104^{\circ} \mathrm{C}$.

${ }^{19} \mathrm{~F}$ n.m.r.spectrum $\left(\mathrm{CH}_{3} \mathrm{CN}\right.$, external $\left.\mathrm{CCl}_{3} \mathrm{~F}\right): \phi_{\mathrm{A}}=90.6$ ppm, 9 lines, area $=1.00 ; \phi_{\mathrm{B}}=79.9 \mathrm{ppm}, \mathrm{d}-\mathrm{m}$, area $=4.13 ;$ $\phi_{\mathrm{SO} 2 \mathrm{~F}}=66.1 \mathrm{ppm}$, broad singlet, area $=0.97 ; \phi_{\mathrm{CFO}}=21.2$ ppm, broad singlet, area $=0.97 ; \mathrm{J}_{\mathrm{AB}}=154.3 \mathrm{~Hz}$. All lines are broadened. 
I.r spectrum (neat sample on $\mathrm{KBr}, \mathrm{cm}^{-1}$ ): 3016 , wi 2966, wi 2952, w-m; 2629, wi 2423, wi 2385, w; 2347, w-m $\left(\mathrm{CO}_{2}\right.$ ?); 2305, $\mathrm{m} ; 2276, \mathrm{~m} ; 2053$, w,vbr; 1826, vs,br; 1414, vs,br; 1288, s; 1233, s-vs; 1195, s-vs; 1126, s-vs; 1078, s,sh; 1040,s; $964, \mathrm{~m}-\mathrm{s}, \mathrm{br} ; 855, \mathrm{vs}, \mathrm{br} ; 792$, sh,s-vs,br; 682 , $\mathrm{m}-\mathrm{s}, \mathrm{br} ; 663, \mathrm{~m}-\mathrm{s} ; 618, \mathrm{~s} ; 583, \mathrm{~s}-\mathrm{vs}, \mathrm{br} ; 493, \mathrm{~m}-\mathrm{s} ; 465, \mathrm{~s}$.

\section{$\underline{A g}+21(25 d):$}

The sample was prepared as described with $\underline{25}$. Initially, strong reaction was observed which slowed down eventually. A colorless liquid was obtained, which left a glassy mass behind, when the solvent was pumped off at room temperature, but no weight corresponding to a stoichiometric composition was obtained $\left(\left[\mathrm{F}_{5} \mathrm{SC}\left(\mathrm{SO}_{2} \mathrm{~F}\right) \mathrm{CFO}\right]-\mathrm{Ag}^{+} \cdot \mathrm{nCH}_{3} \mathrm{CN}\right)$. Upon warming, a weight corresponding to less than a 1:1 composition of $\mathrm{AgF}$ and $\underline{21}$ was obtained. The compound deposited slowly a dark precipitate when exposed to light, but this seems to suppress further decomposition, as the complex could still be detected by ${ }^{19} \mathrm{~F}$ n.m.r. spectroscopy when a $\mathrm{CH}_{3} \mathrm{CN}$ solution was exposed to the irradiation of a sun lamp overnight.

${ }^{19} \mathrm{~F}$ n.m.r. spectrum $\left(\mathrm{CH}_{3} \mathrm{CN}\right.$, external $\left.\mathrm{CCl}_{3} \mathrm{~F}\right): \mathrm{AB}_{4} \mathrm{MX} \phi_{\mathrm{A}}$ $=94.0 \mathrm{ppm}, 9$ lines, area $=1.09 ; \phi_{\mathrm{B}}=79.9 \mathrm{ppm}, \mathrm{d}-\mathrm{m}$, area $=$ $4.0 ; \phi_{\mathrm{M}}=69.7 \mathrm{ppm}, \mathrm{d}-\mathrm{p}$ (not well resolved), area $=0.89$ $\left(\mathrm{SO}_{2} \mathrm{~F}\right) ; \phi_{\mathrm{X}}=17.0 \mathrm{ppm}, \mathrm{d}-\mathrm{p}$, area $=0.78(\mathrm{CFO}) \cdot \mathrm{J}_{\mathrm{AB}}=155.3$ $\mathrm{Hz} ; \mathrm{J}_{\mathrm{BM}}=10.2 \mathrm{~Hz} ; \mathrm{J}_{\mathrm{BX}}=19.7 \mathrm{~Hz} ; \mathrm{J}_{\mathrm{MX}}=6.3 \mathrm{~Hz}$. 
$\underline{\mathrm{NaN}}_{3}+21(46):$

When a solution of $\underline{21}$ in dry acetonitrile was shaken with a few crystals of $\mathrm{NaN}_{3}$ at $0^{\circ} \mathrm{C}$ in an n.m.r. tube, the salt dissolved rapidly, and a pale yellow solution was formed. ${ }^{19} \mathrm{~F}$ n.m.r. spectroscopy indicated the complete consumption of 21 , with the formation of a single anionic species. When the solution was allowed to warm, it started to bubble, and turned dark yellow. From ${ }^{19} \mathrm{~F}$ n.m.r. measurements it is inferred that the compound $\left[\mathrm{F}_{5} \mathrm{SC}\left(\mathrm{SO}_{2} \mathrm{~F}\right) \mathrm{CFO}\right]^{-} \mathrm{Na}^{+}$is formed in this decomposition process of the primary azide anion, and the integrated band intensity is less than $1 / 2$ of the initial intensity of 21 . In a preparative scale experiment, $\mathrm{HCl}$ (aqueous) was added after dissolution of most of the $\mathrm{NaN}_{3}$, and n.m.r. measurements and g.c. indicated the formation of $\mathrm{F}_{5} \mathrm{SCH}_{2} \mathrm{SO}_{2} \mathrm{~F}$, rather than $\mathrm{F}_{5} \mathrm{SCH}\left(\mathrm{SO}_{2} \mathrm{~F}\right) \mathrm{NH}_{2}$, which should have a substantially different chemical shift and retention time. ${ }^{19} \mathrm{~F}$ n.m.r. spectrum of $\left[\mathrm{F}_{5} \mathrm{SC}\left(\mathrm{SO}_{2} \mathrm{~F}\right) \mathrm{CON}_{3}\right]^{-} \mathrm{Na}^{+}\left(\mathrm{CH}_{3} \mathrm{CN}\right.$, external $\left.\mathrm{CCl}_{3} \mathrm{~F}\right): \mathrm{AB}_{4} \mathrm{X} \phi_{\mathrm{A}}=95.9 \mathrm{ppm} ; \phi_{\mathrm{B}}=82.6 \mathrm{ppm} ; \phi_{\mathrm{SO} 2 \mathrm{~F}}=$ $69.5 \mathrm{ppm} ; \mathrm{J}_{\mathrm{AB}}=151.5 \mathrm{~Hz} ; \mathrm{J}_{\mathrm{BSO} 2 \mathrm{~F}}=10.3 \mathrm{~Hz}$.

Pentafluorothiofluorosulfonylchloroacetylfluoride (25a):

To $2.0 \mathrm{~g}$ of $\mathrm{Cs}^{+}\left[\mathrm{F}_{5} \mathrm{SC}\left(\mathrm{SO}_{2} \mathrm{~F}\right) \mathrm{COF}\right]^{-}(5.0 \mathrm{mmol})$ in a $75 \mathrm{ml}$ steel reaction vessel, chlorine $(0.551,210$ torr, room temperature, $6.3 \mathrm{mmol}$ ) was added via vacuum transfer. The vessel was heated to $85^{\circ} \mathrm{C}$ for $2 \mathrm{~h}$, then kept at room 
temperature for $18 \mathrm{~h}$. The volatile products $(1.25 \mathrm{~g})$, as collected by vacuum transfer, were obtained as a clear liquid. Excess chlorine was removed by shaking with $\approx 1 \mathrm{~g}$ of mercury and the product thus obtained by vacuum transfer, a clear and colorless liquid, was analytically pure (1.14 g, $75.3 \%$

${ }^{19} \mathrm{~F}$ n.m.r. spectrum ( pentane, $\operatorname{ccl}_{3} \mathrm{~F}$ ext.) $: \phi_{1}=63.6$ ppm, $m$, int. $=5.1,\left(\mathrm{SF}_{5}\right) ; \phi_{2}=49.3 \mathrm{ppm}, \mathrm{m}$, int. $=1.0$ $\left(\mathrm{SO}_{2} \mathrm{~F}\right) ; \phi_{3}=31.3 \mathrm{ppm}, \mathrm{m}$, int. $=1.0(\mathrm{COF})$.

Infrared spectrum (neat liquid, $\mathrm{KBr}, \mathrm{cm}^{-1}$ ): 1873 (s); 1853 (s); 1458 (vs); 1223 (vs); 1175 (s); 955 (m); 890 (vs); $834(\mathrm{~s}) ; 808(\mathrm{~m}) ; 790 \quad(\mathrm{~m}) ; 739 \quad(\mathrm{vw}) ; 700 \quad(\mathrm{~m}) ; 694$ $(\mathrm{m}) ; 669(\mathrm{vw}) ; 635(\mathrm{~m}-\mathrm{w}) ; 623 \quad(\mathrm{~m}-\mathrm{w}) ; 612 \quad(\mathrm{~m}-\mathrm{s}) ; 579$ (vs): 569 (vs,sh); 504 (w); 496 (w); 472 (w); 417 (w). Mass spectrum (electrom impact, $70 \mathrm{eV}$, mass, species, $>1 \%): 158, \mathrm{C}_{2}{ }^{35} \mathrm{ClFO}_{3} \mathrm{~S}^{+}, 23.4 ; 155, \mathrm{C}^{35} \mathrm{ClF}_{4} \mathrm{~S}^{+}, \mathrm{C}_{2} \mathrm{FO}_{3} \mathrm{~S}_{2}{ }^{+}, 5.5$; 129, $\mathrm{C}_{2}{ }^{35} \mathrm{ClF}_{2} \mathrm{~S}^{+}, 2.2 ; 127, \mathrm{SF}_{5}{ }^{+}, \mathrm{CFO}_{2} \mathrm{~S}_{2}{ }^{+} ; 125, \mathrm{CHO}_{3} \mathrm{~S}_{2}{ }^{+}, 1.1$; 124, $\mathrm{C}_{2} \mathrm{HFOS}_{2}{ }^{+}, 2.9 ; 113, \mathrm{C}_{2}{ }^{35} \mathrm{ClF}_{2} \mathrm{O}^{+}, 5.2 ; 108, \mathrm{SF}_{4}^{+}, 1.5$; 103, $\mathrm{CH}_{2} \mathrm{SF}_{3}^{+}, 2.0 ; 101, \mathrm{CF}_{3} \mathrm{~S}^{+}, 1.7 ; 95, \mathrm{C}^{35} \mathrm{ClOS}^{+}, \mathrm{CFS}_{2}^{+}$, $7.0 ; 94, \mathrm{C}_{2}{ }^{35} \mathrm{ClFO}^{+}, 8.7 ; 91, \mathrm{C}_{2} \mathrm{FOS}^{+},{ }^{34} \mathrm{SF}_{3}{ }^{+}, 4.8 ; 89, \mathrm{SF}_{3}{ }^{+}$, $100.0 ; 86,{ }^{35} \mathrm{ClFS}^{+}, 6.6 ; 85, \mathrm{C}^{35} \mathrm{ClF}_{2}+, 8.5 ; 83, \mathrm{SO}_{2} \mathrm{~F}^{+}, 3.4 ;$ 81, $\mathrm{C}_{2} \mathrm{~F}_{3}{ }^{+}$(rearr.), $11.2 ; 79, \operatorname{csoF}^{+}, 1.3 ; 78, \mathrm{C}_{2} \mathrm{~F}_{2} \mathrm{O}^{+}$ (rearr.), 1.1; 77, $\mathrm{CHS}_{2} \mathrm{O}^{+}, \mathrm{C}_{2} \mathrm{H}_{2} \mathrm{FS}^{+}$(two fragments), 1.4, 2.5; $76, \mathrm{CSO}_{2}^{+}, \mathrm{C}_{2} \mathrm{HFS}^{+}, 1.2 ; 75, \mathrm{C}_{2} \mathrm{FS}^{+}, 8.0 ; 73, \mathrm{C}_{2} \mathrm{HOS}^{+}, 1.1 ; 72$, $\mathrm{C}_{2} \mathrm{OS}^{+}, 1.2 ; 70, \mathrm{SF}_{2}{ }^{+}, 44.8 ; 69, \mathrm{CF}_{3}{ }^{+}$(rearr.), $8.6 ; 67$, $\mathrm{SOF}^{+}, 58.9 ; 66, \mathrm{C}^{35} \mathrm{ClF}^{+}, 19.8 ; 65, \mathrm{SO}_{2} \mathrm{H}^{+}, 5.6 ; 64, \mathrm{SO}_{2}^{+}$, 
$54.3 ; 63, \mathrm{CFS}^{+}, 17.3 ; 60, \mathrm{COS}^{+}, 1.8 ; 51, \mathrm{SF}^{+}, 12.0$. Anal.calcd for $\mathrm{C}_{2} \mathrm{ClF}_{7} \mathrm{O}_{3} \mathrm{~S}_{2}: \mathrm{C}, 7.89 ; \mathrm{Cl}, 11.64 ; \mathrm{F}$, $43.7 ; \mathrm{S}, 21.05$. Found: C, 7.85; Cl, 11.9; F, 44.0; S, 21.23.

\section{Pentafluorosulfurfluorosulfonylchloromethane (25h):}

In a $5.0 \mathrm{ml}$ Pyrex flask $0.74 \mathrm{~g}$ of $\mathrm{F}_{5} \mathrm{SCCl}\left(\mathrm{SO}_{2} \mathrm{~F}\right)(\mathrm{COF})$ (2.4 mmol) were mixed with $0.65 \mathrm{~g}$ water (distilled). The flask was stoppered lightly and kept at room temperature for $21 \mathrm{~h}$. After pipetting off the water layer, adding $\approx$ Ig of powdered $\mathrm{P}_{4} \mathrm{O}_{10}$ in the cold under swirling in small portions, and vacuum transferring away the volatile product, and repeating the drying procedure, $0.61 \mathrm{~g}(97.1 \%)$ of a clear liquid was obtained once. The material was analytically pure as seen by gas chromatography $\left(30 \% \mathrm{SE}-30,2 \mathrm{~m}, 120^{\circ} \mathrm{C}, \mathrm{R}_{f}=\right.$ $15.3 \operatorname{min.}),{ }^{1} \mathrm{H}$ and ${ }^{19} \mathrm{~F}$ n.m.r.

Infrared spectrum (neat liquid, $\left.\mathrm{KBr}, \mathrm{cm}^{-1}\right): 2992$ (m); 1448 (Vs); 1262 (m-w); 1232 (s-vs); 1205 (m-s); 1192 (mw, sh); 874 (vs); 851 (vs); $811 \quad$ (s); $774 \quad$ (m-s); 757 $(\mathrm{w}, \mathrm{sh}) ; 688 \quad(\mathrm{Vw}) ; 669$ (m); $612 \quad(\mathrm{~m}) ; 581 \quad$ (s); $571 \quad$ (s); $566(\mathrm{~s}) ; 499(\mathrm{Vw}) ; 490(\mathrm{w}-\mathrm{m}) ; 463 \quad(\mathrm{~m}) ; 453 \quad(\mathrm{Vw}) ; 423$ $(\mathrm{vw}) ; 405(\mathrm{~m})$.

${ }^{1} \mathrm{H}$ n.m.r. (neat liquid, $\mathrm{CH}_{2} \mathrm{Cl}_{2}$ ext. standard): $\delta=$ $6.14 \mathrm{ppm}$, pentet. $\mathrm{J}_{\mathrm{BH}}=4.20 \mathrm{~Hz}$.

${ }^{19} \mathrm{~F}$ n.m.r. (neat liquid, ext. $\left.\operatorname{ccl}_{3} F\right): \phi_{1}=61.5 \mathrm{ppm}, \mathrm{m}$, int. $=5.0$, (degenerate $A_{4}$ spectrum, $\left.S F_{5}\right): \phi_{2}=49.8 \mathrm{ppm}$, p, int. $=1.0\left(\mathrm{SO}_{2} \mathrm{~F}\right) \cdot \mathrm{J}_{\mathrm{B} 2}=9.5 \mathrm{~Hz}$. 
Mass spectrum (electron impact, $70 \mathrm{eV}$, mass, species,

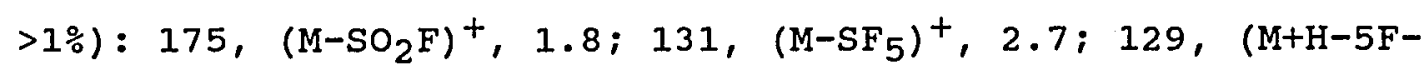
$\mathrm{Cl})^{+}, 2.5 ; 127, \mathrm{SF}_{5}{ }^{+}, 53.1 ; 108, \mathrm{SF}_{4}^{+}, 2.2 ; 91, \mathrm{C}_{2} \mathrm{FOS}^{+}, 2.1$; 89, $\mathrm{SF}_{3}{ }^{+}, 45.7 ; 83, \mathrm{SO}_{2} \mathrm{~F}^{+}, 2.6 ; 79, \mathrm{CFOS}^{+}, 1.8 ; 70, \mathrm{SF}_{2}{ }^{+}$, $7.9 ; 69, \mathrm{H}_{2} \mathrm{SOF}^{+}, \mathrm{CF}_{3}+, 16.7 ; 68, \mathrm{HSOF}^{+}, 1.6 ; 67, \mathrm{SOF}^{+}$, $100.0 ; 64, \mathrm{SO}_{2}^{+}, 8.1 ; 63, \mathrm{CFS}^{+}, 1.2 ; 51, \mathrm{SF}^{+}, 4.8$

Anal.calcd. for $\mathrm{CHClF}_{6} \mathrm{O}_{2} \mathrm{~S}_{2}: \mathrm{C}, 4.64 ; \mathrm{H}, 0.39 ; \mathrm{Cl}$, 13.71; F, 44.1, S, 24.80. Found: C, 4.72; H, $0.34 ; \mathrm{Cl}$, $13.74 ; \mathrm{F}, 44.3 ; \mathrm{S}, 24.84$.

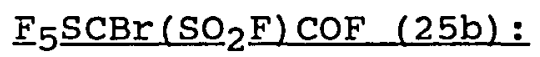

Bromine $(0.37 \mathrm{~g}, 2.31 \mathrm{mmol})$ and 21 (0.95 $\mathrm{g}, 2.36 \mathrm{mmol})$ were gently heated in a $30 \mathrm{ml}$ Carius tube under anaerobic conditions with a heat gun, when most of the bromine was consumed rapidly; heating was continued at $82^{\circ} \mathrm{C}(\mathrm{l} \mathrm{h})$, but a brownish color persisted. The product was vacuum transferred out $(0.67 \mathrm{~g})$, treated with mercury $(\approx 2 \mathrm{~g})$ to remove excess bromine, after which $0.42 \mathrm{~g}$ of crude $\mathrm{F}_{5} \mathrm{SCBr}\left(\mathrm{SO}_{2} \mathrm{~F}\right) \mathrm{COF}$ was collected. This material could not be purified by fractional condensation or distillation and was used as such in subsequent reactions.

I.r. spectrum of the crude material (neat sample, $\mathrm{KBr}$, $\left.\mathrm{cm}^{-1}\right)$ : 2985, VW; 2674, Vw; 1868, s, sh; 1846, vs; 1455, s-vs; $1290, \mathrm{w} ; 1230, \mathrm{~s} ; 1171, \mathrm{~s} ; 1103, \mathrm{w} ; 946, \mathrm{~m}-\mathrm{s} ; 881$, vs; 835 , $\mathrm{s}, \mathrm{sh} ; 814, \mathrm{~s} ; 791, \mathrm{~s} ; 692, \mathrm{~s} ; 650, \mathrm{~m} ; 610, \mathrm{~s} ; 579, \mathrm{~s} ; 568$, $\mathrm{s}, \mathrm{sh} ; 497, \mathrm{~m} ; 492, \mathrm{~m} ; 466, \mathrm{~m} ; 458, \mathrm{~m}$. 
${ }^{19} \mathrm{~F}$ n.m.r. $\left(\mathrm{CCCl}_{3}\right.$, external $\left.\mathrm{CCl}_{3} \mathrm{~F}\right): \phi=74 \mathrm{ppm}$, int. = 4 (impurity); $\phi=67.6 \mathrm{ppm}, \mathrm{m}$, int. $=30\left(\mathrm{SF}_{5}\right) ; \phi=60-62$, several lines, int. $=4$ (impurity) $; \phi=50.6 \mathrm{ppm}, \mathrm{m} ;$ int. $=$ $6\left(\mathrm{SO}_{2} \mathrm{~F}\right) ; \phi=35.3 \mathrm{ppm}, \mathrm{m}$, int. $=6(\mathrm{COF})$.

\section{$\underline{F}_{5} \underline{S C H B r S O}_{2}{ }_{F}(25 i):$}

To $1.31 \mathrm{~g}$ of crude $\mathrm{F}_{5} \mathrm{SCBr}\left(\mathrm{SO}_{2} \mathrm{~F}\right) \mathrm{COF}$ in a $4.0 \mathrm{ml}$ conical vial 5 drops of water were added, and the flask was lightly stoppered; no visible reaction occurred. The mixture was kept at room temperature for 18 hours and occasionally swirled. Phosphorous pentoxide was added with cooling and the volatile materials were transferred out $(0.84 \mathrm{~g})$; a light, slightly yellow liquid was obtained. Gas chromatography ( $20 \% \mathrm{SE}-30$, on Chromosorb W, 3m, $\left.120^{\circ} \mathrm{C}\right): 2$ bands, $R_{f}=5.6$ minutes, area $=14.6 \%$ (same $R_{f}$ as $\left.\mathrm{F}_{5} \mathrm{SCH}_{2} \mathrm{SO}_{2} \mathrm{~F}\right), \mathrm{R}_{\mathrm{f}}=12$ minutes, area $=85.6 \%\left(\mathrm{~F}_{5} \mathrm{SCHBr}\left(\mathrm{SO}_{2} \mathrm{~F}\right)\right)$. Preparative g.C. $\left(20 \% \mathrm{SE}-30,3 \mathrm{~m}, 115^{\circ} \mathrm{C}\right)$ afforded $0.24 \mathrm{~g}$ $(23.5 \%)$ of a colorless liquid.

$1_{\mathrm{H}}$ n.m.r. spectrum $\left(\mathrm{CDCl}_{3}, \mathrm{Si}\left(\mathrm{CH}_{3}\right)_{4}, 300 \mathrm{MHz}\right): \delta=$ $6.40 \mathrm{ppm}, \mathrm{p}, 4.58 \mathrm{~Hz}$.

${ }^{19} \mathrm{~F}$ n.m.r.spectrum $\left(\mathrm{CDCl}_{3}\right.$, external $\left.\mathrm{CCl}_{3} \mathrm{~F}\right): \phi=64-$ $74 \mathrm{ppm}$, distorted $\mathrm{AB}_{4}$ spectrum, maximum at $66.7 \mathrm{ppm}$, int. = $5.2\left(\mathrm{SF}_{5}\right) ; \phi=53.3 \mathrm{ppm}, \mathrm{m}$, int. $=1.0\left(\mathrm{SO}_{2} \mathrm{~F}\right)$.

Infrared spectrum (neat sample, $\mathrm{KBr}, \mathrm{cm}^{-1}$ ): 2997, $\mathrm{m}$; 2922, Vw; 1445, s; 1256, w-m; 1225, m-s; 1166, w; 1072, w, broad; 871, vs; $820, \mathrm{~s} ; 785, \mathrm{~m} ; 761, \mathrm{~m}-\mathrm{s} ; 690, \mathrm{w} ; 663, \mathrm{~m}$; 
$612, \mathrm{~m}-\mathrm{s} ; 578, \mathrm{~s} ; 569, \mathrm{~s} ; 564, \mathrm{~s}, \mathrm{sh} ; 490, \mathrm{~m} ; 463, \mathrm{w} ; 456, \mathrm{w}$; $404, \mathrm{~m}$.

Mass spectrum (e.i., m/e, fragment, $\%>1$, only ${ }^{79} \mathrm{Br}$ Iisted $)=219,\left(\mathrm{M}-\mathrm{SO}_{2} \mathrm{~F}\right)^{+}, 1.6 ; 175,\left(\mathrm{M}-\mathrm{SF}_{5}\right)^{+}, 20.5 ; 129$, ${ }^{34} \mathrm{SF}_{5}{ }^{+}, 1.9 ; 127,{ }^{32} \mathrm{SF}_{5}{ }^{+}, 52 ; 111, \mathrm{CHBrF}^{+},($rearr.), 30.0 ; 108, $\mathrm{SF}_{4}^{+}, 2.2 ; 97, \mathrm{CH}_{2} \mathrm{FS}_{2}^{+}, 4.0 ; 95, \mathrm{CSO}_{2} \mathrm{~F}^{+}, \mathrm{CFS}_{2}^{+}, 1.6$; 93, $\mathrm{CH}_{2} \mathrm{Br}^{+}, 2.4 ; 92, \mathrm{CHBr}^{+}, 11.8 ; 91$, two fragments, $\mathrm{CBr}^{+}$, ?, 2.4, 2.5; 89, $\mathrm{SF}_{3}{ }^{+}, 61.5 ; 83, \mathrm{SO}_{2} \mathrm{~F}^{+}, \mathrm{CHSF}_{2}{ }^{+}, 1.3 ; 80$, $\mathrm{HBr}^{+}, 3.6 ; 79, \mathrm{Br}^{+}, 4.4 ; 70, \mathrm{SF}_{2}{ }^{+}, 10.2 ; 69, \mathrm{CF}_{3}{ }^{+}, 5.0 ; 68$, $\mathrm{FSOH}^{+}(?), 1.1 ; 67, \mathrm{FSO}^{+}, 100.0 ; 64, \mathrm{CHSF}^{+}, \mathrm{SO}_{2}^{+}, 7.5 ; 63$, $\mathrm{CSF}^{+}, 1.2 ; 51, \mathrm{SF}^{+}, 6.3$.

Anal.calcd for $\mathrm{CHBrF}_{6} \mathrm{O}_{2} \mathrm{~S}_{2}: \mathrm{C}, 3.96 ; \mathrm{H}, 0.33 ; \mathrm{F}, 37.6$; $\mathrm{S}, 21.16 ; \mathrm{Br}, 26.37$. Found: C, 4.02; H, 0.37; F, 38.0; S, $21.26 ; \mathrm{Br}, 26.28$.

\section{$\underline{\mathrm{F}}_{5} \underline{\mathrm{SCH}}_{\left(\mathrm{SO}_{2}\right.}{\underline{\mathrm{F}}) \mathrm{CH}_{2}}_{2} \underline{\mathrm{CH}}_{2} \underline{\mathrm{Br}}(25 \mathrm{i}):$}

A $75 \mathrm{ml}$ stainless steel bomb was charged with $0.24 \mathrm{~g}$ of benzoyl peroxide (1.0 mmol, Aldrich), $1.73 \mathrm{~g}$ of crude $\mathrm{F}_{5} \mathrm{SCBr}\left(\mathrm{SO}_{2} \mathrm{~F}\right) \mathrm{COF}(\approx 5 \mathrm{mmol})$ and $0.57 \mathrm{~g}$ of ethylene (21.9 mmol) and heated at $95^{\circ} \mathrm{C}$ for 24 hours. At room temperature, a colorless liquid ( $1.01 \mathrm{~g}$ after degassing) was transferred out; its i.r. and ${ }^{19}$ F n.m.r. spectra was virtually identical with the spectra of authentic $\mathrm{F}_{5} \mathrm{SCH}_{2} \mathrm{SO}_{2} \mathrm{~F}$. The residue in the bomb $(0.78 \mathrm{~g})$, a brown, partially crystalline mass, was dissolved in ether, and both the i.r. and ${ }^{19} \mathrm{~F}$ spectra indicated the absence of a COF group in the crude product, 
but there was a $\mathrm{C}=0$ band at $1690 \mathrm{~cm}^{-1}$. The material that caused this band could not be removed by vacuum distillation, but stirring a $\mathrm{CH}_{2} \mathrm{CL}_{2}$ solution of the collected impure fraction, the pot residue and the rinse of the distillation head with dilute $\mathrm{NaHCO}_{3}$ solution for circa 15 minutes caused its disappearance. The $\mathrm{CH}_{2} \mathrm{Cl}_{2}$ solution was pipetted off, dried $\left(\mathrm{Na}_{2} \mathrm{SO}_{4}\right)$ and transferred to a $10 \mathrm{ml}$ flask. Distillation ( $1 \mathrm{~mm} \mathrm{Hg}$ ) afforded a small amount of colorless liquid $\left(45-46^{\circ} \mathrm{C}\right)$, but lowering the pressure $(\approx 0.5$ $\mathrm{mm} \mathrm{Hg})$, and heating the distillation head with a heat gun yielded some more product $(0.23 \mathrm{~g}, 14.0 \%)$.

$1_{\mathrm{H}}$ n.m.r. spectrum (neat sample, external $\left.\mathrm{Si}\left(\mathrm{CH}_{3}\right)_{4}\right)$ : $\delta_{1}=5.79 \mathrm{ppm}, \mathrm{m}$, partially resolved, probably a septet, $\mathrm{J} \approx$ $5.4 \mathrm{~Hz}$, intensity $=0.97\left(F_{5} \mathrm{SCH}\right) ; \delta_{2}=3.23 \mathrm{ppm}, \mathrm{m}$, intensity $=2.03\left(\mathrm{CH}_{2} \mathrm{CH}_{2} \mathrm{Br}\right) ; \delta_{3}=3.94 \mathrm{ppm}, t, J_{23}=6.0 \mathrm{~Hz}$, intensity $=2.00\left(\mathrm{CH}_{2} \mathrm{Br}\right)$. All lines are broadened.

${ }^{19} \mathrm{~F}$ n.m.r. spectrum (neat liquid, external $\mathrm{CCl}_{3} \mathrm{~F}$ ): $\mathrm{AB}_{4} \mathrm{X} \phi_{\mathrm{A}}=75.3 \mathrm{ppm}$, $\mathrm{d}$ of nine line pattern (the doublet is poorly resolved), intensity $=1.00 ; \phi_{\mathrm{B}}=66.0 \mathrm{ppm}, \mathrm{d}-\mathrm{m}$, intensity $=4.00 ; \phi_{\mathrm{X}}=54.8 \mathrm{ppm}, \approx$ pentet, intensity $=0.94$ $\left(\mathrm{SO}_{2} \mathrm{~F}\right) \cdot \mathrm{J}_{\mathrm{AB}}=149.6 \mathrm{~Hz} ; \mathrm{J}_{\mathrm{BX}}=11.3 \mathrm{~Hz} ; \mathrm{J}_{\mathrm{AH}}{ }^{1} \approx 4.2 \mathrm{~Hz}$.

I.r.spectrum (neat liquid on $\mathrm{KBr}, \mathrm{cm}^{-1}$ ): 3062 , VW; 2960, w; 2940, w,sh; 1428, s-vs; 1364, vw; 1318, w; 1268, $\mathrm{m}, \mathrm{sh} ; 1252, \mathrm{~m} ; 1216, \mathrm{~s} ; 1179, \mathrm{w} ; 1158, \mathrm{vw}, \mathrm{sh} ; 989, \mathrm{w}, \mathrm{br}$; 970, vw,sh; 941, w; 871, vs; $820, \mathrm{~m}-\mathrm{s} ; 809, \mathrm{~m}-\mathrm{s}, \mathrm{sh} ; 775, \mathrm{~m}-$ $\mathrm{s} ; 756, \mathrm{~m}, \mathrm{sh} ; 672, \mathrm{~m} ; 645, \mathrm{vw} ; 613, \mathrm{~m} ; 589, \mathrm{~s} ; 579, \mathrm{~s}, \mathrm{sh}$; 
563, m-s,sh; 512, vw; 495, vw; 475, w; 448, w.

Mass spectrum (e.i., $70 \mathrm{ev}, \mathrm{m} / \mathrm{e}$, fragment, $\% 1$, only

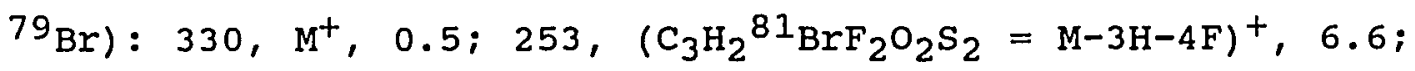
252, $(\mathrm{M}+\mathrm{H}-\mathrm{Br})^{+}, 3.4 ; 251,(\mathrm{M}-\mathrm{Br})^{+}, \mathrm{C}_{3} \mathrm{H}_{2}{ }^{79} \mathrm{BrF}_{2} \mathrm{O}_{2} \mathrm{~S}_{2}{ }^{+}, 71.0$; $246,\left(\mathrm{M}-\mathrm{SO}_{2} \mathrm{~F}-\mathrm{H}\right)^{+}, 6.2 ; 202,\left(\mathrm{M}-\mathrm{SF}_{5}-2 \mathrm{H}\right)^{+}, 7.4 ; 167,(\mathrm{M}-\mathrm{Br}-$ $\left.\mathrm{SO}_{2} \mathrm{~F}-\mathrm{H}\right)^{+}, 4.2 ; 135,\left(\mathrm{M}-\mathrm{CH}_{2} \mathrm{Br}-\mathrm{SO}_{2} \mathrm{~F}-\mathrm{F}\right)^{+}, 1.7 ; 127, \mathrm{SF}_{5}^{+}, 20.3$; 123, $\mathrm{C}_{2} \mathrm{FOS}_{2}^{+}, 5.2 ; 122, \mathrm{C}_{2} \mathrm{H}_{2} \mathrm{O}_{2} \mathrm{~S}_{2}{ }^{+}, 1.9 ; 119, \mathrm{C}_{3} \mathrm{H}_{3} \mathrm{Br}^{+}, 46.1$; 113, $\mathrm{C}_{2} \mathrm{~F}_{3} \mathrm{~S}^{+}, 1.4 ; 111, \mathrm{CFOS}_{2}{ }^{+}, 1.9 ; \mathrm{CHO}_{2} \mathrm{~S}_{2}{ }^{+}, 2.3 ; 108$, $\mathrm{CO}_{2} \mathrm{~S}_{2}{ }^{+}, \mathrm{SF}_{4}^{+}, 1.1 ; 107, \mathrm{C}_{2} \mathrm{FS}_{2}^{+}, 1.8 ; 97, \mathrm{CH}_{2} \mathrm{SO}_{2} \mathrm{~F}^{+}, 4.7 ; 93$, $\mathrm{CH}_{2} \mathrm{Br}^{+}, 16.7 ; 91, \mathrm{C}_{3} \mathrm{H}_{4} \mathrm{FS}^{+}, 3.4 ; 89, \mathrm{SF}_{3}^{+}, 47.4 ; 87, \mathrm{C}_{3} \mathrm{FS}^{+}$, $1.2 ; 83, \mathrm{SO}_{2} \mathrm{~F}^{+}, 2.9 ; 81, \mathrm{CH}_{2} \mathrm{SOF}^{+}, 1.5 ; 79, \mathrm{CSOF}^{+}, 2.7 ; 71$, $\mathrm{C}_{3} \mathrm{H}_{3} \mathrm{~S}^{+}, 1.4 ; 70, \mathrm{SF}_{2}^{+}, 6.5 ; 69, \mathrm{C}_{3} \mathrm{HS}^{+}, \mathrm{CF}_{3}^{+}, 4.6 ; 68, \mathrm{C}_{3} \mathrm{~S}^{+}$, $1.3 ; 67, \mathrm{FOS}^{+}, 25.5 ; 65, \mathrm{CH}_{2} \mathrm{SF}^{+}, 3.1 ; 64, \mathrm{SO}_{2}^{+}, \mathrm{CHSF}^{+}, 2.0$; $60, \mathrm{C}_{2} \mathrm{H}_{4} \mathrm{~S}^{+}, 7.9 ; 59, \mathrm{C}_{2} \mathrm{H}_{3} \mathrm{~S}^{+}, 100.0 ; 57, \mathrm{C}_{2} \mathrm{HS}^{+}, 7.9 ; 55$, $\mathrm{C}_{3} \mathrm{~F}^{+}, 8.7 ; 51, \mathrm{SF}^{+}, 5.9$.

Anal.calcd for $\mathrm{C}_{3} \mathrm{H}_{5} \mathrm{BrF}_{6} \mathrm{O}_{2} \mathrm{~S}_{2}: \mathrm{C}, 10.88 ; \mathrm{H}, 1.52 ; \mathrm{Br}$, $24.13 ; \mathrm{F}, 34.43 ; \mathrm{S}, 19.37$. Found: C, 10.85; H, 1.50; Br, $24.17 ; \mathrm{F}, 34.5 ; \mathrm{S}, 19.33$.

\section{$\underline{F}_{5} \underline{\operatorname{SCBr}}_{2} \underline{\mathrm{SO}}_{2} \underline{\mathrm{F}}(25 f):$}

Bromine was added dropwise to a stirred solution of $\underline{25}$ $(2.00 \mathrm{~g}, 5.0 \mathrm{mmol})$ in a $25 \mathrm{ml}$ flask in $0.5 \mathrm{ml}$ of acetonitrile at room temperature. A white precipitate was formed instantly, and after some time, bubbling and foaming ensued, with the paling of the bromine color. More bromine was added occasionally, until a faint red color persisted 
and no more bubbles were observed ( $\approx 15$ minutes). Stirring was continued for $5 \mathrm{~min}$. ${ }^{19} \mathrm{~F}$ n.m.r. indicated only one product, devoid of a COF group, to be present. Because of the failure to separate the product from the solvent by distillation, the reaction mixture was subjected to fractional condensation $\left(-20,-78,-196^{\circ} \mathrm{C}\right)$, where the material in the $-20^{\circ} \mathrm{C}$ trap was used in three successive trap-to-trap distillations respectively. This resulted in $0.73 \mathrm{~g}(38.4 \%)$ of an almost colorless, glassy, partially crystalline material, m.p. $39-43^{\circ} \mathrm{C}$. The material of the -78 ${ }^{\circ} \mathrm{C}$ trap was subjected to repeated fractional condensations, but it was not possible to obtain a solid material. The product $\left(-10^{\circ} \mathrm{C}\right.$ trap, $\left.0.56 \mathrm{~g}\right)$ showed an almost similar i.r. spectrum to the solid, while the $-78{ }^{\circ} \mathrm{C}$ trap $(0.59 \mathrm{~g})$ contained sizable amounts of $\mathrm{CH}_{3} \mathrm{CN}$. The $-196{ }^{\circ} \mathrm{C}$ trap $(0.64$ g) was almost free of any $\mathrm{SF}_{5}$ product.

19 F n.m.r. spectrum ( $\mathrm{CH}_{3} \mathrm{CN}, \mathrm{CCl}_{3} \mathrm{~F}$ ext.): $\mathrm{AB}_{4} \mathrm{X}$ spectrum, $\phi_{\mathrm{A}}=67.0 \mathrm{ppm}, 9$ lines, int. $=1.00 ; \phi_{\mathrm{B}}=58.0$ ppm, d-m, int. $=4.11 ; \phi_{X}\left(\mathrm{SO}_{2} \mathrm{~F}\right)=39.9 \mathrm{ppm}, \approx s$ (not resolved): $\mathrm{J}_{\mathrm{AB}}=149.0 \mathrm{~Hz}$.

I.r. spectrum (neat samples, on $\mathrm{KBr}, \mathrm{cm}^{-1}$ ): 1441 (vs); 1268 (Vw, sh); 1222 (Vs); 1215 (m); 1100 (m,sh); 1087 (w,sh); 1049 (Vw); 972 (w); 882 (vs); 857 (vs); 831 (vs); 787 (m-s); $767(\mathrm{~m}-\mathrm{s}) ; 749(\mathrm{~m}, \mathrm{sh}) ; 715(\mathrm{~m}-\mathrm{s}) ; 703(\mathrm{~m}-\mathrm{s}) ; 685$ (s); 654 (Vw); 618 (m-s); 605 (s); 566 (vs); 498 (m); 489 (m); 471 (m) $; 463(\mathrm{~m})$. 
Mass spectrum (e.i., $70 \mathrm{eV}$, mass, fragment, $\%>10$ ): 299, $\mathrm{F}_{5} \mathrm{SC}^{79} \mathrm{Br}^{81} \mathrm{Br}^{+}, 53.4$ (triplet, 1:2:1); 281,; 255, $\mathrm{C}^{81} \mathrm{Br}^{79} \mathrm{BrSO}_{2} \mathrm{~F}^{+}, 54.3$ (triplet); 191, $\mathrm{CBr}_{2} \mathrm{~F}^{+}$(rearr.), 24.8 (triplet); $172, \mathrm{C}^{81} \mathrm{Br}^{79} \mathrm{Br}^{+}, 19.4$ (triplet; ) 159, $\mathrm{CH}^{79} \mathrm{BrSOF}^{+}$, $11.0 ; 127, \mathrm{SF}_{5}{ }^{+}, 33.9 ; 92, \mathrm{C}^{79} \mathrm{Br}^{+}, 26.0 ; 89, \mathrm{SF}_{3}{ }^{+}, 92.6 ; 80$, $\mathrm{H}^{79} \mathrm{Br}, 15.7 ; 79,{ }^{79} \mathrm{Br}, \mathrm{CFSO}^{+}, 14.2 ; 70, \mathrm{SF}_{2}{ }^{+}, 20.7 ; 67$, $\mathrm{FSO}^{+}, 100.0 ; 64, \mathrm{SO}_{2}^{+}, 64.8 ; 48, \mathrm{SO}^{+}, 30.1 ; 44, \mathrm{CS}^{+}, 22.1$. Anal.calcd for $\mathrm{CBr}_{2} \mathrm{~F}_{6} \mathrm{O}_{2} \mathrm{~S}_{2}: \mathrm{C}, 3.14 ; \mathrm{Br}, 41.84 ; \mathrm{F}$, $29.8 ; \mathrm{S}$, 16.79. Found: C, 3.32; $\mathrm{Br}, 40.95 ; \mathrm{F}, 29.4 ; \mathrm{S}$, 16.65.

\section{$\underline{\mathrm{F}}_{5} \mathrm{SCCl}\left(\mathrm{SO}_{2} \mathrm{~F}\right) \mathrm{COCl}(25 \mathrm{~g}):$}

$2.12 \mathrm{~g}$ of $\mathrm{Cs}^{+}\left[\mathrm{F}_{5} \mathrm{SC}\left(\mathrm{SO}_{2} \mathrm{~F}\right) \mathrm{COF}\right]^{-}(5.3 \mathrm{mmol})$ and $1.31 \mathrm{~g}$ $\mathrm{Cl}_{2}(18.5 \mathrm{mmol})$ in a $300 \mathrm{ml}$ Pyrex-quartz vessel were irradiatet with a $250 \mathrm{~W}$ GE sunlamp from a distance of $5 \mathrm{~cm}$ $(4 \mathrm{~h})$ and $10 \mathrm{~cm}(12 \mathrm{~h})$. The pressure in the reaction vessel had dropped by $1 / 3$, indicating the consumption of 1 equivalent of chlorine; an i.r. spectrum $(100$ torr, $10 \mathrm{~cm}$ path length, $\mathrm{KBr}$ windows) showed a COF group, but neither $\mathrm{CO}$ nor coclF bands. Irradiation was continued for $24 \mathrm{~h}$ with no change in the i.r. spectrum. Dry acetonitrile ( $1 \mathrm{ml}$ ) was then added by vacuum transfer, and irradiation (12h, $10 \mathrm{~cm}$ ) was continued. After $12 \mathrm{~h}$, the chlorine color had faded and another $0.84 \mathrm{~g}$ of $\mathrm{Cl}_{2}(11.8 \mathrm{mmol})$ were added. After another $17 \mathrm{~h}$ of irradiation $(20 \mathrm{~cm})$, the chlorine color had faded again. The product was subjected to fractional condensation 
$\left(-30,-78,-196^{\circ} \mathrm{C}\right)$. The material in the $-30^{\circ} \mathrm{C} \operatorname{trap}(0.31 \mathrm{~g})$ was (g.c. $5 \%$ QF-1 on Chromosorb W, $1 \mathrm{~m}, 70{ }^{\circ} \mathrm{C}$ ) $78.6 \%$ $\mathrm{F}_{5} \mathrm{SCCl}\left(\mathrm{SO}_{2} \mathrm{~F}\right) \mathrm{COCl}, 6.5 \div \mathrm{F}_{5} \mathrm{SCCl}\left(\mathrm{SO}_{2} \mathrm{~F}\right) \mathrm{COF}, 7.8 \% \mathrm{CH}_{3} \mathrm{CN}$ and $7.5 \%$ of an unknown material. The contents of the $-78^{\circ} \mathrm{C}$ trap were again subjected to fractional condensation $(-45,-78,-$ $196^{\circ} \mathrm{C}$ ). The $-45^{\circ} \mathrm{C}$ trap contained $0.77 \mathrm{~g}$ of a product that contained (g.c.) $45.4 \% \mathrm{~F}_{5} \mathrm{SCCl}\left(\mathrm{SO}_{2} \mathrm{~F}\right) \mathrm{COCl}$ and $14.3 \%$ $\mathrm{F}_{5} \mathrm{SCCl}\left(\mathrm{SO}_{2} \mathrm{~F}\right) \mathrm{COF}$. Almost no product was in the $-78^{\circ} \mathrm{C}$ trap and the material in the $-19^{\circ} \mathrm{C}(0.39 \mathrm{~g})$ contained no $\mathrm{F}_{5} \mathrm{SCCl}\left(\mathrm{SO}_{2} \mathrm{~F}\right) \mathrm{COCl}$. The two products from the trap-to-trap distillations were combined and subjected to preparative gas chromatography $\left(\mathrm{QF}-1,2 \mathrm{~m}, 70^{\circ} \mathrm{C}\right)$. A total of $0.20 \mathrm{~g}$ of a clear colorless liquid were collected. Yield: $11.8 \%$. When the above procedure was carried out with $\mathrm{CH}_{3} \mathrm{CN}$ from the very beginning, the initial formation of $\mathrm{F}_{5} \mathrm{SCCl}\left(\mathrm{SO}_{2} \mathrm{~F}\right) \mathrm{COF}$ was observed ( ${ }^{19}$ F n.m.r.), which upon successive irradiation and chlorine addition decreased, and $\mathrm{F}_{5} \mathrm{SCCl}\left(\mathrm{SO}_{2} \mathrm{~F}\right) \mathrm{COCl}$ became the major product. There were other minor $\mathrm{SF}_{5}$ products, which could not be collected in sufficient quantity so as to allow their identification. From comparisons of chemical shift values, one product could have been $\mathrm{F}_{5} \mathrm{SCHClSO}_{2} \mathrm{~F}$ and another $\mathrm{F}_{5} \mathrm{SCCl}_{2} \mathrm{SO}_{2} \mathrm{~F}$, as conjectured from the similar values of $\mathrm{F}_{5} \mathrm{SCBr}_{2} \mathrm{SO}_{2} \mathrm{~F}\left(\phi_{\mathrm{A}} \approx 66 \mathrm{ppm} ; \phi_{\mathrm{B}} \approx 54 \mathrm{ppm} ; \phi_{\mathrm{X}}=39.5 \mathrm{ppm}, \mathrm{X}=\right.$ $\mathrm{SO}_{2} \mathrm{~F}$ ). The product in this case was washed with water, dried and also subjected to preparative gas chromatography, which allowed the collection of $0.16 \mathrm{~g}$ of $\mathrm{F}_{5} \mathrm{SCHClSO}_{2} \mathrm{~F}$ (12.9\%), 
apparently formed by the hydrolysis of $\mathrm{F}_{5} \mathrm{SCCl}\left(\mathrm{SO}_{2} \mathrm{~F}\right) \mathrm{CoCl}$.

${ }^{19} \mathrm{~F}$ n.n.r. spectrum (neat sample, $\operatorname{CCl}_{3} \mathrm{~F}$ ext.): $\phi=$ $64.5 \mathrm{ppm}, \mathrm{m}$, int. $=5.3\left(\mathrm{SF}_{5}\right) ; \phi=50.6 \mathrm{ppm}, \mathrm{m}$, int. $=1.0$ $\left(\mathrm{SO}_{2} \mathrm{~F}\right)$.

Mass spectrum: (negative c.i., isobutane, mass, species $>5 \%): 257, \mathrm{C}^{35} \mathrm{ClF}_{6} \mathrm{O}_{2} \mathrm{~S}_{2}{ }^{-}, 10.9 ; 223, \mathrm{~F}_{5} \mathrm{SCHSO}_{2} \mathrm{~F}^{-}$, $46.9 ; 167, \mathrm{C}_{2} \mathrm{~F}_{5} \mathrm{OS}^{-}, 6.6 ; 165, \mathrm{CF}_{3} \mathrm{O}_{2} \mathrm{~S}_{2}{ }^{-}, 9.6 ; 146, \mathrm{CF}_{2} \mathrm{O}_{2} \mathrm{~S}_{2}{ }^{-}$, $32.0 ; 130, \mathrm{CF}_{2} \mathrm{OS}_{2}^{-}, 9.5 ; 127, \mathrm{SF}_{5}^{-}, 100.0 ; 83, \mathrm{SO}_{2} \mathrm{~F}^{-}, 37.5$. Infrared spectrum (neat, $\mathrm{KBr}, \mathrm{cm}^{-1}$ ): $1793(\mathrm{~s}), 1769$ (ms,sh); 1454 (Vs); 1229 (vs)； 1022 (s)； 919(vssh)； 890 (vs); 878 (vssh); $836(\mathrm{~s}) ; 798(\mathrm{~s}) ; 754(\mathrm{~s}) ; 737(\mathrm{~s}-\mathrm{m}) ; \quad 691(\mathrm{~m})$; $665(\mathrm{Vw}) ; 615(\mathrm{~s}) ; 599(\mathrm{~s}) ; 577(\mathrm{~s}) ; 563(\mathrm{~s}) ; 515(\mathrm{w}) ; \quad 501(\mathrm{w})$; $491(\mathrm{w}-\mathrm{m}) ; 464(\mathrm{~m})$.

Anal.calcd.: for $\mathrm{C}_{2} \mathrm{Cl}_{2} \mathrm{~F}_{6} \mathrm{O}_{3} \mathrm{~S}_{2}: \mathrm{C}, 7.48 ; \mathrm{Cl}, 22.08 ; \mathrm{F}$, 35.1. Found: C, 7.59; Cl, 22.30; F, 35.2.

Reaction of 25 with $\mathrm{NO}^{+} \mathrm{BF}_{4}-$ in $\mathrm{CH}_{3} \mathrm{CN} \quad(40)$ :

To a solution of $0.69 \mathrm{~g}$ of nitrosonium terafluoroborate $(5.9 \mathrm{mmol})$ in $3.0 \mathrm{ml}$ of dry acetonitrile in a $25 \mathrm{ml}$ round bottomed flask, equipped with magnetic stirring bar, a claisen head, dropping funnel and a Drierite tube, $1.72 \mathrm{~g}$ of $25(4.3 \mathrm{mmol})$ in $2.0 \mathrm{ml}$ of dry acetonitrile was added dropwise. A yellowish color was noticed. After 5 minutes, the claisen head was replaced with a distillation head and the pressure was lowered to $30 \mathrm{~mm} \mathrm{Hg}$. The mixture was stirred for 2 hours at room temperature when almost 
complete transfer of the contents of the flask into the$196^{\circ} \mathrm{C}$ cold trap occurred. The cold-trap contents were partially yellow and had a bluish hue in the cold. Upon heating very little of a yellow oil came over; this material showed bands at 2256 and $2340 \mathrm{~cm}^{-1}$. This oil was combined. with the cold trap contents, which were now blue in the cold and yellowish-green at room temperature.

${ }^{19} \mathrm{~F}$ n.m.x. of this material $\left(\mathrm{CCl}_{3} \mathrm{~F}\right.$ external): $\phi=72.1$ ppm, $\mathrm{m}$, area $=5.9\left(\mathrm{SF}_{5}\right) ; \phi=58.9 \mathrm{ppm}, \mathrm{m}$, area $=1.0$ $\left(\mathrm{SO}_{2} \mathrm{~F}\right) ; \phi=49.7, \mathrm{~m}$, area $=0.7$ (COF). Small signals were also observed at $79.5,70.0,78.6,78.076$ (broad), 56.0, and $48.9 \mathrm{ppm}$. The band at $49.7 \mathrm{ppm}$ (COF) had disappeared after keeping the solution at room temperature for 18 hours and several new sharp signals (low intensity) were observed at $80.3,64.0,57.0$ and $33.6 \mathrm{ppm}$. The main bands were at $\phi=$ $72.9 \mathrm{ppm}\left(\mathrm{m}, \mathrm{SF}_{5}\right), \phi=67.0$ (weak) and $59.3 \mathrm{ppm}$ (weak).

Because of this obvious instability of the alleged primary product $\mathrm{F}_{5} \mathrm{SC}(\mathrm{NO})\left(\mathrm{SO}_{2} \mathrm{~F}\right) \mathrm{COF}$, it was not tried to isolate it. Instead, water $(0.2 \mathrm{ml})$ was added to the $\mathrm{CH}_{3} \mathrm{CN}$ solution, which caused instant discoloration, and some gas bubbles were formed. After 17 hours at room temperature, a single product was observed in the ${ }^{19} \mathrm{~F}$ n.m.r spectrum, which was $\mathrm{SF}_{5} \mathrm{CH}_{2} \mathrm{SO}_{2} \mathrm{~F}$. This was shown by adding a small amount of authentical $\mathrm{SF}_{5} \mathrm{CH}_{2} \mathrm{SO}_{2} \mathrm{~F}$ to the solution in the n.m.r tube, causing only an increase of all resonances that were originally present. 


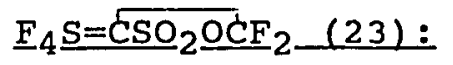

In a vacuum compartment consisting of two $50 \mathrm{ml}$ round bottomed flasks, connected by a transfer line with an outlet to a vacuum line $9.63 \mathrm{~g}(35.7 \mathrm{mmol})$ of sultone 1 and $6.68 \mathrm{~g}$ of $\mathrm{F}_{3} \mathrm{~B} \cdot \mathrm{N}\left(\mathrm{C}_{2} \mathrm{H}_{5}\right)_{3} \quad(39.5 \mathrm{mmol})$ were heated slowly with stirring in one of the flasks at atmospheric pressure; the other flask was held at $-196^{\circ} \mathrm{C}$. When the oil bath temperature reached $76^{\circ} \mathrm{C}$, the solution bubbled slightly and separated suddenly into two layers. Heating was continued for $21 / 2$ minutes, with a final temperature of $80^{\circ} \mathrm{C}$. The reaction flask was cooled $\left(-196^{\circ} \mathrm{C}\right)$, the vacuum compartment was evacuated and then warmed to $60^{\circ} \mathrm{C}$ for 45 minutes. In the receiving flask, cooled to $-196^{\circ} \mathrm{C}, 8.45 \mathrm{~g}$ of product was collected, which consisted $\left({ }^{19}\right.$ F n.m.r.) of a mixture of 2 parts of $\underline{23}$ and 1 part of $\underline{21}$. Yield of $\underline{21}+\underline{23}=94.8 \%$.

\section{Separation of 21 and 23:}

The crude material from above was transferred to a 30 ml reaction flask with a Kontes Teflon valve containing $10.90 \mathrm{~g}$ ( $71.7 \mathrm{mmol})$ of comminuted cesium fluoride (PCR), shaken and kept at room temperature overnight. A second treatment with $8.58 \mathrm{~g}$ of CSF $(56.4 \mathrm{mmol})$ for $3 \mathrm{~h}$ removed the remaining keten completely, leaving $4.02 \mathrm{~g}$ of almost pure $\underline{23}$. Yield $=43.9 \%$ ( with respect to 1 ).

To obtain a sample for analysis, part of the above material was subjected to trap-to-trap distillation, where 
the traps were held at $-10,-63,-110$ and $-196^{\circ} \mathrm{C}$. The material that was collected in the $-63^{\circ} \mathrm{C}$ trap (almost quantitative) was free of one impurity ( $\phi=73 \mathrm{ppm}$ in the ${ }^{19} \mathrm{~F}$ n.m.r. spectrum). A second impurity ( $\phi=68 \mathrm{ppm}$ in ${ }^{19} \mathrm{~F}$ n.m.r., supposedly I) could be removed by heating the material from the trap-to-trap distillation shortly $(1 / 2$ min) with a small amount of $\mathrm{F}_{3} \mathrm{~B} \cdot \mathrm{N}\left(\mathrm{C}_{2} \mathrm{H}_{5}\right)_{3}$. The third impurity $\left(\phi=70 \mathrm{ppm}\right.$, probably $\left.\mathrm{F}_{5} \mathrm{SCH}_{2} \mathrm{SO}_{2} \mathrm{~F}\right)$ could not be removed, but accounted for only $1 \%$. The cesium fluoride was rinsed with several small portions of acetone after the reaction and a total of $4.97 \mathrm{~g}$ of $\mathrm{F}_{5} \mathrm{SC}\left(\mathrm{SO}_{2} \mathrm{~F}\right) \mathrm{COF}^{-} \mathrm{Cs}^{+}$was obtained; no other compound could be detected.

${ }^{19} \mathrm{~F}$ n.m.r. spectrum (neat sample, $\mathrm{CCl}^{3} \mathrm{~F}$ as external standard): $A A^{\prime} B C X X '$ spectrum: $\phi_{A}=51.87 \mathrm{ppm}, \phi_{B}=47.16$ ppm, $\phi_{C}=40.90 \mathrm{ppm}, \phi_{X}=-76.3 \mathrm{ppm}$. Integral $\mathrm{A}: \mathrm{B}: \mathrm{C}: \mathrm{X}=$ $2.0: 1.0: 1.0: 1.7 . J_{A}^{\prime} B=J_{A B}=161.8 \mathrm{~Hz} ; J_{A C}=J_{A^{\prime} C}=164.9$ $\mathrm{Hz} ; \mathrm{J}_{\mathrm{BC}}=20.4 \mathrm{~Hz} ; \mathrm{J}_{\mathrm{AX}}=4.1 \mathrm{~Hz} ; \mathrm{J}_{\mathrm{BX}}=6.0 \mathrm{~Hz} ; \mathrm{J}_{\mathrm{CX}}=5.4 \mathrm{~Hz}$.

${ }^{13} \mathrm{C}$ n.m.r. spectrum: (neat sample, $\mathrm{CDCl}_{3}$ external) $: \delta_{\alpha}$ $=80.7 \mathrm{ppm}$, (approximately p-t), $\mathrm{J}_{\mathrm{SF} 4 \mathrm{C}^{1}}=31.6 \mathrm{~Hz}, \mathrm{~J}_{\mathrm{CFxC}}{ }^{1}=$ $7.8 \mathrm{~Hz} ; \delta_{\beta}=114.5 \mathrm{ppm}, d-t, J_{C}{ }^{2} \mathrm{Fx}=282.4 \mathrm{~Hz}, J_{C}{ }^{2} \mathrm{FB}=23.2$ $\mathrm{Hz}$.

Mass spectrum (electron impact,70 ev,mass, fragment, $>1 \%): 250, \mathrm{M}+\left({ }^{32} \mathrm{~S}\right), 4.6 ; 190,(\mathrm{M}-\mathrm{COS})^{+}$(rearr.), 2.1; 184, $\left(-\mathrm{COF}_{2}\right)^{+}, 1.3 ; 172,(\mathrm{M}-\mathrm{COSF})^{+}$(rearr.), $1.1 ; 170,\left(\mathrm{M}-\mathrm{SO}_{3}\right)^{+}$, $21.7 ; 165, \mathrm{~F}_{3} \mathrm{SCSO}_{2}{ }^{+}, 2.4 ; 151,\left(\mathrm{M}-\mathrm{SO}_{3}-\mathrm{F}\right)^{+}, 10.0 ; 145$, $\mathrm{C}_{2} \mathrm{~F}_{3} \mathrm{~S}_{2}{ }^{+}, 1.6 ; 144, \mathrm{CHFO}_{3} \mathrm{~S}_{2}{ }^{+}, 1.5 ; 143, \mathrm{CFO}_{3} \mathrm{~S}_{2}{ }^{+}, 1.4 ; 127$, 
$\mathrm{SF}_{5}{ }^{+}, \mathrm{FSCSO}_{2}{ }^{+}, 5.3 ; 113, \mathrm{C}_{2} \mathrm{~F}_{3} \mathrm{~S}^{+}, 1.6 ; 105, \mathrm{OSF}_{3}{ }^{+}, 3.2 ; 94$, $\mathrm{C}_{2} \mathrm{~F}_{2} \mathrm{~S}^{+}, 1.5 ; 91, \mathrm{C}_{2} \mathrm{FOS}^{+}, 4.4 ; 89, \mathrm{SF}_{3}^{+}, 100.0 ; 83, \mathrm{SO}_{2} \mathrm{~F}^{+}$ (rearr.), 2.5; 82, $\mathrm{CF}_{2} \mathrm{~S}^{+}, 1.6 ; 70 . \mathrm{SF}_{2}{ }^{+}, 10.9 ; 69, \mathrm{CF}_{3}{ }^{+}$, $4.7 ; 67, \mathrm{FOS}^{+}, 6.6 ; 66, \mathrm{CF}_{2} \mathrm{O}^{+}, 1.9 ; 64, \mathrm{SO}_{2}^{+}, 8.5 ; 63, \mathrm{CFS}^{+}$, $4.9 ; 62, \mathrm{C}_{2} \mathrm{~F}_{2}+, 1.0 ; 60, \mathrm{COS}^{+}, 1.2 ; 51, \mathrm{SF}^{+}, 3.4$. Infrared spectrum (neat, $\mathrm{KBr}, \mathrm{cm}^{-1}$ ): 1415 , s; 1379, vs; $1282, \mathrm{~m} ; 1235, \mathrm{~s} ; 1225, \mathrm{~s} ; 1207, \mathrm{~s} ; 1192, \mathrm{~s} ; 1066, \mathrm{~s} ; 969$, $\mathrm{m} ; 874$, vs; 857 , vs; $763, \mathrm{~s} ; 671, \mathrm{~m} ; 661, \mathrm{~s} ; 624, \mathrm{~m} ; 606$, w; 572 , w; 535, s; 493, w; 472, s; 439,w.

Anal.calcd for $\mathrm{C}_{2} \mathrm{~F}_{6} \mathrm{O}_{3} \mathrm{~S}_{2}: \mathrm{C}: 9.60 ; \mathrm{F}: 45.6 ; \mathrm{s}: 25.63$. Found: C:9.23; F:46.1; S:25.39.

Reaction of 23 with HF (1):

A $30 \mathrm{ml}$ Kel-F vessel was charged via vacuum transfer with $0.04 \mathrm{~g}$ of gaseous $\mathrm{HF}$ (2mmol) and then with $0.34 \mathrm{~g}(1.4$ mmol) of 23. After keeping the vessel at room temperature for $16 \mathrm{~h}$ it was cooled to $-78^{\circ} \mathrm{C}$ and the excess $\mathrm{HF}$ was pumped away through a cold trap $\left(-196^{\circ} \mathrm{C}\right)$. A total of $0.31 \mathrm{~g}$ of product was left behind. The ${ }^{19} \mathrm{~F}$ n.m.r. spectrum of this material $\left(\mathrm{CDCl}_{3}\right)$ showed two major products, whose resonances were coincident with those of sultone 1 and the compound $\mathrm{F}_{5} \mathrm{SCH}_{2} \mathrm{SO}_{2} \mathrm{~F}$. Sultone 1 accounted for $80 \%$ of the total intensity of the integrated spectrum and the latter compound for $18 \%$. No $\underline{23}$ was left behind. The infrared spectrum of the neat sample was identical with the one of 1 . 
Reaction of 23 with $\mathrm{HCl}(42)$ :

Into a $40 \mathrm{ml}$ Carius tube containing $1.08 \mathrm{~g}$ of $\underline{23}$ (4.32 mmol) $19.8 \mathrm{mmol}$ of $\mathrm{HCl}$ (Matheson) was condensed. The vessel was heated to $68^{\circ} \mathrm{C}(92 \mathrm{~h})$ and chilled $\left(-196^{\circ}\right)$. Excess $\mathrm{HCl}$ was removed by pumping off the volatile constituents at$78^{\circ} \mathrm{C}$ through a cold trap $\left(-196^{\circ} \mathrm{C}\right)$. Finally, the reaction product was collected by vacuum transfer at room temperature with occasional warming with a heat gun. The crude product (0.93 g) contained two impurities, which were probably 1 and $\mathrm{SF}_{5} \mathrm{CH}_{2} \mathrm{SO}_{2} \mathrm{~F}$. They could be removed by trap-to-trap distillation $\left(-30,-75,-100,-196^{\circ} \mathrm{C}\right)$, leaving $0.78 \mathrm{~g}$ of $\underline{42}$ in the $-30^{\circ} \mathrm{C}$ trap. Yield $=63.3 \%$

Infrared spectrum (neat, $\mathrm{KBr}, \mathrm{cm}^{-1}$ ): 2992 (m); 1477 (VW)； 1430 (s)； 1317 (m)； 1275 (m)； 1214 (vs); 1178 (w); 1097 (m) ; 1076 (s); 958 (w); 886 (w); 853 (s); 835 (vs); 814 (s); 786 (s); 770 (msh); 743 (s); 658 (s); 642 (w); 610 (w); 589 (s); 561 (VW); 549 (w); 527 (m); 516 (m); 492 (Vw); 478 $(\mathrm{Vw}) ; 452(\mathrm{w}) ; 438(\mathrm{w})$.

${ }^{19} \mathrm{~F}$ n.m.r. (neat sample, $\mathrm{CCL}_{3} \mathrm{~F}$ ext), $\mathrm{ABCDXY}$ system: $\phi_{\mathrm{A}}$ $=141.7 \mathrm{ppm}$ (quartet, int. $=1.0) ; \phi_{\mathrm{BC}}=120.0 \mathrm{ppm}(\mathrm{m}$, int. $=2.0) ; \phi=67.0 \mathrm{ppm}\left(\mathrm{m}\right.$, int. $=1.2 ; \phi_{\mathrm{X}}(\mathrm{Y})=-74.9 \mathrm{ppm}(\mathrm{d}$, int. $=1.0) ; \phi_{Y}(X)=-78.9 \mathrm{ppm}(\mathrm{d}-\mathrm{m}$, int. $=1.0) \cdot \mathrm{J}_{\mathrm{XY}}=100.8$ $\mathrm{Hz}$.

$1 \mathrm{H}$ n.m.r. (300 MHz, $\left.\mathrm{CDCl}_{3}, \mathrm{Si}\left(\mathrm{CH}_{3}\right)_{4}\right): \delta=7.09 \mathrm{ppm}$ (m) .

${ }^{13} \mathrm{C}$ n.m.r. spectrum (neat sample, $\mathrm{CDCl}_{3}$ external): $1_{\mathrm{H}}$ 
coupled, $\delta=113.4 \mathrm{ppm}\left(t, J_{C}^{2} F=294 \mathrm{~Hz}\right), \delta=108.8 \mathrm{ppm}(\mathrm{d}-$ $\left.\mathrm{m}, \mathrm{J}_{\mathrm{C}}{ }^{1} \mathrm{H}=157.5 \mathrm{~Hz}\right) ; 1_{\mathrm{H}}$ decoupled, $\delta_{\beta}=113.4$ (t), $\delta_{\alpha}=$

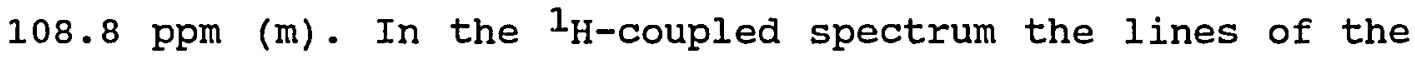
triplet show further signs of coupling but were not resolved.

Mass spectrum (negative ion, mass, species, >1\%): 269, $(\mathrm{M}-\mathrm{O})^{-}, 3.0 ; 179,(\mathrm{M}+\mathrm{H}-\mathrm{Cl}-\mathrm{O}-3 \mathrm{~F})^{-}, 1.6 ; 177,(\mathrm{M}-\mathrm{HCl}-\mathrm{O}-3 \mathrm{~F})^{-}$, $2.9 ; 167,\left(\mathrm{M}-\mathrm{HCl}-\mathrm{SO}_{2} \mathrm{~F}\right)^{-}$(rearr.), 13.5; 166, (M+H-HCl-F$\left.\mathrm{COF}_{2}\right)^{-}, 3.9 ; 165,\left(\mathrm{M}-\mathrm{HCl}-\mathrm{F}-\mathrm{COF}_{2}\right)^{-}, 100.0 ; 161,(\mathrm{M}-\mathrm{HCl}-3 \mathrm{~F}-$ 20) ${ }^{-}, 1.2 ; 144, \mathrm{CHFO}_{3} \mathrm{~S}_{2}^{-}, 2.4 ; 143,\left(\mathrm{M}-\mathrm{ClSF}_{4}\right)^{-}, \mathrm{CFO}_{3} \mathrm{~S}_{2}^{-}$, $6.1 ; 142,\left(\mathrm{M}-\mathrm{HCl}-\mathrm{SF}_{4}\right)^{-}, 43.1 ; 127, \mathrm{SF}_{5}{ }^{-}, \mathrm{FSCSO}_{2}^{-}, 17.0 ; 123$, $(\mathrm{M}-\mathrm{HCl}-5 \mathrm{~F}-20)^{-}, 2.0 ; 120, \mathrm{SF}_{4} \mathrm{C}^{-}, 2.1 ; 108, \mathrm{SF}_{4}{ }^{-}, 5.5 ; 105$, $\mathrm{C}_{2} \mathrm{HOS}_{2}^{-}, 3.7 ; 101, \mathrm{CSF}_{3}^{-}, 3.2 ; 99, \mathrm{CHF}_{2} \mathrm{OS}^{-}, 11.3 ; 96, \mathrm{CHFS}_{2}^{-}$ $4.2 ; 94, \mathrm{C}_{2} \mathrm{~F}_{2} \mathrm{~S}^{-}, 11.8 ; 89, \mathrm{SF}_{3}{ }^{-}, 11.4 ; 85, \mathrm{CF}_{3} \mathrm{O}^{-}$(rearr.), $5.1 ; 83, \mathrm{SO}_{2} \mathrm{~F}^{-}$(rearr.), $\mathrm{CHF}_{2} \mathrm{~S}^{-}, 100.0 ; 79, \mathrm{C}_{2} \mathrm{HF}_{2} \mathrm{O}^{-}, \mathrm{CFOS}^{-}$, $1.4 ; 78, \mathrm{C}_{2} \mathrm{~F}_{2} \mathrm{O}^{-}, 45.2 ; 76, \mathrm{C}_{2} \mathrm{HFS}^{-}, \mathrm{CSO}_{2}^{-}, 12.6 ; 70, \mathrm{SF}_{2}^{-}$, 2.2 .

Anal.calcd for $\mathrm{C}_{2} \mathrm{HClF}_{6} \mathrm{O}_{3} \mathrm{~S}_{2}: \mathrm{C}$, 8.38; $\mathrm{H}, 0.35$; $\mathrm{Cl}, 12.37 ; \mathrm{F}, 39.8 ; \mathrm{S}, 22.37$. Found: C, $8.51 ; \mathrm{H}, 0.40 ; \mathrm{Cl}$, $12.51 ; \mathrm{F}, 39.7 ; \mathrm{S}, 22.18$.

\section{9 by Reaction of 23 with ClF:}

Acid-washed apparatus was used, due to the easy rearrangeability of the product.

An oven-dried $75 \mathrm{ml}$ steel bomb was charged with $2.95 \mathrm{~g}$ of $\mathrm{CCl}_{3} \mathrm{~F}$ (dried over $\mathrm{P}_{4} \mathrm{O}_{10}$ ), $0.31 \mathrm{~g} \underline{23}(1.24 \mathrm{mmol}$ ) and 0.17 
g (3.1 mmol) ClF. After attaining room temperature slowly, the bomb was kept there for 2 days. Fractional condensation in an acid-washed glass apparatus yielded $\left(-196,-40{ }^{\circ} \mathrm{C}\right)$ $0.23 \mathrm{~g}$ of product in the $-40^{\circ} \mathrm{C}$ trap. The $19 \mathrm{~F} \mathrm{n.m.r.} \mathrm{spectrum}$ showed still $\underline{23}$ to be present. Both cold trap fractions were transferred back into the bomb, another $0.19 \mathrm{~g} \mathrm{ClF}(3.5$ mmol) were added and the bomb kept at room temperature for 6 days. Fractional condensation afforded $0.19 \mathrm{~g}$ in the $-50^{\circ} \mathrm{C}$ trap, and after repeating the procedure with the $-196^{\circ} \mathrm{C}$ fraction another $0.06 \mathrm{~g}$ were collected. The product was free of $\underline{23}$ but contained some small impurities $(71,53,48,-70$ ppm in ${ }^{19} \mathrm{~F}$ n.m.r.spectrum). Yield $0.25 \mathrm{~g}$ (66.2\%).

The infrared spectrum was run quickly, because rearrangement to the acyl fluoride took place very readily on the $\mathrm{KBr}$ plates, as could be judged from the slow increase of the co band (1855 $\left.\mathrm{cm}^{-1}\right){ }^{19} \mathrm{~F} \mathrm{n.m.r.} \mathrm{spectrum} \mathrm{(neat} \mathrm{sample,}$ $\mathrm{CCl}_{3} \mathrm{~F}$ ext. $): \phi_{\mathrm{SF} 5}=62.8 \mathrm{ppm}(\mathrm{m})$, int. $=5.00 ; \phi_{\mathrm{CF} 2}(\mathrm{AB}$ system): $\phi_{A}=-77.2 \mathrm{ppm}, \mathrm{d}-\mathrm{p}$, int. $=1.04, \mathrm{~J}_{\mathrm{ASF} 4}=3.6 \mathrm{~Hz}$ (average); $\phi_{\mathrm{B}}=-79.0 \mathrm{~Hz}, \approx \mathrm{d}-\mathrm{p}-\mathrm{m}$, irregular spacing, int. = 1.09. $\mathrm{J}_{\mathrm{AB}}=94.3 \mathrm{~Hz}$.

Infrared spectrum (neat sample, $\mathrm{KBr}, \mathrm{Cm}^{-1}$ ): $1481, \mathrm{~m}$; 1461, m,sh; 1437, s-vs; 1351, vw; 1276, m-s; 1234, s, 1202, vs; 1151, m-s; 1129, m-s; 1090, s-vs; 1046, w-m; 970, m-s; 934, s; $890, \mathrm{Vs} ; 836$, s-vs; $819, \mathrm{~s} ; 782, \mathrm{~m}-\mathrm{s} ; 738$, vw; 692, $\mathrm{m} ; 666, \mathrm{~m}-\mathrm{s} ; 624, \mathrm{~m} ; 609, \mathrm{~m}-\mathrm{s} ; 588, \mathrm{~m} ; 572, \mathrm{~m} ; 551, \mathrm{~m} ; 535$, $m-s ; 503, w ; 483, w ; 454, m ; 434, w-m ; 414, w-m$. 
Mass spectrum (c.i., mass, species, \% < 1): 205, (M-Cl$\left.\mathrm{SO}_{2}\right)^{+}, 1.9 ; 191,\left(\mathrm{M}-\mathrm{Cl}-\mathrm{CF}_{2}-\mathrm{CO}\right)^{+}$(rearr.), 10.6; 163, $\mathrm{C}_{2} \mathrm{H}_{2} \mathrm{~F}_{3} \mathrm{OS}_{2}{ }^{+}, 1.6 ; 127, \mathrm{SF}_{5}{ }^{+}, 2.2 ; 107, \mathrm{C}_{2} \mathrm{FO}_{2} \mathrm{~S}^{+}, 1.8 ; 91$, $\mathrm{C}_{2} \mathrm{FOS}^{+}, 5.9 ; 89, \mathrm{SF}_{3}{ }^{+}, 100.0 ; 85, \mathrm{CF}_{3} \mathrm{O}^{+}$(rearr.), 3.0;83, $\mathrm{SO}_{2} \mathrm{~F}^{+}$(rearr.), $1.8 ; 81, \mathrm{C}_{2} \mathrm{~F}_{3}{ }^{+}$(rearr.), 2.4; 79, $\mathrm{CFOS}^{+}$, $1.6 ; 73, \mathrm{C}_{2} \mathrm{HOS}^{+}, 2.6 ; 71, ?, 5.2 ; 70, \mathrm{SF}_{2}{ }^{+}, 1.9 ; 69, \mathrm{CF}_{3}{ }^{+}$ (rearr.), 4.5; 67, FSO $^{+}, 2.5 ; 63, \mathrm{CFS}^{+}, 1.9 ; 61, \mathrm{CHOS}^{+}$, 1.9 .

Anal. calcd for $\mathrm{C}_{2} \mathrm{ClF}_{7} \mathrm{O}_{3} \mathrm{~S}_{2}: \mathrm{C}, 7.89 ; \mathrm{F}, 43.7 ; \mathrm{S}$, 21.05; Cl, 11.64. Found: C, 7.94; F, 44.2; S, 21.36; Cl, 11.51 .

Synthesis of $\mathrm{F}_{5}$ SCHClCF$_{2}$ Cl:

$\mathrm{F}_{5} \mathrm{SCH}=\mathrm{CF}_{2} \quad(\underline{52}, 8.68 \mathrm{~g}, 45.7 \mathrm{mmol})$ and chlorine was irradiated with stirring with a 250 watts GE sunlamp in a $300 \mathrm{ml}$ Pyrex-quartz vessel. The chlorine was added in portions with the following irradiation times: $1.1 .79 \mathrm{~g}$ (25.2 mol), $15 \mathrm{~cm}$ distance, 4.5 hours (the liquid was still yellow). 2. $1.65 \mathrm{~g}(22.8 \mathrm{mmol}), 19$ hours, $10 \mathrm{~cm}$ distance. The product contained by ${ }^{19} \mathrm{~F}$ n.m.r.spectrocopy $\underline{52}$ (25.2 \%), but also $\mathrm{SF}_{5} \mathrm{Cl}(11.9 \%), \mathrm{S}_{2} \mathrm{~F}_{10}(6.7 \%), \mathrm{F}_{5} \mathrm{SCHClCF}_{2} \mathrm{Cl}(47.4 \%)$ and an unknown compound (probably $\mathrm{F}_{5} \mathrm{SCCl}_{2} \mathrm{CF}_{2} \mathrm{Cl}, 8.9 \%$ ) and more $\mathrm{Cl}_{2}$ was added: $1.0 .92 \mathrm{~g}, 16$ hours of irradiation, 2 . $0.33 \mathrm{~g}, 4$ hours. Only a trace of $\underline{52}$ was left. After reaction, the volatile materials were transferred off at $\mathbf{- 7 8}$ $\mathrm{C}$ and collected in $\mathrm{a}-196^{\circ} \mathrm{C}$ trap (5 hours, $\left.2.12 \mathrm{~g}\right) ; \mathrm{s}_{2} \mathrm{~F}_{10}$ 
and $\mathrm{SF}_{5} \mathrm{Cl}, \mathrm{SiF}_{4}$ were identified by i.r. spectroscopy. The remaining product $(11.00 \mathrm{~g})$ was by ${ }^{19} \mathrm{~F}$ n.m.r. spectroscopy $83.3 \% \mathrm{~F}_{5} \mathrm{SCHClCF}_{2} \mathrm{Cl}, 4.3 \% \mathrm{~S}_{2} \mathrm{~F}_{10}$ and $12.4 \%$ of the alleged $\mathrm{F}_{5} \mathrm{SCCl}_{2} \mathrm{CF}_{2} \mathrm{Cl}\left(\phi_{\mathrm{A}} \approx 63.5 \mathrm{ppm}, \phi_{\mathrm{B}}=42.7 \mathrm{ppm}\right) \cdot$ Only $\mathrm{S}_{2} \mathrm{~F}_{10}$ could be separated by rectification, but not the two $\mathrm{SF}_{5}$ compounds, and the mixture was thus used without further purification to prepare $\mathrm{F}_{5} \mathrm{SCCl}=\mathrm{CF}_{2}$. An analytically pure sample was prepared by preparative scale gas chromatography. ${ }^{19} \mathrm{~F}$ n.m.r. spectrum (neat sample, external $\mathrm{CCl}_{3} \mathrm{~F}$ ): $\mathrm{AB}_{4} \mathrm{XY}, \phi_{\mathrm{A}}=71.2 \mathrm{ppm}, 9$ lines, area $=1.00 ; \phi_{\mathrm{B}}=59.3 \mathrm{ppm}$, $\mathrm{d}-\mathrm{m}$, area $=3.79 ; \phi_{\mathrm{X}}=-55.5 \mathrm{ppm}$, asymmetric $\mathrm{d}-\mathrm{p}-\mathrm{d}$, area $=$ $1.16 ; \phi_{Y}=-62.7 \mathrm{ppm}$, asymmetric $d-d-p$, area $=1.05 . J_{A B}=$ $148.5 \mathrm{~Hz} ; J_{X Y}=176.2 \mathrm{~Hz} ; J_{Y B}=12.8 \mathrm{~Hz} ; J_{X B}=14.1 \mathrm{~Hz} ; J_{X H}$ $=2.3 \mathrm{~Hz} ; \mathrm{J}_{Y \mathrm{H}}=10.5 \mathrm{~Hz}$.

Anal.calcd for $\mathrm{C}_{2} \mathrm{HClF}_{7} \mathrm{~S}: \mathrm{C}, 9.20 ; \mathrm{H}, 0.39 ; \mathrm{Cl}, 27.17$; F, 51.0; S, 12.28. Found: C, 9.32; H, 0.41; Cl, 27.22; F, $51.1 ; S, 12.14$

\section{$\underline{\mathrm{F}}_{5} \mathrm{SCCl}_{\mathbf{S C F}}$}

The $83 \%$ pure $\mathrm{F}_{5} \mathrm{SCHClCF}_{2} \mathrm{Cl}(10.25 \mathrm{~g})$ was added by vacuum condensation into a $300 \mathrm{ml}$ Carius tube that contained $15.12 \mathrm{~g}$ of powdered $\mathrm{KOH}$. The tube was brought to room temperature and shaken for 5 minutes (warming was observed). After keeping it at room temperature for 15 minutes, $6.95 \mathrm{~g}$ of product was transferred out. It was combined with the product of a similar reaction to give $10.34 \mathrm{~g}$ of crude 
product. Distillation gave two fractions, room temperature$44^{\circ} \mathrm{C} \quad\left(4.76 \mathrm{~g}, 94 \% \mathrm{~F}_{5} \mathrm{SCCl}=\mathrm{CF}_{2}, 6 \% \mathrm{~S}_{2} \mathrm{~F}_{10}\right.$ by ${ }^{19} \mathrm{~F}$ n.m.r. spectroscopy), and $44-50^{\circ} \mathrm{C}(5.20 \mathrm{~g})$ which was pure olefin.

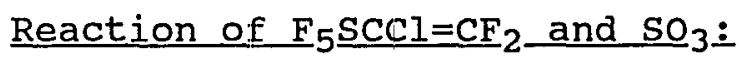

A mixture of $2.03 \mathrm{~g}$ of $\mathrm{SO}_{3}(25.4 \mathrm{mml})$ and $3.48 \mathrm{~g}$ of $\mathrm{F}_{5} \mathrm{SCCl}=\mathrm{CF}_{2}(14.8 \mathrm{mmol})$ was heated in an $80 \mathrm{ml}$ Carius tube to $160^{\circ} \mathrm{C}$ for 96 hours. The product was condensed out and was found to consist (integrated ${ }^{19} \mathrm{~F}$ n.m.r. intensity) to $\approx 50 \%$ of the olefin and $50 \%$ of a material with a multiplet at $\approx$ 50 ppm. The material was heated for 4 more days to 170$180^{\circ} \mathrm{C}$, and its composition was found almost unchanged. More $\mathrm{SO}_{3}(1.70 \mathrm{~g}, 21.3 \mathrm{mmol})$ was added and after heating for 20 hours at $165{ }^{\circ} \mathrm{C}$ all olefin was gone. The product was distilled, and three fractions were obtained, room temperature $-48^{\circ} \mathrm{C}, 48-65^{\circ} \mathrm{C}$ and $65-68^{\circ} \mathrm{C}$, all were fuming liquids. They had all a different composition, and were not analyzed further. None contained an $\mathrm{SF}_{5}$-compound, however (i.r., ${ }^{19} \mathrm{~F}$ n.m.r. spectroscopy), and a sultone was apparently not formed (no $\mathrm{CF}_{2}$ resonance (" $\mathrm{AB}$ "), although the crude product showed some bands in the ${ }^{19} \mathrm{~F}$ resonance range for $\mathrm{CF}_{2}$, which were singlets and thus atypical for an $\mathrm{AB}$ system. The major product had a ${ }^{19} \mathrm{~F}$ resonance at $48 \mathrm{ppm}$ (singlet). 


\section{3 and $\mathrm{CH}_{3} \mathrm{OH}(43)$ :}

Anhydrous methanol $(0.05 \mathrm{~g}, 1.56 \mathrm{mmol})$ was added under swirling dropwise to $0.32 \mathrm{~g}$ of $\underline{23}(1.28 \mathrm{mmol})$ in a $25 \mathrm{ml}$ pear-shaped flask. The methanol was allowed to flow down the side walls. Heat was liberated. The flask was stoppered and kept at room temperature for 140 minutes. An i.r. spectrum of the heavy yellow oil showed the presence of an ester band (1765 $\mathrm{cm}^{-1}$, medium-strength). Separation from the alleged $\mathrm{CH}_{3} \mathrm{OSF}_{4} \mathrm{CH}\left(\mathrm{SO}_{2} \mathrm{~F}\right) \mathrm{COOCH}_{3}$ was effected by repeated trap-to-trap distillation, first with a $-45^{\circ} \mathrm{C}$ and a $-196^{\circ} \mathrm{C}$ trap, and then, using the material from the $-45^{\circ} \mathrm{C}$ trap, with a $-45^{\circ} \mathrm{C}$ and a $-17^{\circ} \mathrm{C}$ trap. The material in the $-17^{\circ} \mathrm{C}$ trap was subjected again to the same procedure, and after this third process, $0.21 \mathrm{~g}$ of a white solid was collected in the $-17^{\circ} \mathrm{C}$ trap. The infrared spectrum showed that there was only a very weak ester band. Yield $=58.2$ \%. M.p. $=20.5-22.0{ }^{\circ} \mathrm{C}$ (sealed tube).

$1_{\mathrm{H}}$ n.m.r. spectrum $\left(\mathrm{CDCl}_{3}, \mathrm{Si}\left(\mathrm{CH}_{3}\right)_{4}, 300 \mathrm{MHz}\right): \delta_{1}=$ $4.11 \mathrm{ppm}, \mathrm{s}$ (signs of shoulders), area $=3.00\left(\mathrm{CH}_{3}\right) ; \delta_{2}=$ $6.37 \mathrm{ppm}, 8$ lines with signs of further splitting, area = $0.96\left(\mathrm{CH}_{\mathrm{H}}-\mathrm{CF}_{2}\right)$.

${ }^{19} \mathrm{~F}$ n.m.r. spectrum (neat sample, external $\mathrm{CCl}_{3} \mathrm{~F}$ ): $\mathrm{ABCDXY}$ system $\phi_{\mathrm{A}}=68.4 \mathrm{ppm}, \mathrm{d}-\mathrm{d}-\mathrm{d}-\mathrm{d}$, area $=1.00 ; \phi_{\mathrm{B}}=73.6$ ppm, $d-d-d-d-d$, area $=1.00 ; \phi_{C}=5,5.3 \mathrm{ppm}, d-d-d$, area $=$ $0.93 ; \phi_{\mathrm{D}}=88.2 \mathrm{ppm}, \mathrm{d}-\mathrm{d}-\mathrm{d}-\mathrm{d}$, area $=1.00 ; \phi_{\mathrm{X}}=-80.3 \mathrm{ppm}$, $\mathrm{d}-\mathrm{m}$, area $=1.02 ; \phi_{\mathrm{Y}}=-74.3 \mathrm{ppm}, \mathrm{d}$, area $=0.97 . \mathrm{J}_{\mathrm{AB}}=\mathrm{J}_{\mathrm{AX}}$ 
$=25.1 \mathrm{~Hz} ; \mathrm{J}_{\mathrm{AC}}=\mathrm{J}_{\mathrm{BC}}=137.2 \mathrm{~Hz} ; \mathrm{J}_{\mathrm{AD}}=\mathrm{J}_{\mathrm{BD}}=115.7 \mathrm{~Hz} ; \mathrm{J}_{\mathrm{CD}}=$ $149.6 \mathrm{~Hz} ; \mathrm{J}_{\mathrm{AY}}=\mathrm{J}_{\mathrm{CX}}=\mathrm{J}_{\mathrm{CY}}=\mathrm{J}_{\mathrm{DX}}=\mathrm{J}_{\mathrm{DY}}=\mathrm{J}_{\mathrm{CH}^{2}} \approx \mathrm{J}_{\mathrm{YH}^{2}}{ }^{2}=0.0$ $\mathrm{Hz} ; \mathrm{J}_{\mathrm{AH}}{ }^{2}=10.58 \mathrm{~Hz} ; \mathrm{J}_{\mathrm{BH}^{2}}=7.82 \pm 0.39 \mathrm{~Hz} ; \mathrm{J}_{\mathrm{DH}}=20.21 \mathrm{~Hz}$; $\mathrm{J}_{\mathrm{XY}}=102.7 \mathrm{~Hz} ; \mathrm{J}_{\mathrm{BX}}=14.47 \pm 0.63 ; \mathrm{J}_{\mathrm{XH}} \approx 6.8 \mathrm{~Hz}$.

I.r.spectrum (neat sample on $\mathrm{KBr}, \mathrm{cm}^{-1}$ ): 2997, $\mathrm{m}$; 2865, Vw; 1459, $m$; 1424, vs; 1319, s; 1281, s; 1216, vs; $1103, \mathrm{~s} ; 1081, \mathrm{vs} ; 1020$, vs; $975, \mathrm{~m} ; 830, \mathrm{vvs} ; 744$, vs; 671 , $\mathrm{m} ; 659, \mathrm{~s} ; 614, \mathrm{~m}-\mathrm{w} ; 596, \mathrm{~m}-\mathrm{w} ; 583, \mathrm{~m}-\mathrm{w} ; 574, \mathrm{w}, \mathrm{sh} ; 556, \mathrm{vw}$; 529 , s; $518, \mathrm{~m}-\mathrm{w}$, sh; 492, vw; 453, m.

Mass spectrum (e.i. mass, species, $\%>1$ ): 251, (M$\left.\mathrm{CH}_{3} \mathrm{O}\right)^{+}, 3.6 ; 231,\left(\mathrm{M}-\mathrm{CH}_{3} \mathrm{O}-\mathrm{HF}\right)^{+}, 2.8 ; 227,(\mathrm{M}-2 \mathrm{~F}-\mathrm{H}-\mathrm{O})^{+}, 1.2 ;$

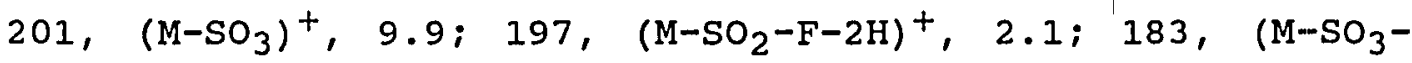
$\mathrm{F})^{+}, 13.0 ; 182,\left(\mathrm{M}-\mathrm{SO}_{3}-\mathrm{F}-\mathrm{H}\right)^{+}, 1.5 ; 173,(\mathrm{M}-4 \mathrm{~F}-2 \mathrm{O}-\mathrm{H})^{+}, \mid 3.1$; $172,(\mathrm{M}-4 \mathrm{~F}-2 \mathrm{O}-2 \mathrm{H})^{+},\left(\mathrm{M}-5 \mathrm{~F}-\mathrm{CH}_{3}\right)^{+}, 1.6 ; 171,(\mathrm{M}-4 \mathrm{~F}-2 \mathrm{O}-3 \mathrm{H})^{+}$, $\left(\mathrm{M}-5 \mathrm{~F}-\mathrm{CH}_{3}-\mathrm{H}\right)^{+}, 47.6 ; 168,(\mathrm{M}-6 \mathrm{~F})^{+},\left(\mathrm{M}-\mathrm{SO}_{3}-\mathrm{CH}_{3}-\mathrm{F}\right)^{+}, 4.4 ; 163$, $\left(\mathrm{M}-\mathrm{SO}_{3}-2 \mathrm{~F}-\mathrm{H}\right)^{+}, 3.5 ; 149,\left(\mathrm{M}-\mathrm{SO}_{3}-2 \mathrm{~F}-\mathrm{CH}_{3}\right)^{+}, 9.4 ; 145$, (M-3F$\left.\mathrm{SO}_{3}\right)^{+}, 3.3 ; 144,\left(\mathrm{M}-3 \mathrm{~F}-\mathrm{H}-\mathrm{SO}_{3}\right)^{+},\left(\mathrm{M}+\mathrm{H}-\mathrm{SF}_{4} \mathrm{OCH}_{3}\right)^{+}, 4.3 ; \mid 139$, $\mathrm{SF}_{4} \mathrm{OCH}_{3}{ }^{+}, 9.8 ; 133, \mathrm{C}_{2} \mathrm{HF}_{4} \mathrm{~S}^{+}, 1.2 ; 127,\left(\mathrm{M}+\mathrm{H}-4 \mathrm{~F}-\mathrm{SO}_{3}\right)^{+}, \mid 3.1 ;$ $124, \mathrm{CO}_{3} \mathrm{~S}_{2}{ }^{+}, 15.7 ; 109, \mathrm{CHO}_{2} \mathrm{~S}_{2}{ }^{+}, 1.1 ; 105, \mathrm{C}_{3} \mathrm{H}_{2} \mathrm{FOS}^{+}, \mathrm{C}_{2} \mathrm{HO}_{3} \mathrm{~S}^{+}$ 23.6; 101, $\mathrm{CH}_{3} \mathrm{OSF}_{2}{ }^{+}, 12.4 ; 94, \mathrm{C}_{2} \mathrm{SF}_{2}+, 4.7 ; 91, \mathrm{C}_{2} \mathrm{FOS}^{+}, 3.4$; $89, \mathrm{SF}_{3}{ }^{+}, 100.0 ; 85, \mathrm{C}_{3} \mathrm{HOS}^{+}, 1.5 ; 83, \mathrm{CHSF}_{2}^{+}, 2.6 ; 82$, $\mathrm{CSF}_{2}{ }^{+}, \mathrm{CH}_{3} \mathrm{OSF}^{+}, 2.8 ; 81, \mathrm{CH}_{2} \mathrm{OSF}^{+}, 2.6 ; 80, \mathrm{CHOSF}^{+}, \mathrm{SO}_{3}^{+}$, $3.5 ; 79, \mathrm{COSF}^{+}, 5.1 ; 75, \mathrm{CH}_{3} \mathrm{OSC}^{+}, 2.3 ; 70, \mathrm{SF}_{2}^{+}, 6.1 ; 69$, $\mathrm{CF}_{3}{ }^{+}$(rearr.), 2.2; 67, FOS ${ }^{+}, 21.0 ; 66, \mathrm{CF}_{2} \mathrm{O}^{+}, 1.6 ; 65$, $\mathrm{SFCH}_{2}{ }^{+}, 9.2 ; 64, \mathrm{SO}_{2}{ }^{+}, \mathrm{CH}_{3} \mathrm{OSH}^{+}, \mathrm{SFCH}^{+}, 12.8$ (two signals); $63, \mathrm{CFS}^{+}, \mathrm{CH}_{3} \mathrm{OS}^{+}, 9.1$ (two signals); $60, \mathrm{COS}^{+}, 2.0$. 
Anal.calcd for $\mathrm{C}_{3} \mathrm{H}_{4} \mathrm{~F}_{6} \mathrm{O}_{4} \mathrm{~S}_{2}{ }^{+}: \mathrm{C}, 12.77 ; \mathrm{H}, 1.43 ; \mathrm{F}$, $40.4 ; \mathrm{S}, 22.72$. Found: $\mathrm{C}, 12.87 ; \mathrm{H}, 1.33 ; \mathrm{F}, 40.0 ; \mathrm{S}, 22.38$.

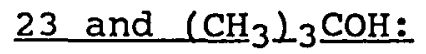

The reaction was run either in a solvent $\left(\mathrm{CCl}_{3} \mathrm{~F}\right)$ or with the pure reactants; in neither case an $A B C D$ spectrum $\left({ }^{19} \mathrm{~F}\right)$ could be detected. It was not possible to separate the constituents by fractional condensation, and the apparent instability of $\mathrm{F}_{5} \mathrm{SCH}\left(\mathrm{SO}_{2} \mathrm{~F}\right) \mathrm{COOC}\left(\mathrm{CH}_{3}\right)_{3}$ excluded other methods. Inferences are thus made from ${ }^{19} \mathrm{~F}$ n.m.r. and i.r. data.

To $0.067 \mathrm{~g}$ of $\left(\mathrm{CH}_{3}\right)_{3} \mathrm{COH}(0.91 \mathrm{mmol}$, Mallinckrodt, reagent grade) in a $50 \mathrm{ml}$ pear-shaped flask with a Kontes Teflon valve connector, $0.22 \mathrm{~g}$ of $\underline{23}$ (0.88 mmol) was vacuum transferred. The bulb was allowed to attain room temperature slowly in a cold Dewar container (initially $-196^{\circ} \mathrm{C}$ ), and swirled when the constituents started to melt. After complete admixture, the vessel was kept at room temperature for one more hour. An i.r. spectrum of this crude material showed a strong ester band at $1760 \mathrm{~cm}^{-1}$, and was otherwise also very similar to the i.r. spectrum of $\mathrm{F}_{5} \mathrm{SCH}\left(\mathrm{SO}_{2} \mathrm{~F}\right) \operatorname{COOC}\left(\mathrm{CH}_{3}\right)_{3}$. The ${ }^{19} \mathrm{~F}$ n.m.r. spectrum (in $\mathrm{CCl} 3 \mathrm{~F}$ ) showed bands corresponding to $\mathrm{F}_{5} \mathrm{SCH}\left(\mathrm{SO}_{2} \mathrm{~F}\right) \operatorname{COOC}\left(\mathrm{CH}_{3}\right)_{3}$ and probably $1 \quad\left(\mathrm{~F}_{5} \mathrm{SCHCF}_{2} \mathrm{OSO}_{2}\right)$. When the solution was kept at room temperature for several days, the bands corresponding to 1 diminished, while bands corresponding to $\mathrm{F}_{5} \mathrm{SCH}\left(\mathrm{SO}_{2} \mathrm{~F}\right) \mathrm{COOC}\left(\mathrm{CH}_{3}\right)_{3}$ (major product) and most likely 
$\left.\mathrm{F}_{5} \mathrm{SCH}_{2} \mathrm{SO}_{2} \mathrm{~F}\right)$ increased.

\section{$\left.\underline{\mathrm{F}}_{5} \mathrm{SCH}_{\left(\mathrm{SO}_{2}\right.} \mathrm{F}\right) \mathrm{COOC}\left(\mathrm{CH}_{3} \perp_{3}(21 \mathrm{~d}):\right.$}

To $0.10 \mathrm{~g}$ of tertiary butanol (1.35 mmol, Mallinckrodt, reargent grade), in a $50 \mathrm{ml}$ pear-shaped flask with a Kontes Teflon valve connector, $0.36 \mathrm{~g}(1.36 \mathrm{mmol})$ of $\underline{21}$ in $2.5 \mathrm{ml} \mathrm{CCl}_{3} \mathrm{~F}$ (Dupont) was vacuum transferred. The flask was swirled while it warmed up, and when all $\left(\mathrm{CH}_{3}\right)_{3} \mathrm{COH}$ had dissolved, the mixture was cooled again by dipping the flask into liquid nitrogen, and was then allowed to warm up slowly in a cold Dewar container. The material that was obtained was used as such, as attempts to isolate it earlier by distillation resulted in the formation of $\mathrm{F}_{5} \mathrm{SCH}_{2} \mathrm{SO}_{2} \mathrm{~F}$; trap-to-trap distillation was also not capable to furnish pure ester. In this case, an originally colorless product was collected that assumed a purple color within hours, and left finally a purple residue upon evaporation.

${ }^{I_{H}}$ n.m.r. spectrum $\left(400 \mathrm{MHz}, \mathrm{CCl}_{3} \mathrm{~F}, \mathrm{Si}\left(\mathrm{CH}_{3}\right)_{4}\right): \delta=$ $1.58 \mathrm{ppm}, \mathrm{s}$, int. $=9.94\left(\mathrm{COOC}\left(\mathrm{CH}_{3}\right)_{3}\right) ; \delta=5.88 \mathrm{ppm}, \mathrm{m}$, int. $=1.00\left(\mathrm{SF}_{5} \mathrm{CH}\right) ;$ an impurity at $\delta=1.29$ and $\delta=2.06$ was identified as $\left(\mathrm{CH}_{3}\right)_{3} \mathrm{COH}$ by adding a drop of an authentic sample to to original sample and which led to a large proportional increase in these two bands. $\left(\mathrm{CH}_{3}\right)_{3} \mathrm{COH}$ accounted for $17.3 \%$ of the t-butyl concentration in the crude ester.

${ }^{19} \mathrm{~F}$ n.m.r. spectrum $\left(\mathrm{CCl}_{3} \mathrm{~F}\right): \phi_{\mathrm{SF} 5}=71.7 \mathrm{ppm}$, narrow 
multiplet, area $=5.00 ; \phi_{\mathrm{SO} 2 \mathrm{~F}}=59.8 \mathrm{ppm}, \mathrm{m}$. area $=0.93$.

Infrared spectrum (neat sample, on $\mathrm{KBr}, \mathrm{cm}^{-1}$ ) of the crude product: $2990, \mathrm{~m}$; 2954, w, sh; 1760, s-vs; 1481, w; 1442, s-Vs; 1401, w; 1377, m-s; 1299, s; 1266, m-s; 1222, ms; 1149, s-Vs; 1040, Vw; 965, wi 879, vs; 835, s; $801, \mathrm{~m}-\mathrm{s}$; $788, \mathrm{~m}-\mathrm{s} ; 773, \mathrm{~m}-\mathrm{s} ; 698, \mathrm{w}-\mathrm{m}, \mathrm{br} ; 664, \mathrm{w} ; 643, \mathrm{w}, \mathrm{br} ; 612, \mathrm{~m}$; 571, s-Vs; 490, w-m; 458, w; 452, w-m; 446, w-m.

G.c. mass spectrum (e.i., $70 \mathrm{eV}$, mass, species, $\%$ > 1): 251, $\left(\mathrm{m}-\left(\mathrm{CH}_{3}\right)_{3} \mathrm{CO}\right)^{+}, 0.4 ; 231,\left(\mathrm{M}-\left(\mathrm{CH}_{3}\right)_{3} \mathrm{CO}-\mathrm{HF}\right)^{+}, 2.7 ;$ 127, $\mathrm{SF}_{5}{ }^{+}, 15.4 ; 105, \mathrm{C}_{2} \mathrm{HO}_{3} \mathrm{~S}^{+}, 1.1 ; 97, \mathrm{CFO}_{2} \mathrm{~S}^{+}, \mathrm{C}_{6} \mathrm{H}_{9} \mathrm{O}^{+}, 1.0 ;$ 91, $\mathrm{C}_{2} \mathrm{FOS}^{+}, 1.1 ; 89, \mathrm{SF}_{3}^{+}, 17.3 ; 70, \mathrm{SF}_{2}^{+}, 2.0 ; 67, \mathrm{FSO}^{+}$, $11.5 ; 64, \mathrm{SO}_{2}{ }^{+}, 3.5 ; 60, \mathrm{COS}^{+}, 3.3 ; 59, \mathrm{C}_{3} \mathrm{H}_{7} \mathrm{O}^{+}, 100.0 ; 58$, $\mathrm{C}_{3} \mathrm{H}_{6} \mathrm{O}^{+}, 6.2 ; 57, \mathrm{C}_{3} \mathrm{H}_{5} \mathrm{O}^{+}, 68.6 ; \mathrm{C}_{3} \mathrm{H}_{4} \mathrm{O}^{+}, 21.0 ; 55, \mathrm{C}_{3} \mathrm{H}_{3} \mathrm{O}^{+} ; 53$ ， $\mathrm{C}_{3} \mathrm{HO}^{+} ; 51, \mathrm{SF}^{+}, 1.9$.

Reaction of 23 and CSF:

Finely ground cesium fluoride $(2.80 \mathrm{~g}, 18.4 \mathrm{mmol})$ was dried $\left(3 \mathrm{~d}, 115^{\circ} \mathrm{C}\right.$, high vacuum) in a $20 \mathrm{ml}$ Pyrex glass reaction vessel, equipped with a Kontes Teflon valve. Then $0.19 \mathrm{~g}$ of $5(0.76 \mathrm{mmol})$ were added by vacuum transfer ($\left.196^{\circ} \mathrm{C}\right)$ and the vessel was maintained at $40^{\circ} \mathrm{C}(19 \mathrm{~h})$. The weight gain of the vessel was $0.16 \mathrm{~g}$, after the volatile material had been removed by vacuum transfer. An infrared spectrum of the solid showed vibrational bands that were attributable to the complex $\mathrm{Cs}^{+}\left[\mathrm{F}_{5} \mathrm{SC}\left(\mathrm{SO}_{2} \mathrm{~F}\right) \mathrm{COF}\right]^{-}$A ${ }^{19} \mathrm{~F}$ n.m.r. spectrum of the acetone extract, which was obtained 
as described below, was also consistent with only the presence of the cesium compound. The reaction mixture was rinsed several times with acetone $(4 \times 3 \mathrm{ml})$, the acetone extract was filtered, the filter residue was washed with several small portions of acetone, and the solution was brought to dryness, leaving $0.15 \mathrm{~g}$ of the cesium salt $\underline{6}$. Yield $=49.1 \%$.

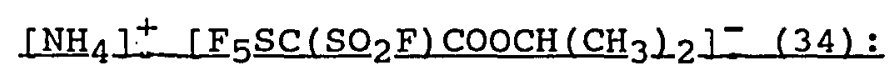

Ammonia was bubbled into a solution of $0.55 \mathrm{~g}$ of $\mathrm{F}_{5} \mathrm{SCH}\left(\mathrm{SO}_{2} \mathrm{~F}\right) \mathrm{COOCH}\left(\mathrm{CH}_{3}\right)_{2}(1.8 \mathrm{mmol})$ in $14 \mathrm{ml}$ of anhydrous ether, cooled to $-25^{\circ} \mathrm{C}$, in a $25 \mathrm{ml}$ round bottom flask, fitted with a claisen-head, Drierite tube and a gas inlet tube. The temperature was allowed to rise continuously to $+15^{\circ} \mathrm{C}$, when a small amount of precipitation was observed. ${ }^{19} \mathrm{~F}$ n.m.r. spectroscopy showed the starting ester to be gone, but attempts to isolate the product failed. In the solid state the compound decomposed rather quickly upon reaching roomtemperature, but was stable in solution. An i.r. spectrum was obtained by allowing the ether to evaporate on a $\mathrm{KBr}$ disk and immediately recording the spectrum.

${ }^{19} \mathrm{~F}$ n.m.r. (in ether, $\mathrm{CCl}_{3} \mathrm{~F}$ ext.): $\mathrm{AB}_{4} \mathrm{X} \phi=96.1 \mathrm{ppm}$, 9 Iines, int. $=1.07,\left(F_{A}\right) ; \phi=82.0 \mathrm{ppm}, \mathrm{d}-\mathrm{m}$, int. $=4.00$ $\left(\mathrm{F}_{\mathrm{B}}\right) ; \phi=65.8 \mathrm{ppm}, \mathrm{p}$, int. $=1.02\left(\mathrm{~F}_{\mathrm{X}}, \mathrm{SO}_{2} \mathrm{~F}\right) ; \mathrm{J}_{\mathrm{AB}}=151.3$ $\mathrm{Hz} ; \mathrm{J}_{\mathrm{BX}}=10.9 \mathrm{~Hz}$.

I.r. (neat sample, $\left.\mathrm{KBr}, \mathrm{Cm}^{-1}\right): 3648, \mathrm{~m} ; 3585, \mathrm{~m} ; 3400-$ 
2900, s, br, peaks at 3037, 2995; 1743, wi 1636, m, sh; 1589, s; 1543, s,sh; 1493, m-s; 1453, s; 1436, s,sh; 1436, $\mathrm{m}-\mathrm{s}, \mathrm{sh} ; 1399$, s; 1366, vs; 1292, s-vs; 1191, s; 1181, s; 1145, $\mathrm{m} ; 1100, \mathrm{~s} ; 1047, \mathrm{~m} ; 910, \mathrm{~m}-\mathrm{s} ; 868, \mathrm{~s}, \mathrm{sh} ; 850$, vs; 810 , vs; 760 , vs; $710, \mathrm{~m}-\mathrm{s} ; 668, \mathrm{~s} ; 620, \mathrm{~s} ; 582, \mathrm{~s} ; 573, \mathrm{~m}-$ $\mathrm{s} ; 494, \mathrm{~m} ; 486, \mathrm{~m} ; 462, \mathrm{~m} ; 424, \mathrm{~m}-\mathrm{s} ; 413, \mathrm{~m}-\mathrm{s}$.

$\left.\underline{\mathrm{F}}_{5} \mathrm{SCH}_{\left(\mathrm{SO}_{2}\right.} \mathrm{NH}_{2}\right) \mathrm{COOCH}\left(\mathrm{CH}_{3} \perp_{2}-(35):\right.$

Gaseous ammonia was introduced slowly into a stirred solution of $\mathrm{F}_{5} \mathrm{SCH}\left(\mathrm{SO}_{2} \mathrm{~F}\right) \mathrm{COOCH}\left(\mathrm{CH}_{3}\right)_{2}(2.4 \mathrm{~g}, 7.7 \mathrm{mmol})$ in $5 \mathrm{ml}$ dioxane in a $50 \mathrm{ml}$ round-bottomed flask. Initially, a temperature-rise was observed, and the rate of $\mathrm{NH}_{3}$ introduction was kept so low that the temperature stayed below $50^{\circ} \mathrm{C}$ (charring is possible). When the temperature of the mixture dropped, $\mathrm{NH}_{3}$ addition was stopped, $2 \mathrm{ml}$ of water as added and most of the solvent was boiled off. The product contained still the starting ester and the treatment with $\mathrm{NH}_{3}$ was repeated. The volume of the solution was further diminished and the product was obtained by twice recrystallizing it from dilute $\mathrm{HCl}\left(\mathrm{H}_{2} \mathrm{O}: \mathrm{HCl}=5: 1\right)$. Yield: $1.2 \mathrm{~g}$ (dried over $\mathrm{P}_{2} \mathrm{O}_{5}$ in the desiccator), $50.5 \%$, creamcolored amorphous mass. M.p. $244-246^{\circ} \mathrm{C}$, darkens; $254^{\circ} \mathrm{C}$, solidifies, forms shiny flakes; $270^{\circ} \mathrm{C}$, melts again, $280^{\circ} \mathrm{C}$, darkens.

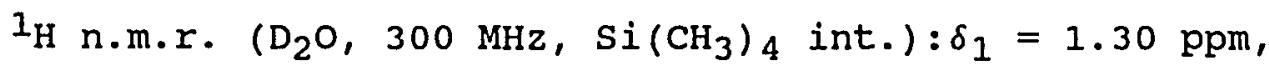
$\mathrm{d}$, int $=6.00\left(\mathrm{CH}\left(\mathrm{CH}_{3}\right)_{2}\right), \delta_{2}=5.13 \mathrm{ppm}$, septet, int. = 
$0.97\left(\mathrm{CH}\left(\mathrm{CH}_{3}\right)_{2}\right) ; \delta_{3}=5.88 \mathrm{ppm}, \mathrm{p}$, int. $=0.77\left(\mathrm{~F}_{5} \mathrm{SCH}\right) ; \mathrm{NH}_{2}$ is not observed; $\mathrm{J}_{12}=6.30 \mathrm{~Hz} ; \mathrm{J}_{\mathrm{HB}}=5.85 \mathrm{~Hz}$.

${ }^{19} \mathrm{~F}$ n.m.r. $\left(\mathrm{H}_{2} \mathrm{O}, \mathrm{CCl}_{3} \mathrm{~F}\right.$ ext. $): \mathrm{AB}_{4} \phi=79.8 \mathrm{ppm}, 9$ lines, int. $=1.0\left(\mathrm{~F}_{\mathrm{A}}\right) ; \phi=69.2 \mathrm{ppm}, \mathrm{d}-\mathrm{m}$, int. $=3.6\left(\mathrm{~F}_{\mathrm{B}}\right) ;$ $\mathrm{J}_{\mathrm{AB}}=151.7 \mathrm{~Hz}$.

I.r. (KBr, neat, $\left.\mathrm{cm}^{-1}\right): 3184, \mathrm{~m}-\mathrm{s} ; 3087 . \mathrm{m}-\mathrm{s} ; 2986, \mathrm{~m}-$ $\mathrm{s} ; 2880, \mathrm{~m} ; 1733, \mathrm{~s} ; 1684, \mathrm{~m}, \mathrm{sh} ; 1460, \mathrm{~m}-\mathrm{s} ; 1440, \mathrm{~m}-\mathrm{s} ; 1393$, $\mathrm{m} ; 1380, \mathrm{~m} ; 1353, \mathrm{~m} ; 1310, \mathrm{~m}-\mathrm{s} ; 1265, \mathrm{~s} ; 1211, \mathrm{~s}-\mathrm{vs} ; 1181$, $\mathrm{s}, \mathrm{sh} ; 1149, \mathrm{~m}, \mathrm{sh} ; 1104, \mathrm{~m}-\mathrm{s} ; 1051, \mathrm{~s} ; 945, \mathrm{vw} ; 904, \mathrm{~s} ; 871$, $\mathrm{s} ; 859, \mathrm{vs} ; 810, \mathrm{~s} ; 783, \mathrm{~m}-\mathrm{s} ; 741, \mathrm{~m}-\mathrm{s} ; 682$, w; 648, m-s; 610, w; 592, m-s; 572, m; 550, m; 521, m; 483, m-w; 417,w. Mass spectrum ( negative ionization, mass, species, $\%$, for int. $>1 \%): 307, \mathrm{M}^{-}, 0.14 ; 249,\left(\mathrm{M}-\mathrm{C}_{3} \mathrm{H}_{7} \mathrm{O}^{-}, 2.3 ; 180\right.$, $\left(\mathrm{M}-\mathrm{SF}_{5}\right)^{-}, 1.2 ; 139, \mathrm{C}_{5} \mathrm{HNO}_{2} \mathrm{~S}^{-}, 2.1 ; 129, \mathrm{C}_{4} \mathrm{HO}_{3} \mathrm{~S}^{-}, 4.0 ; 127$, $\mathrm{SF}_{5}{ }^{-}, 59.7 ; 124, \mathrm{C}_{2} \mathrm{HFO}_{3} \mathrm{~S}^{-}, \mathrm{C}_{2} \mathrm{HOS}_{2}^{-}, \mathrm{CH}_{2} \mathrm{NO}_{2} \mathrm{~S}_{2}^{-}, 7.1 ; 123$, $\mathrm{C}_{2} \mathrm{FO}_{3} \mathrm{~S}^{-}, \mathrm{C}_{2} \mathrm{FOS}_{2}^{-}, \mathrm{CHNO}_{2} \mathrm{~S}_{2}^{-}, 2.4 ; 122, \mathrm{CNO}_{2} \mathrm{~S}_{2}^{-}, 2.4 ; 118$, $\mathrm{C}_{2} \mathrm{NO}_{3} \mathrm{~S}^{-}, 2.2 ; 113, \mathrm{C}_{2} \mathrm{~F}_{3} \mathrm{~S}^{-}, 2.2 ; 110, \mathrm{C}_{2} \mathrm{~F}_{2} \mathrm{OS}^{-}, 4.5 ; 108, \mathrm{SF}_{4}^{-}$ , 100.0; 105, $\left(\mathrm{CCHSO}_{2} \mathrm{NH}_{2}\right)^{-}, 1.6 ; 98,\left(\mathrm{CCOOC}_{3} \mathrm{H}_{6}\right)^{-}, 1.8 ; 96$, $\mathrm{CHFS}_{2}{ }^{-}, 8.1 ; 95, \mathrm{CFS}_{2}^{-}, 2.5 ; 94, \mathrm{CH}_{2} \mathrm{SO}_{2} \mathrm{NH}_{2}{ }^{-}, \mathrm{CC}(0) \mathrm{OC}_{3} \mathrm{H}_{2}{ }^{-}$two fragments)，9.0, 6.9; 93, $\mathrm{CHSO}_{2} \mathrm{NH}_{2}^{-}, 23.6 ; 89, \mathrm{SF}_{3}^{-}, 15.4 ;$ 85, $\mathrm{C}_{4} \mathrm{H}_{5} \mathrm{O}_{2}{ }^{-}, 1.0 ; 83, \mathrm{CHSF}_{2}{ }^{-}, 34.8 ; 82, \mathrm{CSF}_{2}{ }^{-}, 7.4 ; 80$, $\mathrm{SO}_{2} \mathrm{NH}_{2}^{-}, 2.9$;

Anal. calcd for $\mathrm{C}_{5} \mathrm{H}_{10} \mathrm{~F}_{5} \mathrm{NO}_{4} \mathrm{~S}_{2}: \mathrm{C}, 19.54 ; \mathrm{H}, 3.28 ; \mathrm{F}$, $30.9 ; \mathrm{N}, 4.56 ; \mathrm{S}, 20.87$. Found: C, 19.41; H, 3.37; F, 30.2; $\mathrm{N}, 4.44 ; \mathrm{S}, 20.62$. 
$\left[\left(\mathrm{C}_{2} \mathrm{H}_{5} \perp_{3} \mathrm{NH}^{+}\left[\mathrm{F}_{5} \underline{\mathrm{SC}}_{\left(\mathrm{SO}_{2}\right.} \mathrm{F} \mathrm{COOCH}_{3}\right]^{-}-(32 \mathrm{~b}):\right.\right.$

To $0.3385 \mathrm{~g}$ of $\mathrm{F}_{5} \mathrm{SCH}\left(\mathrm{SO}_{2} \mathrm{~F}\right) \mathrm{COOCH}_{3}(1.2 \mathrm{mmol})$ in $2.0 \mathrm{ml}$ anhydrous ether in a $10 \mathrm{ml}$ flask, fitted with a claisenhead, Drierite tube and dropping funnel, $0.15 \mathrm{~g} \mathrm{~N}\left(\mathrm{C}_{2} \mathrm{H}_{5}\right)_{3}$ (1.49 mmol) in $2.0 \mathrm{ml}$ anhydrous ether was added dropwise during 30 seconds with swirling at $-45^{\circ} \mathrm{C}$. An immediate separation of a lower pale yellow layer was observed. The cold-bath was removed and the mixture was allowed to attain room-temperature slowly with occasional swirling. After removal of the solvent in vacuo $0.4288 \mathrm{~g}(1.12 \mathrm{mmol})$ or $93 \%$ of an amorphous, slightly yellow solid was obtained, which was analytically pure.

$I_{\mathrm{H}}$ n.m.r. $\left(\mathrm{CDCl}_{3}, \mathrm{Si}\left(\mathrm{CH}_{3}\right)_{4}\right.$ ext. $): \delta_{1}=1.79 \mathrm{ppm}, t$, int. $=10.1\left(\mathrm{HN}\left(\mathrm{CH}_{2} \mathrm{CH}_{3}\right)_{3}{ }^{+}\right) ; \delta_{2}=3.59$ ppm, quart., int. = $6.3\left(\mathrm{HN}\left(\mathrm{CH}_{2} \mathrm{CH}_{3}\right)_{3}{ }^{+}\right) ; \delta_{3}=4.04 \mathrm{ppm}, \mathrm{s} ;$ int. $=3.0\left(\mathrm{COOCH}_{3}\right) ;$ $\delta_{4}=7.46 \mathrm{ppm}, \mathrm{s}$, broad, int. $\left.=1.0\left(\underline{\mathrm{HN}}\left(\mathrm{C}_{2} \mathrm{H}_{5}\right)_{3}\right)^{+}\right) ; \mathrm{J}_{\mathrm{H}-\mathrm{H}}=$ $7.40 \mathrm{~Hz}$ (ethyl).

$19 \mathrm{~F}$ n.m.r. $\left(\mathrm{CDCl}_{3}, \mathrm{CCl}_{3} \mathrm{~F}\right.$ ext. $): \mathrm{AB}_{4} \mathrm{X} \phi=95.3 \mathrm{ppm}, 9$ lines, int. $=1.0\left(F_{A}\right) ; \phi=82.1 \mathrm{ppm}, \mathrm{d}-\mathrm{m}$, int. $=4.1\left(\mathrm{~F}_{\mathrm{B}}\right)$; $\phi=67.0 \mathrm{ppm}, \mathrm{p}$, int. $=1.0\left(\mathrm{FX}_{\mathrm{X}}, \mathrm{SO}_{2} \mathrm{~F}\right) ; \mathrm{J}_{\mathrm{AB}}=154.2 \mathrm{~Hz} ; \mathrm{J}_{\mathrm{BX}}=$ $10.2 \mathrm{~Hz}$.

I.r. (neat sample, $\left.\mathrm{KBr}, \mathrm{cm}^{-1}\right): 3093, \mathrm{~m}-\mathrm{s} ; 2995, \mathrm{~m}$; $2952, \mathrm{~m} ; 2875, w-m ; 2748, w ; 2495, \mathrm{vw} ; 1640, \mathrm{~s}-\mathrm{vs}$; 1523, vw; $1474, \mathrm{~m}-\mathrm{s} ; 1462, \mathrm{~m} ; 1442, \mathrm{~s} ; 1423, \mathrm{~m} ; 1394, \mathrm{~m}-\mathrm{s} ; 1367, \mathrm{~s}, \mathrm{sh}$; 1355, s; 1306, vs; 1289, vs; 1179, s; 1093, mi 1052, m; $1020, \mathrm{w}-\mathrm{m} ; 939, \mathrm{w}-\mathrm{m} ; 900, \mathrm{vw} ; 864, \mathrm{~s} ; 839, \mathrm{vs} ; 805$, vs; 757 , 
$\mathrm{s} ; 690, \mathrm{~m}-\mathrm{s} ; 666, \mathrm{~s} ; 615, \mathrm{~s} ; 579, \mathrm{~s} ; 572, \mathrm{~m} ; 538$, vw; 485 , vw; 459 , w; $406, w-m$.

Mass spectrum (electron impact, $70 \mathrm{eV}$, mass, species, $\%>2): 251,\left(\mathrm{M}-\mathrm{N}\left(\mathrm{C}_{2} \mathrm{H}_{5}\right)_{3}-\mathrm{CH}_{3} \mathrm{O}\right)^{+}, 11.7 ; 231, \quad\left(\mathrm{M}-\mathrm{N}\left(\mathrm{C}_{2} \mathrm{H}_{5}\right)_{3}-\mathrm{HF}-\right.$ $\left.\mathrm{CH}_{3} \mathrm{O}\right)^{+}, 5.1 ; 168,\left(\mathrm{M}-\mathrm{N}\left(\mathrm{C}_{2} \mathrm{H}_{5}\right)_{3}-\mathrm{SO}_{2} \mathrm{~F}-\mathrm{CH}_{3} \mathrm{O}\right)^{+}, 4.5 ; 155$ ，(M$\left.\mathrm{N}\left(\mathrm{C}_{2} \mathrm{H}_{5}\right)_{3}-\mathrm{SF}_{5}\right)^{+}, \quad 6.5 ; \quad 149, \quad\left(\mathrm{M}-\mathrm{N}\left(\mathrm{C}_{2} \mathrm{H}_{5}\right)_{3}-\mathrm{SO}_{2} \mathrm{~F}-\mathrm{CH}_{3} \mathrm{O}-\mathrm{F}\right)^{+}, \quad 2.3$; $143,\left(\mathrm{M}-\mathrm{N}\left(\mathrm{C}_{2} \mathrm{H}_{5}\right)_{3}-4 \mathrm{~F}-\mathrm{CH}_{3} \mathrm{O}-2 \mathrm{O}\right)^{+}, 5.2 ; 139,\left(\mathrm{M}-\mathrm{N}\left(\mathrm{C}_{2} \mathrm{H}_{5}\right)_{3}-\mathrm{SO}_{2} \mathrm{~F}-\right.$ $\left.\mathrm{COOCH}_{3}-\mathrm{H}\right)^{+}, 3.6 ; 135,\left(\mathrm{M}-\mathrm{N}\left(\mathrm{C}_{2} \mathrm{H}_{5}\right)_{3}-\mathrm{SF}_{5}-\mathrm{HF}\right)^{+}, 3.7 ; 129$ ，(M$\left(\mathrm{N}\left(\mathrm{C}_{2} \mathrm{H}_{5}\right)_{2} \mathrm{C}_{2} \mathrm{H}_{4}-5 \mathrm{~F}-\mathrm{COOCH}_{3}\right)^{+}, 2.7 ; 127, \mathrm{SF}_{5}{ }^{+}, 52.1 ; 125$, (M$\left.\mathrm{N}\left(\mathrm{C}_{2} \mathrm{H}_{5}\right)_{2} \mathrm{C}_{2} \mathrm{H}_{4}-\mathrm{SF}_{5}-\mathrm{CH}_{3} \mathrm{O}\right)^{+}, 19.5 ; 124$, $\left(\mathrm{M}-\mathrm{N}\left(\mathrm{C}_{2} \mathrm{H}_{5}\right)_{3}-\mathrm{SF}_{5}-\mathrm{CH}_{3} \mathrm{O}\right)^{+}$, $3.9 ; 122, \quad\left(\mathrm{M}-\mathrm{N}\left(\mathrm{C}_{2} \mathrm{H}_{5}\right){ }_{2} \mathrm{C}_{2} \mathrm{H}_{4}-\mathrm{SO}_{2} \mathrm{~F}-\mathrm{F}-\mathrm{COOCH}_{3}\right)^{+}, 5.6 ; 105$ ，(M$\left.\mathrm{N}\left(\mathrm{C}_{2} \mathrm{H}_{5}\right)_{3}-\mathrm{SF}_{5}-\mathrm{CH}_{3} \mathrm{O}-\mathrm{F}\right)^{+},\left(\mathrm{C}_{3} \mathrm{H}_{2} \mathrm{FOS}\right)^{+}$(two fragments, 8.8, 10.3; 102, $\mathrm{HN}\left(\mathrm{C}_{2} \mathrm{H}_{5}\right)_{3}{ }^{+}, 2.5 ; 101, \mathrm{~N}\left(\mathrm{C}_{2} \mathrm{H}_{5}\right)_{3}^{+}, 29.1 ; 100$, $\mathrm{N}\left(\mathrm{C}_{2} \mathrm{H}_{5}\right)_{2} \mathrm{C}_{2} \mathrm{H}_{4}^{+}, 11.5 ; 91, \mathrm{C}_{2} \mathrm{FOS}^{+}, 2.4 ; 89, \mathrm{SF}_{3}{ }^{+}, 48.3 ; 87$, $\mathrm{HN}\left(\mathrm{C}_{2} \mathrm{H}_{5}\right)_{2} \mathrm{CH}_{2}^{+}, 11.3 ; 86, \mathrm{~N}\left(\mathrm{C}_{2} \mathrm{H}_{5}\right)_{2} \mathrm{CH}_{2}^{+}, 100.0 ; 79$, CFOS $^{+}$, $4.0 ; 72, \quad \mathrm{~N}\left(\mathrm{C}_{2} \mathrm{H}_{5}\right)_{2}^{+}, \mathrm{CHCOOCH}_{3}^{+}, 7.5 ; 71, \mathrm{~N}\left(\mathrm{C}_{2} \mathrm{H}_{5}\right) \mathrm{C}_{2} \mathrm{H}_{4}{ }^{+}$, $\mathrm{CCOOCH}_{3}+, 2.8 ; 70, \mathrm{~N}\left(\mathrm{C}_{2} \mathrm{H}_{5}\right) \mathrm{C}_{2} \mathrm{H}_{3}{ }^{+}, \mathrm{CCOOCH}_{2}{ }^{+}, \mathrm{SF}_{2}{ }^{+}$(two fragments)，5.7, $3.7 ; 69, \mathrm{~N}\left(\mathrm{C}_{2} \mathrm{H}_{5}\right) \mathrm{C}_{2} \mathrm{H}_{2}{ }^{+}, \mathrm{CCOOCH}^{+}, 3.0 ; 67$, $\mathrm{FSO}^{+}, \mathrm{C}_{4} \mathrm{H}_{5} \mathrm{~N}^{+}, 35.1 ; 63, \mathrm{CFS}^{+}, 3.3 ; 62, \mathrm{C}_{4} \mathrm{~N}^{+}, 2.3$. Anal.calcd for $\mathrm{C}_{9} \mathrm{H}_{19} \mathrm{~F}_{6} \mathrm{NO}_{4} \mathrm{~S}_{2}: \mathrm{C}, 28.19 ; \mathrm{H}, 5.00 ; \mathrm{F}$, $29.7 ; \mathrm{N}, 3.65 ; \mathrm{S}, 16.73$. Found: C, 28.40; H, 4.89; F, 30.1; $\mathrm{N}, 3.78 ; \mathrm{S}, 16.43$.

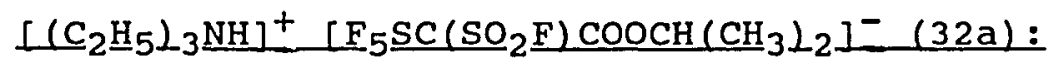

To $2.11 \mathrm{~g}$ of $\mathrm{F}_{5} \mathrm{SCH}\left(\mathrm{SO}_{2} \mathrm{~F}\right) \mathrm{COOCH}\left(\mathrm{CH}_{3}\right)_{2} \quad(6.8 \mathrm{mmol})$, dissolved in $3.0 \mathrm{ml}$ of anhydrous ether, in a $25 \mathrm{ml}$ round- 
bottom flask, equipped with a magnetic stirring bar, Claisen-head, dropping funnel and Drierite tube, $0.80 \mathrm{~g}$ of triethyl amine, dissolved in $4 \mathrm{ml}$ of anhydrous ether, was added dropwise with stirring at $-60^{\circ}$ to $-50^{\circ} \mathrm{C}$ (acetone/dry ice). At $-45^{\circ} \mathrm{C}$ bath-temperature two layers were observed in the reaction flask. Stirring was continued for two minutes, the cold-bath was removed and the solvent was pumped away through a cold trap $\left(-196^{\circ} \mathrm{C}\right)$, leaving $2.80 \mathrm{~g}$ of an analytically pure amorphous white solid. Yield $=100 \%$ M.p. 94-97 $\mathrm{C}$. The solid could be handled in air without difficulty and formed large irregular crystals upon recrystallization from chloroform.

$1 \mathrm{H}$ n.m.r. $\left(\mathrm{CD}_{3} \mathrm{COCD}_{3}, \mathrm{Si}\left(\mathrm{CH}_{3}\right)_{4}\right.$ ext. $): \delta_{1}=6.45 \mathrm{ppm}, \mathrm{s}$, broad, int. $=0.93(\mathrm{NH}) ; \delta_{2}=4.85 \mathrm{ppm}$, sept., int $=0.71$

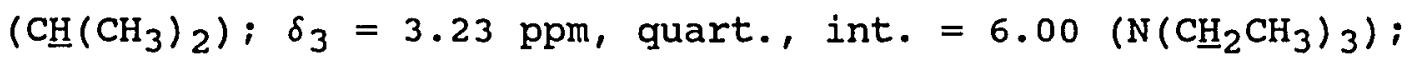
$\delta_{4}=1.24 \mathrm{ppm}, \mathrm{t}$, int. $\approx 8.6$ (overlap, $\left.\mathrm{N}\left(\mathrm{CH}_{2} \mathrm{CH}_{3}\right)_{3}\right) ; \delta_{5}=$ 1.09, d, int. $\approx 6.6$ (overlap, $\mathrm{CH}\left(\mathrm{CH}_{3}\right)_{2} \cdot \mathrm{J}_{25}=6.36 \mathrm{~Hz} ; \mathrm{J}_{34}=$ $7.14 \mathrm{~Hz}$.

${ }^{19} \mathrm{~F}$ n.m.r. $\left(\mathrm{CD}_{3} \mathrm{COCD}_{3}, \mathrm{CCl}_{3} \mathrm{~F}\right.$ ext. $): \mathrm{AB}_{4} \mathrm{X}, \phi=97.0 \mathrm{ppm}$, 9 lines, int. $=1.00\left(F_{\mathrm{A}}\right) ; \phi=82.1 \mathrm{ppm}, \mathrm{d}-\mathrm{m}$, int. $=4.25$ $\left(F_{B}\right) ; \phi=66.3 \mathrm{ppm}, \mathrm{p}$, int. $=1.00\left(\mathrm{~F}_{\mathrm{X}}, \mathrm{SO}_{2} \mathrm{~F}\right) ; \mathrm{J}_{\mathrm{AB}}=154.0$ $\mathrm{Hz} ; \mathrm{J}_{\mathrm{BX}}=10.6 \mathrm{~Hz}$.

Infrared spectrum (neat, $\mathrm{KBr}, \mathrm{cm}^{-1}$ ): 3060, vw; 2992, vw, 2941, vw; 2754, vw; 2677, vw; 2498, vw; 1615, s; 1467, $\mathrm{m} ; 1401, \mathrm{~m} ; 1380, \mathrm{~s} ; 1291, \mathrm{~s} ; 1194, \mathrm{~s} ; 1179, \mathrm{~s} ; 1144, \mathrm{~m}$; 1111, m-s; 1093, s; 1041, s; 910, mi 846, vs; 836, vs, sh; 
$806, \mathrm{~s} ; 755, \mathrm{vs} ; 697, \mathrm{~s} ; 664, \mathrm{~s} ; 610, \mathrm{~s} ; 586, \mathrm{~m} ; 577, \mathrm{~s}$; 570, s; $484, w ; 463, w$.

Mass spectrum (chemical ionization, mass, species, > 2 $\%): 311,\left(\mathrm{M}-\mathrm{N}\left(\mathrm{C}_{2} \mathrm{H}_{5}\right)_{2} \mathrm{C}_{2} \mathrm{H}_{4}\right)^{+}, 4.3 ; 269, \mathrm{C}_{2} \mathrm{H}_{3} \mathrm{~F}_{6} \mathrm{O}_{4} \mathrm{~S}_{2}{ }^{+}, 9.8 ; 251$, $\left(\mathrm{M}-\mathrm{N}\left(\mathrm{C}_{2} \mathrm{H}_{5}\right)_{3}-\mathrm{C}_{3} \mathrm{H}_{7} \mathrm{O}\right)^{+}, 3.3 ; 219, \mathrm{CF}_{3} \mathrm{O}_{3} \mathrm{~S}_{2}{ }^{+}$(rearr.), 3.6;209, $\left(\mathrm{M}-\mathrm{N}\left(\mathrm{C}_{2} \mathrm{H}_{5}\right)_{3}-2 \mathrm{~F}-\mathrm{HF}-\mathrm{C}_{3} \mathrm{H}_{7}\right)^{+}, 3.1 ; 205, \mathrm{CH}_{2} \mathrm{~F}_{5} \mathrm{O}_{2} \mathrm{~S}_{2}{ }^{+}, 6.4 ; 143$, $\left(\mathrm{M}-\mathrm{N}\left(\mathrm{C}_{2} \mathrm{H}_{5}\right)_{3}-\mathrm{SO}_{2} \mathrm{~F}-2 \mathrm{HF}-\mathrm{CO}_{2}\right)^{+} ; 127, \mathrm{SF}_{5}^{+}, 12.4 ; 125$, $\mathrm{C}_{2} \mathrm{H}_{2} \mathrm{FO}_{3} \mathrm{~S}^{+}, 8.9 ; 105, \mathrm{C}_{4} \mathrm{H}_{6} \mathrm{FS}^{+}$(rearr.), 3.1; 103, $\mathrm{C}_{4} \mathrm{H}_{4} \mathrm{FS}^{+}$ (rearr.), 3.3; 102, $\mathrm{NH}\left(\mathrm{C}_{2} \mathrm{H}_{5}\right)_{3}^{+}, 59.5 ; 101, \mathrm{~N}\left(\mathrm{C}_{2} \mathrm{H}_{5}\right)_{3}^{+}, 93.6$; 100, $\left(\mathrm{N}\left(\mathrm{C}_{2} \mathrm{H}_{5}\right)_{3}-\mathrm{H}\right)^{+}, 75.4 ; 99,\left(\mathrm{~N}\left(\mathrm{C}_{2} \mathrm{H}_{5}\right)_{3}-2 \mathrm{H}\right)^{+}, 11.5 ; 91$, $\mathrm{C}_{2} \mathrm{FOS}^{+}, 3.4 ; 89, \mathrm{SF}_{3}{ }^{+}, 76.0 ; 87, \mathrm{NH}\left(\mathrm{C}_{2} \mathrm{H}_{5}\right){ }_{2} \mathrm{CH}_{2}{ }^{+}, 11.4 ; 86$, $\mathrm{N}\left(\mathrm{C}_{2} \mathrm{H}_{5}\right)_{2} \mathrm{CH}_{2}^{+}, 100.0 ; 79$, CFOS $^{+}, 4.3 ; 74, \mathrm{C}_{5} \mathrm{~N}^{+}$, $\left(\mathrm{NH}_{2}\left(\mathrm{C}_{2} \mathrm{H}_{5}\right)_{2}\right)^{+}, 4.6 ; 72, \mathrm{~N}\left(\mathrm{C}_{2} \mathrm{H}_{5}\right)_{2}^{+}, 11.7 ; 71,\left(\mathrm{~N}\left(\mathrm{C}_{2} \mathrm{H}_{5}\right)_{2}-\mathrm{H}\right)^{+}$; $2.2 ; 70, \mathrm{SF}_{2}{ }^{+},\left(\mathrm{N}\left(\mathrm{C}_{2} \mathrm{H}_{5}\right)_{2}-2 \mathrm{H}\right)^{+}$(two fragments), 4.2, 4.4; 67, $\mathrm{FSO}^{+}, 11.8 ; 65, \mathrm{CH}_{2} \mathrm{FS}^{+}, 21.4 ; 61, \mathrm{C}_{3} \mathrm{H}_{7} \mathrm{OH}_{2}^{+}, 3.5 ; 59, \mathrm{C}_{3} \mathrm{H}_{7} \mathrm{O}^{+}$, $53.7 ; 58, \mathrm{C}_{3} \mathrm{H}_{6} \mathrm{O}^{+}, 31.6 ; 57, \mathrm{C}_{3} \mathrm{H}_{5} \mathrm{O}^{+}, 4.2 ; 56, \mathrm{C}_{3} \mathrm{H}_{4} \mathrm{O}^{+}, 7.4 ;$ 55, $\mathrm{C}_{3} \mathrm{H}_{3} \mathrm{O}^{+}$.

Anal.calcd for $\mathrm{C}_{11} \mathrm{H}_{23} \mathrm{~F}_{6} \mathrm{NO}_{4} \mathrm{~S}_{2}: \mathrm{C}, 32.11 ; \mathrm{H}, 5.64 ; \mathrm{F}$, $27.7 ; \mathrm{N}, 3.40 ; \mathrm{S}, 15.59$. Found: C, 32.04; H, 5.45; F, 27.5; $\mathrm{N}, 3.31 ; \mathrm{S}, 15.80$.

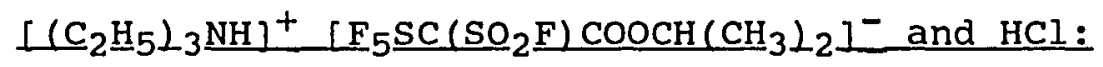

To $0.70 \mathrm{~g}$ of $\left[\left(\mathrm{C}_{2} \mathrm{H}_{5}\right)_{3} \mathrm{NH}\right]^{+}\left[\mathrm{F}_{5} \mathrm{SC}\left(\mathrm{SO}_{2} \mathrm{~F}\right) \mathrm{COOCH}\left(\mathrm{CH}_{3}\right)_{2}\right]^{-}$ $(1.7 \mathrm{mmol})$ in a $5 \mathrm{ml}$ pear-shaped flask, $1.6 \mathrm{ml}$ of concentrated $\mathrm{HCl}$ was added. The solid liquefied immediately and a yellowish oil separated, and after swirling for 2 
minutes, $0.50 \mathrm{~g}$ of this oil was pipetted off. Its i.r. spectrum coincided with the spectrum of $\mathrm{F}_{5} \mathrm{SCH}\left(\mathrm{SO}_{2} \mathrm{~F}\right) \mathrm{COOCH}\left(\mathrm{CH}_{3}\right)_{2}$, except for a few very weak bands from 2500-2700 $\mathrm{cm}^{-1}$ and at $1616 \mathrm{~cm}^{-1}$. Yield : $94.7 \%$

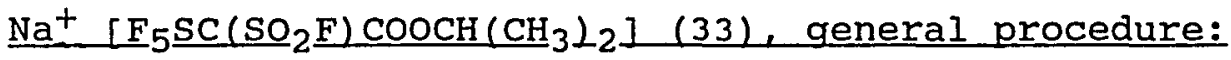

Freshly prepared isopropoxide was stirred in anhydrous ether in a $50 \mathrm{ml}$ flask, equipped with a magnetic stirring bar and fitted with a claisen head, Drierite tube and a rubber septum. The ester, dissolved in $1-2 \mathrm{ml}$ of ether was added with a syringe through the septum. The isopropoxide dissolved in a vigorous reaction, causing the ether to boil. The rate of addition of the ester was reduced, when necessary, in order to moderate the reaction. When additjon was complete, the yellowish-brown solution was stirred for another 30-60 minutes at room temperature. The amount of ether used was 5-10 $\mathrm{ml}$ for $4-7 \mathrm{mmol}$ of isopropoxide; the ester was used in $\approx 0.7-0.9$ fold quantity.

The salt could be prepared by the same method in isopropanol. When the solvent was pumped away a brownish glassy mass remained, which upon re-dissolution did not show the spectrum of the pure anion anymore $\left({ }^{19} \mathrm{~F}\right.$ n.m.r.), nor did it show only one $c o$ band (i.r.). It was also not possible to purify it by successive dissolution (in ether) and precipitation by adding hexane to the solution. In this case a white amorphous mass was obtained, which showed two $\mathrm{C}=0$ 
bands in the i.r. spectrum:1738 (m, broad) and $1637 \mathrm{~cm}^{-1}$ (s) and was very moisture-sensitive.

${ }^{19} \mathrm{~F}$ n.m.r. (in isopropanol, $\mathrm{CCl}_{3} \mathrm{~F}$ ext.): $\mathrm{AB}_{4} \mathrm{X} \phi=95.3$ ppm, 9 lines, int. $=1.0\left(\mathrm{~F}_{\mathrm{A}}\right) ; \phi=82.8 \mathrm{ppm}, \mathrm{d}-\mathrm{m}$, int. $=4.0$ $\left(\mathrm{F}_{\mathrm{B}}\right) ; \phi=67.3 \mathrm{ppm}, \mathrm{p}$, int. $=1.0,\left(\mathrm{~F}_{\mathrm{X}}, \mathrm{SO}_{2} \mathrm{~F}\right) ; \mathrm{J}_{\mathrm{AB}}=150.4$ $\mathrm{Hz} ; \mathrm{J}_{\mathrm{BX}}=10.6 \mathrm{~Hz}$. In ether: $\phi_{\mathrm{A}}=93.5 \mathrm{ppm}, \phi_{\mathrm{B}}=81.7 \mathrm{ppm}$, $\phi_{\mathrm{X}}=66.2 \mathrm{ppm}$.

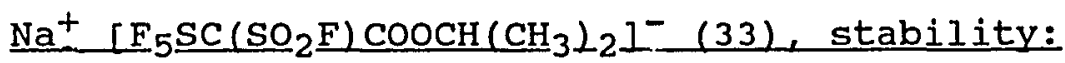
The sodium salt was prepared as described above from $0.33 \mathrm{~g}(4.0 \mathrm{mmol})$ of sodium isopropoxide and $1.21 \mathrm{~g}$ (3.9 mmol) of $\mathrm{F}_{5} \mathrm{SCH}\left(\mathrm{SO}_{2} \mathrm{~F}\right) \mathrm{COOCH}\left(\mathrm{CH}_{3}\right)_{2}$ in $5.0 \mathrm{ml}$ of ether and stirred at room temperature. ${ }^{19} \mathrm{~F}$ n.m.r. spectroscopy showed that the anion signal, which was initially the only observed resonance, disappeared slowly with the reversion to the signal attributable to the starting ester. After six days this process was complete, with the formation of a white precipitate. Distillation ( room temperature - $60^{\circ} \mathrm{C}$ ) gave one uniform fraction $(0.64 \mathrm{~g}, 52.3 \%)$ which was identified by i.r. and ${ }^{19} \mathrm{~F}$ n.m.r. spectroscopy as the starting ester.

\section{$\left.\mathrm{F}_{5} \underline{\mathrm{SCCl}}_{\left(\mathrm{SO}_{2}\right.} \mathrm{F}\right) \mathrm{COOCH}\left(\mathrm{CH}_{3} \mathrm{~L}_{2}-(37):\right.$}

$$
\mathrm{Na}^{+}\left[\mathrm{F}_{5} \mathrm{SC}\left(\mathrm{SO}_{2} \mathrm{~F}\right) \mathrm{COOCH}\left(\mathrm{CH}_{3}\right)_{2}\right]^{-} \text {was prepared freshly from }
$$

sodium isopropoxide $(0.5745 \mathrm{~g}, 7.0 \mathrm{mmol})$ and $\mathrm{F}_{5} \mathrm{SCH}\left(\mathrm{SO}_{2} \mathrm{~F}\right) \mathrm{COOCH}\left(\mathrm{CH}_{3}\right)_{2}(1.845 \mathrm{~g}, 6.0 \mathrm{mmol})$ in a $50 \mathrm{ml}$ pearshaped flask as described above. The septum on the claisen- 
head was replaced by a gas inlet tube that reached just above the liquid level and chlorine gas was introduced at a slow rate. A white precipitate formed instantly; chlorine was added slowly until a greenish-brown color persisted. A distillation unit was then attached to the flask in place of the claisen head, the ether was removed at lowered temperature and frozen out in a $-196^{\circ} \mathrm{C}$ trap. Distillation at 2.5 torr afforded three fractions:room-temperature $-48.5{ }^{\circ} \mathrm{C}$ $(0.360 \mathrm{~g}), 48.5-49^{\circ} \mathrm{C}\left(0.962 \mathrm{~g}\right.$ and $48-28^{\circ} \mathrm{C}(0.139 \mathrm{~g})$. The last two fractions were 97.7 and $97.0 \%$ pure (gas chromatography, QFl, $1 \mathrm{~m}, 130^{\circ} \mathrm{C}$ ), whereas fraction 1 was 82 $\%$ pure chlorinated ester. The impurity was not the starting ester. Yield $\approx 54 \%$. An analytically pure sample was obtained by preparative gas chromatography. The solid residue in the flask $(0.6323 \mathrm{~g})$ was somewhat more than the expected $\mathrm{NaCl}(0.3482 \mathrm{~g})$ and excess $\mathrm{NaOCH}\left(\mathrm{CH}_{3}\right)_{2}(0.0865 \mathrm{~g})$.

$1 \mathrm{H}$ n.m.r. $\left(\mathrm{CDCl}_{3}, \mathrm{Si}\left(\mathrm{CH}_{3}\right)_{4}\right.$ ext. $): \delta=1.85 \mathrm{ppm}\left(\mathrm{CH}_{3}\right.$ ， int. $=6.3) ; \delta=5.80 \mathrm{ppm}(\mathrm{CH}$, int. $=1.0), \mathrm{J}_{\mathrm{H}-\mathrm{H}}=6.47 \mathrm{~Hz}$. ${ }_{1}^{9} \mathrm{~F}$ n.m.r. $\left(\mathrm{CDCl}_{3}, \mathrm{CCl}_{3} \mathrm{~F}\right.$, ext. $): \mathrm{AB}_{4} \mathrm{X}: \phi_{\mathrm{A}}=68.8$ ppm, 9 Iines $\left(F_{\text {ax' }}\right.$ int. $=0.95 ; \phi_{\mathrm{B}}=63.0 \mathrm{ppm} \approx \mathrm{d}-\mathrm{m}$ (Feq' int. $=4.25) ; \phi_{X}=49.8 \mathrm{ppm}, \mathrm{p}\left(\mathrm{SO}_{2} \mathrm{~F}\right.$, int. $\left.=1.0\right) ; \mathrm{J}_{\mathrm{AB}}=$ $150.4 \mathrm{~Hz} ; \mathrm{J}_{\mathrm{AX}}=11.6 \mathrm{~Hz}$.

I.r. $\left(\mathrm{cm}^{-1}\right): 2993$, wi 2945, vw; 1778, s;1766 ms; 1470, wi 1444, s; 1393, w; 1391, w-m; 1347, vw; 1256, s; 1223, s; 1098, s; 1035, Vw; 981, Vw; 916, s; 887 , vs; 877 , vs; 840 , $\mathrm{s} ; 807, \mathrm{~s} ; 784, \mathrm{~m} ; 737, \mathrm{~m}-\mathrm{w} ; 689, \mathrm{w} ; 673, \mathrm{vw} ; 659, \mathrm{w} ; 611, \mathrm{~m}$; 
573, s; 502, w-vw; 482, w; 469, w.

Mass spectrum (e.i., $70 \mathrm{eV}$, mass, species, \%) only the ${ }^{35} \mathrm{Cl}$-signals will be given:343, (M-H $\left.{ }^{35} \mathrm{Cl}\right)^{+}, 1.0 ; 329,(\mathrm{M}-\mathrm{H}-$ $\left.\left.\mathrm{CH}_{3}\right)^{+}, 19.9 ; 285,\left(\mathrm{M}-\mathrm{OCHCH}_{3}\right)_{2}\right)^{+}, 26.5 ; 231,\left(\mathrm{M}-\mathrm{Cl}-\mathrm{OC}_{3} \mathrm{H}_{7}-\mathrm{F}\right)^{+}$, $2.1 ; 217,(\mathrm{M}-\mathrm{Cl}-4 \mathrm{~F}-\mathrm{O})^{+}, \quad 1.2 ; 209,\left(\mathrm{M}-\mathrm{Cl}-\mathrm{SO}_{2} \mathrm{~F}-\mathrm{O}-\mathrm{H}\right)^{+}, 2.4$; 203, $\left(\mathrm{M}-\mathrm{C}_{3} \mathrm{H}_{7}-\mathrm{F}-\mathrm{Cl}-\mathrm{CO}_{2}\right)^{+}, 2.9 ; 202,\left(\mathrm{M}-\mathrm{Cl}-4 \mathrm{~F}-\mathrm{O}-\mathrm{CH}_{3}\right)^{+}, 2.1$; 177, $\left(\mathrm{M}-\mathrm{SF}_{5}-\mathrm{HF}-\mathrm{O}-6 \mathrm{H}\right)^{+}, 9.5 ; 159,\left(\mathrm{M}-\mathrm{SF}_{5}-\mathrm{C}_{3} \mathrm{H}_{6}\right)^{+}, 3.8 ; 158$, $\left(\mathrm{M}-\mathrm{SF}_{5}-\mathrm{OC}_{3} \mathrm{H}_{7}\right)^{+}, 5.2 ; 129,\left(\mathrm{M}-\mathrm{SF}_{5}-\mathrm{HF}-\mathrm{O}-5 \mathrm{H}-\mathrm{C}-\mathrm{Cl}=\mathrm{C}_{4} \mathrm{HO}_{3} \mathrm{~S}^{+}\right.$, $1.3 ; 127, \mathrm{SF}_{5}+, 19.1 ; 96, \mathrm{C}_{4} \mathrm{OS}^{+}, 1.6 ; 94, \mathrm{C}_{2} \mathrm{~F}_{2} \mathrm{~S}^{+}, 6.8 ; 91$, $\mathrm{C}_{2} \mathrm{FOS}^{+} ; 89, \mathrm{SF}_{3}^{+}, 100,0 ; 83, \mathrm{SO}_{2} \mathrm{~F}^{+}, 2.7 ; 79, \mathrm{C}_{5} \mathrm{H}_{3} \mathrm{O}^{+}, 1.8$; $77, \mathrm{C}_{5} \mathrm{HO}^{+}, 1.8 ; 76, \mathrm{C}_{5} \mathrm{O}^{+}, 3.1 ; 75, \mathrm{C}_{2} \mathrm{FS}^{+}, 2.6 ; 70, \mathrm{SF}_{2}{ }^{+}$, $8.2 ; 69, \mathrm{C}_{4} \mathrm{H}_{5} \mathrm{O}^{+}, \mathrm{C}_{3} \mathrm{HO}_{2}{ }^{+}, 2.4,1.1$ (two fragments); 68, $\mathrm{C}_{4} \mathrm{H}_{4} \mathrm{O}^{+}, \mathrm{C}_{3} \mathrm{O}_{2}{ }^{+}, 3.8 ; 67, \mathrm{FSO}^{+}, 39.1 ; 66, \mathrm{C}_{4} \mathrm{H}_{2} \mathrm{O}^{+}, 6.1 ; 65$, $\mathrm{C}_{4} \mathrm{HO}^{+}, 1.8 ; 64, \mathrm{SO}_{2}^{+}, \mathrm{C}_{4} \mathrm{O}^{+}, 12.1 ; 63, \mathrm{CFS}^{+}, 4.0 ; 61, \mathrm{CHOS}^{+}$, $8.1 ; 59, \mathrm{C}_{3} \mathrm{H}_{7} \mathrm{O}^{+}, 13.3 ; 58, \mathrm{C}_{3} \mathrm{H}_{6} \mathrm{O}^{+}, 2.4 ; 51, \mathrm{SF}^{+}, 2.7$.

Anal.calcd for $\mathrm{C}_{5} \mathrm{H}_{7} \mathrm{ClF}_{6} \mathrm{O}_{4} \mathrm{~S}_{2}: \mathrm{C}, 17.42 ; \mathrm{H}, 2.05 ; \mathrm{Cl}$, $10.28 ; \mathrm{F}, 33.1 ; \mathrm{S}, 18.60$. Found: C, $17.56 ; \mathrm{H}, 2.24 ; \mathrm{Cl}$, $10.50 ; \mathrm{F}, 33.2 ; \mathrm{S}, 18.55$.

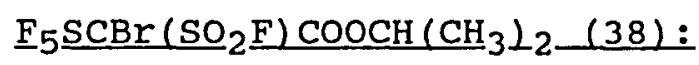

The sodium salt of the ester was prepared as described above from $0.517 \mathrm{~g} \mathrm{NaOCH}\left(\mathrm{CH}_{3}\right)_{2}(6.3 \mathrm{mmol})$ in $10.0 \mathrm{ml}$ ether and $1.37 \mathrm{~g} \mathrm{~F}_{5} \mathrm{SCH}\left(\mathrm{SO}_{2} \mathrm{~F}\right) \mathrm{COOCH}\left(\mathrm{CH}_{3}\right)_{2}(4.4 \mathrm{mmol})$. Bromine was added dropwise with a syringe through the septum until a yellow color persisted. A white precipitate was immediately formed upon addition of $\mathrm{Br}_{2}$. An n.m.r. spectrum $\left({ }^{19} \mathrm{~F}\right)$ showed 
that only one fluoro compound was present. The ether was pumped off from the reaction flask through a cold-trap and distillation at $3 \mathrm{~mm} \mathrm{Hg}$ afforded one fraction, r.t. $-83^{\circ} \mathrm{C}$ $(1.18 \mathrm{~g})$, a slightly brownish heavy liquid. It was a mixture $\left({ }^{19} \mathrm{~F}\right.$ n.m.r.) of probably $\mathrm{F}_{5} \mathrm{SCH}\left(\mathrm{SO}_{2} \mathrm{~F}\right) \mathrm{COOCH}\left(\mathrm{CH}_{3}\right)_{2}$ (12 parts) and the alleged $\mathrm{F}_{5} \mathrm{SCBr}\left(\mathrm{SO}_{2} \mathrm{~F}\right) \mathrm{COOCH}\left(\mathrm{CH}_{3}\right)_{2}$ (88 parts). No separation was achieved by repeated distillation.

19 F n.m.r. spectrum:degenerate $A_{4}$ spectrum $\phi=64.9$ ppm, $m$, int. $=5.18\left(S_{5}\right) ; \phi=49.0 \mathrm{ppm}, \mathrm{p}$, int. $=1.00$ $\left(\mathrm{SO}_{2} \mathrm{~F}\right) ; \mathrm{J}_{\mathrm{BX}}=12.3 \mathrm{~Hz}$.

I.r spectrum of the impure product (neat, $\mathrm{KBr}, \mathrm{cm}^{-1}$ ): 2995, m, 2945, wi 2889, vwi 1764, vs; 1470, mi 1441, vs; 1393, $\mathrm{m} ; 1361, \mathrm{~m} ; 1334, \mathrm{w} ; 1296, \mathrm{~m} ; 1254$, vs; 1222, vs; 1185, $\mathrm{m}, 1148, \mathrm{~m} ; 1097$, vs; 972 , w; 889 , vs; 860 , vs; 838 , s; 821, s-vs; 807, s-vs; 793, s-vs, sh; 785, s, sh; 742 , wi $688, \mathrm{~m} ; 648, \mathrm{~m} ; 611, \mathrm{~s} ; 574$, vs; $497, \mathrm{w}-\mathrm{m} ; 463, \mathrm{w}-\mathrm{m} ; 415, \mathrm{w}-$ m.

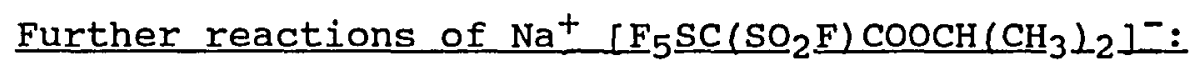

Reactions with other halides were tried by the same method as above. The reaction with acetyl chloride was performed with the white residue that is obtained from the salt solution after removal the solvent in vacuo, but in all cases only the starting ester could be recovered. $\mathrm{Na}^{+}$Anion $^{-}+\mathrm{BrCN}: \quad 39.4 \%$ recovery 
11

11
$+\mathrm{CH}_{2}=\mathrm{CHCH}_{2} \mathrm{Br}: 39.4 \% \quad "$

$+\mathrm{CH}_{3} \mathrm{COCl}: \quad 60 \%$ (crude)

Reactions with $\mathrm{CH}_{2} \mathrm{Br}_{2}$ were also tested in an n.m.r. tube experiment, which indicated that only the original ester was formed. In all cases, however, a white precipitate was formed. With acetyl chloride small amounts of other products with fluorine n.m.r. signals in the SF region were also formed, but could not be identified.

$\underline{\mathrm{F}}_{5}{\underline{\mathrm{SCH}}\left(\mathrm{SO}_{2} \mathrm{~F}\right) \mathrm{CONHCONH}}_{2}(31):$

A solution of $\mathrm{F}_{5} \mathrm{SCHCF}_{2} \mathrm{OSO}_{2}(2.09 \mathrm{~g}, 7.8 \mathrm{mmol})$ in $15 \mathrm{ml}$ of dry ether was added dropwise to a suspension of urea $(0.46 \mathrm{~g}, 7.7 \mathrm{mmol})$ in $50 \mathrm{ml}$ of anhydrous ether at $0^{\circ} \mathrm{C}$. The solution turned quickly cloudy and a sticky precipitate formed. It was stirred at room-temperature for $2 \mathrm{~h}$, and then kept at room-temperature for 3 days. The ether was decanted and evaporated, leaving $1.78 \mathrm{~g}$ of a white amorphous mass with an acidic odor. It was dissolved in the minimum amount of hot ether and allowed to re-precipitate upon cooling. Yield $=1.54 \mathrm{~g}(60.3 \%), \mathrm{m} \cdot \mathrm{p} .=168-172^{\circ} \mathrm{C}$.

${ }^{19} \mathrm{~F}$ n.m.r. ( in ether, $\mathrm{CCl}_{3} \mathrm{~F}$ ext.): $\phi=71.0 \mathrm{ppm}, \mathrm{m}$, int. $=5.0\left(\mathrm{SF}_{5}\right) ; \phi=59.3 \mathrm{ppm}$, int. $1.1\left(\mathrm{SO}_{2} \mathrm{~F}\right)$.

I.r. (neat sample, $\left.\mathrm{NaCl}, \mathrm{cm}^{-1}\right): 3400,3341,3254$, peaks on broad feature, $s$, at $\approx 3300 ; 2967, w ; 1729, \mathrm{~m}-\mathrm{s} ; 1701, \mathrm{~s}$; 1627, $\mathrm{m} ; 1560, \mathrm{~m}$; 1434, $\mathrm{m}-\mathrm{s} ; 1386, \mathrm{~m}$; 1301, $\mathrm{m}$; 1250, wi 1219, m-s; 1178, m; 1099, m-s; 1052, w; 976, m; 952,w; 891, $\mathrm{s} ; 863, \mathrm{vs} ; 850, \mathrm{~s} ; 822, \mathrm{~m} ; 792, \mathrm{w}-\mathrm{m} ; 783, \mathrm{~m} ; 744, \mathrm{~m} ; 736, \mathrm{~m}$; 
685, w; 645, w; 610, w; 600, w; 571, m.

Anal. calcd. for $\mathrm{C}_{3} \mathrm{H}_{4} \mathrm{~F}_{6} \mathrm{~N}_{2} \mathrm{O}_{4} \mathrm{~S}_{2}: \mathrm{C}, 11.62 ; \mathrm{H}, 1.30 ; \mathrm{F}$, $36.8 ; \mathrm{S}, 20.7 ; \mathrm{N}, 9.03$. Found: C, 11.89; H, 1.30; F, 35.3; $S, 18.81 ; \mathrm{N}, 8.81$.

\section{$\underline{\mathrm{F}}_{5} \underline{\mathrm{SC}}^{-}\left(\mathrm{SO}_{2} \underline{\mathrm{F}}\right) \mathrm{CONHCONH}_{2}-\left(\mathrm{C}_{2} \underline{\mathrm{H}}_{5} \perp_{3} \underline{\mathrm{NH}}^{+}(36):\right.$}

To $1.3085 \mathrm{~g}$ of $\mathrm{F}_{5} \mathrm{SCH}\left(\mathrm{SO}_{2} \mathrm{~F}\right) \mathrm{CONHCONH}_{2}(4.2 \mathrm{mmol})$ in 12 $\mathrm{ml}$ of anhydrous ether in a $50 \mathrm{ml}$ pear-shaped flask, fitted with a claisen-head, dropping funnel and a Drierite tube,

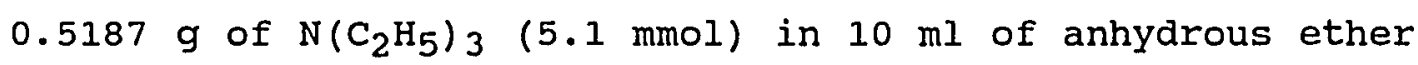
was added dropwise at $-70^{\circ} \mathrm{C}$ with stirring. At $\approx 0^{\circ} \mathrm{C}$ an oily layer was formed, while the ureide disappeared slowly. Removal of the solvent in vacuo left $1.714 \mathrm{~g}$ of an almost white solid (theor. $1.735 \mathrm{~g}$ ), which contained a small impurity ( 19 F n.m.r.). Attempts to recrystallize the material resulted in decomposition.

${ }^{19} \mathrm{~F}$ n.m.r. spectrum (aceton, $\mathrm{CCl}_{3} \mathrm{~F}$ ext.): $\mathrm{AB}_{4} \mathrm{X} \phi=$ $95.7 \mathrm{ppm}, 9$ lines with doublet splitting, $J=4.9 \mathrm{~Hz},\left(F_{A}\right)$, int. $=0.94 ; \phi=82.0 \mathrm{ppm}, \mathrm{d}-\mathrm{m}$, int. $=4.00\left(\mathrm{~F}_{\mathrm{B}}\right) ; \phi=73.1$ ppm, not resolved, int. $=0.99\left(\mathrm{~F}_{\mathrm{X}}, \mathrm{SO}_{2} \mathrm{~F}\right)$.

I.r. of the solid obtained above (neat, $\mathrm{KBr}, \mathrm{cm}^{-1}$ ): 3367 , s,br; 3220, m,br; 2980, s; 2938, m,sh; 2882, m; 2671, $m$, br; 2495, w, br; 2185, w-m (?); 1688, vs, 1652, vs; 1567 , s; 1478, s; 1459, s, sh; 1370, vs; 1232, s-vs; 1167, vs; 1116, s; 1036, $m ; 945, w-m ; 889, m ; 854$, vs; 834 , vs; 754, $\mathrm{s}-\mathrm{vs} ; 734, \mathrm{~s} ; 663, \mathrm{~s} ; 626, \mathrm{~m}-\mathrm{s} ; 580, \mathrm{~s}, \mathrm{br} ; 480 \mathrm{~m}-\mathrm{s}$. 
$\underline{\mathrm{F}}_{5} \mathrm{SCH}_{2} \mathrm{CHClCH}_{2} \mathrm{OC}_{(\mathrm{O}) \mathrm{CH}_{3}}(67):$

$6.50 \mathrm{~g}$ of $\mathrm{CH}_{2}=\mathrm{CHCH}_{2} \mathrm{OCOCH}_{3}$ (Aldrich, $65 \mathrm{mmol}$ ), $11.69 \mathrm{~g}$ $\mathrm{SF}_{5} \mathrm{Cl}$ (PCR, $72 \mathrm{mmol}$ ) and $25 \mathrm{ml} \mathrm{CCl} 3 \mathrm{~F}$ (DuPont) were heated in a $75 \mathrm{ml}$ steel bomb to $95^{\circ} \mathrm{C}$ for 15 days. After venting and bleeding $11.69 \mathrm{~g}$ off the gaseous products, the $\mathrm{CCl}_{3} \mathrm{~F}$ was distilled away at atmosheric pressure, and vacuum distillation (1-2 torr) resulted in four fractions: 1.:$55^{\circ} \mathrm{C}(1.54 \mathrm{~g}) ; 2 .: 55-58^{\circ} \mathrm{C}(3.36 \mathrm{~g}) ; 3 .: 58-61{ }^{\circ} \mathrm{C}(4.78 \mathrm{~g})$; 4. 61-62 ${ }^{\circ} \mathrm{C}(1.54 \mathrm{~g})$. Fraction 1 was $\approx 95 \%$ pure adduct, the remainder being allyl acetate. Fractions 2,3, and 4 had the same ${ }^{1}{ }_{H}$ n.m.r. spectra which showed only a trace of allyl acetate. The cold trap contained $1.96 \mathrm{~g}$ of liquid which was largely allyl acetate. Yield $(2+3+4): 9.68 \mathrm{~g}(56.8 \%)$.

$1_{\mathrm{H}}$ n.m.r. (neat smple, $\mathrm{Si}\left(\mathrm{CH}_{3}\right)_{4}$ ext.): $\delta=2.50 \mathrm{ppm}$, $\mathrm{s}$, int. $3.0\left(\mathrm{CH}_{3}\right) ; \delta=4-5.4 \mathrm{ppm}, \mathrm{m}$, int. 5.5 .

$19 \mathrm{~F}$ n.m.r. (neat sample, $\mathrm{CCl}_{3} \mathrm{~F}$ ext.): $\mathrm{AB}_{4}$ spectrum; $\phi^{\mathrm{A}}=83.2 \mathrm{ppm}(9$ lines $)$, int. $=1.02 ; \phi_{\mathrm{B}}=67.7 \mathrm{ppm}(\mathrm{d}-\mathrm{m})$, int. $=4.00 \cdot \mathrm{J}_{\mathrm{AB}}=154.1 \mathrm{~Hz}$.

Infrared spectrum (neat sample, $\mathrm{NaCl}, \mathrm{cm}^{-1}$ ): 3029 (w); 2973 (w); 2855 (Vw) ; 1752 (vs); 1460 (w-m); 1430 (m,sh); 1420 (m); $1385(\mathrm{~m}-\mathrm{s}) ; 1369$ (m-s); 1318 (Vw); 1302 (VW); 1232 $(\mathrm{s}-\mathrm{vs}) ; 1111$ (w); 1063 (m, sh); 1045 (m); 1026 (m); 945 (m); 873 (s); 846 (vs); 828 (vs); 728 (w); 715 (w-vw); 696 (vw); $636(\mathrm{Vw}) ; 621(\mathrm{w}) ; 599(\mathrm{~m}) ; 565$ (w).

Mass spectrum (chemical ionization, mass, species, \%): $263,\left(\mathrm{M}\left({ }^{35} \mathrm{Cl}+\mathrm{H}\right)^{+}, 100 ; 181,\left(\mathrm{M}\left({ }^{35} \mathrm{Cl}\right)-\mathrm{CH}_{3} \mathrm{COOH}-2 \mathrm{H}-\mathrm{F}\right)^{+}, 11.5\right.$; 
136, $\left(\mathrm{M}\left({ }^{35} \mathrm{Cl}\right)-\mathrm{SF}_{5}\right)^{+}, 1.5 ; 135,\left(\mathrm{M}\left({ }^{35} \mathrm{Cl}\right)-\mathrm{H}-\mathrm{SF}_{5}\right)^{+}, 29.9 ; 113$, $\left(\mathrm{M}+\mathrm{H}-\mathrm{Cl}-3 \mathrm{~F}-\mathrm{CH}_{3} \mathrm{COO}\right)^{+}, 1.9 ; 102, \mathrm{SF}_{3} \mathrm{CH}^{+}, 2.8 ; 101, \mathrm{SF}_{3} \mathrm{C}^{+}$, $62.9 ; 89, \mathrm{SF}_{3}^{+}, 1.6 ; 85, \mathrm{CH}_{3} \mathrm{COOCH}_{2} \mathrm{C}^{+}, \mathrm{SCCCHO}^{+}, 6.4 ; 83$, $\mathrm{CH}_{3} \mathrm{COOC}_{2}{ }^{+}, \mathrm{SF}_{2} \mathrm{CH}^{+}, 4.4 ; 81, \mathrm{CHCOOC}_{2}{ }^{+}, 6.3 ; 79, \mathrm{C}_{5} \mathrm{H}_{3} \mathrm{O}^{+}, 3.3 ;$ 73, $\mathrm{CH}_{3} \mathrm{COOCH}_{2}^{+}, 9.5 ; 71, \mathrm{CH}_{3} \mathrm{COOC}^{+}, 10.8 ; 70, \mathrm{SF}_{2}^{+}, \mathrm{C}_{3} \mathrm{H}_{2} \mathrm{~S}^{+}$, $4.4 ; 69, \mathrm{CHCOOC}^{+}, 12.0 ; 67, \mathrm{C}_{4} \mathrm{H}_{3} \mathrm{O}^{+}, 6.9$.

Anal. calcd for $\mathrm{C}_{5} \mathrm{H}_{8} \mathrm{ClF}_{5} \mathrm{O}_{2} \mathrm{~S}: \mathrm{C}, 22.87 ; \mathrm{H}, 3.07 ; \mathrm{Cl}$, $13.50 ; \mathrm{F}, 36.2 ; \mathrm{S}, 12.21$. Found: C, 23.10; H, 3.19; Cl, $13.61 ; \mathrm{F}, 36.5 ; \mathrm{S}, 12.00$.

$\underline{\mathrm{F}}_{5} \underline{\mathrm{SCH}=\mathrm{CHCH}} 2 \mathrm{OH}(68)$, by aqueous hydrolysis:

$4.00 \mathrm{~g}$ of $\mathrm{F}_{5} \mathrm{SCH}_{2} \mathrm{CHClCH}_{2} \mathrm{COOCH}_{3}(5.2 \mathrm{mmol})$ were stirred at room temperature with $9.0 \mathrm{~g}$ of $23 \% \mathrm{KOH}$ for $20 \mathrm{~h}$. According to a ${ }^{19} \mathrm{~F}$ n.m.r. spectrum, all starting material was gone. The lower layer was pipetted off $(2.59 \mathrm{~g}, 92.3 \%)$. There was apparently no significant amount of water, which had been suggested by the infrared spectrum, as drying over $\mathrm{K}_{2} \mathrm{CO}_{3}$ or $\mathrm{CaO}$ did not alter the infrared spectrum, which showed a broad feature at $1640 \mathrm{~cm}^{-1}$. Vacuum distillation $\left(2.5 \mathrm{~mm} \mathrm{Hg}, 39-42^{\circ} \mathrm{C}\right)$ did also not lead to an altered infrared spectrum.

$\underline{F}_{5} \underline{S C H}=\mathrm{CHCH}_{2} \mathrm{OH}(68)$, prepared in methanolic methoxide (anhydrous conditions):

To a solution of $\underline{67}(2.10 \mathrm{~g}, 8.0 \mathrm{mmol})$ in $2.0 \mathrm{~g}$ of anhydrous methanol in a $10 \mathrm{ml}$ flask, equipped with magnetic 
stirring bar, Claisen head, Drierite tube and dropping funnel, a solution of $0.23 \mathrm{~g}$ of sodium $(0.01 \mathrm{~mol})$ in $5.0 \mathrm{ml}$ anhydrous methanol was added dropwise at $-20^{\circ} \mathrm{C}$ (acetone and dry ice). There was no obvious reaction, so the cold-bath was removed and the reaction flask was allowed to attain room-temperature. When this temperature was nearly reached, a white precipitate formed quickly. Addition of more $\mathrm{CH}_{3} \mathrm{ONa}$ solution caused more precipitate to form. After $\approx 0.8$ times the total volume of methoxide solution had been added, stirring was stopped and the precipitate was allowed to settle. Addition of another drop of $\mathrm{CH}_{3} \mathrm{ONa}$ to the clear colorless supernatent solution caused no more turbidness. After keeping the mixture for an additional 3 hours at room temperature, the methanol was removed by stirring the solution at $\approx 50$ torr for 1 hour (the methanol was collected in a $-196^{\circ} \mathrm{C}$ trap). Distillation at 6-6.5 torr afforded two fractions $\left(54.5-57{ }^{\circ} \mathrm{C}, 0.54 \mathrm{~g}, 57-57.5{ }^{\circ} \mathrm{C}, 0.84 \mathrm{~g}\right)$ as colorless viscid liquids, which had identical infrared spectra. Yield $=1.38 \mathrm{~g}(93.8 \%)$. A sample for $1_{\mathrm{H}}$ n.m.r. spectroscopy was prepared by preparative gas chromatography ( $5 \% \mathrm{QF}-1$ on Chromosorb $\mathrm{W}, 1 \mathrm{~m} .120^{\circ} \mathrm{C}$ ).

$1_{\mathrm{H}}$ n.m.r.spectrum $\left(\mathrm{CDCl}_{3}, 400 \mathrm{MHz}, \mathrm{Si}\left(\mathrm{CH}_{3}\right)_{4}\right): \mathrm{ABM}_{2} \mathrm{X}$ : $\delta_{\mathrm{A}}=6.67 \mathrm{ppm}(\mathrm{m}), \mathrm{SF}_{5} \mathrm{CH}=; \delta_{\mathrm{B}}=6.55 \mathrm{ppm}(\mathrm{m}), \mathrm{SF}_{5} \mathrm{CH}=\mathrm{CH}$, area $\mathrm{A}+\mathrm{B}=2.00 ; \delta_{\mathrm{M}}=4.34 \mathrm{ppm}(\mathrm{s}), \mathrm{CH}_{2}$, area $=2.04 ; \delta_{\mathrm{X}}=1.75$ ppm (s), $\mathrm{OH}$, area $=1.13 . \mathrm{J}_{\mathrm{AB}}=14.8 \mathrm{~Hz}$.

${ }^{19} \mathrm{~F}$ n.m.r. spectrum (neat sample, external $\mathrm{CCl}_{3} \mathrm{~F}$ ): $\mathrm{AB}_{4}$ 
$\phi_{\mathrm{A}}=83.1 \mathrm{ppm}, 9$ lines with doublet splitting, area $=1.0$; $\phi_{\mathrm{B}}=62.3 \mathrm{ppm}$, asymmetric doublet, area $=4.0 ; \mathrm{J}_{\mathrm{AB}}=151.3$ $\mathrm{Hz} ; \mathrm{J}_{\mathrm{AH}}=4.2 \mathrm{~Hz}$.

Infrared spectrum (neat sample, film on $\mathrm{KBr}$ plates, $\left.\mathrm{cm}^{-1}\right): 3664, w ; 3353, \mathrm{~m}-\mathrm{s}, \mathrm{br} ; 3103, \mathrm{w}-\mathrm{m} ; 2923, \mathrm{w} ; 2879, \mathrm{w}$; $1644, w, b r ; 1449, w-m ; 1434, w, s h ; 1370, w ; 1300, w ; 1229$, $\mathrm{w}-\mathrm{m} ;$ 1208, $\mathrm{w}, \mathrm{sh} ; 1097, \mathrm{~m}-\mathrm{s} ; 1030, \mathrm{~m} ; 1009, \mathrm{w}-\mathrm{m} ; 984, \mathrm{w}-\mathrm{m}$; $940, \mathrm{~s} ; 902, \mathrm{~s}-\mathrm{vs} ; 837, \mathrm{vs} ; 764, \mathrm{~s} ; 726, \mathrm{~m} ; 661, \mathrm{~m} ; 648, \mathrm{~m}$; $602, \mathrm{~m} ; 571, \mathrm{~m} ; 540, \mathrm{~m} ; 441, \mathrm{w}-\mathrm{m}$.

Mass spectrum (e.i., $70 \mathrm{eV}, \mathrm{m} / \mathrm{e}$, fragment, $\%>2$ ): $183,(\mathrm{M}-\mathrm{H})^{+}, 0.2 \% ; 135,\left(\mathrm{M}-\mathrm{F}-\mathrm{CH}_{2} \mathrm{O}\right)^{+}, 48.7 ; 127, \mathrm{SF}_{5}{ }^{+}, 16.1$; 116, $\mathrm{SF}_{3} \mathrm{C}_{2} \mathrm{H}_{3}{ }^{+}, 2.4 ; 97, \mathrm{SF}_{2} \mathrm{C}_{2} \mathrm{H}_{3}{ }^{+}, 5.7 ; 91, \mathrm{C}_{3} \mathrm{H}_{4} \mathrm{FS}^{+}, 3.7 ; 89$, $\mathrm{SF}_{3}{ }^{+}, \mathrm{C}_{3} \mathrm{H}_{5} \mathrm{OS}^{+}, 100.0 ; 75, \mathrm{C}_{2} \mathrm{FS}^{+}, 11.1 ; 73,(\mathrm{M}+\mathrm{H}-5 \mathrm{~F}-\mathrm{OH})^{+}$, $2.1 ; 70, \quad \mathrm{SF}_{2}{ }^{+}, 16.5 ; \mathrm{C}_{2} \mathrm{H}_{3} \mathrm{~S}^{+}\left(\mathrm{M}+\mathrm{H}-5 \mathrm{~F}-\mathrm{CH}_{2} \mathrm{OH}\right)^{+}, 6.5 ; 58$, $\mathrm{C}_{2} \mathrm{H}_{2} \mathrm{~S}^{+}, 4.9 ; 57, \mathrm{C}_{3} \mathrm{H}_{5} \mathrm{O}^{+}, 79.4 ; 55, \mathrm{C}_{3} \mathrm{H}_{3} \mathrm{O}^{+}, 22.8 ; 53, \mathrm{C}_{3} \mathrm{HO}^{+}$, $3.5 ; 51, \mathrm{SF}^{+}, 3.4$.

Anal.calcd for $\mathrm{C}_{3} \mathrm{H}_{5} \mathrm{~F}_{5} \mathrm{OS}: \mathrm{C}, 19.57 ; \mathrm{H}, 2.74 ; \mathrm{F}, 51.6$; S, 17.41. Found: C, 19.69; H, 2.79; F, 51.5; S, 17.48.

\section{$\underline{F}_{5} \underline{S C F}_{2} \underline{C F}_{2} I \quad(63):$}

The preparation was similar to the method employed by Hutchinson, except that the reaction was run in a static system (bomb). Yields were comparable $(\approx 35 \%)$ to Hutchinson's $(\approx 30 \%)$. Thus, $13.06 \mathrm{~g} \mathrm{~s}_{2} \mathrm{~F}_{10}(51.0 \mathrm{mmol})$, $21.56 \mathrm{~g}$ of $82 \% \mathrm{JCF}_{2} \mathrm{CF}_{2} \mathrm{~J}$ (rest was $\mathrm{F}_{5} \mathrm{SCF}_{2} \mathrm{CF}_{2} \mathrm{~J}$, this mixture was recycled from earlier runs), $(\approx 50 \mathrm{mmol})$ and $5.50 \mathrm{~g}$ of 
terafluoroethylene (Peninsula Research Corporation, "PCR", $55 \mathrm{mmol}$ ), was heated at $120^{\circ} \mathrm{C}$ for 26 hours in a $75 \mathrm{mI}$ stainless steel bomb behind an explosion shield. The product was collected by vacuum transfer (34.8 $\mathrm{g}$ after outgassing). Repetition in the same vessel with $16.14 \mathrm{~g}$ of $\approx 90 \% \mathrm{C}_{2} \mathrm{~F}_{4} \mathrm{~J}_{2}$ $(\approx 43 \mathrm{mmol}), 10.99 \mathrm{~g} \mathrm{~S}_{2} \mathrm{~F}_{10}(43.3 \mathrm{mmol})$, and $4.50 \mathrm{~g}$ of $\mathrm{C}_{2} \mathrm{~F}_{4}$ at $131^{\circ} \mathrm{C} / 16$ hours yielded $31.30 \mathrm{~g}$ of crude product. Distillation of both products through a rectification column, $12.5 \times 200 \mathrm{~mm}, 0.05^{\prime \prime} \times 0.05^{\prime \prime \prime} \times 0.1 "$ steel helices, yielded disulfur decafluoride (room temperature-29 ${ }^{\circ} \mathrm{C}, 16.66 \mathrm{~g}$ ) and a purple liquid $\left(80-96^{\circ} \mathrm{C}\right)$, which was $\left({ }^{19} \mathrm{~F}\right.$ n.m.r.) $25 \% \mathrm{C}_{2} \mathrm{~F}_{4} \mathrm{~J}_{2}$ and $75 \% \mathrm{~F}_{5} \mathrm{SCF}_{2} \mathrm{CF}_{2}$, while the pot residue $(28.97 \mathrm{~g})$ was $22 \%$ $\mathrm{F}_{5} \mathrm{SCF}_{2} \mathrm{CF}_{2} \mathrm{~J}, 28 \% \mathrm{~F}_{5} \mathrm{~S}\left(\mathrm{CF}_{2} \mathrm{CF}_{2}\right)_{2} \mathrm{I}$ and $60 \% \mathrm{C}_{2} \mathrm{~F}_{4} \mathrm{~J}_{2}$. The reaction was repeated with this pot residue, $14.03 \mathrm{~g}$ of $\mathrm{S}_{2} \mathrm{~F}_{10} \quad(54.9$ mmol) and8.78 $\mathrm{g}$ of $\mathrm{C}_{2} \mathrm{~F}_{4}$ (heated overnight, $130^{\circ} \mathrm{C}$ ). The product was vacuum transferred $(40.0 \mathrm{~g})$, combined with the above distillate, and rectified through the same column: $\mathrm{S}_{2} \mathrm{~F}_{10}$, room temperature- $30^{\circ} \mathrm{C}, 8.70 \mathrm{~g}, \mathrm{~F}_{5} \mathrm{SCF}_{2} \mathrm{CF}_{2}{ }^{\mathrm{T}}, 80-85^{\circ} \mathrm{C}$ (very slow distillation, circa $96 \%$ pure). Yield (with respect to $\left.\mathrm{S}_{2} \mathrm{~F}_{10}\right) \approx 35 \%$. The bomb contained in the end $\approx 11$ $g$ of nonvolatile residue, which was rinsed out with acetone and filtered off: Waxy, off-white mass, shows $\mathrm{CF}$ and $\mathrm{SF}_{5}-$ bands in the infrared spectrum, darkens at circa $260^{\circ} \mathrm{C}$ under exhaustion of purple vapors. This material is probably $\mathrm{F}_{5} \mathrm{~S}\left(\mathrm{CF}_{2} \mathrm{CF}_{2}\right)_{\mathrm{n}} \mathrm{I}$.

$$
{ }^{13} \mathrm{C} \text { n.m.r. spectrum of } \mathrm{F}^{\mathrm{A}} \mathrm{F}^{\mathrm{B}}{ }_{4} \mathrm{SC}_{\alpha} \mathrm{F}^{\alpha}{ }_{2} \mathrm{C}_{\beta} \mathrm{F}^{\beta}{ }_{2} \mathrm{~J} \quad(100.6 \mathrm{MHz} \text {, }
$$


$\left.\mathrm{CDCl}_{3}, \mathrm{Si}\left(\mathrm{CH}_{3}\right)_{4}\right): \delta_{\alpha}=119.72 \mathrm{ppm}(\mathrm{t}-\mathrm{p}) ; \delta_{\beta}=91.30 \mathrm{ppm}, t-$ $t_{i} J_{B C \alpha}=25.9 \mathrm{~Hz} ; J_{C \alpha F \alpha}=305.5 \mathrm{~Hz} ; J_{C \beta F \beta}=323.0 \mathrm{~Hz} ; J C \beta F \alpha$ $=41.0 \mathrm{~Hz} ; \mathrm{J}_{\mathrm{C} \alpha \mathrm{F} \beta}=34.5 \mathrm{~Hz}$.

\section{Sulfurtrioxidation of $\mathrm{F}_{5} \underline{\mathrm{SCF}}_{2} \underline{\mathrm{CF}}_{2} \underline{\mathrm{J}}(65)$ :}

In an all-glass apparatus, consisting of a $25 \mathrm{ml}$ pearshaped flask with a magnetic stirring bar, a short reflux condenser, and a connector to a cold trap $\left(-78^{\circ} \mathrm{C}\right.$, Drierite tube), $2.25 \mathrm{~g}$ of $\mathrm{F}_{5} \mathrm{SCF}_{2} \mathrm{CF}_{2} \mathrm{~J}(6.3 \mathrm{mmol})$ and $21.7 \mathrm{~g}$ of oleum $(\approx 30 \%)$ was heated to $130^{\circ} \mathrm{C}$ for 12 hours. The product $(1.8$ g) was condensed into a capillary tube (2 $\mathrm{mm}$ inner diameter) and cooled to $-78^{\circ} \mathrm{C}$ for 1 hour. Two layers were formed, an upper (circa 1/3) and a lower layer. The tube was immersed in liquid nitrogen to somewhat less than the upper layer, and it could be removed by vacuum transfer. Repeating the$78^{\circ} \mathrm{C}$ bath procedure, some more of the upper layer material was obtained and it was removed in the same way. A total of $0.97 \mathrm{~g}$ of a colorless liquid was collected that did not separate anymore at $-78^{\circ} \mathrm{C}$. This material was not quite pure, but contained much less (by i.r.) of the impurity than samples subjected to fractional condensation. The product showed a strong co absorption at $1890 \mathrm{~cm}^{-1}$, and the impurity an absorption at $1360-1390 \mathrm{~cm}^{-1}$. Yield $\approx 68 \%$.

$\underline{F}_{5} \underline{S C F}=C F_{2}(50):$

To $85 \mathrm{~g}$ cooled (ice-bath) $\approx 30 \% \mathrm{KOH}(30 \mathrm{~g} 85 \% \mathrm{KOH}$ 
pellets $+60 \mathrm{ml} \mathrm{H}_{2} \mathrm{O}$ ) in a $250 \mathrm{ml}$ round-bottomed flask, equipped with a reflux condenser and a magnetic stirring bar, $77.06 \mathrm{~g}$ of $\mathrm{F}_{5} \mathrm{SCHFCF}_{2} \mathrm{Br}(267 \mathrm{mmol})$ were added. The top of the reflux condenser was connected with rubber tubes to two cold-traps $\left(-78^{\circ} \mathrm{C}\right)$, the first of which was a $100 \mathrm{ml}$ Schlenk flask, which was connected to the second trap. Cold tap water was passed through the condenser. With vigorous stirring, the reaction flask was heated very slowly to $\approx 40^{\circ} \mathrm{C}$ in 45 minutes. The reaction started already with the cold solution and the product (b.p. $19^{\circ} \mathrm{C}$ ) escaped as a gas, which was chiefly trapped in the first $-78^{\circ} \mathrm{C}$ cold-trap. After 1 hour, the bottom layer in the reaction flask had disappeared. The reaction flask was heated to $95^{\circ} \mathrm{C}$ for 3 more hours. Gas chromatography showed that the product $(55.0$ g) in the first cold-trap (the second one was almost empty) was $\approx 85 \%$ olefin and $15 \% \mathrm{~F}_{5} \mathrm{SCHFCF}_{2} \mathrm{Br}$. The base treatment was repeated, and in order to minimize loss by evaporation, the reaction vessel (no new base was added) was cooled by swirling in liquid nitrogen until its contents started to congeal. The product, which was kept in the $-78^{\circ} \mathrm{C}$ bath, was poured in, and the procedure was repeated as above. Most of the product was collected in $\approx 30$ minutes. The oil bath temperature was raised $\left(140^{\circ} \mathrm{C}\right)$, and the cooling water was turned off. When the refluxing water had reached the top of the condenser the reaction was stopped. This allowed the collection of $\approx 1$ more $g$ of product. The product in both 
cold-traps was combined and shaken with $\mathrm{P}_{2} \mathrm{O}_{5}$. Yield: 53.57 g or $96.5 \%$ (g.c. pure).

The preparation of $\mathrm{F}_{5} \mathrm{SCH}=\mathrm{CF}_{2}(\underline{52})$ is described ar the beginning of tjhe experimental part.

Synthesis of $\mathrm{F}_{5} \mathrm{SC}(\mathrm{H}, \mathrm{F}) \mathrm{CF}_{2} \mathrm{O} \quad(53,54)$ :

Methyl-tri-n-octylammonium chloride $(1.50 \mathrm{~g}, 3.7 \mathrm{mmol}$,

TCI) and $41.0 \mathrm{~g}$ of freshly prepared $\mathrm{NaOCl}+\mathrm{NaOH}$ solution (calc. $11.8 \%$ in NaOCl, $5 \%$ in $\mathrm{NaOH}$ ) were cooled in a $100 \mathrm{ml}$ round-bottomed flask with stirring in an ice-salt bath to$12^{\circ} \mathrm{C}$. Then, $4.72 \mathrm{~g}$ of $\mathrm{F}_{5} \mathrm{SCF}=\mathrm{CF}_{2}(22.7 \mathrm{mmol})$ in $20 \mathrm{ml}$ of $\mathrm{CCl}_{2} \mathrm{FCClF}_{2}$, precooled to $-10^{\circ} \mathrm{C}$, were added in three portions, with vigorous stirring. After each addition, 2 minutes elapsed before the next addition. The temperature had risen to $-6^{\circ} \mathrm{C}$ after the third addition and had dropped to $-10^{\circ} \mathrm{C}$ three minutes later. ${ }^{19} \mathrm{~F}$ n.m.r indicated that all olefin was gone. The mixture was poured into a separatory funnel and the lower layer was transferred and dried at$12^{\circ} \mathrm{C}\left(\mathrm{Na}_{2} \mathrm{SO}_{4}, 16 \mathrm{~h}\right)$. The liquid was vacuum-transferred and distilled with a spinning band column; the product was removed from the head of the column and condensed in a $-78^{\circ} \mathrm{C}$ trap. Access of moisture to the cold-trap was prevented with a Drierite tube. After $5 \mathrm{~h}, 2.67 \mathrm{~g}(53 \%)$ of product was collected. This material was virtually pure and contained only a trace of Freon 113 (g.c.). The infrared spectrum was identical with the one of a g.c. pure sample of $\mathrm{F}_{5} \mathrm{SCFCF}_{2} \mathrm{O}$. 
Infrared spectrum: (gas phase, $10 \mathrm{~cm}$ path length, $\mathrm{KBr}$, 20 torr): $\left(\mathrm{cm}^{-1}\right) ; 1585$ (m); 1530 (s); 1274 (vs); 1193 (s); 1133 (s); 1031 (m-s); 960 (w); 936 (m-s); 905 (vs); 863 (vs); $824(\mathrm{~m}) ; 795(\mathrm{w}) ; 724(\mathrm{~m}-\mathrm{w}) ; 696(\mathrm{~m}) ; 622$ (m)；599 (ms) ; $581(\mathrm{~m}) ; 544(\mathrm{w}) ; 418(\mathrm{w})$.

Mass spectrum (chemical ionization, mass, fragment, $\%): 209,(\mathrm{M}+\mathrm{H}-\mathrm{O})^{+}, 0.9 ; 127, \mathrm{SF}_{5}{ }^{+}, 9.1 ; 108, \mathrm{SF}_{4}^{+}, 6.5 ; 98$, $\left(\mathrm{M}+\mathrm{H}-\mathrm{SF}_{5}\right)^{+}, 3.4 ; 97,\left(\mathrm{M}-\mathrm{SF}_{5}\right)^{+}, 72.2 ; 89, \mathrm{SF}_{3}{ }^{+}, 43.8 ; 70$, $\mathrm{SF}_{2}{ }^{+}, 5.6 ; 59, \mathrm{C}_{2} \mathrm{FO}^{+}, 4.1 ; 51, \mathrm{SF}^{+}, 12.1 ; 50, \mathrm{CF}_{2}{ }^{+}, 2.9$.

Anal.calcd for $\mathrm{C}_{2} \mathrm{~F}_{8}$ OS: $\mathrm{C}, 10.72 ; \mathrm{F}, 67.8 ; \mathrm{S}, 14.31$. Found, C, 10.54; F, 68.2; S, 14.37 .

$\mathrm{F}_{5} \mathrm{SCHCF}_{2} \mathrm{O}$ was obtained in a similar fashion with $\mathrm{CCl}_{4}$ at $-10^{\circ} \mathrm{C}$. The dried $\left(\mathrm{Na}_{2} \mathrm{SO}_{4}\right) \quad \mathrm{CCl}_{4}$ layer was distilled twice through a $12 \mathrm{~cm}$ Vigreux column and gave a fraction with a boiling range $42.4-46.0{ }^{\circ} \mathrm{C}$ that consisted of $\mathrm{SF}_{5} \mathrm{CHCF}_{2} \mathrm{O}(87 \%$ by g.c.) and $\mathrm{CCl}_{4}$ (13\%). Further purification was achieved with preparative gas chromatography $\left(30 \% \mathrm{SE}-30,3 \mathrm{~m}, 95^{\circ} \mathrm{C}\right) \cdot$ Yield $\approx 30 \%$.

Infrared spectrum (path length $10 \mathrm{~cm}, 10$ torr, $\mathrm{KBr}$, $\left.\mathrm{cm}^{-1}\right): 3065(\mathrm{w}) ; 1535(\mathrm{~m}) ; 1509(\mathrm{~s}-\mathrm{vs}, \mathrm{sh}) ; 1497(\mathrm{vs}) ; 1297(\mathrm{~s})$; 1250 (vs); $1206(\mathrm{w}) ; 1174(\mathrm{vw}) ; 1128(\mathrm{~s}) ; 1049(\mathrm{~s}) ; 1003(\mathrm{w})$; $965(\mathrm{vs}) ; 889(\mathrm{vs}) ; 831(\mathrm{w}-\mathrm{m}) ; 767(\mathrm{w}) ; 738(\mathrm{~s}) ; 677(\mathrm{~m}) ; 651(\mathrm{~m})$; $613(\mathrm{~s}) ; 572(\mathrm{~m}) ; 534(\mathrm{w}) ; 505(\mathrm{w}) ; 435(\mathrm{w})$.

Anal.calcd for $\mathrm{C}_{2} \mathrm{HF}_{7} \mathrm{OS}: \mathrm{C}, 11.66 ; \mathrm{H}, 0.49 ; \mathrm{F}, 64.5 ; \mathrm{S}$, 15.56. Found: $\mathrm{C}, 11.76 ; \mathrm{H}, 0.56 ; \mathrm{F}, 63.7 ; \mathrm{S}, 15.65$.

The samples were generally stored at $-196^{\circ} \mathrm{C}$, since for 
$\mathrm{F}_{5} \mathrm{SCFCF}_{2} \mathrm{O}$ the observation was made that storage at roomtemperature in glass vessels resulted in the formation of $\mathrm{COF}_{2}$.

Reaction of 54 with $\mathrm{CsF}$ in $\mathrm{CH}_{3} \mathrm{CN}$ :

Cesium fluoride $\left(0.05 \mathrm{~g}, 3.3 \cdot 10^{-4} \mathrm{~mol}\right)$ was dried overnight in a $40 \mathrm{ml}$ Carius tube at $115^{\circ} \mathrm{C}$ under high vacuum. Then $0.63 \mathrm{~g}$ of $\underline{54}(2.8 \mathrm{mmol})$ was added by vacuum transfer. The tube was heated for 45 minutes to $115^{\circ} \mathrm{C}$, and although the CsF had darkenen somewhat and it seemed to stick together, the i.r. spectrum of the contents of the vessel. showed only $\underline{54}$. To this, $0.34 \mathrm{~g}$ of dry $\mathrm{CH}_{3} \mathrm{CN}$ was condensed and the tube was kept at $65^{\circ} \mathrm{C}$ for 30 minutes (i.r., still some $\underline{54}$, but also a strong band at $1898 \mathrm{~cm}^{-1}$ ). Heating was continued for 1 hour, when no more $\underline{54}$ was detected in the i.r. spectrum. Fractional condensation ($\left.(35-16)^{\circ} \mathrm{C}, \quad-(78-66)^{\circ} \mathrm{C},-(100-95)^{\circ} \mathrm{C},-196^{\circ} \mathrm{C}\right)$ yielded some separation. The $-35^{\circ} \mathrm{C}$ trap was empty, the $-78^{\circ} \mathrm{C}$ trap contained $0.16 \mathrm{~g}$ of $\mathrm{CH}_{3} \mathrm{CN}$, the $-100^{\circ} \mathrm{C}(0.14 \mathrm{~g})$ trap contained $\mathrm{CH}_{3} \mathrm{CN}$ in mixture with other (unidentified) material. The ${ }^{19} \mathrm{~F}$ n.m.r. spectrum showed several very weak bands, but no $\mathrm{SF}_{5}$ or $\mathrm{CFO}$ group was detectable. The $-196^{\circ} \mathrm{C}$ trap contained a mixture of $\mathrm{SF}_{4}$ and $\mathrm{CF}_{3} \mathrm{CFO}(0.48 \mathrm{~g}$, 76 \%). This latter mixture was stored in a $50 \mathrm{ml}$ Pyrex vessel with rubber septum at room temperature for several weeks, and then subjected to preparative gas chromatography 
(30\% SE-30 45/60, 3m, on Chromosorb $W$, room temperature). The effluent fractions were sucked into an evacuated gas infrared cell. The major band $\left(\approx 77 \%, R_{f}=10.4\right.$ minutes $)$ showed several irregularities and the i.r. samples were taken at various places of the band. Although these samples. showed a continuous change, it was clear from comparisons that initially $\mathrm{SiF}_{4}$, then $\mathrm{SiF}_{4}+\mathrm{CF}_{3} \mathrm{CFO}$ and finally $\mathrm{SiF}_{4}+$ $\mathrm{CF}_{3} \mathrm{CFO}+\mathrm{SOF}_{2}$ were eluted. The minor band $\left(23 \%, \mathrm{R}_{f}=12.9\right.$ minutes) showed the following bands $\left(\mathrm{cm}^{-1}\right): 1212, \mathrm{~s} ; 1179$, vs; 1118, vs; 1047 , vs; $980, \mathrm{vw}$, broad; 909, vs; 890, m, sh; 816 , vs; $655, \mathrm{vw} ; 533, \mathrm{vw}$.

Reaction of 54 and $\mathrm{H}_{2}$ O:

To $1.71 \mathrm{~g}$ of distilled $\mathrm{H}_{2} \mathrm{O}(65 \mathrm{mmol})$ in a $50 \mathrm{ml}$ Pyrexglass reaction vessel that contained a magnetic stirring bar and that could be closed with a Kontes Teflon valve, $1.07 \mathrm{~g}$ of $\underline{54}(4.8 \mathrm{mmol})$ was added by vacuum transfer. After stirring at room temperature overnight $(18 \mathrm{~h})$, the bottom layer was gone. A gas infrared spectrum showed a pressure drop of 20 torr in a total volume of $530 \mathrm{ml}$, as compared to the calculated value for $1.07 \mathrm{~g}$ of epoxide. The infrared spectrum $(10 \mathrm{~cm}, 10$ torr, $\mathrm{KBr}$ ) showed only the epoxide and a weak band at $1374 \mathrm{~cm}^{-1}$. The volatile material was recondensed into the reaction vessel, and stirring was continued (room temperature, $24 \mathrm{~h} ; 50{ }^{\circ} \mathrm{C}, 18 \mathrm{~h}$ ). The pressure had dropped by another 10 torr after this time, and 
only the epoxide was detected in the i.r. spectum. After stirring another $18 \mathrm{~h}$ at $60^{\circ} \mathrm{C}$, a white gel-like mass was observed and three more days of stirring at $60^{\circ} \mathrm{C}$, then keeping it at room temperature $(24 \mathrm{~h})$ did not show any change in the i.r. spectrum, neither was the pressure altered upon expansion of the material in the vessel in the same volume $(530 \mathrm{ml})$. The volatile material was removed (vacuum transfer, $0.81 \mathrm{~g}$ of $\underline{54}, 76 \%$ recovery). The vessel was severly etched as seen after removing the water and the white inorganic mass that remained.

Reaction of 54 and $\mathrm{BF}_{3}$ :

To $0.30 \mathrm{~g}$ of $\underline{54}(1.3 \mathrm{mmol})$ in a $50 \mathrm{ml}$ round bottomed flask, equipped with a Kontes Teflon valve, $6.7 \cdot 10^{-4} \operatorname{mol}$ of $\mathrm{BF}_{3}$ (Matheson) was condensed. No reaction was observed upon warming to room temperature, neither showed the i.r. spectrum any other products than $\mathrm{BF}_{3}$ and $\underline{54}$ after keeping the sample at room temperature for 18 hours.

\section{$\underline{F}_{5} \underline{S C H}=\mathrm{CHOCH}_{3}$ from $\mathrm{F}_{5} \underline{\mathrm{SCH}=\mathrm{CHBr}:}$}

In a $250 \mathrm{ml}$ round bottom flask, equipped with a magnetic stirring bar, $11.59 \mathrm{~g}$ of sodium ( $504 \mathrm{mmol}$ ) were dissolved in $120 \mathrm{ml}$ of anhydrous methanol. A Claisen head, dropping funnel and a Dryerite tube were attached, the solution was cooled in an ice- bath and $80.45 \mathrm{~g}$ (345.3 mmol) of $\mathrm{F}_{5} \mathrm{SCH}=\mathrm{CHBr}$ were added dropwise under stirring to the 
sodium methoxide solution. Sodium bromide started soon to precipitate and the solution had a yellow tinge. Addition was finished after $30 \mathrm{~min}$ and the ice-bath was removed. The solution became warm slowly and was cooled with a water bath (room temperature). After $1 \mathrm{~h}$ the claisen head was replaced by a Drierite tube. Stirring was continued for $96 \mathrm{~h}$ at room temperature, when ${ }^{19} \mathrm{~F}$ n.m.r. indicated that all the bromide had gone. The $\mathrm{NaBr}$ was filtered off $(25.3 \mathrm{~g}, 71 \%$ ) and the reaction mixture was poured into $300 \mathrm{ml}$ of cold water, the lower layer was separated and saturated $\mathrm{NaCl}$ solution (200 ml) was added to the aqueous layer. After standing overnight a little bit more product had precipitated. It was washed with a small amount of saturated $\mathrm{NaCl}$ solution and combined with the original product; after drying $\left(\mathrm{MgSO}_{4}\right), 54.7 \mathrm{~g}$ (86 $\%$ ) of crude product was obtained. Distillation through a Vigreux column at atmospheric pressure yielded $17.7 \mathrm{~g}$ of pure $\mathrm{F}_{5} \mathrm{SCH}=\mathrm{CHOCH}_{3}\left(\mathrm{~b} . \mathrm{p} .114^{\circ} \mathrm{C}\right)$ and $36.2 \mathrm{~g}$ of a mixture the vinyl ether and the acetal $\mathrm{F}_{5} \mathrm{SCH}_{2} \mathrm{CH}\left(\mathrm{OCH}_{3}\right)_{2}$ in a ratio of about 9:1 (by ${ }^{19} \mathrm{~F}$ n.m.r.), boiling range $114-122^{\circ} \mathrm{C}$.

\section{ACid hydrolysis of $\mathrm{F}_{5}{\underline{\mathrm{SCH}}=\mathrm{CHOCH}_{3}}_{3}$}

In a $100 \mathrm{ml}$ round bottom flask, fitted with a $30 \mathrm{~cm}$ reflux condenser, $53.7 \mathrm{~g}$ of a mixture of $\mathrm{F}_{5} \mathrm{SCH}=\mathrm{CHOCH}_{3}$ and $\mathrm{F}_{5} \mathrm{SCH}_{2} \mathrm{CH}\left(\mathrm{OCH}_{3}\right)_{2}$ (ca $94: 6$, by ${ }^{19} \mathrm{~F}$ n.m.r.) were heated to $80-90{ }^{\circ} \mathrm{C}$ with $27 \mathrm{ml}$ of conc. $\mathrm{HCl}$ and vigorous stirring. After $3 \mathrm{~h}$ all starting material appeared to have been 
consumed ( ${ }^{19} \mathrm{~F}$ n.m.r.), but heating was continued for another hour. Yield $51.6 \mathrm{~g}$, mixture of two compounds in the ratio of $34\left(\mathrm{~F}_{5} \mathrm{SCH}_{2} \mathrm{CHO}\right): 66\left(\mathrm{~F}_{5} \mathrm{SCH}_{2} \mathrm{CH}(\mathrm{OH})_{2}(19 \mathrm{~F} \mathrm{n.m.r.})\right.$. Yield $51.6 \mathrm{~g}$. This material was directly used for the preparation of the aldehyde by dehydration with $\mathrm{P}_{4} \mathrm{O}_{10}$ (next paragraph): In this fashion $22.1 \mathrm{~g} \mathrm{P}_{5} \mathrm{O}_{10}$ were used to dehydrate $39.6 \mathrm{~g}$ of the above mixture, leaving a product $(29.55 \mathrm{~g})$ that contained still the dimethyl acetal and some unreacted vinyl ether. The mixture was thus distilled through a vigreux column to obtain $20.98 \mathrm{~g}$ of a mixture of the vinyl ether (20\%) and the aldehyde, boiling range $55-96:{ }^{\circ} \mathrm{C}$. This fraction was heated with an excess of concentrated $\mathrm{HCl}$ for 15 hours in a $50 \mathrm{ml}$ round bottom flask with a $30 \mathrm{~cm}$ reflux condenser to $80-89^{\circ} \mathrm{C}$. A 25 : 75 mixture of the aldehyde and the aldehyde hydrate was obtained (19 g).

\section{$\left(\mathrm{F}_{5} \underline{\mathrm{SCH}}_{2} \underline{\mathrm{CHO}}_{3}:\right.$}

To $18.99 \mathrm{~g}$ of a mixture of $\mathrm{F}_{5} \mathrm{SCH}_{2} \mathrm{CHO}$ and $\mathrm{F}_{5} \mathrm{SCH}_{2} \mathrm{CH}(\mathrm{OH})_{2}$ (25:75\% by ${ }^{19} \mathrm{~F}$ n.m.r.) $16 \mathrm{~g}$ (56.3.mmol) of powdered $\mathrm{P}_{4} \mathrm{O}_{10}$ were added under cooling in a $50 \mathrm{ml}$ round bottomed flask. The mixture was swirled occasionally and after|ca. $30 \mathrm{~min}$ the aldehyde was removed by vacuum transfer $(15.64 \mathrm{~g})$.

The residual phosphorous pentoxide was dissolved in $50 \mathrm{ml}$ of distilled water and extracted with chloroform ( $3 \times 20$ $\mathrm{mI})$; the combined extracts were dried $\left(\mathrm{Na}_{2} \mathrm{SO}_{4}\right)$ and brougt to dryness, leaving an off-white solid, $0.87 \mathrm{~g}$ after repeated 
recrystallization from hexane, m.p. 110.5-111.5 ${ }^{\circ} \mathrm{C}$. An analytically pure sample was obtained by sublimation 10.001 torr, $\left.50^{\circ} \mathrm{C}\right)$.

$l_{\mathrm{H}}$ n.m.r. spectrum $\left(\mathrm{CDCl}_{3}\right.$, external $\left.\mathrm{si}\left(\mathrm{CH}_{3}\right)_{4}\right): \delta_{1}=$ $3.81 \mathrm{ppm}, \mathrm{p}-\mathrm{d}$, area $=2.0\left(\mathrm{CH}_{2}\right) ; \delta_{2}=5.58 \mathrm{ppm}, t$, area $=1.0(\mathrm{CHO}) ; \mathrm{J}_{1 \mathrm{FB}}=7.9 \mathrm{~Hz}, \mathrm{~J}_{12}=4.8 \mathrm{~Hz}$.

${ }^{19} \mathrm{~F}$ n.m.r. spectrum $\left(\mathrm{CDCl}_{3}\right.$, external $\left.\mathrm{CFCl}_{3}\right): \mathrm{AB}_{4} \phi_{\mathrm{A}}=$ $82.0 \mathrm{ppm}$, area $=1.0 ; \phi_{\mathrm{B}}=69.5 \mathrm{ppm}$, area $=4.0, \mathrm{~J}_{\mathrm{AB}}=152$ $\mathrm{Hz}$.

I.r. spectrum (sample squeezed on $\mathrm{KBr}$ plates): 3044 (w); $2988(\mathrm{VW}) ; 2932(\mathrm{VW}) ; 1450$ (VW); $1423 \mathrm{~m}(\mathrm{~m}) ; 1405$ (m); 1368 (ms); 1301 (vw)； 1227 (m)； 1142 (vs); 1068 (s)； 1049 (ms); 901 (vs); 867 (s); 9838 (vs); 830 (vssh); 715 (ms); 651 (s); 607 (ms); 581 (m); 556 (s); 516 (m).

Mass spectrum (e.i., m/e, \%> 1, species): $341,1.8$, $\left(\mathrm{F}_{5} \mathrm{SCH}_{2} \mathrm{CHO}\right)_{2} \mathrm{H}^{+} ; 321 ， 1.1 ，\left(\left(\mathrm{~F}_{5} \mathrm{SCH}_{2} \mathrm{CHO}\right)_{2} \mathrm{H}-\mathrm{HF}\right)_{+} ; 171,14.0$ ， $\mathrm{F}_{5} \mathrm{SCH}_{2} \mathrm{CHOH}_{+} ; 170,1.2, \mathrm{~F}_{5} \mathrm{SCH}_{2} \mathrm{CHO}^{+} ; 169,26.8, \mathrm{~F}_{5} \mathrm{SCH}_{2} \mathrm{CO}^{+}$; $153 ， 5.7, \mathrm{~F}_{5} \mathrm{SCH}_{2} \mathrm{C}^{+} ; 152 ， 3.2, \mathrm{~F}_{5} \mathrm{SC}_{2} \mathrm{H}^{+} ; 151,100.0, \mathrm{~F}_{5} \mathrm{SC}_{2}+$; $127,2.9, \mathrm{SF}_{5}^{+} ; 122,8.6, \mathrm{C}_{3} \mathrm{H}_{3} \mathrm{FO}_{2} \mathrm{~S}^{+} ; 105,1.4, \mathrm{C}_{3} \mathrm{H}_{2} \mathrm{FOS}^{+}$; 103, 2.2, $\mathrm{C}_{3} \mathrm{FOS}^{+} ; 91,9.6, \mathrm{FSC}_{2} \mathrm{O}^{+} ; 89,40.3, \mathrm{SF}_{3}{ }^{+} ; 77,1.3$, $\mathrm{FSCH}_{2} \mathrm{C}^{+} ; 70,1.3, \mathrm{SF}_{2}^{+} ; 65,2.6, \mathrm{CH}_{2} \mathrm{FS}^{+} ; 63,11.5, \mathrm{fs}^{+} ; 62$, $13, \mathrm{CH}_{2} \mathrm{OS}^{+} ; 61, \mathrm{C}_{3} \mathrm{H}_{3} \mathrm{FO}_{2} \mathrm{~S}^{2+}$.

Anal.calcd for $\mathrm{C}_{6} \mathrm{H}_{9} \mathrm{~F}_{15} \mathrm{O}_{3} \mathrm{~S}_{3}: \mathrm{C}, 14.12 ; \mathrm{H}, 1.78 ; \mathrm{F}$, $55.9 ; \mathrm{S}, 18.85$. Found: C, 14.28; H, 1.78; F, 55.9; S, 19.04. 


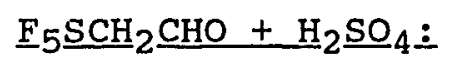

Into an n.m.r. tube, $0.5180 \mathrm{~g}(3.05 \mathrm{mmol})$ of $\mathrm{F}_{5} \mathrm{SCH}_{2} \mathrm{CHO}$

(purified by preparative gas chromatography) were added. Four drops of $96 \% \mathrm{H}_{2} \mathrm{SO}_{4}$ were added at room temperature, and an immediate formation of a white compound was observed. The tube was capped and gently shaken, whereby it warmed somewhat, and within a short time there was only a white solid left in the tube. The typical odor of the aldehyde was gone after $20 \mathrm{~min}$. After keeping the sample at room temperature overnight the product was dissolved in acetone $(\approx 2 \mathrm{ml})$. The volume of the solution was reduced in a stream of air to $\approx 0.5 \mathrm{ml}, \mathrm{CH}_{2} \mathrm{Cl}_{2}(3 \mathrm{ml})$ was added, then saturated $\mathrm{NaHCO}_{3}$ solution with swirling until $\mathrm{CO}_{2}$ formation ceased. Removing the lower layer (pipet), extracting the remaining aqueous layer with methylene chloride ( $1 \mathrm{ml})$, combining the two solutions and drying $\left(\mathrm{Na}_{2} \mathrm{SO}_{4}\right)$ followed. The dried solution was filtered through a filter pipet, the $\mathrm{Na}_{2} \mathrm{SO}_{4}$ was rinsed with $\mathrm{CH}_{2} \mathrm{Cl}_{2}(1 \mathrm{ml})$, the rinse solution was combined with the filtrate and after evaporation of the solvent in a stream of air and drying in the oven $\left(120^{\circ} \mathrm{C}, 15 \mathrm{~min}\right)$ an off-white product (solidified melt) was obtained. The infrared spectrum of this material was identical to the spectra of the products obtained either by the extraction of the $\mathrm{P}_{4} \mathrm{O}_{10}$ residue from the dehydration procedure or from the precipitate collected from the aldehyde after some time of storage in the cold. Yield: $0.4460 \mathrm{~g}(0.87 \mathrm{mmol}), 86 \%$. 


\section{$\underline{F}_{5} \underline{\mathrm{SCH}}_{2}$ CHBrOAC:}

Into a $300 \mathrm{ml}$ dry glass-vessel containing a stirring bar and equipped with a Kontes-Teflon valve, $100 \mathrm{ml}$ of $\mathrm{CCl}_{3} \mathrm{~F}$, previously dried over $\mathrm{P}_{4} \mathrm{O}_{10}$, were vacuum-transferred. Then $12.67 \mathrm{~g}$ of $\mathrm{SF}_{5} \mathrm{Br}(51.5 \mathrm{mmol})$ were condensed to the solvent. The $\mathrm{CCl}_{3} \mathrm{~F}$ was allowed to melt and dissolve the $\mathrm{SF}_{5} \mathrm{Br}$. Freshly distilled vinyl acetate (Aldrich) (10.0 g, $116.3 \mathrm{mmol}$ ) was added by vacuum-transfer, and the reaction vessel was allowed to warm slowly in a cold-bath until the solution started to melt; it was then swirled so as to achieve complete mixing. Another. $7.8 \mathrm{~g}(37.7 \mathrm{mmol})$ of $\mathrm{SF}_{5} \mathrm{Br}$ was added by the same method. The reaction mixture was now allowed to attain room-temperature slowly in the air with stirring. Only slight bubbling was observed. The solvent was then removed (rotary evaporator), leaving $19.8 \mathrm{~g}$ of a lightly yellowish liquid. Distillation through a $12 \mathrm{~cm}$ Vigreux column at gave $8.5 \mathrm{~g}$ of a main fraction, b.p. 45$48^{\circ} \mathrm{C} / 6 \mathrm{~mm} \mathrm{Hg}$. The foreshot and the fraction $48-49^{\circ} \mathrm{C}(2.0 \mathrm{~g}$ together) had the same composition $\left({ }^{1_{H}}\right.$ n.m.r.) as the main fraction. Yield $10.5 \mathrm{~g}, 36.2 \%$. The $48-49^{\circ} \mathrm{C}$ fraction was used for analysis.

$1_{\mathrm{H}}$ n.m.r. $\left(\mathrm{CDCl}_{3}, \mathrm{Si}\left(\mathrm{CH}_{3}\right)_{4}\right.$ ext. $): \delta_{1}=2.10 \mathrm{ppm}, \mathrm{s}$, int. $=3.17\left(\mathrm{CH}_{3}\right) ; \delta_{2}=4.74 \mathrm{ppm}, \mathrm{m}$, int. $=1.92\left(\mathrm{CH}_{2}\right) ; \delta_{3}=$ $7.15 \mathrm{ppm}, \mathrm{d}-\mathrm{d}$, int. $=1.00(\mathrm{CH}) \cdot \mathrm{J}_{23}$ (cis) $=9.6 \mathrm{~Hz}$, $\mathrm{J}_{23}$ (trans) $=3.0 \mathrm{~Hz}$.

${ }^{19} \mathrm{~F}$ n.m.r. (neat sample, $\mathrm{CCl}_{3} \mathrm{~F}$ ext.): $\left(\mathrm{AB}_{4}\right) \phi=81.4$ 
ppm, 9 lines, int. $=0.96\left(\mathrm{~F}_{\mathrm{A}}\right) ; \phi=65.9 \mathrm{ppm}, \mathrm{d}-\mathrm{m}$, int. $=$ $4.0\left(F_{B}\right) ; J_{A B}=146.4 \mathrm{~Hz}$.

I.r. spectrum ( $\mathrm{NaCl}$, neat, $\left.\mathrm{cm}^{-1}\right): 3042, \mathrm{w} ; 3023, \mathrm{w}$; 2988, w-Vw; 1778, vs; 1419, m; 1377, m-s; 1358, w-m; 1312, w; 1203, vs; 1193, vs,sh; 1103, s-vs; 1040, vs; 998, m; 941, $m-s$; 879 , vs; 844 , vs; 817, s-vs; $735, w ; 675$, w; 645, vw; $614, \mathrm{w} ; 602, \mathrm{~m} ; 577, \mathrm{w} ; 564$, vw.

Anal. calcd for $\mathrm{C}_{4} \mathrm{H}_{5} \mathrm{BrF}_{5} \mathrm{O}_{2} \mathrm{~S}: \mathrm{C}, 16.39 ; \mathrm{H}, 2.06 ; \mathrm{Br}$, $27.27 ; \mathrm{F}, 32.42 ; \mathrm{S}, 10.94$. Found: C, 17.19; H, 2.18; Br, $28.86 ; \mathrm{F}, 30.4 ; \mathrm{S}, 9.90$.

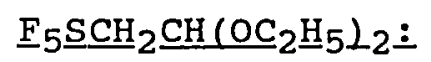

To $22.86 \mathrm{~g}$ of $\mathrm{F}_{5} \mathrm{SCH}_{2} \mathrm{CHClOAC}(92.0 \mathrm{mmol})$ in a $100 \mathrm{ml}$ flask $32.46 \mathrm{~g}$ of absolute ethanol (705.6 mmol, 2.56 -fold excess) were added at room-temperature. The lightly stoppered flask was set aside. After two days there was still some $\mathrm{F}_{5} \mathrm{SCH}_{2} \mathrm{CHClOAC}$ (i.r.), but after $48 \mathrm{~h}$ all of the compound was consumed. The smell of ethyl acetate was noticeable. The mixture was poured into $200 \mathrm{ml}$ of water, washed again with water $(2 \times 30 \mathrm{ml})$, dried $\left(\mathrm{Na}_{2} \mathrm{SO}_{4}\right)$ and distilled through a $12 \mathrm{~cm}$ Vigreux column. $16.47 \mathrm{~g}$ ( $73.4 \%)$ of product boiling from $66-72^{\circ} \mathrm{C} / 19-20.5$ torr was collected.

$$
\begin{aligned}
& I_{\mathrm{H}} \text { n.m.r. }\left(\mathrm{CDCl}_{3}, \mathrm{Si}\left(\mathrm{CH}_{3}\right)_{4}\right): 1.27 \mathrm{ppm}, \mathrm{t},\left(6 \mathrm{H}, \mathrm{CH}_{3}\right), \\
& J_{\mathrm{H}-\mathrm{H}}=7.1 \mathrm{~Hz} ; 3.67 \mathrm{ppm}, \mathrm{m},\left(6 \mathrm{H}, \mathrm{H}_{3} \mathrm{CCH}_{2}+\mathrm{F}_{5} \mathrm{SCH}_{2}\right) ; 4.92 \\
& \text { ppm, } \left.t,(1 \mathrm{H}, \mathrm{CH}), J_{\mathrm{H}-\mathrm{H}}=5.2 \mathrm{~Hz}\right) .
\end{aligned}
$$


${ }^{19} \mathrm{~F}$ n.m.r. (neat sample, $\mathrm{CCl}_{3} \mathrm{~F}$ ext.): $\left(\mathrm{AB}_{4}\right), \phi=83.7$ ppm $\left(F_{A}\right), 9$ lines, $(1 F) ; \phi=66.8 \mathrm{ppm}\left(F_{B}\right), m,(4 F) ; J_{A B}=$ $143.8 \mathrm{~Hz}$.

$$
\text { I.r. }\left(\mathrm{cm}^{-1}\right): 3035, \mathrm{VW} ; 2985, \mathrm{~s} ; 2936, \mathrm{~m} ; 2904, \mathrm{~m} ; 2893 \text {, }
$$
$\mathrm{m} ; 2805, \mathrm{vw} ; 1484$, w; 1458, w, sh; 1448, w-m; 1417, m; 1378, $\mathrm{m}-\mathrm{s} ; 1361, \mathrm{~m} ; 1349, \mathrm{~m} ; 1300, \mathrm{w} ; 1229, \mathrm{w} ; 1159, \mathrm{~m}, \mathrm{sh} ; 1125$, s-vs, 1063, s-vs; 1023, s,sh; 1000, w-m,sh; 935, w-m, 906, s; $865, \mathrm{~s}-\mathrm{Vs} ; 840$, vs; $817, \mathrm{vs} ; 737, \mathrm{w}-\mathrm{m} ; 710, \mathrm{~s} ; 667$, w; $643, \mathrm{~s} ; 630, \mathrm{~m} ; 620, \mathrm{~m} ; 600, \mathrm{~s} ; 566, \mathrm{~m} ; 539, \mathrm{w}$.

Mass spectrum (c.i., $70 \mathrm{eV}$, mass, fragment, $\%$ 2): $243,(\mathrm{M}-\mathrm{H})^{+}, 0.15 ; 201,\left(\mathrm{M}+\mathrm{H}-\mathrm{C}_{2} \mathrm{H}_{5}-\mathrm{CH}_{3}\right)^{+}, 5.0 ; 200,\left(\mathrm{M}-\mathrm{C}_{2} \mathrm{H}_{5}-\right.$ $\left.\mathrm{CH}_{3}\right)^{+}, 4.9 ; 199,\left(\mathrm{M}-\mathrm{C}_{2} \mathrm{H}_{5} \mathrm{O}\right)^{+}, 100 ; 179, \mathrm{C}_{4} \mathrm{H}_{7} \mathrm{~F}_{4} \mathrm{OS}^{+}, 14.2 ; 178$, $\mathrm{C}_{4} \mathrm{H}_{6} \mathrm{~F}_{4} \mathrm{OS}^{+}, 2.5 ; 177, \mathrm{C}_{4} \mathrm{H}_{5} \mathrm{~F}_{4} \mathrm{OS}^{+}, 40.2 ; 171,\left(\mathrm{M}-\mathrm{C}_{2} \mathrm{H}_{5}-\mathrm{C}_{2} \mathrm{H}_{4}\right) \mathrm{O}^{+}$, $26.5 ; 153,\left(\mathrm{M}-\mathrm{C}_{2} \mathrm{H}_{5} \mathrm{O}-\mathrm{C}_{2} \mathrm{H}_{5} \mathrm{OH}\right)^{+}, 3.0 ; 152,\left(\mathrm{M}-2 \mathrm{C}_{2} \mathrm{H}_{5} \mathrm{OH}\right)^{+}, 2.0$; 151, $\mathrm{C}_{2} \mathrm{SF}_{5}{ }^{+}, 54.3 ; 127, \mathrm{SF}_{5}{ }^{+}, 1.2 ; 107, \mathrm{C}_{6} \mathrm{H}_{3} \mathrm{O}_{2}{ }^{+}, 2.5 ; 104$, $\mathrm{C}_{6} \mathrm{O}_{2}{ }^{+}, \mathrm{CH}_{3} \mathrm{SF}_{3}{ }^{+}, 3.5 ; 103, \mathrm{CH}_{2} \mathrm{SF}_{3}{ }^{+}, 59.7 ; 92, \mathrm{C}_{6} \mathrm{H}_{4} \mathrm{O}^{+}, \mathrm{C}_{2} \mathrm{HFOS}^{+}$, $2.7 ; 91, \mathrm{C}_{2}$ FOS $^{+}, 57.4 ; 89, \mathrm{SF}_{3}{ }^{+}, 19.5 ; 87, \mathrm{C}_{2} \mathrm{H}_{2} \mathrm{O}_{2} \mathrm{C}_{2} \mathrm{H}_{5}{ }^{+}, 2.4$; $79, \mathrm{FSC}_{2} \mathrm{H}_{4}^{+}, 2.9 ; 77, \mathrm{FSC}_{2} \mathrm{H}_{2}{ }^{+}, 11.8 ; 75, \mathrm{FSC}_{2}{ }^{+}, \mathrm{C}_{2} \mathrm{H}_{3} \mathrm{OS}^{+}$, $8.0 ; 73, \mathrm{C}_{2} \mathrm{HOS}^{+}, \mathrm{C}_{3} \mathrm{H}_{5} \mathrm{O}_{2}^{+}, 7.9 ; 72, \mathrm{C}_{2} \mathrm{OS}^{+}, \mathrm{C}_{3} \mathrm{H}_{4} \mathrm{O}_{2}^{+}, 2.9 ; 70$, two fragments, $\mathrm{SF}^{+}, \mathrm{C}_{3} \mathrm{H}_{2} \mathrm{O}_{2}^{+}, 2.2,1.9 ; 69, \mathrm{C}_{3} \mathrm{HO}_{2}^{+}, \mathrm{C}_{2} \mathrm{OC}_{2} \mathrm{H}_{5}^{+}$, $3.2 ; 65, \mathrm{C}_{4} \mathrm{HO}^{+}, 1.5 ; 64, \mathrm{C}_{4} \mathrm{O}^{+}, 2.0 ; 63, \mathrm{CFS}^{+}, 71.3 ; 61$, $\left(\mathrm{SC}_{2} \mathrm{H}_{3}+2 \mathrm{H}\right)^{+}, 11.4 ; 59, \mathrm{SC}_{2} \mathrm{H}_{3}{ }^{+}, \mathrm{CH}_{2} \mathrm{OC}_{2} \mathrm{H}_{5}{ }^{+}, 2.3 ; 57, \mathrm{SC}_{2} \mathrm{H}^{+}$, $\mathrm{COC}_{2} \mathrm{H}_{5}{ }^{+}, 4.7 ; 56, \mathrm{SC}_{2}{ }^{+}, \mathrm{COC}_{2} \mathrm{H}_{4}{ }^{+}, 3.6 ; 55, \mathrm{COC}_{2} \mathrm{H}_{3}{ }^{+}, 6.8 ; 54$, $\mathrm{COC}_{2} \mathrm{H}_{2}+1.1$.

Anal.calcd for $\mathrm{C}_{6} \mathrm{H}_{13} \mathrm{~F}_{5} \mathrm{O}_{2} \mathrm{~S}: \mathrm{C}, 29.51 ; \mathrm{H}, 5.37 ; \mathrm{F}, 38.9 ;$ S, 13.13. Found: C, 29.50; H, 5.23; F, 39.0; S, 13.03. 
$\underline{\mathrm{F}}_{5} \mathrm{SCH}_{2} \mathrm{CH}\left(\mathrm{OCH}_{3} \perp_{2}:\right.$

The compound was obtained by a procedure similar to the one for $\mathrm{F}_{5} \mathrm{SCH}_{2} \mathrm{CH}\left(\mathrm{OC}_{2} \mathrm{H}_{5}\right)_{2}$ with methanol.yield: $81.2 \%$. B.p. $83-84^{\circ} \mathrm{C} / 96 \mathrm{~mm} \mathrm{Hg}$.

${ }^{19} \mathrm{~F}$ n.m.r. (neat sample, $\mathrm{CCl}_{3} \mathrm{~F}$ ext.) $: \mathrm{AB}_{4} \phi=83.1 \mathrm{ppm}$, 9 lines, int. $=1.0\left(F_{A}\right) ; \phi=66.5 \mathrm{ppm}, \mathrm{d}-\mathrm{m}$, int. $=4.0$ $\left(F_{B}\right) ; J_{\mathrm{AB}}=144.7 \mathrm{~Hz}$.

I.r. (neat sample, $\mathrm{NaCl}, \mathrm{cm}^{-1}$ ): 2960, Vw; 2945, w; 2847, Vw; 1465, w; 1451, wi 1418, wi 1387, wi 1387, w; 1187, $w-m ; 1126, m ; 1078, m ; 1060, w-m, s h ; 1023, w-m ; 976, w-m$; $879, \mathrm{~m}-\mathrm{s} ; 840$, vs; 817 , vs; $725, \mathrm{w}-\mathrm{m} ; 712, \mathrm{w}-\mathrm{m} ; 641$, w.

\section{$\underline{\mathrm{F}}_{5} \mathrm{SCH}_{2} \mathrm{COOCH}_{3}:$}

To $2.96 \mathrm{~g}$ of $\mathrm{F}_{5} \mathrm{SCH}_{2} \mathrm{CH}\left(\mathrm{OCH}_{3}\right)_{2}(13.7 \mathrm{mmol})$ in a $50 \mathrm{ml}$ round-bottomed flask with a stirring bar $2.96 \mathrm{~g}$ of $\mathrm{m}$ chloroperbenzoic acid $(\approx 85 \%, \approx 14 \mathrm{mmol}$, Aldrich $)$ were added and a reflux condenser was attached. The mixture was heated slowly with stirring to $100^{\circ} \mathrm{C}$ and a homogeneous melt was obtained. After $\approx 2.5 \mathrm{~h}$ the melt was solidified, but after heating overnight $(16 \mathrm{~h})$ it was liquid again. $19 \mathrm{~F}$ n.m.r. indicated the reaction to be incomplete. Another 1.5 $g$ of peracid was added and heating was continued at $96^{\circ} \mathrm{C}$ for $20 \mathrm{~h}$. From the mixture $1.82 \mathrm{~g}$ of crude product was collected by vacuum-condensation. This product was $99 \%$ pure by g.c.. Yield $66.4 \%$. An analytically pure sample was obtained by preparative gas chromatography on a SE-30 column at $100^{\circ} \mathrm{C}$. 
The ester is a clear, colorless pleasant-smelling liquid.

$1_{\mathrm{H}}$ n.m.r. $\left(\mathrm{CDCl}_{3}, \mathrm{Si}\left(\mathrm{CH}_{3}\right)_{4}\right.$ ext. $): \delta=4.58 \mathrm{ppm}, \mathrm{s}$, int. $=3.0\left(\mathrm{CH}_{3}\right) ; \delta=5.08 \mathrm{ppm}, \mathrm{p}$, int. $=2.0\left(\mathrm{CH}_{2}\right) \cdot \mathrm{J}_{\mathrm{HF}}=$ $7.7 \mathrm{~Hz}$.

${ }^{19} \mathrm{~F}$ n.m.r. (neat sample, $\mathrm{CCl}_{3} \mathrm{~F}$ ext.): $\mathrm{AB}_{4} \phi=78.2$ ppm, 9 lines, int. $=1.02\left(\mathrm{~F}_{\mathrm{A}}\right) ; \phi=69.0 \mathrm{ppm}, \mathrm{d}-\mathrm{m}$, int. $=$ $4.00\left(F_{B}\right) \cdot J_{A B}=145.7 \mathrm{~Hz}$.

I.r. (neat, $\mathrm{NaCl}, \mathrm{cm}^{-1}$ ): 3058, w; 3002, w; 2966, w; 2854, Vw; 1757, vs, $(C=0) ; 1441, s ; 1321, s ; 1272, \mathrm{~m} ; 1166$, $\mathrm{s} ; 1009, \mathrm{~m} ; 948, \mathrm{~m} ; 836, \mathrm{vs} ; 787, \mathrm{~m} ; 709, \mathrm{~m} ; 660, \mathrm{~m} ; 611, \mathrm{w}$; 569 , Vw.

Mass spectrum (electron impact, $70 \mathrm{eV}$, mass, species, $\%>1): 181,(\mathrm{M}-\mathrm{F})^{+}, 1.5 ; 180,(\mathrm{M}-\mathrm{HF})^{+}, 1.2 ; 171, \mathrm{C}_{2} \mathrm{H}_{4} \mathrm{~F}_{5} \mathrm{OS}^{+}$, $4.0 ; 170,\left(\mathrm{M}+\mathrm{H}-\mathrm{CH}_{3} \mathrm{O}\right)^{+}, 2.9 ; 169,\left(\mathrm{M}-\mathrm{CH}_{3} \mathrm{O}\right)^{+}, 81.7 ; 168$, (M$\left.\mathrm{CH}_{3} \mathrm{OH}\right)^{+}, 2.1 ; 149,\left(\mathrm{M}-\mathrm{CH}_{3} \mathrm{O}-\mathrm{HF}\right)^{+}, 2.1 ; 131,\left(\mathrm{M}-\mathrm{CH}_{3} \mathrm{O}-2 \mathrm{~F}\right)^{+}$, $2.3 ; 127, \mathrm{SF}_{5}{ }^{+}, 20.8 ; 122, \mathrm{FSCCOOCH}_{3}+, 3.1 ; 119, \mathrm{C}_{3} \mathrm{FO}_{2} \mathrm{~S}^{+}$, $2.2 ; 91, \mathrm{C}_{2} \mathrm{FOS}^{+}, 5.1 ; 89, \mathrm{SF}_{3}{ }^{+}, \mathrm{C}_{2} \mathrm{HO}_{2} \mathrm{~S}^{+}$(two fragments), $100,30.2 ; 74, \mathrm{CH}_{2} \mathrm{COOCH}_{3}{ }^{+}\left({ }^{13} \mathrm{C}\right), 1.7 ; 73, \mathrm{CH}_{2} \mathrm{COOCH}_{3}{ }^{+}\left({ }^{12} \mathrm{C}\right)$, $46.3 ; 72, \mathrm{CH}_{2} \mathrm{COOCH}_{2}{ }^{+}, 11.0 ; 70, \mathrm{SF}_{2}{ }^{+}, 6.8 ; 69, \mathrm{C}_{3} \mathrm{HO}_{2}{ }^{+}, 8.6$; 65, $\mathrm{CH}_{2} \mathrm{FS}^{+}, 3.1 ; 62, \mathrm{CH}_{2} \mathrm{OS}^{+}$(rearr.), 2.7; 61, $\mathrm{CHOS}^{+}$ (rearr.), 64.6; 60, $\mathrm{Cos}^{+}, \mathrm{C}_{2} \mathrm{H}_{4} \mathrm{O}_{2}{ }^{+}, 4.3 ; 59, \mathrm{C}_{2} \mathrm{H}_{3} \mathrm{O}_{2}{ }^{+}, 36.9$; $51, \mathrm{SF}^{+}, \mathrm{H}_{2} \mathrm{SO}^{+}$(two fragments), $2.2,2.1$.

Anal.calcd. for $\mathrm{C}_{3} \mathrm{H}_{5} \mathrm{~F}_{5} \mathrm{O}_{2} \mathrm{~S}: \mathrm{C}, 18.00 ; \mathrm{H}, 2.52 ; \mathrm{F}, 47.5 ;$ S,16.02. Found: C,18.17; H,2.58; F,48.2; S,15.96. 
$\underline{\mathrm{F}}_{5} \underline{\mathrm{SCH}}^{\mathrm{CHBrOAC}) \mathrm{COOC}_{2}} \underline{\mathrm{H}}_{5}$

Into a thoroughly dry $100 \mathrm{ml}$ Pyrex-glass Carius tube that contained a magnetic stirring bar, $10.01 \mathrm{~g}$ of $\mathrm{ACOCH}=\mathrm{CHCOOC}_{2} \mathrm{H}_{5} \quad(63.4 \mathrm{mmol})$ and $45 \mathrm{ml}$ of $\mathrm{CCl}_{3} \mathrm{~F}$ (Dupont, dried over $\mathrm{P}_{4} \mathrm{O}_{10}$ ) was added. The solution was degassed three times by freeze-pump-thaw-freeze cycles, and then $18.15 \mathrm{~g}$ $(87.7 \mathrm{mmol})$ of bromine-free $\mathrm{SF}_{5} \mathrm{Br}$ was added via vacuum transfer. The lower part of the tube (circa $3 \mathrm{~cm}$ ) was immersed in an ice bath, and the solution was stirred and irradiated (GE-250 W sunlamp, $80 \mathrm{~cm}$ distance) for 14 hours. When the volatile materials were condensed into a very dry cold trap, it was found that the residue contained still some olefin, and the volatile materials and an additional $4.36 \mathrm{~g}$ of $\mathrm{SF}_{5} \mathrm{Br}(21.1 \mathrm{mmol})$ were recondensed into the carius tube. Irradiation at ice-temperature was continued for 7.5 hours $(50 \mathrm{~cm}$ distance). A check of the $i . r$. spectrum showed still some olefin to be present, and the volatile materials were recondensed and irradiation was continued for another 10 hours $\left(30 \mathrm{~cm}\right.$ distance) at $0^{\circ} \mathrm{C}$. The solution was by now distinctly yellow and a precipitate had appeared; no more $\mathrm{C}=\mathrm{C}$ bond was detected in the infrared spectrum (the Carius tube was stored between the operations in an ice bath). After vacuum transfer of the volatile materials, $20.5 \mathrm{~g}$ of a lightly brown oil remained behind $($ yield (crude) $=88.7 \%$ ) The ${ }^{19} \mathrm{~F}$ n.m.r. spectrum showed that there was very little of the impurity at $-120-130 \mathrm{ppm}$; when the reaction is not 
carried out a low temperature there is much more of this impurity. Part of this crude product was distilled $(5.01 \mathrm{~g}$, 0.017 torr), and a fraction, boiling range $55-70^{\circ} \mathrm{C}(1.81 \mathrm{~g}$, first fraction, oil bath temperature $100^{\circ} \mathrm{C}$ ), contained some of the C-F impurity ( $\phi-120-130 \mathrm{ppm})$ and showed some enrichment of the $\phi \approx 52 \mathrm{ppm}$ impurity; the second fraction, b.p. $58-61^{\circ} \mathrm{C},\left(1.20 \mathrm{~g}\right.$, oil bath temperature $=90^{\circ} \mathrm{C}$, very slow distillation), a colorless oil, was free of the C-F impurity. There is another contaminant, an $\mathrm{SF}_{5}$ compound $\phi_{\mathrm{B}} \approx$ $52 \mathrm{ppm}$ (2\% integrated intensity), and possibly another contaminant buried under the $\mathrm{B}_{4}$-resonance of the main product (shoulder). The samples were stored in the refrigerator, as they turned yellowish at room temperature within hours. Yield (extrapolated) $\approx 56 \%$

The purity of the second fraction is estimated from ${ }^{19} \mathrm{~F}$ n.m.r. measurement to $98 \%$

$1_{\mathrm{H}}$ n.m.r. spectrum (neat sample, external $\left.\mathrm{Si}\left(\mathrm{CH}_{3}\right)_{4}\right)$ : $\delta_{1}=1.68 \mathrm{ppm}, t$, area $=3.1\left(\mathrm{CH}_{3} \mathrm{CH}_{2}\right) ; \delta_{2}=2.55 \mathrm{ppm}, \mathrm{s}$, area $=3.0\left(\mathrm{CH}_{3} \mathrm{C}(\mathrm{O}) 0\right) ; \delta_{3}=4.74 \mathrm{ppm}$, quartet, area $=2.0$ $\left(\mathrm{CH}_{3} \mathrm{CH}_{2}\right) ; \delta_{4}=5.53 \mathrm{ppm}, \mathrm{d}-\mathrm{p}$, area $\left.=1.0 \quad \underline{\mathrm{h}} \operatorname{coOC}_{2} \mathrm{H}_{5}\right) ; \delta_{5}=$ $7.63 \mathrm{ppm}, \mathrm{d}$, area $=0.9,\left(\mathrm{CH}_{3} \mathrm{C}(\mathrm{O}) \mathrm{OC} \underline{\mathrm{H}}\right) \cdot \mathrm{J}_{13}=7.22 \mathrm{~Hz} ; \mathrm{J}_{45}=$ $10.8 \mathrm{~Hz} ; \mathrm{J} 4 \mathrm{~B}=5.7 \pm 0.2 \mathrm{~Hz}$ (coupling to $\mathrm{SF}_{5}, \mathrm{AB}_{4}$ ). All lines are broadened.

${ }^{19} \mathrm{~F}$ n.m.r. spectrum (neat sample, external $\mathrm{CCl}_{3} \mathrm{~F}$ ) $: \phi_{\mathrm{A}}$ $=79.0 \mathrm{ppm}, 9$ lines, area $=1.0 ; \phi_{\mathrm{B}}=67.3 \mathrm{ppm}, \mathrm{d}-\mathrm{m}$, area $4.0 ; \mathrm{J}_{\mathrm{AB}}=149.7 \mathrm{~Hz}$.

Infrared spectrum (neat sample on $\mathrm{KBr}, \mathrm{cm}^{-1}$ ): 3025 , 
$\mathrm{Vw}, \mathrm{sh} ; 2992$, w; 2945,vw; 1784,s; 1755,s; 1470,w; 1449,w; $1440, \mathrm{w} ; 1373, \mathrm{~m} ; 1354, \mathrm{w} ; 1308, \mathrm{~m} ; 1262, \mathrm{~m} ; 1195, \mathrm{~s} ; 1164$, $\mathrm{m}, \mathrm{sh} ;$ 1116, m, ; 1101, m, sh; 1054, s; 1034, m, sh; 969, vw; $940, \mathrm{vw} ; 890, \mathrm{~s} ; 854$, vrs; $795, \mathrm{~m} ; 735, \mathrm{vw} ; 697, \mathrm{w}, \mathrm{br} ; 671$, wi 665, wi 621, wi 599, mi 570, mi 525, w.

Mass spectrum (e.i., $70 \mathrm{eV}$, mass, species, $\%>1 \%$ ): 285, $(\mathrm{M}-\mathrm{Br})^{+}, 1.7 ; 197,\left(\mathrm{M}-\mathrm{Br}-\mathrm{COOC}_{2} \mathrm{H}_{5}-\mathrm{CH}_{3}\right)^{+}, 2.2 ; 194$, (M$\left.\mathrm{Br}-\mathrm{COOC}_{2} \mathrm{H}_{5}-\mathrm{O}-2 \mathrm{H}\right)^{+}, 1.1 ; 168, \mathrm{~F}_{5} \mathrm{SCHCO}^{+}, 1.3 ; 166, \mathrm{C}_{3} \mathrm{H}_{3} \mathrm{~F}_{5} \mathrm{~S}^{+}$, $2.2 ; 149, \mathrm{C}_{2} \mathrm{HF}_{4} \mathrm{OS}^{+}, 7.1 ; 146, \mathrm{C}_{5} \mathrm{H}_{3} \mathrm{FO}_{2} \mathrm{~S}^{+}, 1.9 ; 127, \mathrm{SF}_{5}^{+}$, $1.4 ; 89, \mathrm{SF}_{3}^{+}, 6.7 ; 88, \mathrm{C}_{2} \mathrm{O}_{2} \mathrm{~S}^{+}, \mathrm{C}_{3} \mathrm{HFS}^{+}, 1.0 ; 87, \mathrm{C}_{3} \mathrm{FS}^{+}, 3.1$; $73, \mathrm{C}_{3} \mathrm{H}_{5} \mathrm{O}_{2}{ }^{+}, 1.1 ; 71, \mathrm{C}_{3} \mathrm{H}_{3} \mathrm{O}_{2}{ }^{+}, 5.1 ; 70, \mathrm{SF}_{2}{ }^{+}, \mathrm{C}_{3} \mathrm{H}_{2} \mathrm{O}_{2}{ }^{+}, 1.9$; $69, \mathrm{C}_{3} \mathrm{HO}_{2}+, 3.2 ; 45, \mathrm{C}_{2} \mathrm{H}_{5} \mathrm{O}^{+}, 3.8 ; 44, \mathrm{C}_{2} \mathrm{H}_{4} \mathrm{O}^{+}, 3.9 ; 43$, $\mathrm{CH}_{3} \mathrm{CO}^{+}, \mathrm{C}_{2} \mathrm{H}_{3} \mathrm{O}^{+}, 100.0$.

Anal.calcd for $\mathrm{C}_{7} \mathrm{H}_{10} \mathrm{BrF}_{5} \mathrm{O}_{4} \mathrm{~S}: \mathrm{C}, 23.03 ; \mathrm{H}, 2.76 ; \mathrm{Br}$, $21.88 ; \mathrm{F}, 26.0$. Found: $\mathrm{C}, 22.77 ; \mathrm{H}, 2.67 ; \mathrm{Br}, 22.21 ; \mathrm{F}, 25.4$.

\section{Acidic Hydrolysis of $\mathrm{F}_{5} \mathrm{SCH}_{2} \mathrm{CHClOAC:}$}

The adduct $\mathrm{F}_{5} \mathrm{SCH}_{2} \mathrm{CHClOAC}(3.02 \mathrm{~g}, 12.2 \mathrm{mmol})$ was stirred vigorously with $5 \mathrm{ml}$ of concentrated $\mathrm{HCl}$ in a $50 \mathrm{ml}$ round bottomed flassk with a short reflux condenser at 70$73^{\circ} \mathrm{C}$ for 6 hours. The product $(0.96 \mathrm{~g}, 46.5 \%)$ contained only a small amount of acetic acid and had only a weak oH band, but was otherwise identical with $\mathrm{F}_{5} \mathrm{SCH}_{2} \mathrm{CHO}$ (i.r.spectrum). The product was not further purified. 


\section{$\mathrm{F}_{5} \mathrm{SCH}_{2} \mathrm{CH}\left(\mathrm{OCH}_{3}\right) \mathrm{OC}(\mathrm{O}) \mathrm{CH}_{3}:$}

To $7.92 \mathrm{~g}$ of $\mathrm{F}_{5} \mathrm{SCH}_{2} \mathrm{CHClOC}(0) \mathrm{CH}_{3}(31.9 \mathrm{mmol})$ in $10 \mathrm{ml}$ of anhydrous $\mathrm{CH}_{3} \mathrm{OH}$, kept in a $100 \mathrm{ml}$ round bottomed flask, equipped with magnetic stirring bar, claisen head,| Drierite tube and dropping funnel, was added $2.15 \mathrm{~g}$ of $185 \% \mathrm{KOH}$, dissolved in $10 \mathrm{ml}$ anhydrous methanol (32.6 mmol) A slight excess is necessary because the starting material and the product cannot be separated by distillation when the reaction is not complete. The base solution was added within 20 minutes at $-78^{\circ} \mathrm{C}$, and the solution was then brought slowly to room temperature. The methanol was distilled off at atmospheric pressure. A small amount of water, was then added and the precipitate was removed $(5.50 \mathrm{~g})$. Nol starting material was present. Distillation (3-4 torr, $\left.30-37^{\circ} \mathrm{C}\right)$ gave $1.58 \mathrm{~g}$ of $\left.\left.\mathrm{F}_{5} \mathrm{SCH}_{2} \mathrm{CH}\right) \mathrm{OCH}_{3}\right) \mathrm{OC}(\mathrm{O}) \mathrm{CH}_{3}$. The contents of the cold trap $\left(-196^{\circ} \mathrm{C}\right)$ were distilled to give $2.85 \mathrm{~g}$ of a mixture $\left(\mathrm{F}_{5} \mathrm{SCH}_{2} \mathrm{CH}(\mathrm{OH})_{2}+\mathrm{F}_{5} \mathrm{SCH}_{2} \mathrm{CHO}\right)$. Yield $\approx 45 \%$, and some $\left.\left.\mathrm{F}_{5} \mathrm{SCH}_{2} \mathrm{CH}\right) \mathrm{OCH}_{3}\right) \mathrm{OC}(\mathrm{O}) \mathrm{CH}_{3}(0.36 \mathrm{~g})$. Yield $=(1.58+0.36) \mathrm{g}=$ $1.94 \mathrm{~g}(24.8 \%)$. An analytically pure sample was obtained by preparative g.c. on a Carbowax (20 \%) column, $3 \mathrm{ft}, 100{ }^{\circ} \mathrm{C}$, $1 \mathrm{ml} \mathrm{He} / \mathrm{sec}$.

$$
\begin{aligned}
& l_{\mathrm{H}} \text { n.m.r. spectrum }\left(\mathrm{CDCl}_{3}, \mathrm{Si}\left(\mathrm{CH}_{3}\right)_{4} \text { ext. }\right): \delta_{1}=2.65 \\
& \text { ppm, s, } 1.00 \mathrm{H}\left(\mathrm{OCH}_{3}\right) ; \delta_{2}=4.03 \mathrm{ppm}, \mathrm{s}, 1.00 \mathrm{H},\left(\mathrm{C}(0) \mathrm{CH}_{3}\right) ; \\
& \delta_{3}=4.37 \mathrm{ppm}, \mathrm{d}-\mathrm{p}, 2.07 \mathrm{H},\left(\mathrm{SF}_{5} \mathrm{CH}_{2}\right) ; \phi_{4}=6.70 \mathrm{ppm}, t, 0.98 \\
& \mathrm{H},(\mathrm{CH}) . \\
& J_{\mathrm{CH} 2-\mathrm{B}}=8.23 \mathrm{~Hz} ; J_{\mathrm{H}-\mathrm{H}}=5.13 \mathrm{~Hz} .
\end{aligned}
$$


${ }^{19} \mathrm{~F}$ n.m.r. spectrum $\left(\mathrm{CDCl}_{3}\right.$, external $\left.\mathrm{CCl}_{3} \mathrm{~F}\right): \mathrm{AB}_{4}$ system, $\phi_{\mathrm{A}}=83.67 \mathrm{ppm}, 9$ lines, $1.07 \mathrm{~F} ; \phi_{\mathrm{B}}=68.79 \mathrm{ppm}, \mathrm{d}-$ $\mathrm{m}, 4.00 \mathrm{~F} \cdot \mathrm{J}_{\mathrm{AB}}=147.4 \mathrm{~Hz}$.

Infrared spectrum (neat sample, $\mathrm{KBr}, \mathrm{cm}^{-1}$ ): 3041 , Vw; 3013, vw; 2973, w; 2948, wi 2858, wi 1755, s; 1453, w-m; $1420, \mathrm{w}-\mathrm{m} ; 1377, \mathrm{~m} ; 1360, \mathrm{w}, \mathrm{sh} ; 1300, \mathrm{vw} ; 1255, \mathrm{~m}, \mathrm{sh} ; 1230$, $\mathrm{s} ; 1190, \mathrm{~m}-\mathrm{s} ; 1142, \mathrm{~m} ; 1128, \mathrm{~m} ; 1083, \mathrm{~m}, \mathrm{sh} ; 1078, \mathrm{~m} ; 1050$, $\mathrm{m} ;$ 1014, s; $992, \mathrm{~m} ; 941, \mathrm{~m}, \mathrm{broad} ; 879, \mathrm{~s} ; 842$, vs; 824 , svs; 714, w-m; 655, w, sh; 641, m; 604, m; 581, wi 564, w-m; 558, w-m; 549, w, sh; 581, vw; 566, w; 557, w; 550, vw.

Mass spectrum (e.i., mass, species, $\%>1$ ): 185, (M$\left.\mathrm{CH}_{3} \mathrm{COO}\right)^{+}, 90.7$ (+ peaks at 187 (3.8) and $186(4.9), \mathrm{S}+\mathrm{C}$ isotope peaks); $184,\left(\mathrm{M}-\mathrm{CH}_{3} \mathrm{COOH}\right)^{+}, 19.7 ; 169,\left(\mathrm{M}-\mathrm{CH}_{3} \mathrm{COOH}-\right.$ $\left.\mathrm{CH}_{3}\right)^{+}, 1.6 ; 165,\left(\mathrm{M}-\mathrm{CH}_{3} \mathrm{COO}-\mathrm{HF}\right)^{+}, 12.3 ; 163,\left(\mathrm{M}-\mathrm{CH}_{3} \mathrm{O}-\mathrm{CH}_{3}-\mathrm{O}-\right.$ $\mathrm{F})^{+}, 3.0 ; 153,\left(\mathrm{M}-\mathrm{CH}_{3} \mathrm{COOH}-\mathrm{CH}_{3} \mathrm{O}\right)^{+}, 5.3 ; 149$, $\left(\mathrm{M}-\mathrm{CH}_{3} \mathrm{COOH}-\mathrm{CH}_{3}-\right.$ $\mathrm{HF})^{+}, 2.3 ; 127, \mathrm{SF}_{5}{ }^{+}, 12.0 ; 122, \mathrm{C}_{3} \mathrm{~F}_{2} \mathrm{OS}^{+}, 3.4 ; 103, \mathrm{C}_{4} \mathrm{H}_{7} \mathrm{O}_{3}{ }^{+}$, $1.4 ; 101, \mathrm{C}_{4} \mathrm{H}_{5} \mathrm{O}_{3}+, 2.5 ; 96, \mathrm{~F}_{2} \mathrm{SC}_{2} \mathrm{H}_{2}{ }^{+}, 1.1 ; 91, \mathrm{FSCCO}^{+}, 1.9$; 89, $\mathrm{SF}_{3}{ }^{+}, 43.6 ; 87, \mathrm{C}_{3} \mathrm{H}_{3} \mathrm{O}_{3}{ }^{+}, 2.3 ; 83, \mathrm{C}_{4} \mathrm{H}_{3} \mathrm{O}_{2}{ }^{+}, \mathrm{F}_{2} \mathrm{SCH}^{+}, 1.3 ;$ $81, \mathrm{C}_{4} \mathrm{HO}_{2}^{+}, 1.9 ; 78, \mathrm{C}_{2} \mathrm{H}_{3} \mathrm{FS}^{+}, 3.7 ; 77, \mathrm{C}_{2} \mathrm{H}_{2} \mathrm{FS}^{+}, 74.5 ; 76$, $\mathrm{C}_{2} \mathrm{HFS}^{+}, 11.9 ; 75, \mathrm{C}_{2} \mathrm{H}_{3} \mathrm{OS}^{+}, \mathrm{C}_{2} \mathrm{FS}^{+}, 8.7 ; 74, \mathrm{C}_{2} \mathrm{H}_{2} \mathrm{OS}^{+}, 7.6 ; 73$, $\mathrm{C}_{2} \mathrm{HOS}^{+}, 3.3 ; 70, \mathrm{C}_{3} \mathrm{H}_{2} \mathrm{O}_{2}{ }^{+}, \mathrm{SF}_{2}{ }^{+}, 6.2 ; 69, \mathrm{C}_{3} \mathrm{HO}_{2}{ }^{+}, 1.1 ; 65$, $\mathrm{CH}_{2} \mathrm{FS}^{+}, 3.9 ; 64, \mathrm{CHFS}^{+}, 1.0 ; 63, \mathrm{CFS}^{+}, 100.0 ; 61$, $\left(\mathrm{CH}_{3} \mathrm{OCHO} \cdot \mathrm{H}\right)^{+}, 13.2 ; 60, \mathrm{CH}_{3} \mathrm{COOH}^{+}, 18.5 ; 59, \mathrm{CH}_{3} \mathrm{COO}^{+}, 1.2$; $58, \mathrm{CH}_{2} \mathrm{COO}^{+}, 17.0 ; 57, \mathrm{CHCOO}^{+}, 17.2$.

Anal.calcd for $\mathrm{C}_{5} \mathrm{H}_{9} \mathrm{~F}_{5} \mathrm{O}_{3} \mathrm{~S}: \mathrm{C}, 24.59 ; \mathrm{H}, 3.72 ; \mathrm{F} .38 .9$; S, 13.13. Found: C, 24.66; H, 3.75; F, 39.4; S, 13.24 . 
$\underline{\mathrm{F}}_{5} \mathrm{SCHBrCH}_{2} \mathrm{OCH}_{3}:$

Sodium $(0.67 \mathrm{~g}, 29.1 \mathrm{mmol})$ was dissolved in $11.5 \mathrm{ml}$ of anhydrous methanol in a $50 \mathrm{ml}$ pear-shaped flask. To this solution $5.86 \mathrm{~g}$ of $\mathrm{SF}_{5} \mathrm{CBr}=\mathrm{CH}_{2}(25.2 \mathrm{ml})$ were added dropwise (1 minute, dropping funnel) with (magnetic) stirring. The dropping funnel was replaced by a Drierite tube. After $\approx 10$ minutes, the mixture turned yellow and became warm. The ${ }^{19} \mathrm{~F}$ n.m.r. spectrum showed that the reaction was only $\approx 95 \%$ complete after $24 \mathrm{~h}$ at room temperature. After 20 more hours of stirring at room temperature, $10 \mathrm{ml}$ of $4 \mathrm{~m} \mathrm{HCl}$ was added dropwise. A thick precipitate appeared that changeed quickly to an oil. The oily lower layer was removed $(4.69 \mathrm{~g})$, and the remaining phase was extracted ( $\left.3 \times \mathrm{ml}_{2} \mathrm{CH}_{2} \mathrm{Cl}_{2}\right)$, the extracts were combined with the first obtained oil, and the $\mathrm{CH}_{2} \mathrm{Cl}_{2}$ was then distilled off at atmospheric pressure through a $12 \mathrm{~cm}$ Vigreux column. Distillation of the residue at $39-42^{\circ} \mathrm{C}$ (9 torr) yielded $3.98 \mathrm{~g}(59.7 \%$ ) of product. A sample for analysis was obtained in at $41-42^{\circ} \mathrm{C}$. The pot residue $(0.79 \mathrm{~g})$ had the same i.r.spectrum as the main product.

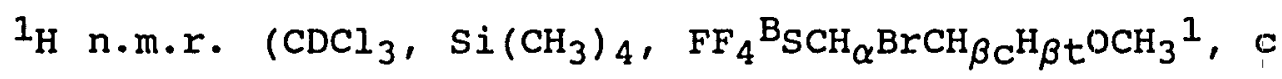

$$
\begin{aligned}
& =\text { cis, } t=\text { trans }): \delta_{1}=4.00 \mathrm{ppm}, s, 3.10 \mathrm{H}\left(\mathrm{CH}_{3}\right) ; \delta_{\beta}=4.55 \\
& \text { ppm (center), } \mathrm{m}, 2.07 \mathrm{H},\left(\mathrm{CH}_{2}\right) ; \delta_{\alpha}=6.10 \mathrm{ppm} \text {, septet, } 1.00 \\
& \mathrm{H},(\mathrm{CHBr}) \cdot \mathrm{J}_{\mathrm{CH} \alpha-\mathrm{B}}=5.75 \mathrm{~Hz} ; \mathrm{J}_{\mathrm{H} \alpha-\mathrm{H} \beta \mathrm{t}}=11.50 \mathrm{~Hz} ; \mathrm{J}_{\mathrm{H} \alpha-\mathrm{H} \beta \mathrm{C}}=0 \\
& \mathrm{~Hz} ; \mathrm{J}_{\mathrm{H} \beta \mathrm{C}-\mathrm{H} \beta \mathrm{t}}=- \text {. } \\
& { }^{19} \mathrm{~F} \text { n.m.r. (neat sample, } \mathrm{CCl}_{3} \mathrm{~F} \text { external): } \mathrm{AB}_{4} \text {-system); }
\end{aligned}
$$


$\phi_{\mathrm{A}}=78.67 \mathrm{ppm}, 9$ lines, $1.0 \mathrm{~F} ; \phi_{\mathrm{B}}=57.22 \mathrm{ppm}, \mathrm{d}-\mathrm{m}, 3.8 \mathrm{~F}$; $J_{\mathrm{AB}}=146.6 \mathrm{~Hz}$.

Infrared spectrum (neat sample, $\mathrm{KBr}, \mathrm{cm}^{-1}$ ): 3004, w; 2942, wi 2901,w,sh; 2840, wi 1471, w; 1458, wi 1389, w; 1298. vw,br; 1263, vw; 1210, w, sh; 1196, w; 1127, m; 1110, $\mathrm{w}-\mathrm{m}, \mathrm{sh} ;$ 1075, w; 1054, w; 965, w; 936, vw; 923, vw; 842, vs; 766, w, br; 713,w-m; 663, sh,w; 654,w-m; 597, m; 587, wi 571, wi 551, wi 528, vw; 511, vw.

Mass spectrum (c.i., mass, species, $\%$ 1): (for $\mathrm{Br}-$ fragments only listing of ${ }^{79} \mathrm{Br}$ ) $\left.233, \mathrm{M}-\mathrm{CH}_{3} \mathrm{O}\right)^{+}, 1.7$; 185, (M$\mathrm{Br})^{+}, 3.6 ; 165,(\mathrm{M}-\mathrm{Br}-\mathrm{HF})^{+}, 2.2 ; 139,\left(\mathrm{M}-\mathrm{HBr}-\mathrm{CH}_{3} \mathrm{OCH}_{2}\right)^{+}$, $95.7 ; 138, \mathrm{C}_{2} \mathrm{H}_{3}{ }^{79} \mathrm{BrS}^{+}, 4.4 ; 135,\left(\mathrm{M}-\mathrm{Br}^{-} \mathrm{CH}_{3} \mathrm{O}-\mathrm{F}\right)^{+}, 1.8 ; 127$, $\mathrm{SF}_{5}{ }^{+}, 6.5 ; 125,(\mathrm{M}-\mathrm{Br}-3 \mathrm{HF})^{+}, 5.5 ; 123$, $(\mathrm{M}-\mathrm{Br}-3 \mathrm{HF}-2 \mathrm{H})^{+}, 1.2$; 109, $\left(\mathrm{M}+\mathrm{H}-\mathrm{Br}-3 \mathrm{HF}-\mathrm{CH}_{3}\right)^{+}, 1.7 ; 108, \mathrm{SF}_{4}{ }^{+}, 2.4 ; 107, \mathrm{FSC}_{3} \mathrm{H}_{4} \mathrm{O}^{+}$, $3.5 ; 106, \mathrm{FSC}_{3} \mathrm{H}_{3} \mathrm{O}^{+}, 2.2 ; 105, \mathrm{FSC}_{3} \mathrm{H}_{2} \mathrm{O}^{+}, 2.8 ; 101, \mathrm{CSF}_{3}{ }^{+}$, $4.0 ; 95, \mathrm{C}_{2} \mathrm{H}_{4} \mathrm{FOS}^{+}, 3.5 ; 94, \mathrm{C}_{2} \mathrm{H}_{3} \mathrm{FOS}^{+}, 1.3 ; 93, \mathrm{C}_{2} \mathrm{H}_{2} \mathrm{FOS}^{+}$, $3.3 ; 91, \mathrm{C}_{2} \mathrm{FOS}^{+}, 1.1 ; 89, \mathrm{SF}_{3}{ }^{+}, 21.9 ; 87, \mathrm{SC}_{2} \mathrm{OCH}_{3}^{+}, 1.7 ; 79$, $\mathrm{FSC}_{2} \mathrm{H}_{4}{ }^{+}, 1.5 ; 77, \mathrm{FSC}_{2} \mathrm{H}_{2}{ }^{+}, 7.9 ; 76, \mathrm{FSC}_{2} \mathrm{H}^{+}, 1.3 ; 75, \mathrm{FSC}_{2}{ }^{+}$, $3.9 ; 70, \mathrm{SF}_{2}+, 2.8 ; 69, \mathrm{CF}_{3}{ }^{+}, 1.5 ; 67, \mathrm{FOS}^{+}$(rearr.), 1.4; 63, FSC $^{+}, 6.1 ; 61$, CHOS $^{+}$, (rearr.), 1.7; 59, $\mathrm{C}_{2} \mathrm{H}_{3} \mathrm{~S}^{+}, 4.2$; 58, $\mathrm{C}_{2} \mathrm{H}_{2} \mathrm{~S}^{+}, 11.9 ; 57, \mathrm{C}_{2} \mathrm{HS}^{+}, 2.4 ; 56, \mathrm{C}_{2} \mathrm{~S}^{+}, 1.9 ; 55$, $\mathrm{C}_{3} \mathrm{H}_{3} \mathrm{O}^{+}, \mathrm{C}_{3} \mathrm{~F}^{+}, 3.1$ and 1.9 .

Anal.calcd for $\mathrm{C}_{3} \mathrm{H}_{6} \mathrm{BrF}_{5} \mathrm{OS}: \mathrm{C}, 13.59 ; \mathrm{H}, 2.28 ; \mathrm{Br}$, $30.15 ; \mathrm{F}, 35.8 ; \mathrm{S}, 12.10$. Found: C, 13.73; H, 2.33; $\mathrm{Br}$, $30.04 ; F, 35.5 ; S, 12.05$. 


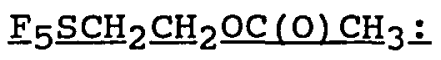

A mixture of $3.34 \mathrm{~g}$ silver acetate $(19.8 \mathrm{mmol}), 10 \mathrm{ml}$ of glacial acetic acid and $4 \mathrm{~g}$ of $\mathrm{F}_{5} \mathrm{SCH}_{2} \mathrm{CH}_{2} \mathrm{Br}(17.0 \mathrm{mmol}$ ) was refluxed in a $25 \mathrm{ml}$ round bottomed flask, while being magnetically stirred, for $36 \mathrm{~h}$. A Drierite tube was fitted to the top of the reflux condenser. The insoluble salt was filtered off and rinsed with $10 \mathrm{ml}$ of diethyl ether. Water was added to the filtrate, and the bottom layer was separated and neutralized with $\mathrm{NaHCO}_{3}$. Extraction of the aqueous phase with ether $(3 \times 10 \mathrm{ml})$, combining the extracts with the original ether layer, adding $5 \mathrm{ml}$ of water and small amounts of solid $\mathrm{NaHCO}_{3}$ until bubbling ceased completely, removing the top layer (separatory funnel), drying $\left(\mathrm{MgSO}_{4}\right)$ and distilling the product at atmosheric pressure resulted 4 cuts, of which the first two $\left(-48^{\circ} \mathrm{C}\right)$ were ether (g.c.), and the cuts from $48-98^{\circ} \mathrm{C}$, and from $98-$ $112^{\circ} \mathrm{C}$, as well as the pot residue showed two bands in g.C. $\left(R_{f}=13.3 \mathrm{~min}=\mathrm{F}_{5} \mathrm{SCH}_{2} \mathrm{CH}_{2} \mathrm{OC}(0) \mathrm{CH}_{3}\right), 61 \% ; R_{\mathrm{f}}=5.4 \mathrm{~min}=$ $\mathrm{F}_{5} \mathrm{SCH}_{2} \mathrm{CH}_{2} \mathrm{Br}(39 \%)$, Carbowax, $\left.20 \%, 1 \mathrm{~m}, 90^{\circ} \mathrm{C}\right)$. A total of $1.58 \mathrm{~g}$ of product was obtained. A sample for analysis was obtained with preparative gas chromatography (20\% Carbowax, $\left.1 \mathrm{~m}, 90^{\circ} \mathrm{C}\right)$. The compound is a colorless liquid with a pleasant odor.

${ }^{1} \mathrm{H}$ n.m.r. spectrum $\left(\mathrm{CDCl}_{3}\right.$, external $\left.\mathrm{Si}\left(\mathrm{CH}_{3}\right)_{4}\right): \delta_{1}=$ $2.56 \mathrm{ppm}, \mathrm{S}, 3.00 \mathrm{H}\left(\mathrm{CH}_{3}\right) ; \delta_{2}=4.40 \mathrm{ppm}, \mathrm{m}(\approx$ sextet $)$, $1.96 \mathrm{H}\left(\mathrm{SF}_{5} \mathrm{CH}_{2}\right) ; \delta_{3}=4.98 \mathrm{ppm}, 1.92 \mathrm{H}\left(\mathrm{SF}_{5} \mathrm{CH}_{2} \mathrm{CH}_{2}\right) ; \mathrm{J}_{23}=$ 
$5.7 \mathrm{~Hz} ; \mathrm{J}_{2 \mathrm{~B}} \approx 7.3 \mathrm{~Hz}$ ( $\mathrm{B}$ refers to the $\mathrm{AB}_{4}$ system of $\mathrm{SF}_{5}$ ).

${ }^{19} \mathrm{~F}$ n.m.r.spectrum $\left(\mathrm{CDCl}_{3}, \mathrm{CCl}_{3} \mathrm{~F}\right.$ external reference): $\mathrm{AB}_{4}$ system, $\phi_{\mathrm{A}}=83.57 \mathrm{ppm}, 9$ lines, $1.00 \mathrm{~F} ; \phi_{\mathrm{B}}=66.57 \mathrm{ppm}$, $\mathrm{d}-\mathrm{m}, 3.94 \mathrm{~F} ; \mathrm{J}_{\mathrm{AB}}=144.2 \mathrm{~Hz}$.

I.r.spectrum (neat sample, $\mathrm{KBr}, \mathrm{cm}^{-1}$ ): 3039, vw; 2966, vw, br; 2930, w; 2858, wi 1750, s; 1465, w; 1449, w; 1421, w; 1393, w; 1370, w-m; 1334, vw; 1283, w, sh; 1240, m-s; 1134, w, sh; 1082, w-m; 1052, m-s; 979, w; 947, vw; 835, vs; $816, \mathrm{~s} ; 751, \mathrm{vw}$, br; $711, \mathrm{vw}$, br; 672, vw; 639, w; 605, w; 587 , wi 566, w; 522, w; 534, vw; 520, vw; 493, w.

Mass spectrum (c.i., mass, fragment, $\%$ 1): 215, $(\mathrm{M}+\mathrm{H})^{+}, 2.2 ; 195,(\mathrm{M}+\mathrm{H}-\mathrm{HF})^{+}, 4.6 ; 155, \mathrm{~F}_{5} \mathrm{SCH}_{2} \mathrm{CH}_{2}{ }^{+}, 1.1 ; 153$ ， $\mathrm{F}_{5} \mathrm{SC}_{2} \mathrm{H}_{2}{ }^{+}, \quad 1.4 ; \quad 135, \mathrm{C}_{2} \mathrm{H}_{3} \mathrm{~F}_{4} \mathrm{~S}^{+}, 23.1 ; 133, \mathrm{C}_{2} \mathrm{HF}_{4} \mathrm{~S}^{+}$， $\mathrm{F}_{3} \mathrm{SCH}_{2} \mathrm{CH}_{2} \mathrm{O}^{+}, 100.0 ; 127, \mathrm{SF}_{5}{ }^{+}, 8.7 ; 122, \mathrm{~F}_{4} \mathrm{SCH}_{2}{ }^{+}, 2.4 ; 109$, $\mathrm{HSF}_{4}{ }^{+}, 1.4 ; 97, \mathrm{C}_{2} \mathrm{H}_{3} \mathrm{~F}_{2} \mathrm{~S}^{+}, 1.6 ; 91, \mathrm{C}_{2} \mathrm{FOS}^{+}, 2.4 ; 89, \mathrm{SF}_{3}{ }^{+}$, $51.9 ; 87, \mathrm{C}_{2} \mathrm{H}_{4} \mathrm{OC}(0) \mathrm{CH}_{3}{ }^{+}, 100 ; 86, \mathrm{C}_{2} \mathrm{H}_{3} \mathrm{OC}(0) \mathrm{CH}_{3}{ }^{+} ; 4.7 ; 75$, $\mathrm{C}_{2} \mathrm{H}_{3} \mathrm{OS}^{+}, 15.6 ; 73, \mathrm{C}_{2} \mathrm{HOS}^{+}, 1.2 ; 70, \mathrm{SF}_{2}^{+}, 5.0 ; 67, \mathrm{C}_{4} \mathrm{H}_{3} \mathrm{O}^{+}$, $1.7 ; 65, \mathrm{C}_{4} \mathrm{HO}^{+}, 1.4 ; 63, \mathrm{CFS}^{+}, 1.9 ; 61, \mathrm{C}_{2} \mathrm{H}_{5} \mathrm{~S}^{+}, 24.0 ; 59$, $\mathrm{CH}_{3} \mathrm{COO}^{+}, 1.5 ; 57, \mathrm{CHCOO}^{+}, 1.4 ; 55, \mathrm{C}_{3} \mathrm{H}_{3} \mathrm{O}^{+}, 1.5$.

Anal.calcd for $\mathrm{C}_{4} \mathrm{H}_{7} \mathrm{~F}_{5} \mathrm{O}_{2} \mathrm{~S}: \mathrm{C}, 22.43 ; \mathrm{H}, 3.29 ; \mathrm{F}, 44.4$; S, 14.97. Found: C, 22.72; H, 3.32; F, 44.0; S, 14.91.

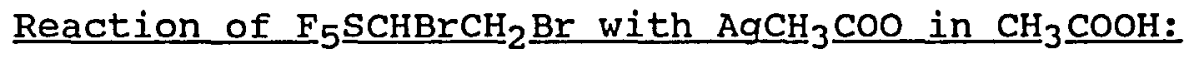

A mixture of $4.81 \mathrm{~g}$ of $\mathrm{F}_{5} \mathrm{SCHBrCH}_{2} \mathrm{Br}(15.3 \mathrm{mmol}), 5.30$ $\mathrm{g}$ of $\mathrm{AgCH}_{3} \mathrm{COO}(28.5 \mathrm{mmol})$ and $15 \mathrm{ml}$ of glacial acetic acid in a $50 \mathrm{ml}$ round bottomed flask, fitted with a short reflux 
column and a Drierite tube, was refluxed for 4 days at an oil bath temperature of $120-130^{\circ} \mathrm{C}$. A ${ }^{19} \mathrm{~F}$ n.m.r. spectrum taken after 3 days of refluxing showed the presence of three $\mathrm{SF}_{5}$ compounds, one of them being the starting material. The volatile materials were vacuum transferred out, $10 \mathrm{ml}$ of water was added, and the precipitated liquid $(2.79 \mathrm{~g})$ was separated. Gas chromatography showed that only little $\mathrm{CH}_{3} \mathrm{COOH}$ was present. The product had a faint ester-like odor, but a sample of the main product, as collected by preparative g.C. $\left(30 \% \mathrm{SE}-30,140^{\circ} \mathrm{C}, 3 \mathrm{~m}\right)$, was identical with the compound $\mathrm{SF}_{5} \mathrm{CBr}=\mathrm{CH}_{2}$, as shown by infrared spectrocscopy. Yield $=72 \%$.

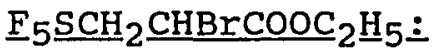

Crude $\mathrm{SF}_{5} \mathrm{Br}(41.42 \mathrm{~g}, 200.1$ nimoles) was transferred to a $75 \mathrm{ml}$ steel vessel held at $-196^{\circ} \mathrm{K}$, then $19.78 \mathrm{~g}(197.8$ mmol) of ethyl acrylate, dried over $\mathrm{MgSO}_{4}$, were condensed in at the same temperature and the vessel was allowed to attain slowly room temperature. When the vessel had reached (10$15)^{\circ} \mathrm{C}$, it was noticed that the temperature climbed rapidly to about $50{ }^{\circ} \mathrm{C}$, whence it dropped slowly to room temperature. The vessel was kept at room temperature for $2 \mathrm{~h}$, then warmed to $55^{\circ} \mathrm{C}$ for $19 \mathrm{~h}$. The contents of the vessel were then condensed out (58.93g). From the vessel $4.72 \mathrm{~g}$ of a viscous liquid could also be poured out; the reaction had been run in the same vessel before, without noticing the 
non-volatile oil, total mass balance $=104 \%$. The combined products from the bomb were distilled with a $12 \mathrm{~cm}$ Vigreux column (3 torr), yielding one fraction, $21.55 \mathrm{~g}$, at (66.5$67.8)^{\circ} \mathrm{C}$. Upon raising the temperature the residue turned yellow; the pressure was lowered to $0.005-0.020$ torr (dynamic vacuum) and $3.07 \mathrm{~g}$ of a fraction boiling $>110^{\circ} \mathrm{C}$ (out of thermometer range) was collected. The cold trap contained $1.08 \mathrm{~g}$ of material, which was mainly ethyl acrylate (1H n.m.r.). Yield $=35.5 \%$ of theory.

$1_{\mathrm{H}}$ n.m.r.spectrum (neat sample, external $\left.\mathrm{Si}\left(\mathrm{CH}_{3}\right)_{4}\right): \delta$ $=1.33 \mathrm{ppm}, \mathrm{t},\left(\mathrm{CH}_{3}\right)$, relative area $=3.00 \mathrm{H} ; \delta=4.30 \mathrm{ppm}$, $\left(\mathrm{CH}_{3} \underline{\mathrm{C}}_{2}\right), J=7.2 \mathrm{~Hz} ; \delta=3.6-5.0 \mathrm{ppm}, \mathrm{m}\left(\mathrm{SF}_{5} \mathrm{CH}_{2} \mathrm{CH}+\right.$ $\mathrm{CH}_{3} \mathrm{CH}_{2}$ ), total area (quartet + multiplet) $=5.04$ (theoretially 5.00).

${ }^{19} \mathrm{~F}$ n.m.r.spectrum $\left(\mathrm{CHCl}_{3}\right.$, external $\left.\mathrm{CFCl}_{3}\right): \mathrm{AB}_{4}$ spectrum, $\delta_{A}=81.49 \mathrm{ppm}, \delta_{\mathrm{B}}=65.83 \mathrm{ppm}, \mathrm{d}-\mathrm{m} ; \mathrm{J}_{\mathrm{AB}}=147.4$ $\mathrm{Hz}$. Neat sample: $\delta_{A}=81.00 \mathrm{ppm}, \delta_{B}=65.17 \mathrm{ppm}$.

I.r.spectrum (neat sample on $\mathrm{KBr}$ plates, $\mathrm{cm}^{-1}$ ): 3042 , W; 2988, W-m; 2946, w-Vw; 2912, vw; 2881, vw; 1750, vs; $1477, \mathrm{w}, \mathrm{sh} ; 1469, \mathrm{w}-\mathrm{m} ; 1456, \mathrm{w}-\mathrm{m} ; 1417, \mathrm{~m} ; 1398, \mathrm{~m} ; 1378 \mathrm{~m}-$ $\mathrm{s} ; 1356, \mathrm{~m} ; 1311, \mathrm{~m}-\mathrm{s} ; 1262, \mathrm{~m}-\mathrm{s} ; 1241, \mathrm{~s} ; 1206, \mathrm{w}, \mathrm{sh} ; 1187$, m-s; 1158, m-s; 1116, w,sh; 1097, wi 1089, w,sh; 1034, m; 1018, m; 988, m; 965, w-vw; 926, w; 877, s-vs; 851, vs; 832 , vs; $802, \mathrm{~m}-\mathrm{s} ; 740, \mathrm{w}, \mathrm{br} ; 698$, vw; 673, vw; 648, vw; 623, vw; $602, \mathrm{~m} ; 577, \mathrm{~s} ; 564, \mathrm{~m} ; 481, \mathrm{w}$. Mass spectrum (e.i., $70 \mathrm{eV}$, mass, fragment, $\%>1$ ): 
179, $\mathrm{C}_{5} \mathrm{H}_{7} \mathrm{BrO}_{2}{ }^{+}, 6.3 ;$ 155, $\mathrm{SF}_{5} \mathrm{C}_{2} \mathrm{H}_{4}{ }^{+}, 18.6 ; 153, \mathrm{SF}_{5} \mathrm{C}_{2} \mathrm{H}_{2}{ }^{+}$, $28.1 ; 151, \mathrm{~S}_{5} \mathrm{C}_{2}{ }^{+}, 2.1 ; 135, \mathrm{C}_{2}{ }^{79} \mathrm{BrO}_{2}{ }^{+}, 3.2 ; 135, \mathrm{SF}_{4} \mathrm{C}_{2} \mathrm{H}_{3}{ }^{+}$, $2.9 ; 127, \mathrm{SF}_{5}{ }^{+}, 13.5 ; 126, \mathrm{SF}_{3} \mathrm{C}_{3} \mathrm{H}^{+}, 1.5 ; 125, \mathrm{SF}_{3} \mathrm{C}_{3}{ }^{+}, 15.0 ;$ 109, $\mathrm{C}_{3} \mathrm{H}_{3} \mathrm{~F}_{2} \mathrm{~S}^{+}, 9.1 ; 109, \mathrm{SF}_{4}^{+}, 66.2 ; 107, \mathrm{C}_{3} \mathrm{H}_{4} \mathrm{FOS}^{+}, 12.5$; 106, $\mathrm{C}_{3} \mathrm{H}_{3} \mathrm{FOS}^{+}, 65 ; 105, \mathrm{C}_{3} \mathrm{H}_{2} \mathrm{FOS}^{+}, 10.2 ; 99, \mathrm{C}_{5} \mathrm{H}_{7} \mathrm{O}_{2}^{+}, 9.2$; $89, \mathrm{SF}_{3}{ }^{+}, 32.7 ; 85, \mathrm{C}_{4} \mathrm{H}_{5} \mathrm{O}_{2}{ }^{+}, 2.1 ; 73, \mathrm{C}_{3} \mathrm{H}_{5} \mathrm{O}_{2}{ }^{+}, 10.6 ; 71$, $\mathrm{C}_{3} \mathrm{H}_{3} \mathrm{O}_{2}{ }^{+}, 2.5 ; 70, \mathrm{SF}_{2}{ }^{+}, 5.3 ; 67, \mathrm{C}_{4} \mathrm{H}_{3} \mathrm{O}^{+}, 3.6 ; 56, \mathrm{C}_{3} \mathrm{H}_{3} \mathrm{O}^{+}$, $\mathrm{C}_{2} \mathrm{~S}^{+}$(two fragments), 4.9, 3.7; 55, (?), 30.9; 55, $\mathrm{C}_{3} \mathrm{H}_{3} \mathrm{O}^{+}$, $100.0 ; 54, \mathrm{C}_{3} \mathrm{H}_{2} \mathrm{O}^{+}, 5.2 ; 53, \mathrm{C}_{3} \mathrm{HO}^{+}, 6.3 ; 51, \mathrm{SF}_{2}{ }^{+}, 2.1$.

Anal.calcd for $\mathrm{C}_{4} \mathrm{H}_{8} \mathrm{BrF}_{5} \mathrm{O}_{2} \mathrm{~S}: \mathrm{C}, 19.56 ; \mathrm{H}, 2.63 ; \mathrm{Br}$, $26.02 ; \mathrm{F}, 30.9 ; \mathrm{S}, 10.45$. Found: C, $20.10 ; \mathrm{H}, 2.58 ; \mathrm{Br}$, $28.68 ; \mathrm{F}, 29.4 ; \mathrm{S}, 9.86$.

\section{Attempted dehydrohalogenation of $\mathrm{F}_{5} \underline{\mathrm{SCH}}_{2} \mathrm{CHBrCOOC}_{2} \underline{\mathrm{H}}_{5}$ :}

No tractable products were obtained from the reaction with aqueous $\mathrm{KOH}$. Both $\mathrm{Br}$ - and $\mathrm{F}$ - could be detected in the solution after a while. It was thus tried to carry out the reaction with organic nitrogen bases:

$1:$ with $\mathrm{N}, \mathrm{N}$-dimethyl aniline:

To $5.00 \mathrm{~g}$ of $\mathrm{F}_{5} \mathrm{SCH}_{2} \mathrm{CHBrCOOC}_{2} \mathrm{H}_{5}$ (16.3 mmoles) in a 50 ml round bottomed flask, equipped with a magnetic stirring bar, $2.99 \mathrm{~g}$ of $\mathrm{N}, \mathrm{N}$-dimethylaniline $(24.7 \mathrm{mmoles})$ were added at room temperature. A $24 \mathrm{~cm}$ reflux condenser was then fitted on the flask and the stirred mixture was slowly heated in an oil bath. When the oil bath temperature had reached 80-90 ${ }^{\circ} \mathrm{C}$ a reaction occurred suddenly and much 
material was blown out through the condenser. The dark blue residue was kept at that temperature for another 15 minutes. After the mixture had cooled down to room temperature, it was treated repeatedly with $\mathrm{CHCl}_{3}$ until the rinses were only slightly blue. There was a large amount of almost black tarry residue.The chloroform solution was repeatedly washed with $5 \% \mathrm{HCl}$ until the acid layer was almost colorless. The extract was dried $\left(\mathrm{MgSO}_{4}\right)$, concentrated (rotary evaporator) and finally transferred on a vacuum line, yielding a small amount of an almost colorless oily product. $1_{H}$ n.m.r. spectrum $\left(\mathrm{CDCl}_{3}\right): \mathrm{d}-\mathrm{t}$, centered at $\delta=1.77 \mathrm{ppm}, \mathrm{CH}_{3}$, intensity $\approx 1: 1$; two doublets, $\delta=6.66 \mathrm{ppm}, \delta=7.27 \mathrm{ppm}$ and a multiplet, $\delta=4-5 \mathrm{ppm} \cdot{ }^{19} \mathrm{~F}$ n.m.r. $\left(\mathrm{CDCl}_{3}\right)$ : showed only starting material to be present. The product that was formed was apparently a mixture of starting material and a compound that does not contain an $\mathrm{SF}_{5}$-group. The reaction was repeated by heating slowly a similar base - starting material mixture $\left(\mathrm{C}_{6} \mathrm{H}_{5} \mathrm{~N}\left(\mathrm{CH}_{3}\right)_{2}\right)$; the result was the same.

2. Reaction with diazabicyclononane:

Reaction of diazabicylononane (neat) with the ester resulted in charring and destruction of all starting material. The ${ }^{19} \mathrm{~F}$ n.m.r. spectrum of this mixture showed a singlet at 73.6 ppm, which is probably $\mathrm{SF}_{4} \cdot\left(\delta=72.7 \mathrm{ppm}\right.$ for $\mathrm{SF}_{4}$ in $\mathrm{CDCl}_{3}$ ). Employing ethereal solutions of both the ester and diazabicyclononane at $-10^{\circ} \mathrm{C}$ resulted in formation of a brown solution. The reaction was thus finally run at $-78{ }^{\circ} \mathrm{C}$ : 
In a $50 \mathrm{ml}$ round bottomed flask equipped with magnetic stirring bar, $1.0 \mathrm{~g}$ of $\mathrm{SF}_{5} \mathrm{CH}_{2} \mathrm{CHBrCOOC}_{2} \mathrm{H}_{5}$ (3.26 mmoles) was dissolved in $15 \mathrm{ml}$ anhydrous ether. A dropping funnel containing $0.40 \mathrm{~g}$ diazabicyclononane (Aldrich) (3.26 mmoles) in $2 \mathrm{ml}$ of ether (anhydrous) with a Drierite tube was fitted on the flask and it was cooled in an acetone-dry ice bath to $-78{ }^{\circ} \mathrm{C}$. The base solution was added dropwise during 10 minutes. A white precipitate formed immediately upon addition of the base. When addition was completed the mixture was allowed to attain slowly room temperature $(\approx 45$ min). The white precipitate had dissolved during the warming up process, leaving an almost colorless clear solution. It was kept in the refrigerator overnight, when a light brown oil had separated the next morning (i.r.spectrum: no $\mathrm{SF}_{5}$, $0.22 \mathrm{~g})$. The remaining solution was freed of solvent by distillation, leaving $0.82 \mathrm{~g}$ of a brownish oil. It showed only a weak $\mathrm{SF}_{5}$ band in the i.r.spectrum and traces of starting material in the fluorine n.m.r.spectrum. No other fluorine compound was found. The ${ }^{1} \mathrm{H}$ n.m.r.spectrum shows as the only product the product which was obtained earlier in the attempted dehydrohalogenation with $\mathrm{N}, \mathrm{N}$-dimethylaniline and some diethyl ether. This material was identified as 2bromoacrylic acid by comparison with an authentic sample. The product polymerized rather quickly to a rubbery translucent mass. 
Crystal Data and Methods used in X-ray analysis: $\left[\mathrm{HN}\left(\mathrm{C}_{2} \mathrm{H}_{5}\right)_{3}\right]^{+}\left[\mathrm{F}_{5} \mathrm{SC}\left(\mathrm{SO}_{2} \mathrm{~F}\right) \mathrm{COOCH}_{3}\right]^{-}:$

Monoclinic, $\mathrm{P} 21 / \mathrm{n}, \underline{\mathrm{a}}=8.758(2) \AA, \underline{\mathrm{b}}=9.645(2) \AA, \underline{\mathrm{c}}=$ 19.167(4) $\AA, \beta=97.92(3)^{\circ} ; \mathrm{V}=1603.6(6) \AA^{3} ; \mathrm{Z}=4$; density $=1.588 \mathrm{~g} / \mathrm{cm}_{3} i$ crystal size $=0.5 \times 0.4 \times 0.4 \mathrm{~mm} ;$ reflexions collected: 2998; independent reflexions: 1991 (Rint = $1.81 \%) ;$ observed reflexions: $1683(\mathrm{~F}>3.0 \sigma(\mathrm{F})) ; \mathrm{R}=4.62 \%$ (obs. data), $\mathrm{R}=5.59 \%$ (all data); hydrogen atoms: riding model, fixed isotropic U. Diffractometer: Siemens-Stoe AED2 (MoK $\alpha$, graphite monochromator); program used: SHELXTL PLUS (PC Version).

\section{$\left[\mathrm{F}_{5} \mathrm{SCH}\left(\mathrm{SO}_{2} \mathrm{~F}\right) \mathrm{CH}_{2}\right]_{2} \mathrm{O}:$}

Tetragonal, P4, $\underline{\mathrm{a}}=11.069(2) \AA, \underline{\mathrm{c}}=6.0780(10) \AA ; \mathrm{V}=$ $744.7(2) \AA^{3} ; Z=2 ;$ density $=2.187 \mathrm{~g} / \mathrm{cm}^{3} ;$ crystal size $=$ $0.2 \times 0.2 \times 0.5 \mathrm{~mm}$; reflexions collected: 2164; independent refelions: 970 ( $\left.R_{\text {int }}=1.56 \%\right)$; obseved reflexions: $898(F>$ $3.0 \sigma(F)) ; \mathrm{R}=3.82 \%$ (obs. data) $\mathrm{R}=4.22 \%$ (all data); hydrogen atoms: riding model, fixed isotropic U. Apparatus and methods as above.

$\mathrm{F}_{5} \mathrm{SCH}\left(\mathrm{SO}_{2} \mathrm{~F}\right) \mathrm{CON}\left(\mathrm{C}_{2} \mathrm{H}_{5}\right)_{2}:$

Monoclinic, P21/a (\#14), $a=10.945(2) \AA, b=8.932(2)$, $c=12.564(1), \mathrm{Z}=4$; density $2.19 \mathrm{~g} / \mathrm{cm}^{3} ;$ crystal size: $0.3 \times 0.25 \times 0.25 \mathrm{~mm}$; total reflexions: $796 . \mathrm{R}_{\mathrm{W}}=0.079$. Diffraktometer: Rigaku AFC6 $\left(\right.$ MoK $_{\alpha}$ graphite monochromator). 


\section{$\left[\mathrm{F}_{5} \mathrm{SCH}_{2} \mathrm{CHO}_{3}:\right.$}

Rhombohedral, R3m, $\underline{a}=10.266(2) \AA, \underline{c}=26.336(8) \AA ; V$ $=2404 \AA^{3}, \mathrm{Z}=18 ;$ density $=2.13 \mathrm{~g} / \mathrm{cm}^{3} ;$ crystal size: 0.5 mm maximal dimension;total reflexions: $916 ; \mathrm{R}_{\mathrm{W}}\left(\mathrm{F}_{0}\right)=0.0763$, Diffractometer: upgraded syntex $\mathrm{P}_{1}$ (MoK $\alpha$ graphite monochromator); program used: Nicolet SHELXTL (version 5.1, 1985). 


\section{REFERENCES}

PART I

1.Denbigh and Whytlaw-Gray, J.Chem.Soc., 1346 (1934).

2. Gmelins Handbuch der anorganischen Chemie, Erg.bd. 2 (1978),

Schwefel, Springerverlag.

3.R.Willenbring, J.Mohtasham, R.Winter, G.L.Gard, Can.J.Chem.,67, 2037 (1989).

4.A.K.Vijh, J.Chem.Ed., 47, 681 (1970).

5.R.E.Eibeck, W.Meary, Kirk-Othmer's Encyclopedia of Chemical Technology, 3rd Ed. 10, 799, (1980). $\mathrm{SF}_{5} \mathrm{C} \equiv \mathrm{N}$ was recently synthesized: O.Lösking, H.Willner, Angew. Chem.Int.Ed.Engl., 28, 1255 (1989). As an isomerization product of $\mathrm{SF}_{5} \mathrm{~N} \equiv \mathrm{C}$ : J.Thrasher, K.V.Madappat,ibid., 1256.

6.R.N.Haszeldine, R.E.Banks in The Chemistry of organic Sulfur compounds, volume $2, N$. Kharasch and C.Y.Meyers, editors, Pergamon Press, 1966, p.182.

7.G.L.Gard, C.Woolf, R.M.Shaw, U.S.Patent 3,506,774 (1970).

8.R.E.Banks, "Fluorocarbons and their Derivatives", McDonald Technical and Scientific Literature, 2nd Ed. 1970, p. 169.

9.I.L.Knunyanz, G.A.Sokolski, Angew.Chem.Int.Ed.Engl., 11, $583(1972)$.

10.N.P.Aktaev, G.A.Sokolski, I.L.Knunyanz, Izv.Akad.Nauk SSSR Ser.Khim., 2416 (1975) (Engl.).

11.A.F.Eleev, S.F.Pletnev, G.A.Sokolski, I.L.Knunyanz, Mendeleev, Chem.Journal, 23, No. 2, 45 (1978) (Engl.).

12.C.G.Krespan, J.Fluorine Chem., 8, 105 (1976).

13.A.F.Eleev, G.A.Sokolski, I.L.Knunyanz, Izv.Akad.Nauk SSSR Ser.Khim., 641 (1979) (Engl.).

14.I.L.Knunyanz, G.A.Sokolski, Angew.Chem.Int.Ed.Engl., 11, 583 (1972). 
15.I.L.Knunyanz et al, Izv.Akad. Nauk SSSR Ser.Khim., 1265, 1432 (1963). D.C.England, C.G.Krespan, "Fluoroketenes" PartI-VI. Part I: J.Am.Chem.Soc., 88, 5582 (1966); Part II: J.org.Chem., 33, 816 (1968); Part III: ibid., 35, 3300 (1970); Part IV: ibid., 35, 3308 (1970); Part V: ibid, 35, 3312 (1970); Part VI: ibid., 35, 3322 (1970). Y.A.Cheburkov, N.Mukhamadaliev, I.L.Knunyanz, Tetrahedron, 24, 1341 (1967).

16.D.C.England, C.G.Krespan, J.Am.Chem.Soc., 87, 4019 (1965).

17.J.Ciabattoni, H.W.Anderson, Tetrahedron Lett., 3377 (1967).

18.D.C.England, C.G.Krespan,"Fluoroketenes", Part I: J.Am.Chem.Soc. , 88, 5582 (1966).

19.D.C.England, Angew.Chem.Int Ed.Engl. 12, 1023 (1973).

20.C.G.Krespan, J.Fluorine Chem., $\underline{8}, 105$ (1976).

21.V.L.Isaev, T.D.Truskanova, R.N.Sterlin, I.L.Knunyanz, Mendeleev Chem.Journal, 23(1), 16 (1978) (Engl.).

22.D.C.England, C.G.Krespan, "Fluoroketenes", Part I: J.Am.Chem.Soc., 88, 5582 (1966).

23.Yu.E.Aronov, Yu.A.Cheburkov, I.I.Knunyanz, Izv.Akad.Nauk USSR, Ser.Khim., 1689 (1967) (Engl.).

24. References 18 and 23.

25.W.B.Farnham, W.J.Middleton, W.C.Fultz, B.E.Smart, J.Am.Chem. Soc. , 108, 3125 (1986).

26.N.Mukhamadaliev, Yu.A.Cheburkov, I.L.Knunyanz, IzV.Akad.Nauk SSSR Ser.Khim. 1949 (1965) (Engl.).

27.Yu.A.Cheburkov, N.Mukhamadaliev, Yu.E.Aronov, I.L.Knunyanz, Izv.Akad.Nauk.SSSR Ser.Khim., 1440 (1965) (Engl.).

28.A.F.Eleev, N.V.Vasil'ev, G.A.Sokolski, J.org. Chem. USSR, 21, 250 (1982), (Engl.). A.F.Eleev, G.A.Sokolski, I.L.Knunyanz, Izv.Akad.Nauk.SSSR.Ser.Khim., 26, 1444 (1977) (Engl.).

29.B.E.Smart, W.J.Middleton, J.Am.Chem.Soc., 109, 4982 (1987).

30.I.L.Krylov, A.P.Kutepov, G.A.Sokolskii, Mendeleev Chem. Journal, 28, 107 (1983). 
31.M.V.Galakhov, V.F.Cherstkov, V.F., A.R.Sterlin, L.S.German, IzV.Bull.Akad.Nauk USSR Ser.Khim., 36, 886 (1987) (Engl.).

32.R.J.De Pasquale, J.org.Chem., 38, 3025 (1973).

33.R.E.Banks and R.N.Haszeldine in The Chemistry of organic Sulfur Compounds, edited by N.Kharasch and C.Y.Meyers, Pergamon Press, 1966, page 183.

34.T.Krügerke, J.Buschmann, G.Kleemann, P.Luger, K.Seppelt, Angew. Chem.Int. Ed.Engl. 26, 799 (1987).

35.G.Kleemann, K.Seppelt, Chem. Ber. 116, 645 (1983).

36.T.Krügerke, K.Seppelt, Chem. Ber. 121, 1977 (1988).

37.J.I.Darragh, G.Haran, D.W.A.Sharp, J.Chem.Soc. Dalton Trans. (1973) 2289.

38.T.Abe, J.N.Shreeve, J.Fluorine Chem., 3, 198 (1973).

39. These values are: $F_{5} S-C l \leq 2.0 \mathrm{eV}, F_{5} S-F \approx 3.2-3.4 \mathrm{eV}$; Gmelins Handbuch der anorganischen Chemie, Bd. 2 (1978); Springer-Verlag.

40.G.Kleemann, K.Seppelt, Chem. Ber. 116, 645 (1983).

41.J.Hutchinson, J.Fluorine Chem., $\underline{3}, 429(1973 / 74)$.

42.D.C.England, C.G.Krespan, J.Am.Chem.Soc., 88, 5582 (1966).

43.D.L.Dyatkin, L.G.Zhurarkova, B.T.Martynov, F.I.Mysov, S.R.Sterlin, I.L.Knunyanz, J.organomet.Chem. 31, C15 (1971).

44.W.B.Farnham, W.J.Middleton, W.C.Fultz, B.E.Smart, J.Am.Chem.Soc., 108, 3125 (1986).

45.D.Morton, R.E.Banks, R.N.Haszeldine, J.Chem.Soc.Perkin Trans.I, 1266 (1974).

46.B.L.Dyatkin, S.R.Sterlin, L.G.zhuravkova, B.I.Martynov, E.I.Mysov, I.L.Knunyanz, Tetrahedron, 29, 2759 (1973).

47.I.Yu.Kryukova, L.N.Kryukov, V.L.Isaev, R.N.Sterlin, I.I. Knunyanz, Mendeleev Chem.Journal, 23(1), 20 (1978) (Engl.).

48.Yu.E.Aronov, Yu.A.Cheburkov, I.I.Knunyanz, Izv.Akad.Nauk USSR, Ser.Khim., 1689 (1967) (Engl.). 
49.H.J.Reich, et al. Tetrahedron, 39, 949 (1983); A.G.Brook, M.A.Quigley, G.J.D.Peddle, N.V.Schwartz, C.M.Warner, J.Am.Chem.Soc., 82, 5102 (1960); H.Bock, H.Alt, H.Seidel, J.Am.Chem.Soc., 91, 355 (1968). The compound $\mathrm{CH}_{3} \mathrm{C}(0) \mathrm{Si}_{3}$ is apparently not colored (Brook et al.).

50.A.G.Brooks, F.Abdeskaken, G.Gutekunst, N.Plavac, Organometallics 1, 994 (1982). H.J.Reich et al, Tetrahedron 39, 949 (1983).

51.L.H.Cross, G.Cushing, H.L.Roberts, Spectrochim.Acta, 17, 344 (1961).

52.R.J.Terjeson, J.Mohtasham, G.L.Gard, Inorg. Chem. 27, 2916 (1988).

53. Described in the second half of this manuscript.

54.J.M.Canich, M.M.Ludvig, G.L.Gard, J.M.Shreeve, Inorg. Chem., 26, 4403 (1984).

55. $\mathrm{F}_{5} \mathrm{SCF}_{2} \mathrm{SO}_{2} \mathrm{~F}$ has been made recently by the direct fluorination (with $\mathrm{F}_{2}$ ) of $\mathrm{F}_{5} \mathrm{SCHFSO}_{2} \mathrm{~F}$ : G.L.Gard, A.Waterfeld, R.Mews, J.Mohtasham, R. Winter, to be published.

56. Reference 27 .

57.a.) G.Kleemann, K.Seppelt, Angew.Chem.Int.Ed.Engl., 17, 516 (1978) . b.):H.Bock, J.E.Boggs, G.Kleemann, D.Lentz, H. Oberhammer, E.M.Peters, K.Seppelt, A.Simon, B.Solouki, Angew.Chem.Int.Ed.Engl., 18, 944 (1979). C.:) A.Simon, E.M.Peters, D.Lentz, K.Seppelt, Z.anorg.allg. Chem., 468, 7 (1980). d.:) S.Sunder, H.H.Eysel, G.Kleemann, K.Seppelt, Inorg.Chem., 18, 3208 (1979).

58.G.Kleemann, K.Seppelt, Chem.Ber., 116, 645 (1983). 59.T.Abe, J.M.Shreeve, J.Fluorine Chem., 조 187 (1973).

60.T.Krügerke, J.Buschmann, G.Kleemann, P.Luger, K.Seppelt, Angew.Chem.Int.Ed.Engl., 26, 799 (1987).

61.B.Pötter, K.Seppelt, Inorg.Chem., 21, 3147 (1982).

62.B.Pötter, K.Seppelt, Chem.Ber., 117, 3255 (1984).

63.T.Grelbig, B.Pötter, K.Seppelt, Chem.Ber., 120, 815 (1987).

64.K.K.Johri, D.D.DesMarteau, J.org.Chem., 48, 242 (1983).

65.T.Krügerke, K.Seppelt, Chem. Ber., 121, 1977 (1988). 
66.J.M.Canich, M.M.Ludvig, G.L.Gard, J.M.Shreeve, Inorg.Chem., 23, 4403 (1984).

67.a.) A.Elsäßer, W.Sundermeyer, D.S.Stephenson, Chem. Ber. 118, 116 (1985); also, B.S.Smart, W.J.Middleton, J.Am.Chem.Soc. 109, 4982 (1987). b.) J.Heine, G.-V. Röschenthaler, Chem.Ber. 120, 1445 (1987). C.) J.Grobe, Duc Le Van, Chem.Ber., 123, 1047 (1990). d.) ref. 18 in C.). e.) R.N.Haszeldine et al, J.Chem.Soc. Perkin Trans.I, 487 (1980).

68.N.Borden, J.W.Emsley, J.Feeney, L.H.Sutcliffe, Trans. Faraday Soc., 59, 620 (1963).

69.R.K.Harris, K.J.Packer, J.Chem.Soc., 4736 (1961).

70.B.L.Dyatkin, N.I.Delyagina, S.R.Sterlin, Russ.Chem.Rev., 45, 607 (1976).

71. It will be noted that electron density as an intensive quantity cannot be redistributed. This terminology, although common, is clearly incorrect.

72.A.E.Bayliff, R.D.Chambers, J.Chem.Soc. Perkin Trans. I, 201 (1988).

73.W.Adcock, N.Abeywickrma, J.org.Chem., 47, 2945 (1982).

74 .R.Höfer, O.Glemser, Z.Naturforsch. , 30b, 458 (1975).

75.J.Bittner, J.Fuchs, K.Seppelt, Z.anorg.allg.Chem., 557, 182 (1988).

76.T.Krügerke, J.Buschmann, G.Kleemann, P.Luger, K.Seppelt, Angew. Chem. Int. Ed. Engl. , 26, 799 (1987) [ $\mathrm{F}_{4} \mathrm{~S}=\mathrm{CHCFO}$. B.Pötter, K.Seppelt, Inorg.Chem., 21, 3147 (1982) $\left[\mathrm{F}_{4} \mathrm{~S}=\mathrm{CHCH}_{3}\right]$. B. Pötter, K.Seppelt, Chem.Ber., 117, 3255 (1984); T.Grelbig, B.Pötter, K.Seppelt, Chem.Ber., 120, 815 (1987) $\left[\mathrm{F}_{4} \mathrm{~S}=\mathrm{CHCF}_{3}, \mathrm{~F}_{4} \mathrm{~S}=\mathrm{C}\left(\mathrm{CH}_{3}\right) \mathrm{CF}_{3}\right]$.

77.R.I.Corio, R.C.Hirst, J.Chem.Education, 46, 345 (1969).

78. The iterative program LAOCN5 (quantum chemical exchange service, Bloomington, Indiana) was used to calculate the spectral parameters; the spectrum was then generated with the program PCPMR (Serena software, Bloomington, Indiana).

79.A.Simon, E.M.Peters, D.Lentz, K.Seppelt, Z.anorg.allg. Chem. 468,7 (1980).

80.T.Meier, R.Mews, J.Fluorine Chem. 42, 81 (1989). 
81:R.J.Terjeson, J.Mohtasham, G.L.Gard, Inorg.Chem., 27, $2916(1988)$.

82.G.Kleemann, K.Seppelt, Chem.Ber., 116, 645 (1983) [Cis$\mathrm{SF}_{4} \mathrm{BrCH}_{3}$, cis-SF $4 \mathrm{ClCH}_{3}$ ] . J.S.Thrasher, J.L.Howell, M.Clark, A.F.Clifford, J.Am.Chem.Soc., 108, 3526 (1988) [cis $-\mathrm{SF}_{4} \mathrm{OCH}_{3} \mathrm{~N}=\mathrm{C}=\mathrm{O}$, cis $-\mathrm{SF}_{4} \mathrm{OCH}_{3} \mathrm{NHC}(\mathrm{O}) \mathrm{OCH}_{3}$ ]

83. In $\mathrm{CH}_{2}=\mathrm{SF}_{4}$ this band is found at $1167 \mathrm{~cm}^{-1}$, S.Sunder, H.H.Eysel, G.Kleemann, K.Seppelt, Inorg.Chem., 18, 3208 (1979). In $\mathrm{CH}_{3} \mathrm{CH}=\mathrm{SF}_{4}$ the band is found at $1200 \mathrm{~cm}^{-1}$, B.Pötter, K.Seppelt, Inorg.Chem., 21, 3147 (1982).

84. The crystal structures of $\left(\mathrm{F}_{5} \mathrm{SCH}\left(\mathrm{SO}_{2} \mathrm{~F}\right) \mathrm{CH}_{2}\right)_{2} \mathrm{O}$ [29] and $\mathrm{F}_{5} \mathrm{SC}\left(\mathrm{SO}_{2} \mathrm{~F}\right) \mathrm{COOCH}_{3}-\mathrm{HN}\left(\mathrm{C}_{2} \mathrm{H}_{5}\right)_{3}{ }^{+}[\underline{32 \mathrm{~b}}]$ were kindly determined by Dr. Mathias Noltemeyer, Inst. $f$. anorganische Chemie, Universität Göttingen, and of $\mathrm{F}_{5} \mathrm{SCH}\left(\mathrm{SO}_{2} \mathrm{~F}\right) \mathrm{CON}\left(\mathrm{C}_{2} \mathrm{H}_{5}\right)_{2}[2 \mathrm{27}]$ by $\mathrm{Dr}$. D.A.Keszler, oregon state University, Corvallis, Oregon.

85.M.A.James, T.S.Cameron, O.Knop, M.Neumann, M.Falk, Can.J. Chem., 63,1750 (1985).

86.J.Bittner, J.Fuchs, K.Seppelt, Z.anorg.allg.Chem., 557, 182 (1988).

87.W.Heilemann, R.Mews, S.Pohl, W.Saak, Chem.Ber., 122, 427 (1989).

88.T.Ottersen, Acta Chem. Scand. Ser.A, A29, 939 (1975).

89.C.I.Merrill, M.Lustig, G.H.Cady, C.A., 60, 6463 (1964).

90.B.Cohen, A.G.McDiarmid, Inorg.Chem., 4, 1782 (1965), $\left(138^{\circ} \mathrm{C}\right)$. T.A.Kovacina, A.D.Berry, W.B.Fox, J.Fluorine Chem., I, 436, (1976), $\left(150^{\circ} \mathrm{C}\right)$.

91.H.L.Roberts, Quart.Rev., 30 (1961), p.39

92.C.W.Tullock, D.D.Coffman, E.I>Muetterties, E.I. , J.Am.Chem.Soc. , 86, 357 (1964).

93.R.A.Bekker, B.L.Dyatkin, I.L.Knunyanz, Izv. Akad. Nauk USSR, Ser.Khim., 2575 (1970) (Engl.).

94.C.J.Schack, R.D.Wilson, M.G.Warner, Chem. Comm. 1110 (1969) .

95.K.O.Christe, E.C.Curtis, C.J.Schack, A.Roland, spectrochim. Acta, 33, 69, (1967).

96.J.Wessel, G.Kleemann, K.Seppelt, Chem. Ber. 116, 2399 (1983). 
97.G.A.Oláh, S.J.Kuhn, J.org.Chem., 21, 1319 (1956).

98.H.Jonas, Z.anorg.allg.Chem. 265, 273 (1951).

99.T.A.Kovacina, A.D.Berry, W.B.Fox, J.Fluorine Chem., I, 436 (1976). 
PART II

1.G.G.Belen'kij, L.S.German, I.L.Knunyanz, Izv. Akad. Nauk SSSR Ser.Khim.1., 2780 (1967).

2.H.Millauer, W.Schwertfeger, G.Siegemund, Angew. Chem.Int. Ed.Engl., 24, 161 (1985).

3. Examples are given in ref.5.

4.E.P.Moore, Jr., U.S.Pat. 3,338,978 (1967).

5.a.) Representative reactions of $\mathrm{CF}_{2}$ from this source are given by P.B.Sargeant, J.org.Chem., 35, 678 (1970). b.) The reversibility of the reaction was shown by $W$.Mahler, P.R.Resnick, J.Fluorine Chem., 3, 451 (1973/74).

6. $\left(\mathrm{F}_{3} \mathrm{C}\right)_{3} \mathrm{PF}_{2}$ was first described by W.Mahler, Inorg. Chem., $\underline{2}, 230$ (1963), and an example and further references are given in ref. [5b].

7.P.Tarrant, E.G.Allison, K.P.Barthold, E.L.Stump, Fluor. Chem. Rev. $\underline{5}, 77$ (1971).

8. Coudures, C.; Pastor, R.; Canbon, A.; J. Fluorine Chem. $\underline{24}, 93(1984)$.

9. Examples of this method are given by: McBee, E.T., Burton, T.M. J.Am.Chem.Soc., 74, 3022, 3902 (1952); McBee, E.T.; Pierce, O.R.; Kilbourne, H.W. J.Am.Chem.Soc., 75, 4091 (1953).

10.a.:) N.O.Brace,J.org.Chem., 27, 3033 (1962); S.P.Khrlakyan, V.V.Shokina, I.L.Knunyanz, IzV.Akad.Nauk SSSR Ser.Khim, 72 (1965) [addition to allyl acetate]; b.:) J.D.Park, F.E.Rogers, J.R.Lacher, J.Org.Chem., 26, 2089 (1961) [addition to allyl alcohol].

11.T.I.Filyakova, N.V.Peschanskii, M.I.Kodess, A.Ya.Zapevalov, I.P.Kolenko, J.org.Chem.USSR., 24, 327 (1988); I.P.Kolenko, T.I.Filyakova, A.Ya.Zapevalov, E.P.Lur'e, Izv.Akad.Nauk SSSR, Ser.Khim.; 282323 (1979) (Engl.).

12.M.R.Bryce, ,R.D.Chambers, J.R.Kirk, J.Chem.Soc. Perkin Trans.I 1391 (1984).

13.I.L.Knunyanz, V.V.Shokina, E.I.Mysov, Izv.Akad.Nauk SSSR Ser.Khim., 2725 (1973).

14. These examples are taken from ref 7 , pages 93 and 94 . 
15.R.A.DeMarco, W.B.Fox, J.org.Chem., 47, 3773 (1982).

16. Ref.2, ref 165 .

17.R.E.Banks. "Fluorocarbons and their Derivatives", McDonald Technical and Scientific Literature, 2nd Ed. 1970 , p. 169.

18.a.) R.Dresdner, J.A.Young, J.Org.Chem. 24, 566 (1959) and b.) R.N.Haszeldine, R.E.Banks in The Chemistry of Organic Sulfur Compounds, Volume 2, N.Kharasch and C.Y.Meyers, editors, Pergamon Press, 1966, p.183.

19.G.L.Gard, C.Woolf, R.M.Shaw, U.S.Patent 3,506,774 (1970).

20.Ref. 17 b.) p. 182 .

21.A.W.Marcellis, R.E.Eibeck, J.Fluorine Chem., 5,71 (1975).

22.F.W.Hoover, D.D.Coffman, J.org.Chem. 299, 3562 (1964).

23.J.D.Park, E.R.Iarsen, H.V.Holler, J.R.Lacher, J.Org.Chem., 23, 1166 (1958).

24.R.Debuhr, J.Howbert, J.M.Canich, H.F.White, G.L.Gard, J.Fluorine Chem., 20, 515 (1982).

25.D.Morton, R.E.Banks, R.N. Haszeldine, J.Chem.Soc. Dalton Trans. (1974), 1266.

26.E.F.Witucki, J.Fluorine Chem., 20, 803 (1982).

27.R.N.Haszeldine, F.Nyman, J.Chem.Soc., 2684 (1956).

28.D.Burton et al, J.Am.Chem.Soc. 95, 8467 (1973).

29.C.G.Krespan, D.C.England, J.Am.Chem.Soc., 103, 5598

(1981). R.E.Banks et al, J.Fluorine Chem., 20, 133 (1980).

30.E.A.Kauck, J.H.Simons, Brit.Pat. 672,720 (1952).

31.E.I.DuPont de Nemours\&Compnay, Brit.Pat. 904,877 (1962).

32.A.Sekiya, D.DesMarteau, Inorg. Chem., 19, 1330 (1980).

33.D.Sianesi, A.Pasetti, F.Tarli, J.org. Chem. 31, 2312, $(1966)$.

34.J.Bittner, J.Fuchs, K.Seppelt, Z.anorg.allg.Chem. 557, 182 (1988).

35.D.E.Morin, U.S.Patent 3213134 (1965). 
36.R.N.Haszeldine, F.Nyman, J.Chem.Soc., 2684 (1956).

37.D.L.Warnell, U.S.Patent 725741 (1966).

38.R.A.DeMarco, W.B.Fox, J.org.Chem., 47, 3773 (1982) .

39.H.C.Roberts, Quart.Rev., 30 (1961). The compound was obtained from $\mathrm{F}_{5} \mathrm{SCHFCF}_{2} \mathrm{Cl}$ and $\mathrm{KOH}$ in petrolether by J.R.Case, N.H.Ray, H.C.Roberts, J.Chem.Soc., 2070 (1961), and with KOH powder by R.E.Banks, R.N.Haszeldine, W.D.Morton, J.Chem.Soc. C, 1947 (1969).

40.The program PCPMR (Serena Software, Bloomington, Indiana) was used. Approximate values for $\mathrm{J}_{\mathrm{BF}}{ }^{2}, \mathrm{~J}_{\mathrm{XF}}{ }^{1}$ and $\phi_{\mathrm{F}}{ }^{1}-\phi_{\mathrm{F}}{ }^{2}$ were extracted from the spectrum and successively changed.

41.K.W.Jolley, L.H.Sutcliffe, K.L.Williamson, Spectrochim. Acta 30A, 1455 (1974).

42.R.J.Terjeson, J.Mohtasham, G.L.Gard, Inorg. Chem., 27, 2916 (1988).

43.M.Spraul, H.Keul, B.Pfeffer, J.Hähnle, K.Grjiesbaum, Magn.Res.in Chem. 23, 524 (1985). 
PART III

1.C.Hansch, R.M.Muir, T.Fujita, P.P.Mahoney, F.Geiger, M.Streich J.Amer.Chem.Soc. , 85, 2817 (1963); C.Hansch, J.Fukunaga, Chemtech, Z, 120 (1977); C.Hansch, J.Iwasa, T.Fujita, J.Am.Chem.SoC. 86, 5175 (1964); R.Filler in Organofluorine Chemicals and their Industrial Applications, Ed. R.Banks, Ellys Harwood Ltd., Publ., Chichester, (1979).

2.C.Heidelberger, Ann.N.Y.Acad.of Sciences. 255, 317 (1975).

3.B.Schwarz, D.Cech, Journal f.Prakt.Chemie, 326, 985 (1984).

4.A.Gianotti, P.Tower, J.Sheley, P.Conte, C.Spiro, J.Fitchen, M.Riscoe, J.Biol.Chem. (in press) 1990.

5.R.Filler, J.Fluorine Chem., 33, 361, (1986)

6.E.E.Gilbert, G.I.Gard, U.S.Patent 3475453 (1969).

7.C.Woolf, G.L.Gard, J.Fluorine Chem., 1, 487 (1971/72).

8.C.W.Tullock, U.S.Patent 3228981 (1966).

9.N.H.Ray, British Patent 941393 (1963).

10.N.H.Ray, H.I.Roberts, U.S.Patent 3086048 (1963).

11. $\mathrm{SF}_{5} \mathrm{Cl}$ addition: J.D.Case, N.H.Ray, H.L.Roberts, J.Chem.Soc., 2066 (1961). SF 5 Br addition: J.Steward, L.Kegley, H.F.White, G.L.Gard, J.org.Chem., 34, 760 (1969).

12.M.Tremblay, Can.J.Chem. , 43, 219 (1965); J.Hutchinson, J.Fluorine Chem., $3,429(1973 / 74)$.

13.W.Sheppard, J.Amer.Chem.Soc., 84, 3064 (1962) (AgF 2$)$; G.A.Selvey, G.H.Cady, J.Amer.Chem.Soc., 72, 3624 (1950) $\left(\mathrm{CoF}_{3}\right)$.

14.A.L.Clifford, K.K.El-Shamy, H.J.Emeleus, R.N.Haszeldine, J.Chem.Soc., 2372 (1953).

15.E.A.Tyczkowski, L.A.Bigelow, J.Amer.Chem. Soc., 75, 3523 (1953) $\left(\mathrm{F}_{2} / \mathrm{N}_{2}\right)$.

16.J.R.Case, N.H.Ray, H.L.Roberts, J.Chem.Soc., 2066 (1961); A.D.Berry, W.B.Fox, J.Org. Chem., 43, 365 (1978). 
17.H.L.Roberts, Quart.Rev., 30, (1961), p.42.

18.H.W.Sidebottom, J.M.Tedder, J.C.Walton, Trans.Faraday Soc., 65, 2103 (1969).

19.R.A.DeMarco, W.B.Fox, J.Fluorine Chem., 12, 137 (1978).

20.T.Grelbig, T.Krügerke, K.Seppelt, Z.anorg.allg.Chem. 544, 74 (1987).

21.R.Gerhardt, K.Seppelt, Chem.Ber., 122, 463 (1989).

22.B.Pötter, K.Seppelt, Inorg.Chem., 21, 3147 (1982);

B.Pötter, G.Kleemann, K.Seppelt, Chem.Ber., 117, 3255 (1984).

23.F.W.Hoover, D.D.Coffman, J.org.Chem., 29, 3567 (1964).

24.R.A.Banks, R.N.Haszeldine, J.Chem.Soc., 1266 (1974).

25.R.Debuhr, J.Howbert, J.M.Canich, H.F.White, G.L.Gard, J.Fluorine Chem., 20, (1982) 515.

26.a.): $\mathrm{X}=\mathrm{H}$ : R.J.Terjeson, J.Mohtasham, G.L.Gard, Inorg.Chem., 27,2916, (1988). b.): (X=F): J.M.Canich, M.M.Ludvig, G.L.Gard, J.M.Shreeve, ibid. 23, 4403 (1984).

27.G.I.Gard, J.Fluorine Chem., 1, 487 (1971/72) .

28.I.I.Knunyanz et al, Izv.Akad.Nauk SSSR, SER.Khim. 26, 1023 (1977 (Engl.). I.L.Knunyanz et al, Dokl.Akad.Nauk SSSR, 165, 827 (1965).

29.C.G.Krespan, J.Fluorine Chem. $\underline{8}, 105$ (1976) •

30.T.Fuchikami, A.Yamanouchi, I.ojima, Synthesis, 766 (1984).

31.T.Fuchikami, I.ojima, Tetrahedron Letters, 23, 4099 (1982).

32.C.Heidelberger, D.Parsons, D.Remy, J.Am.Chem.Soc., $\underline{84}$, 3597 (1962).

33.Y.Kobayashi, K.Yamamoto, T.Asai, M.Nakano, I.Kumadaki, J.Chem.Soc. Perkin Trans.I, 2755 (1980).

34.E.ziegler, H.Sterk, Mh.Chem., 98, 1104 (1967).

35.a.): N.H.Ray, British Patent 941392. b.): N.H.Ray, J.Chem.Soc. (1963) 1440. 
36.D.D.Coffman, W.Chester, C.W.Tullock, U.S.Patent 3102903 (1963).

37.F.W.Hoover, D.D.Coffman, J.org.Chem., 29, 3567 (1964).

38."The Chemistry of the Ether Linkage", Ed. S.Patai, Wiley, page 333 (1967).

39.E.Mundlos, R.Graf, J.Liebigs Ann., 677, 109 (1964).

40.L.N.Ragulin, M.A.Beharentsev, G.A.Sokol'skii, I.L.Knunyanz, Izv.Akad.Nauk.SSSR Ser.Khim., 10, 2176 (1968).

41.D.D. Coffman, W. Chester, C.W.Tullock, U.S. Patent 3102963 (1963).

42.C.S.Marvel, J.Dec, H.G.Cooke, J.C.Cowan, J.Am. Chem. Soc., 62, 3495 (1940).

43.H.Oediger, F.Möller, K.Eiter, Synthesis, 591 (1972).

44.C.S.Marvel, J.Dec, H.G.Cooke Jr., J.C.Cowan, J.Am. Chem. Soc., 62, 3495 (1940).

45.S.Akiyoshi, K.okuno, J.Am. Chem. Soc. 74, 5759 (1952) $\left(\mathrm{JCH}_{2} \mathrm{CH}(\mathrm{OR})_{2}\right) ;$ P.Bedoukian, J.Am.Chem. SoC. 66,651 $(1944)\left(\mathrm{BrCH}_{2} \mathrm{CH}(\mathrm{OR})_{2}\right)$.

46.D.L.Heywood, B.Phillips, J.org.Chem., 25, 1699 (1960).

47.D.D.Coffman, W.Chester, C.W.Tullock, Can.Pat. 728186 (1962).

48.G.G.Odian, Principles of Polymerization, 2nd Edition, 1981, J.Wiley \& Sons Inc., p. 236.

49. $\mathrm{ACOCH}=\mathrm{CHCOOC} \mathrm{H}_{5}$ was first obtained by H.v.Pechmann, Chem.Ber. 25, 1040 (1892). It was made according to P.Freeman et al., J.Org.Chem. 39, 546 (1974), but without cooling. Both Freeman et al. and M.Perezamador, M.Salmon and F.Walls, Chem.Abst. 67, 43386 (1967) describe $\beta$-acetyl ethylacrylate as yellow liquids. It was found that slow distillation resulted in a completely colorless oily product.

50.S.J.Archer, H.M.N.H.Irving, K.R.Koch, L.R.Nassimbeni, J. Crystallogr.Spectrosc.Res. 15, 333 (1985).

51.S.J.Archer, A.Irving, H.M.N.H.Irving, J.Crystallogr. Spectrosc. Res. 16, 283 (1986). 


\section{APPENDIX}

COMPOUND REFERENCE TABLE

$\underline{1}$

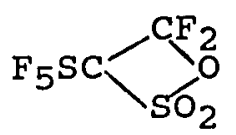

$\underline{3}$<smiles>[R6]SC(=C=O)C(F)(F)F</smiles>

$\underline{5}$<smiles></smiles>

$\underline{6}$<smiles>[R5]SC([R5])([R6])C</smiles>

$\underline{7}$

$\underline{8 a}$

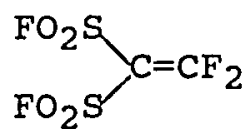

$\mathrm{F}_{4} \mathrm{~S}=\underset{\mathrm{H}}{\mathrm{C}}-\mathrm{COF}$

$\underline{9}$

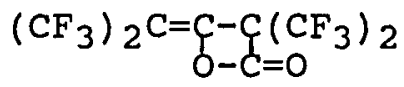

$11 \mathrm{a}, \mathrm{b}$<smiles>[R]OC(=O)C(C)C(=O)OCC(=O)O</smiles>

$15 \quad\left(\mathrm{CF}_{3}\right)_{2} \mathrm{CHSO}_{2} \mathrm{~F}$

$17 \mathrm{Cs}^{+}\left(\mathrm{CF}_{3}\right)_{2} \mathrm{CSO}_{2} \mathrm{~F}^{-}$

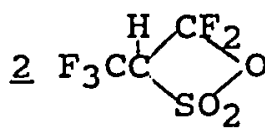<smiles>CCOC(=O)C(C(=O)O)C(F)(F)F</smiles>

$\underline{5 a}$<smiles>O=C=CC=[SbH2]</smiles>

8 $\quad \mathrm{CF}_{2}=\underset{\mathrm{CF}_{3}}{\mathrm{G}-\mathrm{CFO}}$

$\underline{8 b} F_{2} \mathrm{OS}=\mathrm{C}_{\mathrm{H}}-\mathrm{CFO}$

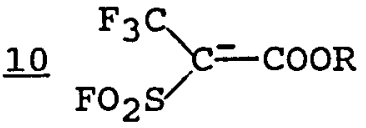<smiles>O=P([O-])(O)[Mg]C(Cl)(Cl)C(F)(F)F</smiles>

$14\left(\mathrm{CF}_{3}\right)_{2} \mathrm{CSO}_{2} \mathrm{~F}^{-}$

$16 \mathrm{CF}_{2}=\underset{\mathrm{CF}_{3}}{\mathrm{C}-\mathrm{SO}_{2} \mathrm{~F}}$

$\underline{18} \quad \mathrm{~F}_{3} \mathrm{~B} \cdot \mathrm{N}\left(\mathrm{C}_{2} \mathrm{H}_{5}\right)_{3}$ 
19

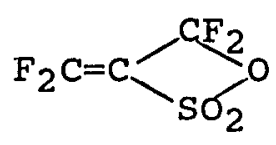

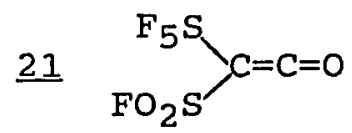<smiles>COC(=O)C([AsH2+])[SbH2]</smiles><smiles>[Te][Te]</smiles><smiles>CC(=O)OC(C)C(=O)Sc1ccccc1</smiles>

$\underline{22}$<smiles>O=CCC(C=O)S(=O)(=O)F</smiles>

$24 \quad \mathrm{~F}_{4} \mathrm{~S}=\underset{\mathrm{SO}}{\mathrm{SO}}-\mathrm{CFO}$

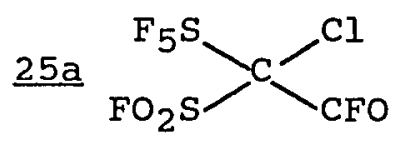

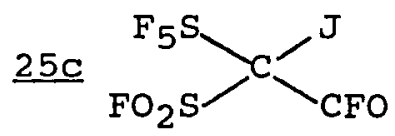

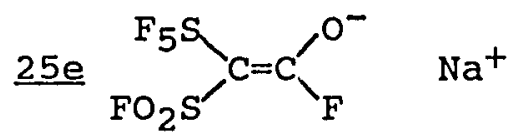

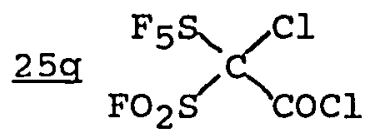

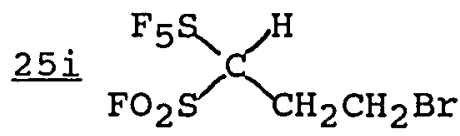

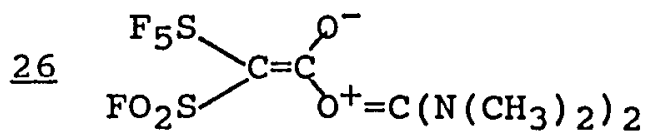

$$
{ }_{\mathrm{FO}_{2} \mathrm{~S}} \stackrel{\mathrm{H}-\mathrm{C}}{\mathrm{F}_{5}} \mathrm{C}_{\mathrm{C}_{2} \mathrm{H}_{5}}
$$

$\underline{20}$<smiles>O=[Sb]1O[Te]C1C(F)(F)[18F]</smiles><smiles>COC(=O)C(S)(S)C(=O)OC(C)C</smiles>

$\underline{21 C}$<smiles>[R20]OC(=O)C(=[Z16])S[R6]</smiles><smiles>[R20]C(S)[R6]#[R6]</smiles>

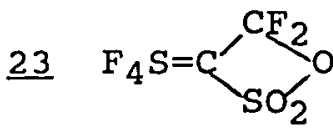

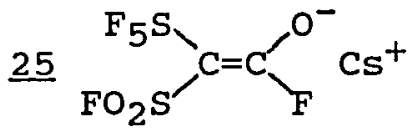
$\underline{25 b}$

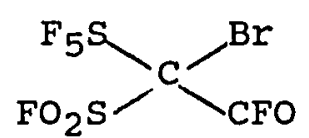



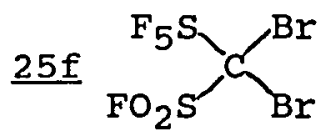<smiles>[134Sc]</smiles><smiles>O=S(=O)(F)C(Cl)SC(F)(F)F</smiles>
$25 j$

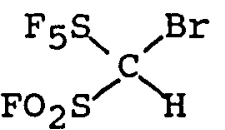

$\underline{28}$<smiles>O=PSC(S)=C1OCO1</smiles> 


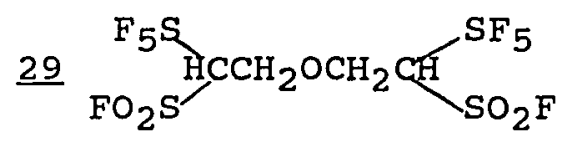

31. ${ }_{\mathrm{FO}_{2} \mathrm{~S}}^{\mathrm{F}_{5} \mathrm{~S}} \mathrm{O} \stackrel{\mathrm{O}}{\mathrm{O} N H} \mathrm{ONH}_{2}$

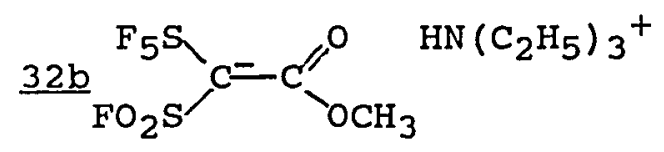

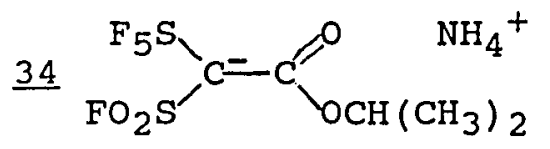<smiles>CCCCCCCCCCCCCCCCC(=O)NC(N)=O</smiles><smiles>CC(C)OC(=O)C(Br)(SC(C)C)SC(C)C</smiles>

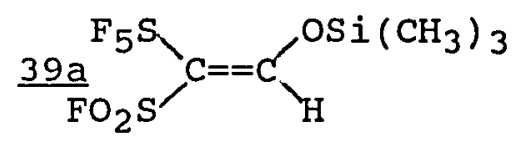

40<smiles>[R5]SC([R5])([R5])C(=O)F</smiles>

41a $\quad \begin{gathered}\mathrm{F}_{5} \mathrm{SC}=\mathrm{CF} \\ \mathrm{O}_{2} \mathrm{~S}-\mathrm{O}\end{gathered}$

$43 \quad \stackrel{\mathrm{H}_{3} \mathrm{CO}}{\mathrm{F}_{4} \mathrm{~S}-\stackrel{\mathrm{H}}{\mathrm{C}}-\mathrm{CF}_{2}}$

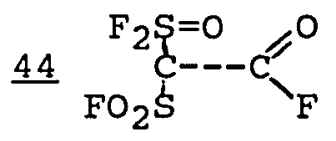<smiles>[R2]C(=O)C(=S)S[R6]#[Z16]</smiles>

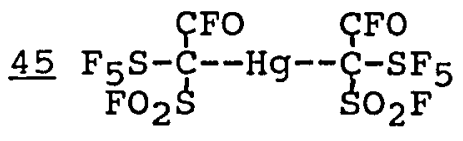

$\underbrace{\mathrm{F}_{5} \mathrm{~S}}_{\mathrm{FO}_{2} \mathrm{~S}} \stackrel{\mathrm{HCCO}-\mathrm{C}=\mathrm{CH}_{2}}{\mathrm{CH}_{3}}$

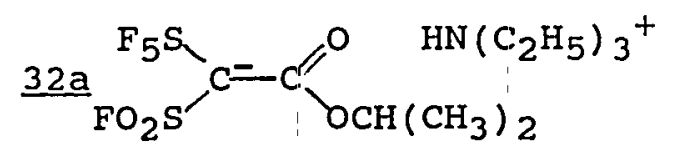<smiles>C#[R6]S[C-](SC)C(=O)OC(C)C</smiles><smiles>CC(C)OC(=O)C([S+](=O)[O-])[Sn](=O)[O-]</smiles><smiles>CC(C)OC(=O)C(Cl)(S(=O)(=O)O)S(=O)(F)(F)F</smiles>

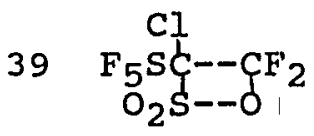

$\underline{39 b}$

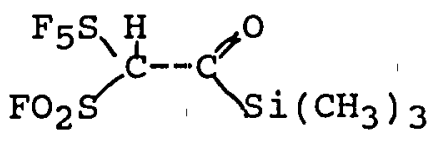

$\underline{41}$

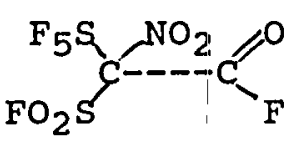

$\underline{42}$

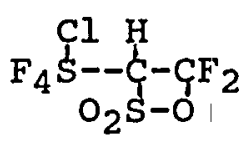

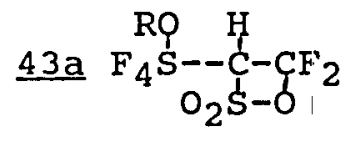

44a $\begin{gathered}\mathrm{F}_{3} \mathrm{~S}=\mathrm{O} \\ \mathrm{FO}_{2} \mathrm{~S}=\mathrm{C}=\mathrm{O}\end{gathered}$

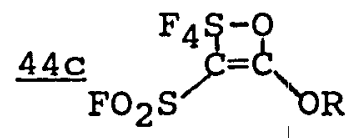

46

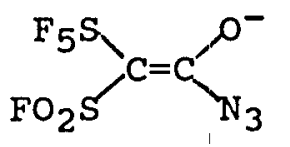


$47 \mathrm{~F}_{3} \mathrm{CCFCF}_{2}$

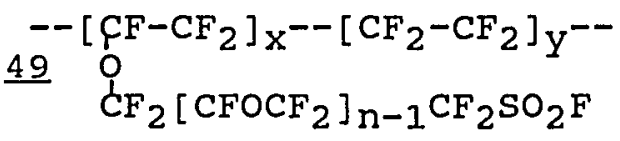

$\underline{51} \mathrm{~F}_{5} \mathrm{SOCF}_{2} \mathrm{CFO}$

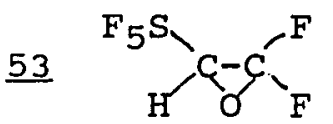

$\underline{55}$
$\underline{48}\left(\mathrm{~F}_{3} \mathrm{CGFCF}_{2}\right)_{\mathrm{n}}$

$\underline{50}$<smiles>FC(F)=C(F)[AsH2+]</smiles>

$\underline{52}$

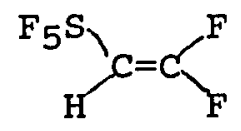

$\underline{54}$

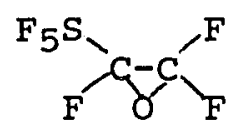

56a $\mathrm{F}_{5} \mathrm{~S}\left(\mathrm{CF}_{2}\right)_{\mathrm{n}} \mathrm{CX}=\mathrm{CF}_{2}$

58 $\mathrm{F}_{5} \mathrm{SCH}_{2} \mathrm{CH}_{2} \mathrm{Br}$

60 $\mathrm{F}_{5} \mathrm{SCHBrCH}_{2} \mathrm{Br}$

$62 \mathrm{~F}_{5} \mathrm{SCHBrCH}_{2} \mathrm{OC}(\mathrm{O}) \mathrm{CH}_{3}$

64 $\quad \mathrm{F}_{5} \mathrm{SCF}_{2} \underset{\mathrm{Cl}}{\mathrm{Cl}}=\mathrm{CF}_{2}$

66 $\quad \mathrm{F}_{5} \mathrm{SCF}_{2} \mathrm{CFCF}_{2}$

68 $\mathrm{F}_{5} \mathrm{SCH}=\mathrm{CHCH}_{2} \mathrm{OH}$
57 $\mathrm{FO}_{2} \mathrm{SCF}_{2} \mathrm{CF}=\mathrm{CF}_{2}$

59 $\mathrm{F}_{5} \mathrm{SCH}_{2} \mathrm{CH}_{2} \mathrm{OC}(\mathrm{O}) \mathrm{CH}_{3}$

$\underline{61}$

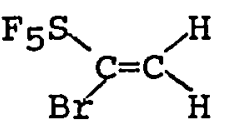

$63 \quad \mathrm{~F}_{5} \mathrm{SCF}_{2} \mathrm{CF} 2 \mathrm{~J}$

$\underline{65} \mathrm{~F}_{5} \mathrm{SCF}_{2} \mathrm{CFO}$

$67 \mathrm{~F}_{5} \mathrm{SCH}_{2} \mathrm{CHClCH}_{2} \mathrm{OC}(\mathrm{O}) \mathrm{CH}_{3}$

$69 \mathrm{~F}_{5} \mathrm{~S}-\mathrm{G}-\mathrm{CF}_{3}$ 